\title{
STATE-OWNED ENTERPRISE GOVERNANCE IN THE PACIFIC: THE APPLICATION OF LOCAL VALUES AND PRACTICES \\ IN SAMOA AND TONGA
}

\author{
BY \\ ELISABETH POPPELWELL
}

\author{
A thesis \\ submitted to Victoria University of Wellington \\ in fulfilment of the requirements for the degree of \\ Doctor of Philosophy
}

Victoria University of Wellington 



\section{Abstract}

This research examined how state-owned enterprises (SOEs) in two Pacific countries approach their governance roles in a context where concepts of good corporate governance are changing internationally. The research considered whether corporate governance practice can be enhanced by the application of local cultural values and principles, and whether there are lessons learned from these two countries that could be shared more broadly.

The study explored insights from current and former SOE board chairs, directors, CEOs, senior public officials from the Kingdom of Tonga (Tonga) and the Independent State of Samoa (Samoa), and subject matter experts, who discussed their experiences and insights about approaches to corporate governance. The research also examined the literature on the rationale for the concept of 'good governance' which emerged in the latter half of the twentieth century, and corporate governance principles that support SOE models, to provide context for participant responses.

Twenty-six interviews were undertaken in Tonga and Samoa between July and September 2019. Twelve participants were interviewed about Tonga's SOEs, 12 participants were interviewed about Samoa's SOEs, and two participants were interviewed about both countries' approaches to SOE governance.

The research finds that the principles of good corporate governance are dynamic and responsive, and can be modified to fit local situations. Despite the challenges implementing corporate governance principles, SOE directors and officials from Tonga and Samoa are asking how these tools can be applied in their country and are actively adapting and innovating the corporate governance model to improve local application. There are important assertive signs of ambiculturalism reshaping the good governance narrative with a Pacific flavour. 


\section{Acknowledgements}

I would like to thank the following people, without whom I would not have been able to complete this research.

I would like to express my sincere gratitude to the participants who gave their time generously and whom their knowledge and insights were integral to the research.

I am deeply grateful to my supervisor Professor John Overton for his enthusiasm for the research, his support, positivity, encouragement, and patience. I thank Professor Overton for providing guidance and feedback throughout the course of my PhD degree. He always made himself available when I needed a sounding board, and made me feel confident in my abilities to complete this research.

My gratitude also extends to Professor Warwick E Murray and Dr Amanda Thomas for their constructive feedback on my research proposal.

I would like to offer my special thanks to the government officials from Tonga and Samoa, and staff at the New Zealand High Commissions in Nuku'alofa and Apia for their advice.

I extend my sincere thanks to the New Zealand Ministry of Foreign Affairs and Trade, and to VUW's Faculty of Graduate Research for the funding opportunities they provided.

My thanks also to the staff at the School of Geography, Environment and Earth Sciences; the Ethics Committee; and to staff at the Faculty of Graduate Research.

Last but not least, I would like to thank my husband, Murray Costello, for his love, support, and unwavering belief in me. I thank also my children, Dan and Hannah, who sent me messages of love during the course of my studies.

I dedicate this work to my late parents Betty and Bill Poppelwell, and my siblings, Ann, Mary, John, Kate (decd.), Mark, and Matthew. 


\section{TABLE OF CONTENTS}

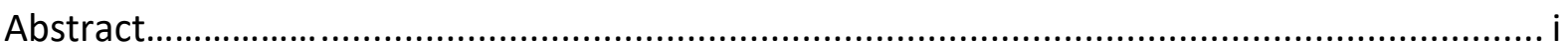

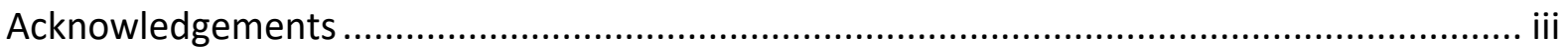

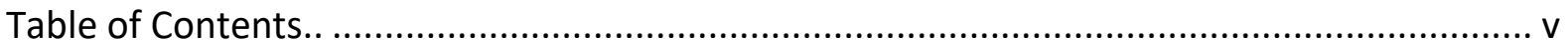

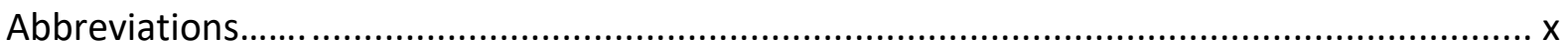

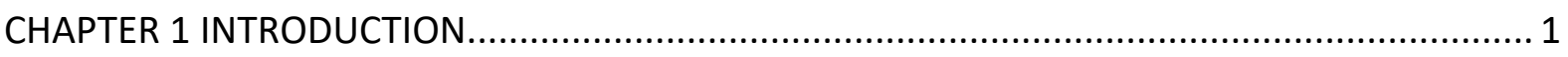

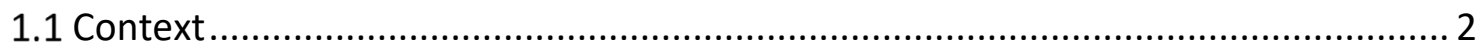

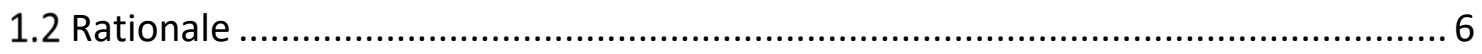

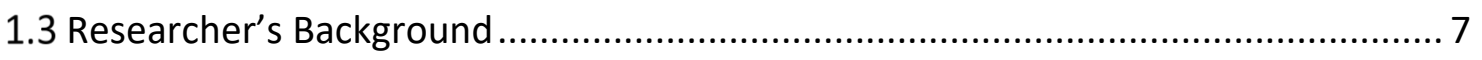

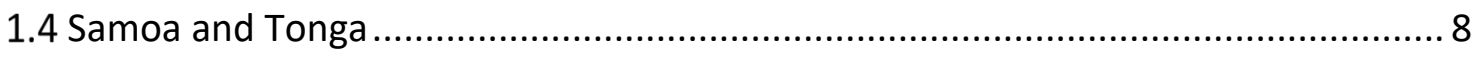

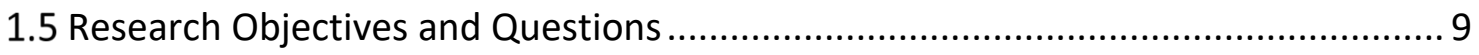

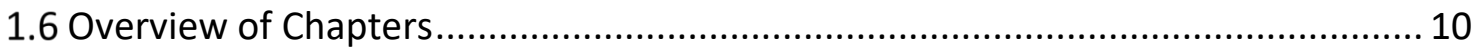

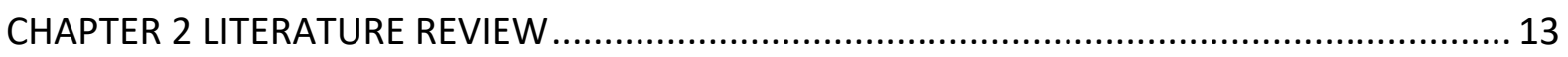

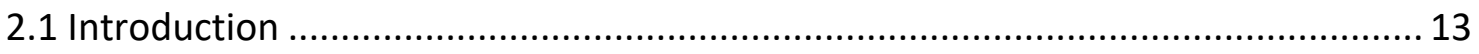

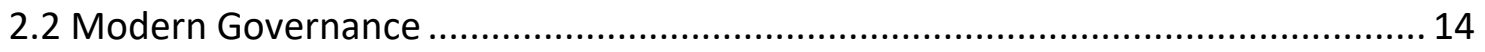

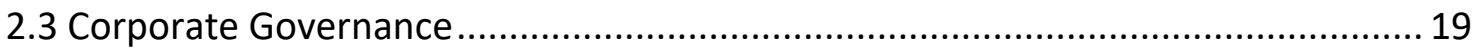

2.4 Corporate Governance Theories and Models ................................................. 23

2.5 Corporate Governance in the Public Sector .................................................. 29

2.6 Public Sector Reforms in International Development ......................................... 31

2.7 The Good (Corporate) Governance Paradigm ................................................... 35

2.8 Current Global Issues in Corporate Governance .......................................... 48

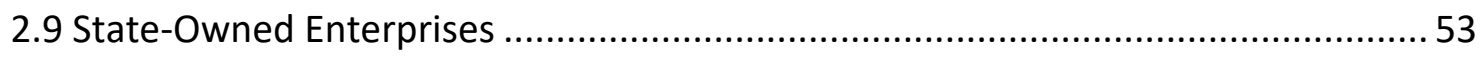

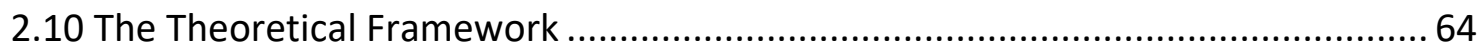

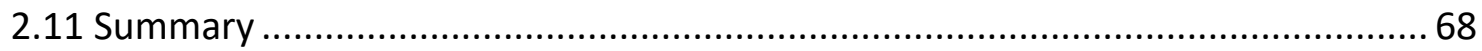




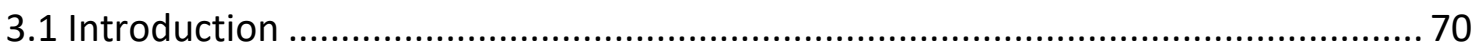

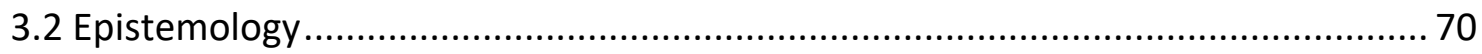

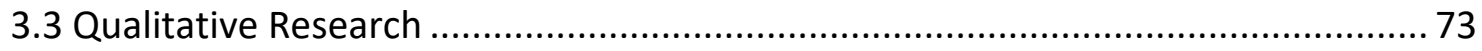

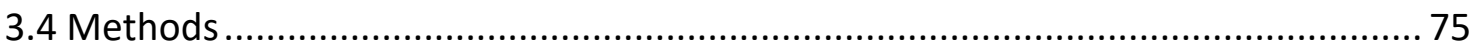

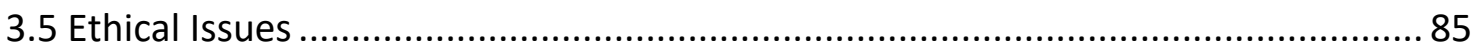

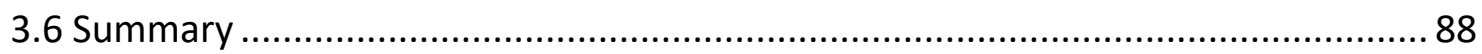

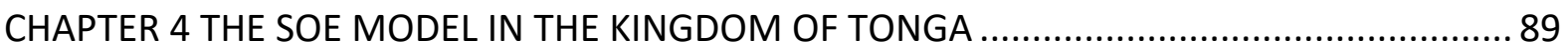

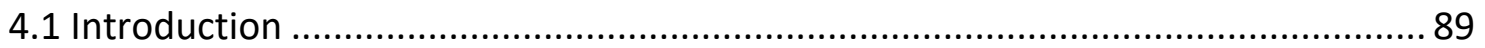

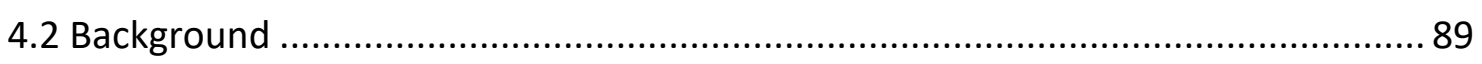

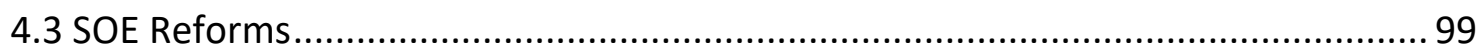

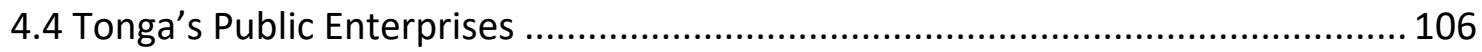

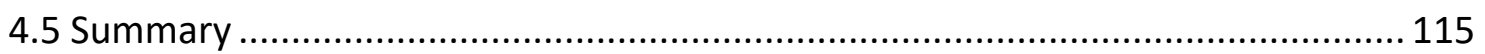

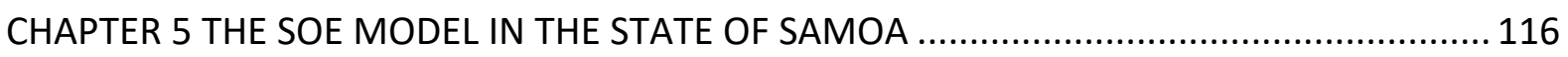

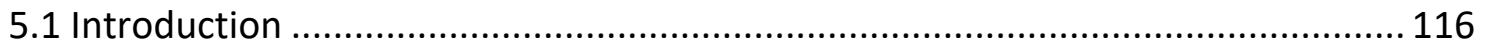

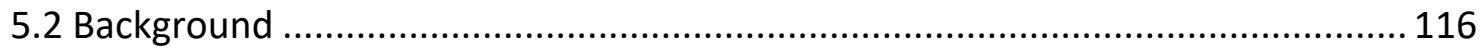

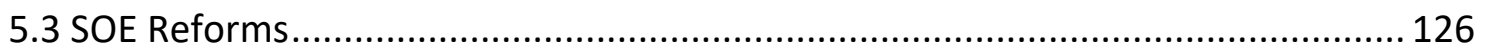

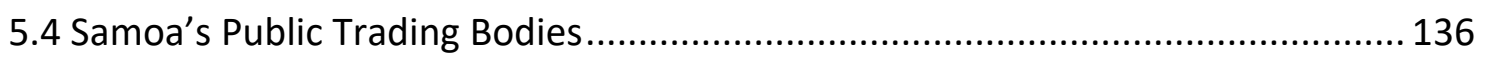

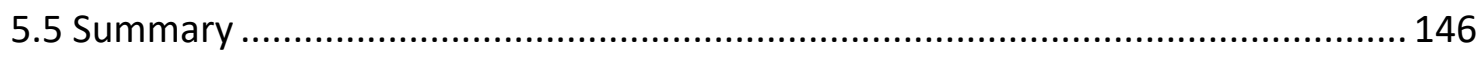

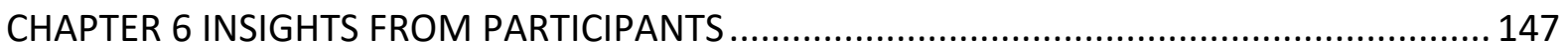

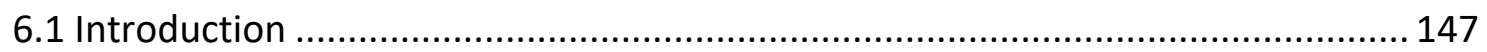

6.2 Tonga - Understanding of Corporate Governance Principles.............................. 147

6.3 Samoa - Understanding of Corporate Governance Principles............................ 155

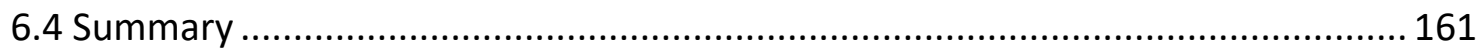




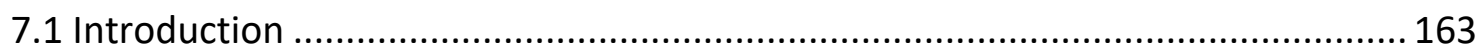

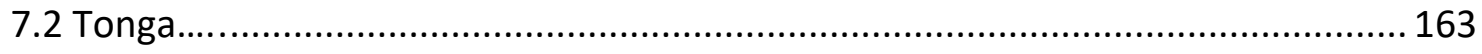

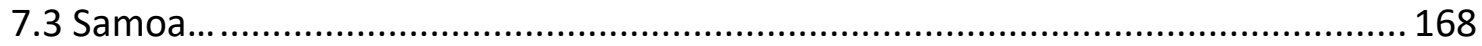

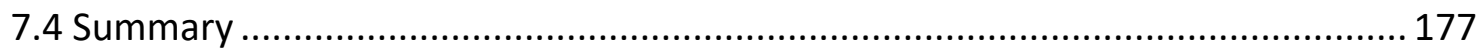

CHAPTER 8 CHALLENGES DELIVERING CORPORATE GOVERNANCE ................................. 181

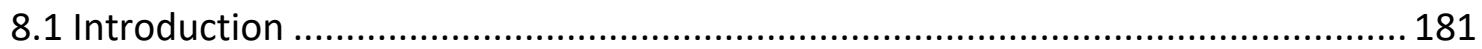

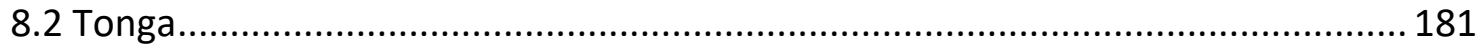

8.3 Samoa

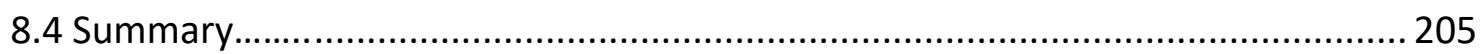

CHAPTER 9 OVERCOMING CHALLENGES IMPLEMENTING CORPORATE GOVERNANCE....... 208

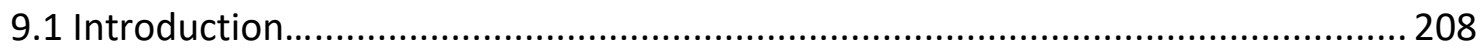

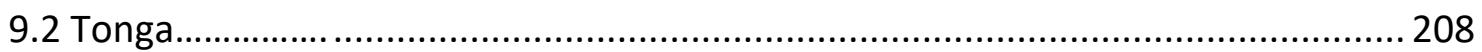

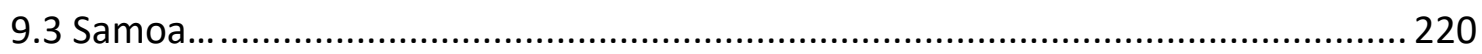

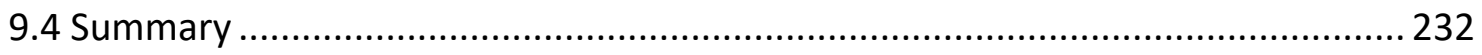

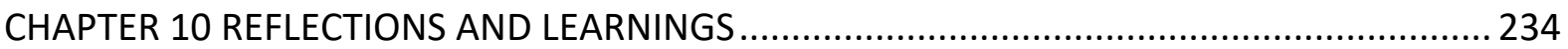

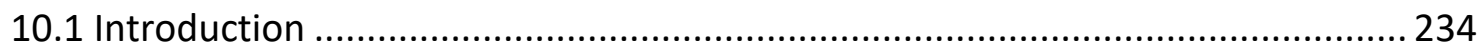

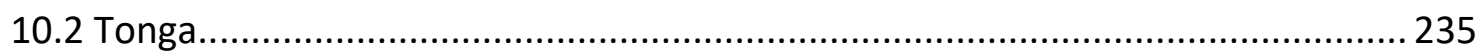

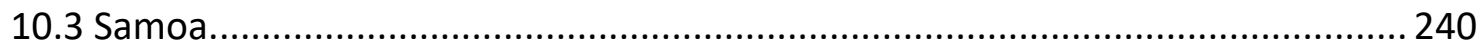

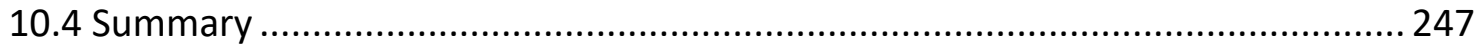

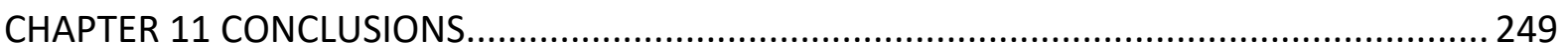

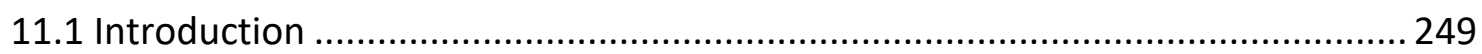

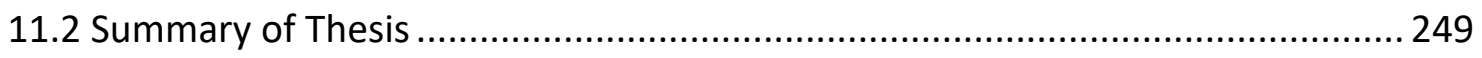

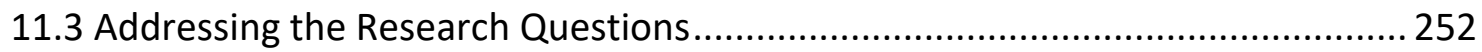

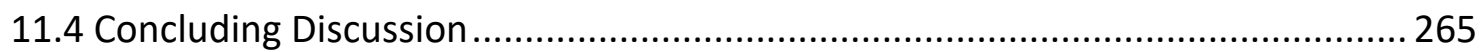


References

\section{Tables}

Table 1.1 Overview of chapters

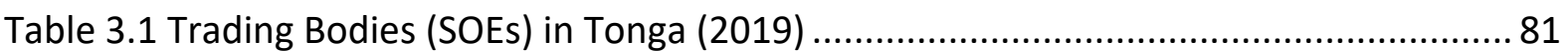

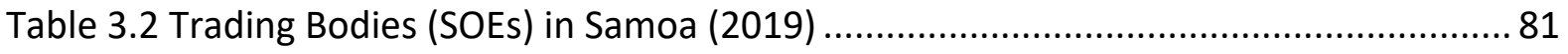

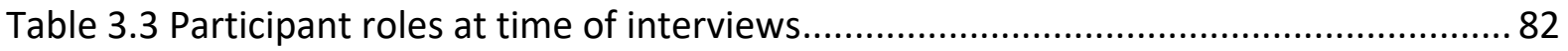

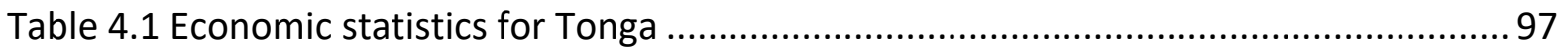

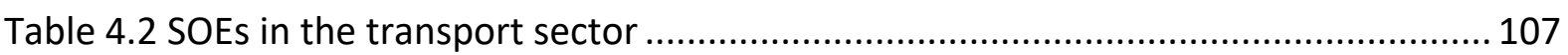

Table 4.3 SOEs in the information, communications, and technology sector ...................... 109

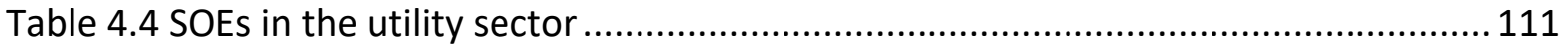

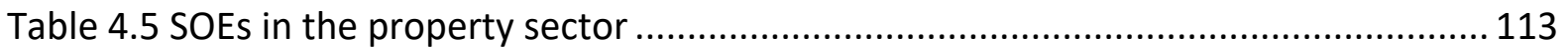

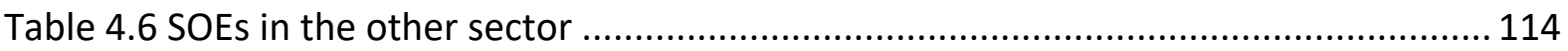

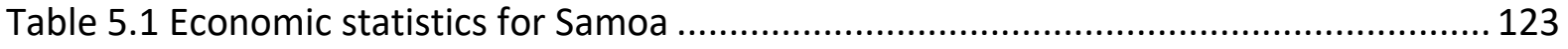

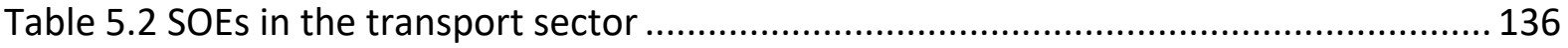

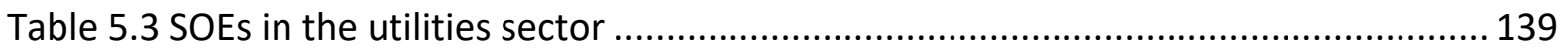

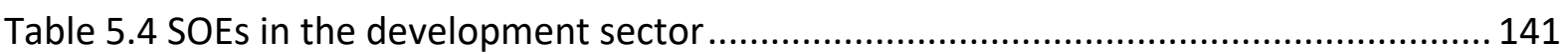

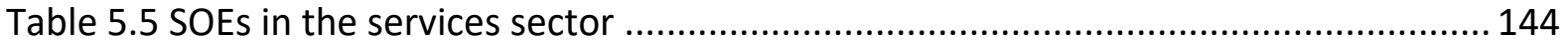

Table 6.1 Understanding of corporate governance principles in Tonga ............................ 148

Table 6.2 Understanding of corporate governance principles in Samoa ........................... 155

Table 8.1 Challenges implementing SOE corporate governance in Tonga ......................... 182

Table 8.2 Challenges implementing SOE corporate governance in Samoa ......................... 196

Table 9.1 Overcoming challenges implementing corporate governance by SOEs in Tonga 209 
Table 9.2 Overcoming challenges implementing corporate governance by SOEs in Samoa 220

Table 10.1 Reflections and Learnings on SOEs in Tonga .................................................... 235

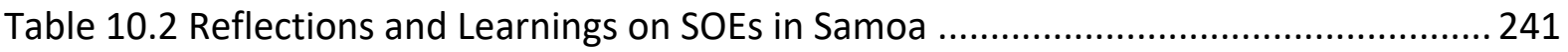

\section{Figures}

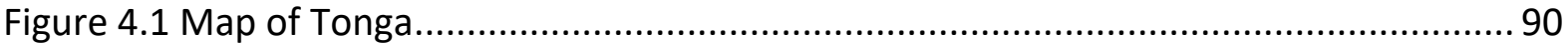

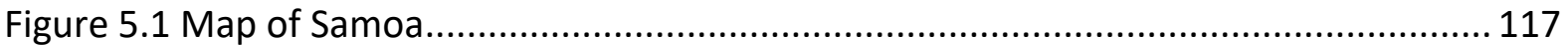




\section{ABBREVIATIONS}

\begin{tabular}{|c|c|}
\hline ACCA & Association of Chartered Certified Accountants \\
\hline CSO & Community Service Obligations \\
\hline CSR & Corporate social responsibility \\
\hline DAC & Development Assistance Criteria \\
\hline DFID & United Kingdom Department for International Development \\
\hline DFAT & Australia Department of Foreign Affairs and Trade \\
\hline ECLAC & Economic Commission for Latin America and the Caribbean \\
\hline ESG & Environmental, social and governance \\
\hline GDP & Gross Domestic Product \\
\hline GFC & 2007/08 global financial crisis \\
\hline GNI & Gross National Income \\
\hline GPO & Government Policy Obligation \\
\hline IFC & International Finance Corporation \\
\hline IMF & International Monetary Fund \\
\hline MDGs & United Nations Millennium Development Goals \\
\hline MFAT & New Zealand Ministry of Foreign Affairs and Trade \\
\hline NGO & Non-government organisation \\
\hline NPG & New public governance \\
\hline NPM & New public management \\
\hline NPS & New public service \\
\hline PE & Public enterprise \\
\hline PPP & Public-private partnerships \\
\hline PSDI & Pacific Private Sector Development Initiative \\
\hline SAPs & Structural adjustment programmes \\
\hline SIOD & Samoa Institute of Directors \\
\hline UNDP & United Nations Development Programme \\
\hline UNDESA & United Nations Department of Economics and Social Affairs \\
\hline UNESCAP & United Nations Economic and Social Commission for Asia and the Pacific \\
\hline
\end{tabular}




\section{CHAPTER 1 INTRODUCTION}

Since the 1980s the term 'good governance' has been worked and re-worked by those in the international development sector, firstly as a tool to improve economic development (Asian Development Bank (ADB), 2011; Mellor \& Jabes, 2004; World Bank, 1989) and then to improve regional security (Fairclough, 1991; Mellor \& Jabes, 2004; United Nations Economic and Social Commission for Asia and the Pacific (UNESCAP), 2009). It has been used by social movements to bring issues such as human rights and corruption into the mainstream (AusAid, [2006], 2007; Huffer \& So'o, 2005; Roberts et al., 2007), and it could also be argued that some donors use good governance frameworks as a form of political influence over recipient countries (Currie-Alder, 2014; Nederveen Pieterse, 2004).

There is much research on what constitutes good or effective governance but most of the corporate governance literature is from Western economies. Previous work I have been involved with in the Pacific as a member of donor evaluation exercises has highlighted a lack of recognition of local conditions and values when implementing Western models of governance (political and corporate). This has led to concerns that corporate governance of SOEs is not effective in the Pacific (ADB, 2016a), but it also raises the question of whether there are different approaches to corporate governance that the global community can learn from. State-owned enterprises (SOEs) play an important role in the Pacific to ensure the public has access to essential services that support social and economic wellbeing, and this makes SOEs a useful area to study as a defined sector.

This thesis examines the role of SOE boards in two Pacific countries, and how they implement notions of 'good' corporate governance principles within local settings. This chapter outlines the: context for this study (1.1); rationale (1.2); researcher's background (1.3); rationale for examining Tonga and Samoa (1.4); and objectives and key research questions (1.5). It also provides an overview of chapters in this dissertation (1.6). 


\subsection{CONTEXT}

\subsubsection{Call for values-based system of governance}

In governance practice, norms, principles and values often play a rather obscure implicit role (Kooiman \& Jentoft, 2009), and the former United Nations (UN) Secretary-General Kofi Annan, in his speech on Governance and values, contended that values-based governance is perhaps the single most important factor in eradicating poverty and promoting development:

"How do we put values back at the heart of governance and the way we behave as nations, businesses and individuals?" (Kofi Annan, 2009)

Annan called for the urgent adoption of a values-based system of governance to guide the international community in tackling the economic, climate, food, and poverty crises. Although Annan was not specifically referring to corporate governance, within international development reform, the corporate governance framework of rules and practices has been an integral part of public service reform initiatives by international donor agencies.

\subsubsection{Changing perspectives on 'good' corporate governance}

Outside of the international development sector, there is a growing awareness of the need for changes in the corporate sector by governance reformers, shareholders, and investors who have come to understand the trade-offs between short-term returns and long-term social, environmental and economic prosperity (Sampford \& Connors, 2006; UN Global Contact, 2004). The changing perspective is focusing on an expectation that even privately owned enterprises should consider the wellbeing of a wider range of stakeholders (Fink, 2018; Nestor, 2018; O'Kelley et al., 2018). In larger economies, there has been a drive for long-term sustainability, greater transparency, and governors having the skills and experience needed to support this (Lipton et al., 2016). This discussion is largely brought about by the $2007 / 08$ global financial crisis (GFC) and the growing interest in more environmental and social responsibility (i.e. social licence to operate), diversity of thinking on boards, and trust and integrity as core leadership qualities (Lipton, 2018). The discussion also includes broadening the range of corporate governance tools, and looking beyond Western concepts of good corporate governance (Chen \& Miller, 2011; Nicholson et al., 2019). 
The reputation of an enterprise is one of its most important financial assets. By understanding the aspirations of consumers, an enterprise can offer products and services that match consumers' ethical thresholds, and at the same time improve shareholder profit (for example, The Body Shop). There is also a growing demand for directors to be more accountable in light of recent scandals, such as the 2007-2010 United States subprime mortgage crisis and the 2009-2015 Volkswagen diesel emissions scandal. No country is free from challenges with poor board performance and poor governance practices such as lack of transparency and accountability, and unmanaged conflicts of interest. These are challenges faced by most economies (large and small) in achieving good corporate governance, not just developing countries. However, issues with governance seem more pronounced in small island countries or emerging economies.

\subsubsection{Global perspectives on SOE governance}

This thesis is focused on the subject of state-owned enterprises (SOEs) which were introduced by governments under the 1980s/90s neoliberal public sector reforms, to apply corporate governance principles to the provision of public services. SOEs are a mixed market model, sitting between the state and the private sector. SOEs are based on a model that by introducing market disciplines into government-owned operations, performance of the enterprise is improved and services are delivered more effectively and efficiently (Laking, 2012).

Many governments from developing countries receive international aid and support to implement 'good' governance frameworks for their SOEs, and recent reviews have highlighted issues with poor governance and performance of SOEs in small island states (ADB, $2009,2014,2016 a)$. The pool of people suitable to undertake SOE governance roles in these countries is small, and there is (as is often the case in new democracies) regular political churn, and high turnover of CEOs and chairs. This affects the ability of a board to function effectively, whereby they have to navigate between what type of directors government ministers want and finding directors with suitable skills who want to be on a SOE board. 
Part of the discussion in the on-going call for values-based corporate governance is how international concepts of good corporate governance of SOEs work within local contexts. In SOE models, good governance decision-making depends on the government of the day, where there can be tension between the needs of an SOE and the public interest, such as balancing profit-seeking with long-term strategic interest and social responsibility (New Zealand Office of the Auditor-General, 2014).

In New Zealand, the government can dictate how SOEs are managed, from solely as a revenue source, as with Television New Zealand in the 1990s, or to provide public good services such as the weather forecasting provided by New Zealand's national weather authority, MetService. In New Zealand some SOEs were privatised but were later bought back by the government, for example Kiwirail. Some SOEs have performed poorly, such as Solid Energy New Zealand, which entered voluntary liquidation in 2015 after owing \$400 million to its creditors. Similarly, the government repurchased a controlling interest in Air New Zealand in 2001, to save it from bankruptcy. NZ Post is responsible for providing postal services in New Zealand and is facing, as are other mail services internationally, a dwindling market. However, it is legally obligated to maintain a certain level of service under a deed of understanding it signed with the New Zealand government following corporatisation. SOEs in New Zealand also have obligations under the Treaty of Waitangi ${ }^{1}$, yet are expected to follow the same governance principles and practices as those enterprises in the private sector who do not have these Treaty obligations.

Corporate governance of SOEs continues to be a major challenge internationally (Organisation for Economic Co-operation and Development (OECD), 2005; Whincop, 2005; Bernier, 2015; Bruton, et al., 2015; Grossi et al., 2015). These challenges involve models, mechanisms, and processes aimed at preventing poor governance practices such as personalisation of power, corruption, and an unaccountable government. (OECD, 2005; Florio \& Fecher, 2011; Verhoest et al., 2012; Grossi et al., 2015). However, SOEs are also expected

\footnotetext{
${ }^{1}$ A provision in Section 9 of the State-Owned Enterprises Act (1986) stated, "Nothing in this Act shall permit the Crown to act in a manner that is inconsistent with the principles of the Treaty of Waitangi." The 1840 Treaty (Te Tiriti o Waitangi) is New Zealand's (Aotearoa's) founding document, which was meant to outline a partnership agreement between Māori and the British Crown over land.
} 
by the public to have higher 'moral' standards, for example to balance pricing and profits, be efficient and 'buy local', and face numerous challenges to meet changing corporate governance expectations, as well as delivering services and meeting performance obligations for their shareholders, predominantly the state. These expectations are particularly challenging for small island countries with limited resources and a small private sector. Foreign investment can be a double-edged sword for small nations, carrying risks to their sovereignty, self-determination, and local values.

\subsubsection{SOE governance in the Pacific}

SOEs are an important feature of Pacific Island economies, and have formed part of the public sector reforms since the 1990s. They provide core infrastructure services in the power, water, sanitation, postal services, airports, broadcasting, seaports, and telecommunications sectors, and are mainly monopolies. Reforms have been aimed at privatising some enterprises, improving governance, regulatory and legal frameworks, and introducing more public-private partnerships (PPP) (ADB, 2009, 2011, 2016a).

The pressure for public sector reform in the South Pacific came from international aid agencies and financial institutions (Larmour, 2005). Financial support was conditional on 'good governance' reforms, concerned with economic performance which targeted the size of government, rather than its composition, centralisation, or lack of accountability to elected leaders (Larmour, 1998). Reformers saw privatisation of SOEs as a way of raising revenue for the government budget and reducing the need for further subsidies (and aid), and to make them become more efficient (ibid). This has proved problematic, with agencies such as ADB suggesting that it will take time to see these changes (ADB, 2004, 2016).

The 2016 ADB Finding balance report stated that returns from SOEs in most Pacific countries are not meeting their capital costs and are a significant drain on island economies. A 2019 news item on Radio New Zealand (RNZ) noted that SOEs in the Marshall Islands are heavily subsidised, and 90 percent of SOE managers are resisting completing business plans and contracts for community service obligations (RNZ, 2019). My initial research of 2015-2018 media material on Samoa following on from the reforms of 1990s, illustrate several issues 
about good governance practice and approaches being taken to resolve them. That these issues are being publicly reported and discussed highlights a focus on governance practice. The issues reported include: improving board performance; concerns over accountability and transparency; effective and collaborative leadership; the need for merit-based appointments; the level of board resignations; and adapting traditional governance to contemporary political and policy challenges (Samoa Observer, 2015-2018). The universal applicability of 'good governance' by public sector reformers has been criticised by Barrie Macdonald in Governance and reform in the South Pacific (Macdonald, 1998) because it did not necessarily fit with local conditions. One of Macdonald's examples was that the democratic character of government in Kiribati, combined with local culture and circumstances, made it very difficult to develop economic reforms (ibid). SOE reforms in Pacific Island countries is discussed further in chapter 2 Literature Review.

\subsubsection{Changing views of SOE governance}

In the traditional SOE model SOEs may only be aiming to achieve improvements to wellbeing if directed to do so by the state. However, there is a changing view that the primary goal of SOEs is not to solely make profit, but to fulfil its public service mandate and create public value (Daiser et al., 2017, p.457), which has not been the case in New Zealand or in Pacific Island countries that have adopted New Zealand's model. The changing perspectives show that SOEs can have a different purpose, mission, and objectives that relate to some aspect of public service and/or social outcomes (PWC, 2015). Emphasis on preparing some SOEs for privatisation (which was part of early reforms) is declining (World Bank, 2020a). Governments have become more cautious in response to public criticism that assets were sold off too cheaply, and privatisation caused large layoffs and increases in service prices (ibid).

\subsection{RATIONALE}

While there is much research on the key factors of what constitutes good or effective corporate governance (e.g. it promotes: transparency and fair markets; accountability and efficient allocation of resources; consistency with the rule of law; and effective supervision and enforcement (Cadbury Report, 1992; OECD, 2015a)), most of the corporate governance literature is from large Western economies. This research seeks to examine the role of SOE 
boards in two small Pacific countries, and how they implement notions of corporate governance principles within local governance settings.

As a development issue, this research looks at the factors, including values, within a governance system that board directors see are important, and how they are implemented by SOE boards. This is because good governance of SOEs is essential if they are to operate efficiently and effectively and deliver quality affordable services in countries with limited resources, small economies, and capacity issues regarding leaders who have the necessary skills to govern SOE boards.

This study aims to stimulate interdisciplinary research on issues affecting governance of SOEs, considering their growing importance in society and their changing nature post COVID-19. It fills a gap in the corporate governance literature, especially in the context of Pacific SOEs, and is among the first to examine the model in Tonga and Samoa - not from an evaluative performance perspective, but from an exploratory learning perspective. This research explores how two countries with small populations who have not tended to be part of learning exercises for other countries but rather are assessed on how they have performed financially, shed light on approaches taken by their SOEs and governments to embed Western models within their countries' values and local practices.

The research takes an Appreciative Inquiry approach and a 'sitting in the middle' perspective to gain insight on how SOE board directors make sense of the international discourse on good corporate governance; what makes sense to them in the local context, within their cultural values and protocols; and how they bring them together to make sense of each other's worlds. The research explores how discourse on 'good' SOE governance affects the way boards work in Tonga and Samoa.

\subsection{RESEARCHER'S BACKGROUND}

For the last 20 years, I have undertaken social research and evaluation projects mainly for New Zealand government agencies, with the last eight years focusing on New Zealand's aid investment in the Pacific. This involved me both commissioning or undertaking evaluations 
on behalf of the New Zealand Ministry of Foreign Affairs and Trade (MFAT). These included: evaluations of MFAT's country aid programmes in the Cook Islands, Niue, Samoa, Tokelau, Tonga, and Vanuatu; evaluation of MFAT's Partnership Fund; evaluation of MFAT's Pacific infrastructure activities; and a strategic review of MFAT's maritime projects in the Pacific. Assessing governance of these aid investments was part of the evaluation process. Other governance projects included an evaluation of Te Puni Kōkiri's governance training trial for Iwi to undertake their responsibilities within a pre- and post-Treaty settlement environment, and desk-based research for the New Zealand Institute of Directors on the latest international thinking on board evaluations. Much of my research and evaluation work involved attitudinal and behavioural insights, using mixed methodologies, and interviewing a range of participants from different cultures, from community members to government ministers, and the approach I took in this study has largely been influenced by these experiences.

The discussions with participants from these previous pieces of work, raised questions regarding perceptions of Western models of (political and corporate) governance and how they fitted with the local environment in the Pacific. In particular, I noted the lack of recognition of local conditions and values, and questioned whether there are different approaches to good corporate governance for SOEs that the global community can learn from.

\subsection{TONGA AND SAMOA}

In Tonga and Samoa, SOEs are the main providers of key public services, including public utilities and transport. This research examines these countries as they provide different contexts to investigate governance of their SOEs. These include:

- Different forms of government - Tonga is a constitutional monarchy and Samoa is a constitutional republic.

- Strong communal and kinship social structures, but different approaches to working with Western concepts of governance.

- Issues of scale, with a similar number of SOEs to New Zealand, yet with very different population sizes. 
The research provides an opportunity to explore how notions of well-being and values fit within the current corporate governance discussion on creating shared value, and Kofi Annan's call for adoption of a values-based system of governance.

Many of the issues in good governance practiced by SOE boards are relevant to all countries. Tonga and Samoa face similar challenges SOE boards face in New Zealand and elsewhere, such as the need for long-term decision-making while working within short political cycles, achieving social outcomes while making profits, relevant skillsets for chairs and directors, and recruiting to ensure diversity, and diversity of thought on boards. Tonga and Samoa have broadly similar SOE portfolios and legislative frameworks to other Pacific Island countries, including New Zealand, and their learnings can be applicable throughout the Pacific region and elsewhere.

I envisage that this research will contribute to better understandings about how local context might be impacting on corporate governance performance of SOEs. Access to external financial resources to improve economic wellbeing has been a challenge for Pacific countries. A better understanding by external investors and donors of how SOE governance models are applied in Pacific nations may build confidence and trust to engage and invest in countries with relatively small populations.

\subsection{RESEARCH OBJECTIVES AND QUESTIONS}

\subsubsection{Objectives}

Boards of directors of SOEs play an important role in corporate governance and performance. This research examines what factors induce board directors to make certain decisions, and whether they apply an Indigenous values-based system of governance. It examines the issues through an international development lens and uses Foucault's concept of discourse to analyse knowledge and power to help to explain the current challenges facing SOEs. Through better understanding of the impact of corporate governance practices on SOE performance, policy can be revised. 
Conceptually, corporate governance relates to the way SOEs are managed, controlled, and held to account (OECD, 2015b). The OECD's 2015 Guidelines on corporate governance of state-owned enterprises are guidelines for good practice, and the research uses these guidelines as a reference. While previous research has identified generic good corporate governance principles (OECD, 2015a), and SOEs in Tonga and Samoa have been evaluated based on these principles (ADB, 2009, 2014, 2016a), this research looks beyond current corporate governance frameworks, and considers how Tonga and Samoa are applying their own Indigenous solutions to help them implement the SOE governance model.

\subsubsection{Research Questions}

This research examines what corporate governance means for these boards, and whether there are learnings from these countries on how to operate corporate governance within different cultural contexts. In doing so, the overarching research question is:

What does 'good corporate governance' mean in Pacific SOEs?

The following secondary questions are also considered:

- Q1. How does the international discourse on 'good' corporate governance affect the way SOE boards work in Samoa and Tonga?

- Q.2 Do SOE boards in Samoa and Tonga take local values into account in defining and practicing good corporate governance?

- Q.3 Can their approaches and learnings be applied elsewhere to other parts of the Pacific and outside of the Pacific?

\subsection{OVERVIEW OF CHAPTERS}

This research is not a comparison of Tonga and Samoa SOEs; rather it gathers insights from each country. Although some findings may be similar or have small differences, this is not central to the thesis. The structure of each findings' chapter is not uniform, in particular chapter 7, Applying Local Values and Practices. This tells a story in itself, where the reader will recognise differences in the patterns of the main themes that emerge from each country. 
Table 1.1 Overview of chapters

\begin{tabular}{|c|c|}
\hline Chapters & Content \\
\hline $\begin{array}{l}\text { Chapter } 1 \\
\text { Introduction }\end{array}$ & $\begin{array}{l}\text { Context. } \\
\text { Rationale. } \\
\text { Researcher's background. } \\
\text { Research objectives and question. }\end{array}$ \\
\hline $\begin{array}{l}\text { Chapter } 2 \\
\text { Literature review }\end{array}$ & $\begin{array}{l}\text { Modern governance. } \\
\text { Corporate governance. } \\
\text { Corporate governance theories and models. } \\
\text { Corporate governance in the public sector. } \\
\text { Public sector reforms in international development. } \\
\text { The good corporate governance paradigm. } \\
\text { Current global issues in corporate governance. } \\
\text { SOEs in international development. } \\
\text { Theoretical framework. }\end{array}$ \\
\hline $\begin{array}{l}\text { Chapter } 3 \\
\text { Methodology }\end{array}$ & $\begin{array}{l}\text { Epistemology. } \\
\text { Qualitative research. } \\
\text { Methods. } \\
\text { Ethical issues. }\end{array}$ \\
\hline $\begin{array}{l}\text { Chapter } 4 \\
\text { The SOE model in } \\
\text { Tonga }\end{array}$ & $\begin{array}{l}\text { Outlines SOE boards in Tonga, and sets up the SOE board context } \\
\text { in which the research is conducted. }\end{array}$ \\
\hline $\begin{array}{l}\text { Chapter } 5 \\
\text { The SOE model in } \\
\text { Samoa }\end{array}$ & $\begin{array}{l}\text { Outlines SOE boards in Samoa, and sets up the SOE board } \\
\text { context in which the research is conducted. }\end{array}$ \\
\hline $\begin{array}{l}\text { Chapters 6-10 } \\
\text { Findings (insights from } \\
\text { participants) }\end{array}$ & $\begin{array}{l}\text { The interviews are analysed by the following topics and by each } \\
\text { country: } \\
\text { Ch } 6 \text {. Participant understanding of corporate governance } \\
\text { principles. } \\
\text { Ch } 7 \text {. Whether participants consider local values and practices } \\
\text { when implementing these principles. } \\
\text { Ch } 8 \text {. Challenges faced in implementing these principles. } \\
\text { Ch } 9 \text {. Approaches undertaken (or being considered) to address } \\
\text { these issues. } \\
\text { Ch. } 10 \text {. Reflections and learnings that can be shared with the SOE } \\
\text { sector. }\end{array}$ \\
\hline $\begin{array}{l}\text { Chapter } 11 \\
\text { Conclusions }\end{array}$ & $\begin{array}{l}\text { Summary of thesis. } \\
\text { Addressing the research questions. } \\
\text { Concluding discussion: How the research informs the global } \\
\text { discussion on good corporate governance. }\end{array}$ \\
\hline
\end{tabular}

Table 1.1 above outlines the dissertation structure and maps out the chapters. In order to answer the research questions above, the research firstly discusses the key concepts and foundations in corporate governance. The literature review looks at the wider body of literature on modern governance, with a focus on corporate governance and its role in the 
global public sector reforms of the late $20^{\text {th }}$ century, including the use of SOEs to help implement these reforms. It includes a discussion on the neoliberal discourse on 'good governance' within the historical context of global financial crises, and provides insights into why approaches were adopted by international development and aid agencies. The final chapter concludes with the research's contribution to the global discussion on good corporate governance. 


\section{CHAPTER 2 LITERATURE REVIEW}

\subsection{INTRODUCTION}

The previous chapter provided context and rationale for the study and outlined the key research questions. The literature review contributes to understanding how the international discourse on 'good' corporate governance affects the way SOE boards work in Tonga and Samoa. This chapter also provides context to the interview responses, and positions the research within the historical context of the late twentieth century global financial crises which precipitated the growth of neoliberal policies and introduced corporate governance principles into the public service. It also provides insights into attempts by successive reforms to embed good governance principles in the public sector, including SOEs.

This is a study about SOE governance in the Pacific and in order to do this research, key foundational concepts in modern governance need to firstly be reviewed. These include corporate governance and its role in public sector reform; the discourse on good governance in international development; and the SOE model. The literature discusses how this model, along with markets and networks, has been used to implement neoliberal policies to control the role the hierarchic state plays in people's lives, and the role of government in delivering public services. It is important to understand these concepts and the impact they are having on the governance of Pacific SOEs.

Section 2.2 provides a brief description of modern governance, which sets the scene for how the adoption of corporate governance approaches played a significant role in public sector reforms from the 1980s onwards. Section 2.3 describes corporate governance, and this will contribute to the discussion on 'good' corporate governance for SOES in later sections. Section 2.4 outlines two key corporate governance theories and three models. This shows how theories are developed in response to one's world view and events (such as the separation of ownership and control in businesses), and how models are developed in response to different countries' approaches to ensuring boards are accountable. Section 2.5 examines the conditions that influenced the corporate governance model in the public sector and Section 2.6 examines public sector governance reforms in international development. 
Section 2.7 explores the rationale for the term 'good governance', the changing values in good governance as influenced by global events, and its evolution to broader concepts including corporate social responsibility and ambicultural corporate governance. Section 2.8 discusses the current global issues in corporate governance that the research aims to respond to and add to the body of knowledge on the application of good corporate governance in SOEs. Section 2.9 examines the rationale for the SOE model as a solution to public sector debt, particularly for countries receiving aid and other international support. As part of positioning the research, Michel Foucault's 'Art of Government' is examined in Section 2.10 with regard to the de-centred notion of power and the role it plays in governance. The section also outlines the theoretical framework for the research based on the discussed literature. Section 2.11 provides a summary of the chapter.

\subsection{MODERN GOVERNANCE}

Governance is one of the most frequently used concepts in the social sciences that includes different meanings and perceptions (Ansell \& Torfing, 2016). While 'government' refers to political institutions and restricted to the activities of the state, 'governance' is a broader concept and can be found in the family, community, local, and national institutions including government. It is possible to have governance without government (Heywood, 1997; United Nations Development Programme (UNDP), 1997).

One definition of governance is the exercise of political power to manage a nation's affairs (UNDP, 1995, p.18). Here, governance can be understood in terms of three major components: the form of political authority that exists in a country; the means through which authority is exercised in the management of economic and social resources; and the ability of governments to discharge government functions effectively, efficiently, and equitably (ibid). ${ }^{2}$ In public administration, governance can refer to the practice at all levels of administrative and political authority to manage a country's business. This can include the processes and institutions that people and groups use to communicate their interests, exercise their legal rights, meet their obligations, and mediate their differences (UN Department of Economics

\footnotetext{
${ }^{2}$ The Organization of Economic Cooperation and Development (OECD) defines governance as the exercise of political, economic, and administrative authority to manage a nation's affairs (OECD, 2006), which seems more like a definition of government.
} 
and Social Affairs (UNDESA) et al., 2012), "The institutional and human capacities for governance determine the way in which the effectiveness of public policies and strategies is attained, especially in-service delivery" (UNDESA et al., 2012, p.3).

Governance is also the product of changes in the state. The years following World War Two saw a dominance of hierarchical, bureaucratic governance. Although hierarchy enables control by using formal authority as a means of coordination it was seen as weakening collaboration and lateral innovation (Adler, 2001). The 1980s saw the introduction of markets and privatisation, reflecting the wider rise of neoliberalism (Hood, 1991; Ball, 2007, 2011). This modern (or new) governance describes changes in the role of the state following the public-sector reforms of the 1980s and 1990s (Bevir, 2013). Mark Bevir (2007, 2009, 2012, 2013) explained that governance becomes a broader concept of ruling and refers to a pattern of ruling, organisation, and coordination, where civil society can rule mainly independently of the state. It is less focused on hierarchical structures found in the state, and more focused on linkages within society and the state, public bodies and private bodies, and public bodies and voluntary bodies. It can describe all processes of social organisation and social coordination, and the way in which organisations and civil society can operate independently of the state (Bevir, 2012; Grossi et al., 2015).

During this period of reform the World Bank subtly re-emphasised governance from the exercise of political power to a broader exercise over economic and social resources, and then to an even more broader definition encompassing an accountable authority, with a strong civil society. The 1989 World Bank study defined governance as, "the exercise of political power to manage a nation's affairs" (World Bank, 1989, p.60). Then a 1992 World Bank report described governance as, "the manner in which power is exercised in the management of a country's economic and social resources for development" (World Bank, 1992, p.1). In 1994 the World Bank described governance as, "epitomized by predictable, open, and enlightened policymaking (that is, transparent processes); a bureaucracy imbued with a professional ethos; an executive arm of government accountable for its actions; and a strong civil society participating in public affairs; and all behaving under the rule of law" (World Bank, 1994, p.vii). 
In her address to the World Conference on Governance in Manila, Philippines, Deputy United Nations Secretary-General Louise Fréchette spoke that governance "is not something that the state does to society, but the way society itself, and the individuals who compose it, regulate all the different aspects of their collective life" (Fréchette, 1999). Fréchette appears to be describing a more democratic governance where it becomes the process through which institutions, businesses and citizens' groups articulate their interests, exercise their rights and obligations and mediate their differences.

Mark Bevir (2012) identified four key facets of new or modern governance, that governance: 1) is more hybrid and less hierarchical whereby the state or government operates through market and contract relations, networks and partnerships; 2) is more multijurisdictional, there are more overlaps between bodies working in different jurisdictions and form partnerships to solve problems; 3) has greater plurality of stakeholders, with more involvement of voluntary and private sector actors, alongside public sector actors in the decision-making processes, in service delivery, and in policy implementation; and 4) is about networks, when there is a growth of organisations working together in networks.

This section briefly highlighted how modern governance, as a broad concept, has different features depending on where it is found within society and how its power is exercised, either by the state or independent of the state using markets and networks. The next section discusses the reforms of the 1980s and 1990s that influenced the shift of governance, and thereby power, from the state to markets and networks. This proved critical, as with power comes the ability to influence the behaviour of others.

\subsubsection{Markets and networks}

Changes in modern governance can be seen occurring in two waves of reform in the latter half of the twentieth century (Bevir, 2012). The first wave was under neoliberalism, which emphasised the contracting out of services where the public sector would get private sector organisations to deliver services. There was the selling off of public goods and services, and introduction of new public management (NPM) techniques towards market mechanisms. The rationale for the neoliberal and NPM movements are discussed further in Section 2.5. The 
first wave focused on market relations, rearranging the role of the state, and individual responsibility with regard to economic, political, and social arrangements within society (Das, 2019; Dawes \& Lenormand, 2020). In the United Kingdom, the first wave of reform was associated with Thatcherism, and drew on economic modernism to justify marketisation and NPM in the 1980s. NPM introduced the contracting out of services that had traditionally been undertaken by the state, applying corporate governance principles to the public sector, and the privatisation of government services with the selling off of public activities and public goods to the market (Harvey, 2005). Although the first wave of reforms was supposed to create markets, it led to a proliferation of networks for the delivery of public services (Bevir, 2013). Markets rely on price to co-ordinate supply and demand and promote flexibility, but can corrode trust and undermine relations that support knowledge sharing and equity (Adler, 2001). Greany and Higham (2018) argued that these new market mechanisms coexisted with new forms of hierarchical governance as the state became both market maker and regulator.

The second wave of reforms was still a move away from hierarchical bureaucracies (and to a certain extent markets) and towards networks (Bevir, 2009). This was because there was a growing concern that the spread of markets within governance had impacted the state's ability to control the coordination between different bodies involved in delivering public services (ibid). To respond to this challenge, the state developed strategies for managing these networks through partnerships, 'whole of government' agendas, and bringing a range of organisations together to collaborate in public and private sectors as an attempt to maintain the aim of earlier reforms while building state capacity and oversight (Bevir, 2012). Bevir added that this meant a move away from neoliberalism towards an emphasis on the whole of government agenda for dealing with fragile states, global security situations, or adverse events. It also focused on greater innovation and efficiency, public-private partnerships, and joined-up governance (ibid).

These reforms led to arguments that the state was being 'hollowed out' (Rhodes, 1997). In public services, this meant the need for inter-agency working was emphasised and networks were seen as a response to the fragmentation created by markets. However, the new networks did not just recreate older ones; private and third sector actors took on extensive 
public sector roles and sector boundaries were blurred in 'public-private partnerships' (Ball, 2007). From the late 1990s, networks were also seen to be displacing markets as a dominant mode of co-ordination, possibly reflecting the ICT revolution and globalisation (Castells, 1996; Rhodes, 1997). The state increasingly depended on other organisations to deliver its policies, services, and establish a pattern of rule (Bevir, 2013). This increased involvement of non-state actors has had a critical influence on the regulatory state (Jordana \& Levi-Faur, 2004; Shamir, 2010; Talesh, 2016), and there were calls for the pendulum to move again, not back to when the state held the majority of the power-base, but for more autonomy over some services.

More recently the state has been seen to be adapting, in a move from 'government to governance' with hierarchical command and control being replaced by models that enable steering at a distance. Commentators (Jessop, 2011; Kjaer, 2004; Levi-Faur, 2012) explained that one way to understand this new role of the state is as 'meta-governance', which sees the state seek overarching authority by setting and adapting the conditions in which governance occurs, including by actively mixing and managing combinations of hierarchy, markets and networks to try to achieve its goals. Stephen Ball commented that this perspective can afford the state significant powers, although governance failure will remain (Ball, 2011).

The mixing and overlaying of different governance structures can create tensions that are felt particularly in local contexts. As Newman and Clarke (2009, p.127) argued, "responsibility for managing tensions and dilemmas becomes devolved to individual agents ... [and] tend to be experienced as personal, professional or ethical dilemmas". However, Woods and Simkins (2014) maintained that there is the potential for a range of outcomes, including: healthy diversity in response to local need; undesirable fragmentation and threats to equity; and/or national pressure for conformity.

In modern governance, 'meta-governance' refers to the need of formal public organisations to exercise some control over devolved and decentralised decision-making organisations (Meuleman, 2011). For example, the state shifts attention to other forms of governance including corporate governance. Issues with governance, however, remain with economic 
power becoming as strong (if not stronger) as political power, as described by Berle and Means in 1932.

"The rise of the modern corporation has brought a concentration of economic power which can compete on equal terms with the modern state - economic power versus political power, each strong in its own field. The state seeks in some aspects to regulate the corporation, while the corporation, steadily becoming more powerful, makes every effort to avoid such regulation... The future may see the economic organism, now typified by the corporation, not only on an equal plane with the state, but possibly even superseding it as the dominant form of social organization. The law of corporations, accordingly, might well be considered as a potential constitutional law for the new economic state, while business practice is increasingly assuming the aspect of economic statesmanship" (Berle \& Means, 1932, p.357).

This section outlined the reforms of the 1980s and 1990s which led the state to shift from hierarchical governance to governance with markets and networks, thereby introducing NPM techniques to emulate market mechanisms. The next section discusses corporate governance approaches that apply in markets which governments sought to adopt in these reforms.

\subsection{CORPORATE GOVERNANCE}

Corporate governance is a broad concept and there are multiple definitions depending on one's world view. Overall, corporate governance is regarded as a key element in improving growth and ensuring market integrity and financial stability. It involves a set of relationships between a company's management, board, shareholders, and other stakeholders. It provides a structure through which the objectives of a company are set, and the means of attaining those objectives and monitoring performance (OECD, 2015a). Shleifer and Vishny (1997) commented that, "Corporate governance deals with the ways in which suppliers of finance to corporations assure themselves of getting a return on their investment" $(1997$, p.737). 
The purpose of corporate governance is to ensure an organisation is governed for its longterm prosperity and that of the society within which it operates, and it is underpinned by the principles of openness, integrity, and accountability (OECD, 2015a). The OECD 2015 report, The G20/OECD principles of corporate governance, considered that good corporate governance facilitates long term growth, and for an organisation to prosper in the long term it needs to take into account country-specific economic, legal, and cultural differences (ibid).

International development financial institutions, such as the International Finance Corporation (IFC) ${ }^{3}$ and the World Bank, look at whether organisations adopt governance principles as an indicator of business quality, and this informs decisions about investment in the organisation. It is based on their view that good corporate governance helps companies operate more efficiently, improves access to capital, mitigates risk, and safeguards against mismanagement (Center for International Private Enterprise, 2002). Good corporate governance is also viewed as making companies more accountable and transparent to investors, aimed at giving companies the tools to respond to stakeholder concerns. The IFC promotes the adoption of good corporate governance practices and standards in emerging markets as a way for these countries to increase their access to capital and encourage new investments, with the aim of boosting economic growth and employment opportunities (World Bank, 2014).

Corporate governance evolved following the development of the modern company and the separation of ownership and control (Berle \& Means, 1932). The Report of the Committee on the Financial Aspects of Corporate Governance (The Cadbury Report) described corporate governance as:

"... the system by which companies are directed and controlled. Boards of directors are responsible for the governance of their companies. The shareholders' role in governance is to appoint the directors and the auditors and to satisfy themselves that an appropriate governance structure is in place. The responsibilities of the board include setting the company's strategic aims, providing the leadership to put

\footnotetext{
${ }^{3}$ The IFC is a sister organisation of the World Bank.
} 
them into effect, supervising the management of the business and reporting to shareholders on their stewardship. The board's actions are subject to laws, regulations and the shareholders in general meeting" (The Cadbury Report, 1992, para 2.5).

On an organisational level, the term is used to refer to the "structures, systems and processes concerned with ensuring the overall direction, control and accountability of an organisation" (Cornforth \& Chambers, 2010, p.99).

Berle and Means (1932) and Fama and Jansen (1983) defined corporate governance as a set of internal and external controls to reduce the conflict of interest between the managers and shareholders stemming from the separation of ownership and control. Here, corporate governance aims to provide oversight of management (through monitoring) to achieve better strategic outcomes for the organisation (OECD, 2015a). Corporate governance also requires distance between governance and management, and aims to provide accountability to providers of capital to maintain distance from management and avoid capture (Berle \& Means, 1932).

Poor corporate governance can weaken a company's potential, leading to financial difficulties and in some cases causing long-term damage to a company's reputation. The Cadbury Report (Cadbury Committee, 1992) outlined a voluntary code to help overcome an increasing lack of investor confidence in the honesty and accountability of listed companies, brought about largely from the sudden collapse of companies despite having apparently healthy published accounts. The intention of the aspirational voluntary code was to improve standards of corporate governance, and enable the recommendations to be implemented in ways that make sense in particular circumstances. The Committee also aimed to get across to boards of directors the extent of their responsibility, what governance was for, and what their roles were in creating and sustaining an effective governance board.

The G20/OECD principles of corporate governance first published in 1999 and updated in 2015 (OECD, 2015a) are seen as an international benchmark, with ambitious principles that aim to 
promote financial stability, investment, and growth. These are intended to serve as a reference point for policy makers and other stakeholders to help them examine and develop legal and regulatory frameworks for corporate governance that reflect their own economic, social, legal and cultural circumstances, and by market participants as they develop their own practices to support economic efficiency, sustainable growth, and financial stability (ibid).

This benchmark reflects corporate governance principles of transparency, accountability, and fairness and covers six key areas: 1) measures to ensure an effective corporate governance framework, including appropriate supervisory, regulatory and enforcement institutions; 2) the rights of shareholders, including equitable treatment, and key ownership functions are specified; 3 ) the need for sound economic incentives throughout the investment chain, with a focus on institutional investors acting in a fiduciary capacity; 4) the role of stakeholders in corporate governance; 5) what is needed to ensure timely and accurate disclosure on all material matters regarding the corporation; and 6) what is needed to ensure the strategic guidance of the company by its board and the effective monitoring of management (ibid).

Siems and Alvarez-Macotela (2017) questioned whether the systemic complexity and failures in corporate governance can be addressed through generic principles of corporate governance. They argued that the effectiveness of conventional policy tools such as legislation and regulation to achieve widespread behavioural change depends on the systemic integration of the overall policy instruments, and on developing an understanding of how better to engage stakeholders in cooperative behavioural change. They suggested that this framework should be seen as a 'common frame of reference' in the ongoing debate about corporate governance reform.

There is no single model in corporate governance as legislation and companies are diverse and are constantly evolving (Association of Chartered Certified Accountants (ACCA), 2018). The next section, however, briefly describes three main theories that shape and influence governance responses to historical events: agency theory, shareholder primacy and stakeholder primacy. It also describes three board models that illustrate different approaches to corporate governance, and discusses the role of directors. 


\subsection{CORPORATE GOVERNANCE THEORIES AND MODELS}

Bridging the gap between theory and practice in corporate governance is an ongoing issue, and perhaps contributes to the successive waves of reforms that fail to deliver the intended results when put into practice. Mark Bevir suggested that formal theories in governance should be seen as guides to activity, rather as tools that can deliver on a promise to deliver efficient and effective governance (Bevir, 2013).

There are several theories of corporate governance which describe the relationship between various stakeholders of a business while carrying out the activity of the business. They each aim to inform board structure, directors' roles, duties of management, and organisational and social responsibilities, rather than regulatory structures. Different theories allow interpretation of 'facts' in different ways, and give different meanings affected by historical responses (Mansbach \& Taylor, 2018).

\subsubsection{Agency Theory (Principal-Agent Problem)}

Agency theory is a change management theory aimed at improving governance and performance (Miles, 2012). It evolved following the development of the modern enterprise characterised by the separation of ownership and control, also referred to as separation of management and finance (Berle \& Means, 1932). Under this theory, corporate governance focuses on how to guarantee financiers a return on their investments (Shleifer \& Vishny, 1997). It defines the relationship between the principals (such as shareholders of company) and agents (such as directors of company), whereby the principals of the company hire the agents who delegate the work of running the business to managers. The shareholders expect the agents to act and make decisions in the best interest of the principals. However, the agents may give way to self-interest and opportunistic behaviour, so incentives and disincentives need to be used to 'correct' the priorities of agents (Berle \& Means, 1932; Indreswari, 2006; Jensen \& Meckling, 1976; Williamson, 1964).

The separation of ownership from control is core to the principal-agency problem faced by companies. Agency theory assumes both the principal and the agent are motivated by self- 
interest which leads to inevitable inherent conflicts. Agents are supposed to act in the sole interest of their principals, but if both parties are motivated by self-interest, agents are likely to pursue self-interested objectives that differ from (and even conflict) with the goals of the principals (ibid). One objection to agency theory is that it relies on an assumption of selfinterested agents who seek to maximise personal economic wealth (Bruce et al., 2005). However, Gomez-Mejia et al., (2005) argued that although agency theory rests on an assumption of self-interest, that does not necessarily reflect opportunism as it does not make any reference to pay-performance sensitivity. Agency theory does not explicitly recognise contextual factors, however, it does give greater opportunity for generalisability.

In 1932, Adolf Berle and Gardiner Means advocated for embedding voting rights for all shareholders, to improve greater transparency, and accountability, and in their revised 1967 edition, they pointed to the disparity that existed between stakeholders who have shares and those who do not.

Agency theory contributed to the rationale for governance reforms in the latter half of the twentieth century (discussed in Section 2.2), by prescribing a series of measures to ensure the alignment of principal and agent interests in corporations. The spread of agency theory moved beyond corporate governance to reconfigure the state's role in the lives of the public during the 1980s and 1990s public sector reforms.

\subsubsection{Shareholder and Stakeholder Primacy}

Milton Friedman's shareholder theory argued that a company's only responsibility is to increase profit for its investors, and that spending shareholder money on activities that do not directly contribute to increasing shareholder wealth is not being responsible to shareholders (Friedman, 1962). This theory has been challenged following the 2007/08 GFC, with critics (Kennedy, 2000; Koslowski, 2000; Stout, 2012) arguing that shareholder primacy encourages short-term decision-making, which may not be in the best interests of the company. Studies also revealed the correlation between the increase in shareholder primacy and the growth of wealth inequality (Ireland, 2005; Lysandrou, 2011). It ignores the complex network of natural and social relationships in which organisations are embedded, and doesn't 
recognise that those who undertake socially or environmentally responsible activities can add value to both shareholders and consumers (Aghion \& Williamson, 1998). Critics also argued that long-term investment does increase value to shareholders and the corporation, not through higher cash flow but through lower cash flow risk.

Eccles and Youmans (2015) contended that under the ideology of shareholder primacy most boards of directors believe they are prevented from considering stakeholders other than shareholders in determining important strategic decision-making and reporting. Their research showed that there are legal foundations for directors to consider other stakeholders, and that a board's duty is to the interests of the corporation itself rather than the shareholders. They argued that it is the role of the board to decide which audiences are most significant for the corporation to create value over the short, medium, and long term.

Stakeholder theory comes from the management discipline of the 1970s, further developed by R. Edward Freeman (1984) to incorporate corporate accountability to a broad range of stakeholders. ${ }^{4}$ The term 'stakeholders' refers to groups of people who have a legitimate claim on the firm (Freeman, 1984, 1997), as opposed to agency theory where the agents are working for and serving the shareholders. Freeman defined stakeholders as "any group or individual who can affect or is affected by the achievement of the organization's objectives" (Freeman, 1984, p.46). Stakeholder theorists suggest that managers in organisations have a network of relationships to serve, including suppliers, employees, and business partners. The theory proposes that corporate board decision-making should be more holistic in its thinking and that board planning should consider social, financial, and environmental wellbeing, and wider stakeholder needs as well as shareholder needs (Freeman, 1984). The theory speaks of the importance of ethical business practice to achieve long-term growth and prosperity for companies (Donaldson \& Preston, 1995) based on creating value for a broad set of partners or stakeholders, including the community and customers (Freeman et al., 2010).

Stakeholder theory has influenced the composition of SOE boards, where directors are sought from both civil society and the business community, with the aim of creating a sustainable

\footnotetext{
${ }^{4}$ The term can also be traced back to the early 1960s (see Alkhafaji, 1989).
} 
and profitable organisation. However, Benn and Dunphy (2007) argued that despite the importance of stakeholder engagement, the theory is limited in addressing accountability. The key argument here is that if organisations are accountable to multiple stakeholders, there is a risk of ill-defined objectives, and accountability can be easily lost (Mbele, 2015; West, 2009).

John Kay and Aubrey Silberstone (1995) proposed a trusteeship model based on stakeholder theory, which promotes the company as a social institution rather than as a 'creature of private contract' (Kay \& Silberstone, 1995; Patterson, 2001). Directors are seen as trustees of tangible and intangible assets of the company rather than as the agents of the shareholders. This shifts the emphasis away from immediate shareholder value towards the balance of stakeholder interests including current and future stakeholders. Patterson (2001) noted that by using the concept of trust, this approach avoids the problems of tying the definition of stakeholders to contractual relationships. However, Patterson acknowledged the problem of how stakeholders are to be identified under this approach.

These different corporate governance theories have been shaped by the growth of economic power leading to the separation of ownership from control, and what is deemed good governance practice. The debate continues whether this means the enterprise should only be accountable to the shareholder, or whether good governance means the enterprise should take all its stakeholders' wellbeing into consideration. The next section discusses how these theories have been applied globally to different models of corporate governance.

\subsubsection{Models of Corporate Governance}

The term 'model' is problematic when referring to models of corporate governance, as it simplifies the reality that models are applied in different countries and local variances evolve. While general features remain, models are developed in response to country-specific factors such as economic and social conditions, and are adapted to each country's cultural values (Morck, 2005). Companies apply corporate governance principles differently according to their country's regulations and legislation, and whether these countries had experienced colonisation, or how early corporate governance had been introduced (ibid). 
While the literature cites many different models of corporate governance, three principal models are the Anglo-American model, the German Model (also referred to as two-tier), and the Japanese model. Although they take different approaches, all of these models are aimed at improving corporate governance.

\section{Anglo-American Model (Single-Tier Model)}

Historically, (as discussed in Section 2.4.1) governance evolved as a mechanism to deal with the consequences of the agency problem. The Anglo-American (or Anglo-Saxon) model is based on Agency Theory (Pande, 2011). The model has been mainly applied in the United Kingdom, United States, Canada, Australia, and New Zealand, and is described as having a shareholder emphasis. The key features of this model are that it relies on a single-tier board of directors that is usually made up of non-executive directors that are elected by shareholders (Mallin, 2011). This is a shareholder-oriented model in which shareholder rights are recognised and given importance. They have the right to elect all the members of the board and the board directs the management of the company. In New Zealand and the United Kingdom the CEO may sit on the board in an ex officio role, whereas in the USA CEOs can have a dual role as board chair as well as being part of the executive (Bowen, 2008).

The proponents of stakeholder theory argue that the traditional Anglo-American view of the company is too narrow in its focus on shareholders, and that it should be extended to other groups associated with the company, including employees and community groups (Keasey, et al., 2005). A wider stakeholder constituency in key decision-making structures and processes is an acknowledgement of the limitations of an Anglo-American model of governance that favours the shareholders (Mbele, 2015).

\section{German Model (Two-Tier Model)}

The German or Two-Tier Model takes into consideration shareholders' property rights and a company's relationships with its employees. It is based on co-determination which is a system in which both managers and workers are involved in making important decisions for a company. Workers are granted seats on the board as stakeholders and have the right to vote 
for representatives on the board of directors. It has a two-tiered board of directors with an executive board, made up of company executives, which run the day-to-day operations, and a supervisory board which represents shareholders and employees, which is responsible to the executive board and reviews major business decisions. No other country has gone as far as Germany, although most big EU members have some sort of co-determination with the majority of European countries adopting a two-tier board model (Clark, 2007; Clark et al., 2018; Fernando, 2012; Rossouw \& Sison, 2006; Tricker, 2009; Ungureanu, 2012).

\section{Japanese Model}

Under the Japanese model, the shareholders as well as the interests of lenders are recognised. Companies raise much of their capital through banking and other financial institutions, who work closely with the management. The shareholders and these financial institutions together appoint the board of directors and president (Lessambo, 2014).

\section{Mixed-Model}

The above models show that different countries have different board models and that there is no single board model which is appropriate for every country as every economy has its own economic, legal, organisational, and social environment. The different models of corporate governance raise questions about whether there are other models being applied; a combination of Western corporate governance models within an Indigenous governance framework of practices that reflect a country's cultural values. Licht $(2001$, p.149) supported this view, and suggested that culture is the "mother of all path dependencies" and argued that corporate governance models worldwide should be mapped according to culture rather than legal system to give a more accurate and useful picture. Henry and Kiel (2004) also maintained that the choice of a particular theoretical perspective depends on 'contextual factors', such as board power, environmental uncertainty, and information asymmetry. There are commentators who propose that a blend of these theories and models better describes effective and efficient good governance practice, rather than hypothesising that good corporate governance is based solely on one theory or model (Stiles \& Taylor, 1993, 2001; Yusoff \& Alhaji, 2012). 


\subsubsection{Role of Directors}

The board of directors plays a central role in governance quality (Cadbury, 1992; Larcker \& Tayan, 2019; Lipton, 2016; OECD, 2015a) and its role in the corporate governance system can change depending on the model the organisation uses. Generally, the ultimate power rests with the shareholders, who cannot act directly but only through their directors who are their elected representatives (Lipton \& Steinberger, 1978). For SOEs, directors' appointments are approved by the government.

Directors are considered to owe a fiduciary duty to their shareholders. Traditionally, this meant they were supposed to act as prudent business people, acting in good faith and on a reasonable basis to ensure the business is operated for the benefit of its shareholders (ibid). More recently there has been a call to broaden directors' concerns to include employees, consumers, the community, environment, and the national welfare. This call recommends that director obligations should include facilitating an environment that is conducive for longterm investment and sustainable growth, and involve enabling factors such as CSR, quality employment, and human capital (Lipton, 2016). Martin Lipton argued that these are important levers against the dangers of rising inequality and political tensions (ibid). The Association of Chartered Certified Accountants (ACCA) suggested that getting the diversity and balance in the boardroom right can be a powerful tool for leadership in achieving organisational effectiveness and facilitating a healthy corporate culture (ACCA, 2018).

This section discussed the development of corporate governance in the private sector and described the way in which companies are directed and controlled, and patterns of rule within businesses - its systems, institutions, and norms by which corporations are directed and controlled (Bevir, 2013). The next section discusses the influence of corporate governance in the public sector reforms following a series of global financial crises in the 1970s and 1980s.

\subsection{CORPORATE GOVERNANCE IN THE PUBLIC SECTOR}

Neoliberalism (based on neoclassical economic theory and rational choice theories) and the New Public Management (NPM) movement grew in popularity as solutions adopted by governments to reinvigorate their economies, following a series of global financial crises in 
the 1970s and 1980s. In the social sciences, neoliberal ideology maintains that the market and competition deliver benefits and efficiencies that could not be achieved by public-sector planning (Harvey, 2005). Applying neoliberal governance theory to government policy was proposed by neoclassical economists as a way of reducing governments' budgets for public services, as well as reducing the role of the state in peoples' daily lives and shifting the locus of power to the market (Nederveen Pieterse, 2010). This was achieved by transforming the public service through the spread of markets and networks (see Section 2.2.1), market mechanisms, and contracting out of services traditionally undertaken by government departments (Bevir, 2012, 2013).

The term NPM was coined by scholars (Hood, 1991; Hood \& Jackson, 1991) working in the areas of public administration. This movement proposed a new organisational design of the public sector, and aimed at applying private sector management models within the public service to deal with shrinking departmental budgets, improving efficiency, and increasing the focus on the 'customer'. By the 1990s, NPM was viewed by proponents of the model as the 'gold standard' and 'best practice' for administrative reform (Farazmand \& Pinkowski, 2006; Osborne, 2006). A key feature of the NPM reforms has been the adoption by public sector bodies of modes of organisation and governance usually more associated with the private sector. One of the arguments for these reforms was that bringing corporate governance approaches from the private sector into the public sector would improve accountability for spending, and the performance of public services (Dunleavy \& Hood, 1994; McCourt, 2013).

Neoliberal ideology and subsequent neoliberal policies had a major impact in the 1980s and 1990s on economic reforms in the UK, New Zealand, the USA, and Scandinavia. They included the contracting out of services which had previously been undertaken by government departments, or the selling of government assets to the private sector if they were a monopoly in a sector and were seen by their government as impacting on competition. Policies introduced private sector-style corporate governance based on the ideology that government departments were not the best institutions to foster efficiency or innovation (Dunleavy \& Hood, 1994). Public sector reforms were mainly associated with the goal of reducing government expenditure on the public service. The implementation of NPM brought 
about changes in the public sector ethos and approach through new management practices, marketisation, and contracting out of core services to private companies and non-profit or non-government organisations (NGOs). It also created 'arm's length' executive agencies responsible for implementation, with (in theory) a greater focus on performance management and results, instead of focussing on inputs and outputs (ibid).

Although the NPM reforms were widespread, there was a mixed record of success (Pollitt \& Bouckaert, 2004). Critics of the reforms argued that governments must be accountable to the public and that NPM and neoliberal reforms on the public sector risked undermining this trust (Denhardt \& Denhardt, 2011). In 1990 David Lange, former Prime Minister of New Zealand ${ }^{5}$ said that the role of government, "Is there to be the securer of its citizens' welfare. Where the market works well, it should be given its head. Where the market results in manifest inequity, or poor economic performance, the Government must get involved" (Lange, 1990, p.24).

The NPM reforms were criticised for the weakening of democratic accountability and for their failure to make the needs of citizens the primary focus (Minogue, et al., 1998). There were also concerns that NPM had resulted in the fragmentation of government policy and delivery across agencies and service providers (Denhardt \& Denhardt, 2000; Christensen \& Laegreid, 2007). The neostructural 'whole-of-government' approach that began to be promoted in the early $21^{\text {st }}$ century was a way to address this lack of coherence, aiming to place citizens at the centre of reforms (rather than favouring the market), policy design, and the co-production of public services (Robinson, 2015). Neostructuralism is discussed further in Section 2.7.1.

The next section discusses the rationale for extending these reforms into international development policy, along with the introduction of structural adjustment programmes.

\subsection{PUBLIC SECTOR REFORMS IN INTERNATIONAL DEVELOPMENT}

During the late 1970s and the 1980s there was a growing concern by donors and financial institutions that some recipient states were at risk of defaulting on loans due to a series of global financial crises. Reformers also viewed public bureaucracies in developing countries as

\footnotetext{
${ }^{5}$ David Lange was Prime Minister of New Zealand 1984-1989 and Attorney General 1989-1990.
} 
bloated, inefficient, ineffective, self-serving, and shaped by undesirable underlying political economic factors (Roll, 2014). They considered that by implementing policies aimed at protecting market freedoms, they could deal with corruption and promote development through increasing aid effectiveness (Robinson, 2015) using markets and networks (as discussed above). This prompted donors and international banks to tie international development assistance to neoliberal reforms, where recipient states were funded only when they adopted these reforms. This included structural adjustment loan programmes (discussed further in Section 2.6.1), but the financial obligations meant the public service was often a target of reforms aimed at cost containment and efficiency improvements that focused on reducing the size of the public service, rationalising the number of departments and agencies, and pushing through pay and employment reforms (Nunberg \& Nellis, 1995).

Prior to these reforms, aid agencies had channelled aid through government agencies as leading agents in development either through direct budget support or long-term programme support for health and education (Grugel \& Hammett, 2016; Overton \& Murray, 2016). The introduction of neoliberal reforms in the public sector saw aid agencies shifting towards project-based discrete activities, such as infrastructure projects (road building or power schemes) with a defined timeframe, as well as a shift away from working with government agencies to collaboration with civil society organisations as this was seen to be more costeffective, and because these groups were seen to be closer to the affected communities (Grugel \& Hammett, 2016).

Public sector reforms promoted by international development banks such as the World Bank and the ADB were also influenced by NPM organisational practices as well as neoliberal economic policy experiments being implemented by other countries from large economies (Ayeni, 2001; Conteh \& Huque, 2014; Nederveen Pieterse, 2010; World Bank, 2014). The agencies viewed these tools as ways to improve what they perceived as ineffective economies. The 1981 Berg Report called for greater economic efficiency and less state intervention and state-dominated policies (World Bank, 1981). In 1985 the US Treasury Secretary, James Baker, proposed a plan that allowed developing states to restructure their debt in return for neoliberal reforms such as tax cuts, privatising SOEs, and reducing trade 
barriers. These reforms resulted in major changes to the way in which aid was delivered (Grugel \& Hammett, 2016).

Donors also collaborated with other agents (i.e. NGOs and other civil society agencies) to deliver aid-funded projects, as this was seen as more cost-effective than working with the recipient state. This period of reform led to the reduction of aid funding, and the recipient state's role in economic development (ibid). As outlined by Overton and Murray (2016), the envisaged efficiencies did not occur as was expected, except for the weakening of state bureaucracies and reduction in public services. Unemployment and food prices continued to increase; and the other increase was in development agencies delivering aid projects, particularly NGOs.

\subsubsection{Structural Adjustment Programmes}

Structural adjustment programmes (SAPs) had a major impact on the economies of developing countries and the global spread of NPM because of reforms imposed by international donor agencies which countries had to accept to get financial assistance (Turner \& Hulme, 1997; Knack, 2001). The structural adjustment programmes follow the neoliberal view that development economics should be integrated into general economics (Nederveen Pieterse, 2010, p.36-37). SAPs have three main goals: increasing economic growth, correcting balance of payments deficits, and alleviating poverty (Gwynne \& Kay, 1999). Nederveen Pieterse argued that, "Structural adjustment represents a radical break with the development tradition, less because of its neoliberal thrust than because of the implicit argument that all societies must adjust to global economic imperatives" (Nederveen Pieterse, 2010, p.36-37).

As discussed in Section 2.2.1, the adoption of NPM which found support in the 1990s was motivated primarily by the widespread failure of the first wave of public sector reforms in the 1980s (Robinson, 2015). Good governance and corporate governance in the context of development could be seen as quite different things. Applying a model developed for large Western economies to developing countries with emerging economies was always going to be problematic. Countries such as New Zealand were already adapting the model to fit its context. The 2015 United Nations Development Programme (UNDP) report From old public 
administration to the new public service implications for public sector reform in developing countries argued that there is often a discrepancy between the drive for public sector reform efforts in developing country contexts, and wider shifts in the nature of governance and contemporary approaches to public management grounded in OECD experience (Robinson, 2015). The UNDP report suggested that public sector reform in developing countries needs to embrace change selectively, and draw on a range of public management models that are appropriate to different contexts while putting the needs and interests of citizens at the heart of reform efforts. It argued that a shift in focus reflects changes in the wider global environment and complex policy problems, which in turn require more coherent responses from governments and greater collaboration across public sector agencies.

The UNDP report examined four different models, the limitations of hierarchy and rigidity associated with the traditional Public Administration approach, and the problems of plurality and fragmentation associated with the NPM perspective that followed. It discussed the benefits of New Public Governance (NPG) and the New Public Service (NPS) approach, both of which have drawn on elements of traditional models and NPM. NPG, as proposed by Osborne (2006), places citizens rather than government at the centre of its frame of reference. NPS starts with the premise that the focus of public management should be citizens, community, and civil society. Here, the primary role of the public service is to help citizens articulate and meet their shared interests, rather than to control or steer society (Denhardt \& Denhardt, 2000, p.554). The report argued that this is in sharp contrast to NPM in which transactions between public managers and customers reflect individual self-interest and are framed by market principles. Its final argument is for the need to shift from a preoccupation with organisational form and function, and place greater emphasis on citizen engagement and the motivations and incentives that drive the public service (Robinson, 2015). The centrality of citizens as co-producers of policies and the delivery of services fundamentally distinguishes NPS from the other models.

The discourse on 'good governance' by international development institutions followed the failure of structural adjustment, and is used to influence the behaviour change of recipient 
countries. The term 'good governance' is not static, and emphasis on different aspects shifts depending on changing global conditions. This is discussed further in the next section.

\subsection{THE GOOD (CORPORATE) GOVERNANCE PARADIGM}

The focus on good governance stems from the struggle to restore sustained growth during the developing-country debt crises of the 1980s (Sundaram, 2015). The 'good governance' paradigm evolved in international development literature to describe the neoliberal and NPM movement of the 1980s and 1990s with regard to how public institutions should conduct public affairs and manage public resources (Gisselquist, 2012; Grindle, 2004; Maldonado, 2010; UNESCAP, [2009]). According to Nederveen Pieterse, neoliberalism rejects the 'limitations of the special case' in development theory and argues that poor countries are mainly poor because of mismanagement (Nederveen Pieterse, 2010, p.43). The neoliberal concept of good governance has a minimal state, with the state making policy decisions and leaving other agencies (the private sector, NGOs, community groups) to deliver public services. Following on from the discussion in Section 2.2, this new governance model included providing the conditions for private service providers to compete with public service providers to provide better services. The governance of essential public services, traditionally the realm of the state, would need to rely on the private and voluntary sectors to manage and deliver services, such as running prisons, building roads, and delivering humanitarian aid (Bevir, 2012, 2013). It involved freeing the market from state control and regulation, reducing government expenditures for social services, and selling SOEs to private investors.

However, neoliberal policy in the development sector was challenged by theorists and aid agencies, in particular about its failure to deliver on poverty reduction and security. In 1989, the World Bank shifted its emphasis away from structural adjustment loans to 'good governance'. Good governance was part of the discussion on how a state should be designed to achieve economic development and was promoted by international development agencies and financial institutions as a governance solution. It was argued that improved public management performance and economic development would help reduce welfare dependency, and work towards the eradication of poverty (Kaufmann et al., 1999). 
In the 1989 World Bank study Sub-Saharan Africa-from crisis to sustainable growth, the term 'governance' was first used to describe the need for institutional reform of the public sector in Sub-Saharan countries. It concluded that underlying the region's raft of development problems lay 'a crisis of governance' (Lateef, 2016). This was because in the 1980s the economic performance of the countries in the region had worsened despite the implementation of the Bank's structural adjustment programmes (Maldonado, 2010). For the World Bank during this period $(1989,1992,1994)$, good governance referred to the activity of governing by private, NGO, and voluntary organisations, as well as public institutions. It looked to Western forms of public sector management to achieve efficiency and effectiveness, a legal framework for development and respect for human rights, and accountability and transparency through the exchange and free flow of information (Bevir, 2012). The World Bank and the International Monetary Fund (IMF) made loans conditional on 'good governance'.

Critics of neoliberalism called for a balance between market and state. Recognising their strengths and weaknesses, it was seen that a secure and durable state was necessary for security against terrorism, but there were still advocates for civil society to have a bigger role in governance (Stiglitz, 1998). By 2005, almost half of the conditions imposed on the recipients of loans concerned public sector governance (Bevir, 2012).

Neostructural thinking also followed from the critical reviews of structural adjustment programmes. The following sections discuss the approach taken to re-build the role of the state through neostructuralism, and the changing values of good corporate governance including corporate social responsibility and ambicultural corporate governance.

\subsubsection{Neostructuralism}

Neostructural thinking is based on the premise that a strong state and government is essential to improve the capabilities and well-being of a society. The state needs to be robust to provide basic social services such as welfare, health, and education. It is also strengthened to play a more interventionist role and, as an extension of neoliberalism, neostructuralism supports globalisation and the ideology that economic growth can be achieved through market-led 
growth with deregulated markets and free trade (Bárcena \& Prado, 2016; Murray \& Overton, 2011a, 2011b).

In international aid development, neostructuralism focuses on rebuilding the role of states and was a response to the adoption of the Washington Consensus in the 1990s. It developed from a document by the UN and Economic Commission for Latin America and the Caribbean (ECLAC) Changing production patterns with social equity: The prime task of Latin American and Caribbean development in the 1990s (UNECLAC, 1990). For developing countries, neostructuralism means needing to overcome some of the major local obstacles to their development, including low and volatile growth, low productivity, and unequal distribution of income (Bárcena \& Prado, 2016). Aid shifted to higher level modalities and sector-wide approaches focusing on poverty alleviation, which required states to use good governance principles to take more of a lead and partner approach with donor agencies and countries (Murray \& Overton, 2011a, 2011b).

In the late 1990s, the World Bank did a re-think on the role of the state in good governance. Its 1997 report proposed that the state is central to development, including its role in the institutional environment underlying the economy, through its ability to enforce a rule of law to underpin transactions (World Bank, 1997). This report, which presented a state reform framework strategy (matching the state's role to its capability and raising state capability by reinvigorating public institutions), argued against reducing government to a minimalist state, explaining that sustainable economic and social development requires an effective state to provide goods and services, not as a direct provider of growth but as a partner and facilitator (ibid). The thinking was that a minimalist state could be captured by vocal interest groups, therefore bringing government closer to some people and taking it further away from others. The report discussed raising state capability by reinvigorating public institutions by redesigning good governance through effective rules, restraints, and incentives to encourage local accountability. This is because the increased opportunities for participation does bring risk, and greater demands may be made on the state. However, the World Bank argued that the use of communication and consensus building to make reform understandable to citizens and organisations, would enhance its chances of success (World Bank, 1998). 
The new aid strategies of the 2000s were intended as a move away from the neoliberal market-focused approach of the previous 30 years. Murray and Overton (2011a, 2011b) argued that the neostructural aid regime was reflected in two key documents - the 2000 Millennium Development Goals (MDGs), which called on aid donors to increase resources and address the MDG poverty-related goals. It also promoted the need for a strong, accountable and transparent state sector. Aid agencies argued that a strong state would be better able to meet the MDG goals and deal with security issues which, in the 1990s, had become a growing global issue in dealing with terrorism (Murray \& Overton, 2011a, 2011b. The second document, the 2005 Paris Declaration, outlined five key principles of good/effective aid practice. These self-determining governance principles intended that recipient states would 'own' their own development strategies, that a partnership approach between donor and recipient should be emphasised (to align with the strategies of both partners), that donors should work together in harmony to avoid donor fatigue for recipient states, and that donors and recipient states should be mutually accountable and transparent, manage for results, and measure effectiveness.

These new aid strategies, along with the Development Assistance Committee (DAC) of the OECD ${ }^{6}$ aim to empower recipient states to meet aid strategies, however, they also put added pressure on states to have systems closely aligning with that of their donors' financial management system, their view on good governance and the management of government services, and increased public consultation and involvement, stretching recipient state capacities (Overton \& Murray, 2016). Donors may argue that this is part of accountability and transparency to help the donor have oversight on how tax-funded aid is managed, but this has been called an 'inverse sovereignty effect' where "states were being reconstructed in the image of donor states, rather than on the basis of local values" (Overton \& Murray, 2016, p.442). Ensuring recipient states adopt donor definitions of good governance could also mean adopting donor governance systems, such as the state sector reforms that transformed government agencies to public enterprises (SOEs).

\footnotetext{
${ }^{6}$ DAC monitors development assistance and sets development co-operation standards.
} 
Following the $2007 / 08$ GFC, aid focused on the market economy to improve global security rather than direct poverty alleviation. Donors tied aid investment to their own economic and strategic interests (Gurtner, 2010) such as trade, access to cheap labour, regional security, and securing the environment for a global market economy. The shift in development ideology came on the back of Western economies (such as the UK's Labour Government) exploring 'Third Way' concepts, and Latin America's neostructural approaches to economic growth. Commentators (Leiva, 2008) pointed to the latter term - neostructuralism - to best sum up this era of aid, which focused on poverty and inequality, and strengthening democracy and the capacity of the state, and therefore local sovereignty.

Discussions on good governance in development have continued to change, and the 2000s saw international development agencies re-examine the term 'good governance', the next section discusses the changing views on what constitutes good or effective governance for the twenty first century, beyond solely economic performance.

\subsubsection{Changes to 'good' governance}

Just over a decade after the World Bank's 1989 study Sub-Saharan Africa - from crisis to sustainable growth, where the term 'governance' was first used to describe the need for institutional reform of the public sector, its 2002 World Development Report Building institutions for markets confirmed that 'one size does not fit all'; that institutions need to develop in tune with a state's particular conditions and culture, and that it is better to build on existing strengths rather than attempt to import foreign structures and concepts to promote a better balance between state, market, and civil society. The report stated that while some countries have harnessed market-oriented reforms to improve the welfare of their people, markets in other countries have not given people enough incentives to engage in wider trade, use their skills and resources more fully, or gain opportunities to increase their income, largely caused by a lack of strong judicial and regulatory institutions (World Bank, 2002). The World Bank recognised that economic reform on its own could not ensure development, and political reform was required to reduce corruption and misgovernment (Murray \& Overton, 2011a). 
The World Bank still viewed public sector management, accountability, a legal framework for development, and transparency as core elements of governance, and as instruments needed to improve the welfare of all citizens in developing countries (Maldonado, 2010). Whereas, the UK's Department for International Development (DFID) focused on legitimacy (i.e. that government should have the consent of the governed), accountability (ensuring transparency, being answerable for actions, and media freedom), competency (effective policymaking, implementation, and service delivery), and respect for the law and human rights (DFID, 2011).

In 2009, ten years on from the World Bank thinking that good governance should have the state central to development, the former UN Secretary-General Kofi Annan called for the urgent adoption of a values-based system of governance to guide the international community in tackling the economic, climate, food, and poverty crises that were occurring following the 2007/08 global financial crisis. Ten years after this call to action the good governance debate continues, with measures of public and private sector success changing. Good governance was once seen as a 'cure all', but good governance practice is again being questioned in both the public and private sectors (Grindle, 2007; Lipton, 2017). The World Bank overestimated the impact of governance reform on economic growth, and the focus on governance reform has not proved as effective as promised in fostering development (Sundaram, 2015). Its use of indicators failed to take into account country-specific challenges and conditions, with statistical analysis selection bias and a lack of consideration of the interlinkages among the range of variables (Sundaram, 2015; Grindle, 2010).

Nearly thirty years on from the 1989 World Bank report, international development agencies looked at the feasibility of achieving good governance, and now promoted 'good fit' solutions where appropriate (DFID, 2017; World Bank, 2017). In 2017, the World Bank argued against the notion of 'good governance' and set out universal requirements of 'effective governance' for development under the headings of Commitment, Coordination, and Cooperation. It proposed three levers of change - contestability, incentives, and preferences and beliefs, and three drivers - elite bargains, citizen engagement, and international influence (World Bank, 2017). In the same year, DFID's policy report Economic development strategy: Prosperity, 
poverty and meeting global challenges focused on governance reform that supports states building effective, accountable and transparent institutions that engage with the private sector to target governance-related barriers to investment; continue to help civil society groups question, challenge and collaborate with power-holders on economic development issues that matter to them; support codes of conduct, certificates and standards; encourage businesses to be responsible, transparent and accountable across their value chains; and work with partner governments to improve the management and transparency of public finances (DFID, 2017).

While the earlier definitions still represent the basis of the World Bank's perception of good governance, the World Bank's change of position on good governance is an acknowledgement that its policies did not have the desired impact on improving the wellbeing of communities it had aimed to assist. Insular views, neoliberal ideology, and lack of consultation with recipient countries are contributing factors to the lack of desired impact (Sarwar, 2016; World Bank, 2017).

The application of corporate governance principles is still seen as a valid approach to help overcome inefficient governance, cronyism, and corruption. However, it would be naïve to suggest that this alone will improve organisational performance and economic growth. The ongoing discussion is still calling for values-based corporate governance, board diversity in corporate governance practice (Page, 2007; Conley et al, 2012), and the need to recalibrate the relationship between organisations, shareholders, and stakeholders.

This 2017 DFID report reflected the growing support to include measures of social and environmental wellbeing along with economic wellbeing in re-defining good governance within international development. Amartya Sen (Sen, 1987, 1999) argued that by paying greater attention to ethical considerations and examining current practices, economies can become more productive, "it is not my purpose to write off what has been or is being achieved, but definitely to demand more" (Sen, 1987, p. 112). In the corporate sector, this could be traced back to the 1950s, and the following section discusses this further focusing on corporate social responsibility and ambicultural corporate governance. 


\subsubsection{Corporate Social Responsibility}

Stakeholder theory reflects the premise that business ethics and corporate social responsibility (CSR) are important principles in corporate governance systems. McWilliams and Siege defined CSR as "actions that appear to further some social good, beyond the interests of the firm and that which is required by law" (McWilliams \& Siegel, 2001, p.117). The idea of CSR has its roots in the writings of Andrew Carnegie and others (Freeman \& Liedtka, 1991). Carnegie believed for capitalism to work, two principles needed to be applied; the charity principle (where more fortunate members of society assist either directly or indirectly its less fortunate members), and the stewardship principle (businesses and wealthy individuals see themselves as the stewards, or caretakers, of their property (ibid).

During the 1950s, the primary focus was on businesses' responsibilities to society. Howard R. Bowen (1953) defined specific social responsibilities of companies as business executives that make decisions according to the values of society. He described it as following ethical behaviour towards stakeholders, along with the spirit of the legal and regulatory environment within which the company operates. CSR aims to ensure corporate practices are accountable to society. It conveys a 'self-imposed' underlying morality in the way a company behaves toward society (Bowen, 1953).

A.B. Carroll (1979) argued that economic and social objectives of businesses are an integral part of a business framework and not incompatible aspects. His conceptual 'building block' framework, 'Pyramid of Corporate Social Responsibility' represented four main responsibilities - the economic, legal, ethical, and discretionary (philanthropic) expectations that society has of organisations at a given point in time (Carroll, 1979, 1991), with economic responsibility placed as the foundational base of the pyramid. At the same time, society is conveying a message to businesses that they are expected to obey the law and comply with regulations because law and regulations are society's classification of the basic ground rules on which business is to operate in a civil society. Carroll (2016) added that in developing countries, multinationals will consider whether to invest there or not based on whether a 
legal and regulatory framework exists or not, as a legal infrastructure is essential to provide a foundation for legitimate business growth.

Edward Freeman (who is discussed in Section 2.4.2 with regard to Stakeholder theory - the other major concept in business ethics) extended the scope of CSR by proposing that it relates to "any group or individual who can affect or is affected by the achievement of the organization's objectives" (Freeman, 1984, p.46). Freeman noted that the traditional corporate strategy attention to shareholder's concerns could involve actions that are immoral or unethical, as well as illegal. He acknowledged the growing importance of ethics, as demonstrated by the development of codes of ethics in businesses and the increasing number of ethics courses in business schools. Freeman proposed the concept of stakeholder management as an integrating force to address CSR, ethical/moral considerations, and values. The stakeholder theory of the firm, as discussed in Section 2.4.2, is used as a basis to analyse those groups to whom the firm should be responsible (Moir, 2001).

However, Freeman and Jeanne Liedtka (1991, p.91) later argued that CSR is not a useful idea. They provided seven reasons: 1) CSR derives primarily from economics and fails to include other fields such as history, religion, and culture; 2) different models of CSR all accept the terms of the debate based on Milton Friedman's $(1962,1970)$ argument that sees corporations only as profit maximisers; 3) CSR accepts the prevailing business rhetoric of 'capitalism: love it or leave it'; 4) CSR is inherently conservative, starting with the standard received wisdom and then attempts to 'fix' its unintended consequences; 5) CSR promotes incompetence by leading managers to involve themselves in areas beyond their expertise i.e. repairing society's ills; 6) CSR accepts a view of business and society as separable from each other, each with a distinct ethic, linked by a set of responsibilities; and 7) the language of rights and responsibilities is limiting and often irrelevant to the world of the practicing manager.

Freeman and Liedtka (1991, p.96) suggested that there are at least three avenues to replace the old language of CSR with more beneficial conversations. They proposed: 1) corporations are connected networks of stakeholder interests. This expands the conversation to include 
suppliers, employees, and customers, making them legitimate partners in the dialogue; 2) corporations are places in which both individuals and communities engage in caring activities that are aimed at mutual support and unparalleled human achievement. This proposition pushes the language beyond rights and responsibilities to a focus on the ethic of care, which recognises the needs and affirms the self and its linkage with others; and 3) corporations are means through which human beings are able to create and recreate, and describe and redescribe, their visions for self and community. Their proposition urged readers to see the possibilities in institutions for different ways of living together to pursue the joint ends of individual and collective good (ibid).

CSR literature shows that understanding of corporate responsibility has evolved from being limited to the generation of profit to include a broader set of responsibilities (Crane et al., 2008). The latest view is that as expectations of corporate behaviour have changed, so has the view of the main responsibility of companies, that it should be the generation of shared value (Agudelo et al., 2019). Carroll (2015) saw an increase in: stakeholder engagement; prevalence and power of ethically sensitive consumers; the level of sophistication of NGOs; and employees as a CSR driving-force, along with increased CSR activity across the global supply chain. Agudelo et al. concluded that the future of CSR will also have to take into consideration the latest technological advances and their role as part of new business frameworks and strategies. It will need an overarching and holistic framework based on the principles of social responsibility in a way that combines the notions of sustainability, the generation of shared value, and the belief that companies can redefine their purpose to do what is best for the world (Agudelo et al., 2019).

However, there are critics of CSR or stakeholder thinking (Bebchuk \& Tallarita, 2020; Gatti \& Ondersma, 2021; Karnani, 2019; West, 2009). Andrew West (2009) noted that within the CSR literature there is no attempt to define what is meant by 'some social good' or to question whether this is the same across various jurisdictions. Karnani (2019) argued CSR is just a financial calculation for executives, like any other aspect of their business, and won't improve the wellbeing of vulnerable stakeholders. Bebchuk and Tallarita (2020), and Gatti and Ondersma (2021), maintained that 'stakeholderism' is contrary to the interests of the 
stakeholders it is supposed to serve; by imposing substantial costs on shareholders, stakeholders, and society, reducing corporate leaders' accountability, delaying reforms, and hurting economic performance. Findings from a 2020 study suggested that CSR activities can create shareholder value as long as management is properly monitored by long-term investors (Nguyen et al., 2020).

\title{
2.7.4 Ambicultural corporate governance
}

Along with the discussion that good corporate governance is expected to consider ethics such as CSR and ESG and the well-being of stakeholders including employees and business partners, more attention is also being given to Indigenous governance approaches in corporate governance. For example, the Australian Government's Office of the Registrar of Indigenous Corporations outlined on its website that:

\begin{abstract}
"Indigenous corporate governance must often be performed in conjunction with other types of governance. However, widespread expectations that Indigenous corporations will somehow meet all the governance needs at a site can overload the corporations and their directors, and can raise legal issues about their decisionmaking" (Office of the Registrar of Indigenous Corporations, n.d.).
\end{abstract}

This statement implied that any Indigenous approach taken needs to fit in with the Western corporate governance model that has been established prior to the appeal for the application of Indigenous corporate governance. However, the Australian Forum for Directors of Indigenous Organisations acknowledged the governance framework of Aboriginal organisations is more complex than most:

\footnotetext{
"In order to make good decisions, Directors and Executives must constantly reconcile how compliance processes and corporate governance responsibilities interact with cultural obligations" (Forum for Directors of Indigenous Organisations, n.d.).
}

A paper on comparative corporate governance in emerging markets proposed that scholars: 
"move away from applying Western models to the EM [emerging market] reality and seek to apply context-dependent concepts such as trust, informal norms, process, political power, rule of man, etc., that can help capture the important nuances of these countries that have changed so dramatically so quickly, and how they compete in their integration into the global markets" (Aguilera \& Haxhi, 2019, p. 37).

Acknowledging that all cultures adapt and evolve in time and with new technology, the 2006 Waka Umanga (Māori Corporations) report noted that:

"The culture of the people is not limited to historic conceptions. A credible [governance] structure is one that conforms to the peoples' current understanding of themselves as a tribe or general Māori community, of where they have been as a people, of who they are now and where they seek to be" (New Zealand Law Commission, 2006, p.69).

Ming-Jer Chen $(2002,2008)$ discussed the interplay and interrelation between the two concepts of competition and cooperation and proposes a new concept, 'transparadox', a hybrid of the either/or and both/and perspectives that characterise Western and Eastern thought. Chen argued that transparadox provides a way of thinking about ideas that appear to contradict each other, but which may be 'two sides of the same coin'. Chen proposed that principles that on the surface seem to be oppositional, such as competition and cooperation, are interrelated or interdependent and often connected by a series of implicit links. Chen proposed that making these links explicit will increase understanding that even seemingly great differences are not irreconcilable. Following on from transparadox, Chen (along with Danny Miller, 2010) also coined the term 'ambicultural' in reference to combining the best of disparate cultures, openness to new ways of thinking, a capacity for transcending divisions by embracing ideas from other parts of the world, and an ability to see the wisdom and strength in other cultural and business paradigms, culminating in a deeper understanding of their own culture. 
A 2017 study of Māori businesses argued that 'ambicultural' corporate governance practices are being adopted by indigenous businesses, in which Indigenous and Western corporate practices and worldviews are being harmonised to create and enhance economic and cultural well-being through creative governance. Nicholson et al., (2019) proposed that Indigenous governance can offer powerful insights into how Indigenous stewardship of resources can be merged with commerce to transform both organisations and societies. They argued that to transform societies, including business institutions, into environmentally, spiritually, socially, and culturally sustainable societies, an Indigenous ambicultural governance approach is valuable (ibid). The researchers supported previous academic assertions (Chen \& Miller, 2010, 2011) that the continuity of socially and culturally embedded knowledge handed down through Indigenous cultures has the potential to facilitate change in business. They argued that governance has an important role in the socioeconomic landscape, particularly when such a landscape seeks to recalibrate its activities by addressing collective well-being, while maintaining financial viability (Nicholson et al., 2019). Although their research is focused on the private sector, much of the findings could also be applied to SOEs.

The study explored endeavours to bring together Indigenous and Western practices for the purposes of creating both wealth and well-being in the service of society. The researchers emphasised the need to return to the idea of business serving the well-being of communities, and suggested that this can be done through a relational stewardship model ${ }^{7}$ (described in te reo Māori as kaitiakitanga) (Nicholson et al., 2019). The study presented a strategy model as a decision-making tool that facilitates both tangible and intangible benefits for organisational success and collective well-being. This proposed that by infusing culture and purpose throughout the business and working in an intimate way with the community and the organisation, corporate governance lends itself to flexible cultural reframing (Spiller \& Nicholson, 2017).

\footnotetext{
${ }^{7}$ Not to be confused with Stewardship theory which is defined by Davis et al $(1997, p .25)$ as a model based on a steward whose behaviour "protects and maximises shareholders wealth through firm performance, because by so doing, the steward's utility functions are maximised". Where Agency theory can depict subordinates as individualistic, opportunistic, and self-serving, Stewardship theory depicts subordinates as collectivists, proorganisational, and trustworthy (ibid).
} 


\subsubsection{Section summary}

Section 2.7 discussed the evolving nature of the 'good governance' paradigm, introduced as a concept in international development with regard to how public institutions should conduct public affairs and manage public resources through applying neoliberal and NPM theories. The failure to deliver on poverty reduction and security shifted the good governance emphasis away from structural adjustment programmes to a re-think on the role of the state. More recently, there has been a call to recalibrate the relationship between stakeholders and shareholders, with good governance seen as a collaboration amongst stakeholders working together to achieve long-term value. Nevertheless, there is no 'one size fits all' model for best practice good governance, largely due to differences in countries' legal systems, institutional frameworks and cultural traditions. However, there has been a move to more ethical approaches, whereby consideration of local context and social responsibility are becoming part of good corporate governance practices, also noting that implementing corporate governance principles and frameworks won't necessarily result in good profit performance outcomes. The following section examines current global issues in corporate governance as identified by specialists and academics.

\subsection{CURRENT GLOBAL ISSUES IN CORPORATE GOVERNANCE}

Following the 2007/08 GFC there has been a drive for long-term sustainability, greater transparency for stakeholders, and recruitment of governors with the right skills and experience to drive performance (Lipton, 2016; Lipton et al., 2016; World Economic Forum, 2016). Along with these discussions, there has also been a growing interest for decisionmaking to be more holistic and include more environmental and social responsibility, to build and maintain a 'social licence' to operate (Lipton, 2016, 2018).

Recent calls for change have been led by indexed fund investors wanting to ensure their investment on behalf of their stakeholders is safe for the long-term. To instil public and investor confidence, measures of public and private sector success have changed from solely economic markers to more holistic success measures - social, economic, environmental, and cultural indicators (Levy \& Kaplan, 2008). This is a big change from the early 1960s, when 
Milton Friedman (1962) argued that a company's only responsibility is to increase profits for its investors (as discussed in Section 2.4.2).

The reputation of a corporation is one of its most important financial assets. By understanding the aspirations of consumers, an organisation can offer products and services that match their consumers' ethical thresholds, and at the same time improve shareholder profit. There is also a growing demand for CEOs and governments to be more 'accountable' in light of recent scandals, such as the already mentioned Volkswagen diesel emissions scandal (Clarke, 2017). Boards of directors are facing more pressure from stakeholders and consumers to deal with climate change, cyber-security, poor management performance, and a wider range of legislative obligations, such as health and safety (O'Kelley \& Martin, 2017).

Management and governance both address control of corporations, however, governance requires an examination of underlying purpose and legitimacy. Recent governance discussion (Coffee \& Palia, 2016; Lipton, 2016, 2018; Mallin, 2018) identified the following features in the paradigm shift to new 'good' corporate governance:

- sustainable long-term investment in an environment affected by the impact of globalisation and digitisation on the workforce, as well as climate change

- broader stakeholder engagement to ensure on-going social licence to operate - to be more 'hand in glove' with community environmental expectations and workforce concerns (to retain talent)

- board composition reflecting society and ensuring a diversity of relevant skillsets and experience.

Research undertaken by Russell Reynolds Associates annually on global and regional trends in corporate governance showed continued development of the following key global trends: board quality and composition; deeper focus on oversight of corporate culture; investors placing limits on shareholder primacy and emphasising long-termism; ESG continuing to be a critical issue; and activist investors continuing to impact boards (O'Kelley et al., 2018). 
In the last 30 years, codes of good corporate practices (e.g. Cadbury, 1992, King Reports 1994, 2002, 2009 and 2016; OECD, 2015a; Sarbanes-Oxley Act of 2002) have been introduced in different parts of Europe, Australia, New Zealand, South Africa, and the USA, and have been subsequently modified for SOEs. However, despite these modifications there are still struggles in the SOE environment globally between legislative compliance and performance. Some of the findings in a 2015 South African dissertation emphasised limitations of the theoretical frameworks underpinning corporate governance in SOEs, as well as a need for detailed understanding of the corporate governance issues facing SOEs (Mbele, 2015).

Using capital to generate long-term wealth creation and economic prosperity is behind the World Economic Forum commissioned The new paradigm work (Lipton et al., 2016). The report is seen as a road map and an emerging corporate governance framework. The framework recalibrates the relationship between stakeholders and shareholders, and considers corporate governance as a collaboration among corporations, shareholders, and other stakeholders working together to achieve long-term value (ibid). This is a laudable aspiration.

This paradigm is consistent with a changing perspective on good corporate governance, with an expectation that even privately owned enterprises should consider the wellbeing of a wider range of stakeholders (Fink, 2018; Nestor, 2018; O’Kelley et al., 2018). It included a reemphasis of the concept of CSR (discussed further in Section 2.7.4) which encompasses business ethics, corporate philanthropy, corporate citizenship, sustainability, and environmental responsibility. The 2018 UK Financial Reporting Council (FRC) Corporate governance code, and the 2020 FRC UK stewardship code closely parallel The new paradigm by committing companies to sustainable long-term investment (Lipton \& Savitt, 2019). The stewardship code established a benchmark to create long-term value for clients and

\footnotetext{
${ }^{8}$ The King reports on governance are guidelines for South African companies issued by the King Committee on Corporate Governance. The Institute of Directors in Southern Africa owns the copyright and the King Code of Corporate Governance. Compliance with the King Reports is a requirement for companies listed on the Johannesburg Stock Exchange.
} 
beneficiaries that will lead to sustainable benefits for the economy, the environment and society (FRC, 2019). Here investment and stewardship and ESG ${ }^{9}$ issues are integrated.

However, The new paradigm and 'stakeholderism' have their critics (Bebchuk \& Tallarita, 2020; Gatti \& Ondersma, 2021). Bebchuk and Tallarita (2020) argued that stakeholder governance should be rejected as little more than a public relations exercise, with vague guidelines, that will enable unaccountable decision-making by CEOs and corporate board members whose economic incentives are aligned with shareholders - not workers or community members.

While good governance is viewed as a set of processes or organisational features that aim to improve performance, Larcker and Tayan (2019) argued that these are not shown to improve governance quality. The UK corporate governance code (2018) stated that a chief executive should not become chair of the same company. However, Larcker and Tayan (2019) maintained that research shows no consistent benefit from requiring an independent chair. They cited several pieces of research including a meta-analysis by Dalton et al. (1998) across 31 studies and found no correlation between chair status and performance. They also cited the Krause et al., (2013) review of 48 studies which found that independence status has no impact on performance, managerial entrenchment, organisational risk taking, or executive pay practices.

COVID-19 is having big impact globally on economies, and in turn corporate governance. Boards are having to make difficult decisions with regard to dividends, and potential reputational risk. For example, should they maintain dividends while employees are being laid off or furloughed, and what impact may this have on shareholders reliant on dividend income? Lynn Paine (2020) discussed in her article that the new environment is being characterised by an increasingly complex set of pressures and demands from various stakeholder groups, heightened expectations for societal engagement and corporate citizenship, and radical uncertainty about the future (Paine, 2020). These factors are

\footnotetext{
${ }^{9}$ ESG (environmental, social and governance) describes areas that characterise a sustainable, responsible or ethical investment.
} 
complicating board decision-making and challenging the shareholder-centric model (agency theory) of governance that has guided boards and business leaders for the past several decades.

This model appears to be giving way to a model of governance that puts the health and resilience of the company at its centre. Paine argued that COVID-19 has made clear that society depends on well-functioning companies to meet basic needs (food, shelter, communication etc.), and that companies do not exist solely to maximize returns to shareholders. This implies changes to the role of boards in the nature and scope of that accountability. Boards, therefore, should be concerned with returns to shareholders, as well as a full range of factors that enable the company to create value over time. Paine argued that the pandemic has challenged core premises of the agency-based model of governance in ways that have important implications for boards, and suggested five ways the board's job is likely to change in the post-Covid era. These are:

- more structured attention to stakeholders

- more attention to how business and society intersect

- more comprehensive approach to compensation

- more deliberative decision-making

- more attention to board composition and director race and ethnicity.

The 2021 OECD report, The future of corporate governance in capital markets following the COVID-19 crisis stressed that the road to recovery from COVID-19 will require well-functioning capital markets that can allocate substantial financial resources for long-term investments. It also highlighted four priorities for policy makers: 1 ) the need to adapt corporate governance frameworks (rules and practices) to the post-COVID-19 reality and to address some of the weaknesses revealed by the pandemic, in particular areas such as increased ownership concentration; 2 ) to improve the management of environmental, social and governance (ESG) risk management; 3 ) digitalisation and the need to facilitate access to equity markets for sound businesses; and 4) ensure insolvency frameworks support recovery and resilience, audit quality and creditor rights (Celik \& Blume, 2021; OECD, 2021). 
The following section examines the SOE model, including early discussion on how the COVID19 pandemic is having on the model. It firstly discusses its role in the previous global crises of the late 20 th century and the early $21^{\text {st }}$ century, which saw growth of SOEs during the public sector reforms including in developing economies. Secondly, the section examines governance of SOEs and SOE reforms in Pacific Island countries.

\subsection{STATE-OWNED ENTERPRISES}

State-owned enterprises (SOEs) are a mixed market model, sitting between the state and the private sector. In the traditional SOE model they may only be aiming to achieve improvements to wellbeing if directed to do so by the state. SOEs are based on a model that by introducing market disciplines into government-owned operations, performance of the enterprise is improved and services are delivered more effectively and efficiently (Laking, 2012). Although in a 2017 systematic analysis of empirical literature on corporate governance of SOEs, the authors stated that the primary goal of SOEs is not to make profit but to fulfil its public service and create public value (Daiser et al., 2017, p.457). This is not the case in New Zealand or in Pacific Island countries that have adopted New Zealand's model. SOEs can have a different purpose, mission, and objectives that relate to some aspect of public service and/or social outcomes (PWC, 2015).

SOEs are defined by the OECD Guidelines on corporate governance of state-owned enterprises as any corporate entity recognised by national law as an enterprise, and in which the state exercises ownership or which is under the control of the state. The state could exercise control either by being the ultimate beneficiary owner of the majority of voting shares or through other means (OECD, 2015b). It stated that good governance of SOEs is essential for efficient and open markets at both the domestic and international level. In reference to its guidelines the report referred to good governance of SOEs as critical to ensure their positive contribution to economic efficiency and competitiveness. 


\subsubsection{Growth of SOEs}

SOEs have played a large role in developing economies since the latter half of the twentieth century, aimed at helping them to become part of the global economy and reducing government budget deficits (Lieberman, 2018; Wong, 2018; World Bank, 2020a). The growth in the SOE model was mainly due to the political and economic reforms associated with the focus on neoliberal economic policies, and market liberalisation, including the privatising of public services aimed at overcoming the global oil crisis of the 1970 s and subsequent recession (see also Section 2.6). As discussed earlier in this chapter, development banks and aid agencies saw these reforms as an opportunity to make recipient countries more accountable to donor funds, reduce poor or corruptive public service and administrative practices and decision-making, and improve organisational performance. SOEs were seen as a way to improve efficiency of public service delivery and/or as a step towards privatisation or hybridisation, such as public private partnerships (PPP).

SOEs are also used to alleviate fiscal stress, as most SOEs do not count towards states' budgets. For example, SOEs can be used in areas where the government wants to generate revenue to help pay for other public services such as education and health, but find it politically difficult to introduce new taxation.

The main incentive for this shift to markets and networks and corporate governance was the view that the SOE model would improve organisational efficiency. International development financial institutions, donors, and governments used SOEs to introduce market disciplines and lessen state involvement in service delivery to reduce the size of government and to improve the financial performance of public enterprises receiving donor investment (OECD, 2005; World Bank, 2014). The SOE model was used because it was thought that it would provide goods and services better than public service government departments, and much donor investment was tied to these reforms.

SOEs were initially financed by government allocations, supplier credits, directed credits through state-owned development banks, and development partners. Many SOEs had forms of trade protection, such as import substitution policies with high tariffs, other exchange 
controls, and tax incentives. In infrastructure and other sectors (i.e. utilities, transport, oil and gas, mining, petrochemicals, steel, and fertilizers), these companies operated as state-owned monopolies (Baer, 1994).

SOEs account for 20 percent of investment, 5 percent of employment, and up to 40 percent of domestic output in countries around the world (World Bank, 2014), and SOEs have risen as significant actors in the global economy. The proportion of SOEs among Fortune Global 500 companies has grown from 9.8 percent in 2005 to 22.8 percent in 2014, with USD389.3 billion of profit and USD28.4 trillion in assets (The UN Human Rights Council, 2016). As of late 2020, SOEs accounted for 71 percent of the Morgan Stanley Capital International ${ }^{10}(\mathrm{MSCl})$ indexes (World Bank, 2020a).

\subsubsection{Governance of SOEs}

Corporate governance of SOEs is a major challenge in many economies, both big and small, in developing and developed countries (Syrett \& Bertotti, 2012; Schwarting, 2013). The OECD Guidelines on corporate governance of state-owned enterprises are used as an international benchmark and agreed standard. The guidelines provide recommendations to governments on how to ensure SOEs operate efficiently, transparently and in an accountable manner, and how governments should exercise the state ownership function (OECD, 2015b).

The OECD guidelines were first developed in 2005 as a supplement to the 1999 OECD Principles of corporate governance. The guidelines were updated in 2015 to address new issues that had arisen concerning SOEs. They aimed to provide advice on how governments can ensure that SOEs are at least as accountable to the general public as a listed company should be to its shareholders. According to these guidelines, a well-functioning SOE operates in a sound competitive, efficient, transparent, accountable, and regulatory environment. It promoted economic and social development according to commonly agreed good practices. These generic best practice principles aimed to contribute to fairer and more competitive

\footnotetext{
${ }^{10} \mathrm{MSCl}$ is an investment research firm that provides stock indexes, portfolio risk and performance analytics, and governance tools to institutional investors and hedge funds. $\mathrm{MSCl}$ is known for its benchmark indexes including the $\mathrm{MSCl}$ Emerging Market Index and MSCI Frontier Markets Index.
} 
markets, value creation, and growth and development for improving the provision of essential services to all members of society (OECD, 2015b).

The guidelines outlined the responsibilities of SOE boards, and requires them to act with integrity and be held accountable for their actions, have the necessary authority, and competencies and objectivity to carry out their functions of strategic guidance and monitoring of management. The emphasis of the SOE model in New Zealand and other Pacific Island countries, which have applied the New Zealand model largely due to New Zealand's aid investment in the Pacific, can and has changed depending on the government of the day.

The state is responsible for ensuring that there is robust legislation and regulation in place, although this can be delegated to an independent authority. SOEs are in an interesting position in that the state is the principal shareholder, and also responsible for the legislation and regulations they operate under. This means that boards of directors need to have the necessary skills to govern at arms-length from the majority shareholder, although government ministers approve appointments to SOE boards. This balancing act between political appointments and directors operating at arms-length is experienced by SOEs globally, and there can be tension between the needs of an SOE and needs of the public (Mbele, 2015; OECD, 2015b).

These tensions have been outlined by the New Zealand Office of the Auditor-General and include:

- balancing profit-seeking with long-term strategic interest and social responsibility

- different information requirements to those in the private sector; and

- ensuring that the company's performance is compared to the right benchmarks (NZ Office of the Auditor-General, 2014).

Another issue is that SOEs come under the Companies Act, which does not differentiate between private companies and SOEs. 
Corporate governance reform of SOEs can be viewed as an effective way of improving the performance of SOEs (OECD, 2015b; World Bank, 2020a). Needing to do this could also be seen as a failure by reformers to implement generic Western models without in-depth appreciation of the complexity of different cultures and capacity and capability of different economies. Reforms can also be used as an alternative for countries seeking to restructure SOEs without privatisation, or for governments to carry out corporatisation of SOEs before eventual privatisation.

Privatisation of SOEs is based on economic theory that when certain conditions are met (that there are competitive markets with private enterprises supplying goods and services) the government no longer needs to be the leading shareholder in that sector (World Bank, 2014; Greene, 2014). This is based on the economic premise that competition helps reduce prices for consumers while increasing quality and choice. However, when there is market failure or the market is not attractive to the private sector, the state will have to intervene and provide the good or service, if it is deemed to be an 'essential service' such as airport authority or postal service, or areas where the public demands lower prices and larger output, such as water or electricity distribution (Greene, 2014).

Risks for SOEs include being insulated from marketplace incentives, innovation pressure from competitors, profit pressure from shareholders, the principal-agent problem where the management may focus on enhancing its own position rather than public good, and the wrong type of incentives. There can also be excessive external interference, such as inappropriate political relationships with management and/or the board, and management and/or board appointments based on political relationships rather than managerial or director expertise (Greene, 2014; World Bank, 2020a).

SOEs that are privatised often need strong regulation to avoid corrupt behaviours and protect the public from excessive charges for essential services such as water and power (Baer, 1994; Gupta, et al., 1999). Other possible costs of privatisation of SOEs can include higher prices and resulting consumer dissatisfaction; enterprise closures and loss of employment, adverse effects to specific regions and interest groups; and backlash regarding increased salaries for 
management (ibid). Privatisation of assets previously owned by the Crown can cause constitutional, political, moral, and social dilemmas, and in New Zealand the government inserted a provision that required those exercising power under the SOE Act to comply with the principles of the Treaty of Waitangi.

The OECD Guidelines on corporate governance of state-owned enterprises discussed two risks associated with state control. On the one hand, excessive state interference can lead to lack of accountability and lack of efficiency. On the other hand, passive ownership and lack of oversight can have the same results and weaken the incentives of employees. To address these risks, the guidelines proposed that sufficient checks and balances are needed to maintain professional and accountable ownership and management of the firm (OECD, 2015b). Even when SOEs maintain rigorous corporate governance, a board's plans may be affected by public policy priorities that may impact the SOE's performance, or political demands from the 100 percent shareholder (the government) about pricing of services or quality/quantity location of supply. In the last decade there has been discussion and debate on the significant corporate governance challenges facing SOEs (Syrett \& Bertotti, 2012; Schwarting, 2013; World Bank, 2020a). Political and external influence has also been a longrunning issue for SOEs around the world, especially with good corporate governance moving from a shareholder position to a more stakeholder focus. The World Bank's 2020 Evaluation of its support to reform SOEs - 2008-2018, noted that country characteristics are among factors that are predictive of success, and control of corruption is strongly associated with SOE reform success (World Bank, 2020a).

\subsubsection{SOE Reforms in Pacific Island Countries}

In Pacific Island countries, the state participates in the economy through SOEs especially where there are areas of the economy that lack private sector interest (Amosa, 2007; Duncan \& Voigt-Graf, 2008). There is also a general viewpoint (embedded in a country's cultural values) that the state is the best means of serving its people through models such as SOEs (Duncan \& Voigt-Graf, 2008; Orlegge, 2005; Saldanha, 2004). 
SOE reform in Pacific Island countries started in the 1990s and was aimed at scaling down state involvement in public service delivery through encouraging private sector involvement (Amosa, 2007; Namoga, 2011). These reforms, similar to those undertaken in New Zealand and elsewhere in the West, were aimed at introducing corporate governance practices and encouraging SOEs to act like private enterprises to improve efficiency and achieve higher returns for the government, as well as to reduce political influence on SOEs (Duncan, 2005).

Morris O. Namoga's 2011 dissertation, Corporate governance and board performance: empirical evidence from Pacific Island countries, argued that SOEs in the Pacific have suffered corporate governance issues similar to those occurring in larger economies in their ability to generate profit. Namoga stated that this is in part due to board appointments often being subjected to 'socio-political manipulations' and that boards do not necessarily have the skills required by SOEs. In addition, although the state is expected to operate at arms' length by allowing the board and management to run the SOE, government ministers do intervene in operational matters of the enterprise. ${ }^{11}$

Principles of good governance do not always provide the expected outcomes, and a 2009 ADB report, Finding balance: Making state-owned enterprises work in Fiji, Samoa, and Tonga, pointed to examples where a country may have a comprehensive governance framework, policy, or legislation, but suffers from a lack of implementation. There are also examples of countries with less developed governance frameworks, but in practice they have adopted effective governance behaviours that go beyond the strict requirements of the law. Here effective or good governance focuses on implementation and outcomes, rather than comprehensive governance frameworks (ADB, 2009).

In the 2016 ADB Finding balance series, the SOE portfolios of nine Pacific Island countries (including Tonga and Samoa) were assessed, as well as those for Jamaica and Mauritius. The report stated that SOEs in the Pacific are a significant drain on island economies, noting that

\footnotetext{
${ }^{11}$ This is not unique to small Pacific island countries. There are examples of this happening in New Zealand also, such as in 2017 when the NZ Minister of Transport blocked SOE KiwiRail from releasing information to the public (https://www.scoop.co.nz/stories/PA1706/S00085/ministers-office-interferes-in-kiwirail-decision-making.htm, retrieved October 2020).
} 
returns from SOEs in most countries are not meeting their capital costs, with only six registering returns above zero. The study, which used global benchmarks to assess financial performance of SOEs in island countries (including in the South Pacific), found that while SOEs are established to address perceived market failures or increased accountability in public service delivery, these goals are rarely achieved. It reported that historical and financial indicators show long-term government ownership of SOEs can result in outcomes that contradict financial goals. Only one of the 10 SOE portfolios in the study produced a return sufficient to cover capital costs from 2010 to 2014, despite subsidised capital, monopoly market power, and ongoing government cash transfers. One of the lessons discussed in the study is that "reform takes time and political commitment, but it works". However, research by Cedric Saldanha highlighted that reforms need to be driven from within if they are to be successful (Saldanha, 2004).

The 2016 ADB review stated that chronic SOE portfolio underperformance highlights a fundamental flaw in the SOE model and assessed that:

- It is not an effective long-term ownership structure.

- While the SOE model attempts to replicate private ownership, it cannot replace market disciplines.

- So long as SOEs remain under majority public ownership, politicians will avoid commercial decisions with potential short-term political costs.

- SOE reform has been ongoing for decades. Globally, policymakers are aware of SOEs' performance issues, fiscal costs, and negative impact on growth and poverty alleviation (ADB, 2016a).

The study argued that privatisation, along with robust regulatory arrangements, is the most effective mechanism for long-term improvements in state asset productivity. However, it acknowledged that full privatisation is not always politically realistic, nor the most suitable reform mechanism. It suggested that partial privatisation, including PPPs, could help improve SOE performance. One of the authors, Laure Darcy, explained in a press release that: 
"Although improvements in SOE performance have been achieved in many countries, sustaining them has proven difficult ... Committing to a reform agenda that increases private sector participation in SOEs and service delivery is the most effective way to lock in gains" (Asian Development Bank, 2016b).

It is important to note that low SOE returns are not unique to the Pacific (nor to island economies), and are common throughout the world. For example, in New Zealand, (which undertook SOE reform in the late 1980s), performance has declined from 2000 onwards, as political commitment and accountability for achieving commercial returns has declined (ADB, 2016a).

Fellow author of the ADB report, Christopher Russell, when interviewed on radio stressed the importance of sharing learnings to improve SOE performance:

"The lessons learnt from SOE reform are universal and one of the great benefits associated with a bench-marking activity is it means that you know we can all learn from each other. We can learn what to do and we can also learn what not to do" (RNZ, 2016).

There are different leadership models in the Pacific and the concept of leadership is key to the diverse practices of governance in the Pacific, and this has had an impact on SOE reform. A 2008 discussion paper maintained that cultural understandings of leadership penetrate contemporary institutions, and that this impacts on the requirements of 'good' governance. While the notion of culture is not static, maintaining custom and tradition can be seen as part of one's identity, for example 'what makes us Tongan or Samoan', and is part of social cohesion, especially within the vast social diversity within the Pacific region. The paper highlighted the tension between externally driven notions of good governance and democracy, with local values in Pacific societies (McLeod, 2008).

"[This] highlights the tensions between universal discourses such as good governance and cultural relativism, begging questions pertaining to the right of 
donors to expect Pacific Islanders to comply with externally derived agendas" (McLeod, 2008, p.12). [Furthermore]: "any analysis of the fit between social and universal ideas about governance using Western frameworks .... will inevitably show that Pacific Islands fail to meet certain criteria" (ibid, p.14).

Interview responses reflect this discussion in outlining challenges with implementing corporate governance in SOEs in Tonga and Samoa.

\subsubsection{Future of SOEs}

SOEs hold a unique position and visibility in the communities where they provide services. They can be viewed as representing the state, and this perception can have an impact on the country's economy, greater than that of private enterprises. Some commentators argue that for this reason it is important that SOEs set an example of following good corporate governance practice, including human and labour rights (United Nations Human Rights Council (UNHR), 2016). Governance failure by SOEs could risk the state's credibility and undermine the rule of law (Wilcox et al., 2012). Unfortunately, the reputations of SOEs in many countries have been marred by corporate governance issues, from preferential regulatory treatment, direct subsidies, and inefficiencies, to lack of transparency and accountability, and operating with impunity (UNHR, 2016). There is a growing concern from the United Nations about human rights abuses by SOEs, such as labour rights abuses and adverse impacts on communities.

Commentators see that SOEs are likely to remain an important instrument in any government's toolbox for societal and public value creation, given the right context (PWC, 2015). The level of state ownership had been rising globally prior to the COVID-19 pandemic (De La Cruz et al., 2019). Post-Covid there is evidence that governments may go to greater lengths to protect strategic enterprises such as agriculture, medicines, water, and power. Food businesses may be subject to the next wave of state investment, to ensure food security. Only weeks before COVID-19 became a pandemic, the Dubai government announced the delisting of Dubai Ports, the largest company listed on the local exchange, to bring it back under state ownership. Saudi Arabia has re-established new state-owned firms in healthcare, 
entertainment, and other sectors to support national sovereign rights (Amico, 2020). In responding to COVID-19 crisis, governments in Spain, France, and the UK have also announced nationalisations. Amico commented that faced with a choice of lending to or investing in failing national champions, a number of governments have opted for the latter, nationalising airlines, hospitals, automotive firms, and other 'crown jewels' (ibid).

Simon Wong (2018) noted that in New Zealand, the State-Owned Enterprises Act 1986 acknowledges that an SOE may pursue non-commercial objectives but "requires ministers to enter into an agreement with the [SOE] to pay for any goods or services that they wish [an SOE] to provide to any person" (KiwiRail, 2017). The 2011 Genesis Energy strategic plan stated that it:

\begin{abstract}
"will seek full compensation from the Crown for any activities or obligations which will result in a reduction of the company's net profit or net worth, which the company is required by the Crown to undertake under the provisions of the Act, and for which a commercial return is not forthcoming" (Genesis Energy, 2011).
\end{abstract}

However, smaller economies such as Tonga and Samoa often have fewer resources and struggle to implement similar clauses in their public enterprise legislation.

In its 2020 evaluation report, the World Bank recommendations on outstanding challenges in SOE reforms included: applying a selectivity framework for SOE reform that considers country governance conditions, control of corruption, and sector and enterprise-level competition; and applying Maximising Finance for Development (MFD) and its imbedded Cascade approach (which emphasises the use of private sector finance whenever possible) for SOE reform, with the aim of enhancing internal coordination, mobilising private financing and capacity, especially for ownership reforms (World Bank, 2020a).

Bevir (2012) contended that formal theories such as neoliberalism and NPM cannot deliver fully on their promise or offer predictions of what will happen. They cannot tell policy makers that certain tools or instruments, or particular organisational arrangements will deliver 
efficient or effective governance. Bevir argued, however, that these theories are guides to activity, and the reason why there have been successive waves of reforms of the public sector is because once these theories are put into practice they fail.

In summary, the SOE model was used by policymakers as part of neoliberal public reforms to reduce state influence in the delivery of public services. It was perceived that the private sector's approach to accountability and performance would place its corporate governance in a better position to deliver these public services more efficiently and effectively. SOEs still play an important role globally, including developing countries, with aid agencies seeing public sector reforms as a way to influence and reduce corruptive practices. Although an objective of the SOE model was to provide a revenue stream, in the post-COVID-19 era, SOEs may be used more by governments to protect strategic enterprises, with some being nationalised, while others may have a PPP model applied to them as a way to access external investment, with non-essential enterprises being privatised. What may not change is the level of government influence with future versions of the SOE model.

\subsection{THE THEORETICAL FRAMEWORK}

Better understanding of how corporate governance practices are being applied by SOEs in small island states can support a global review of government and board roles in SOE governance. My research is related to social and policy issues, and this approach lends itself to empirical grounding of findings that will help to improve social life in general and specific conditions in particular, for example, giving voice to those in developing countries and the reciprocity of learnings about corporate governance of SOEs.

The research takes a development perspective, not an economic or a public sector management and administration approach. Development discourse is examined in Foucauldian terms of power and knowledge systems. In Michel Foucault's view, knowledge is connected to power (DuBois 1991, Escobar, 1985; Foucault, 1972; Marglin \& Marglin, 1990; Nederveen Pieterse, 2010; Rabinow, 1991) and as discussed in this literature review, international aid agencies applied or tied neoliberal principles of modern governance to aid 
investment in developing countries in the late twentieth century and early $21^{\text {st }}$ century, including the use of the SOE model to deliver public services.

The literature review included a discussion on the different theories and models of corporate governance and the promotion of neoliberal thinking and its application to public sector

governance. This research positions itself within an ambicultural approach to corporate governance which integrates and embraces best practice from seemingly conflicting ideologies (Chen \& Miller, 2010; Spiller \& Nicholson, 2017). This study makes an assumption that there are core governance factors that contribute to long-term sustainable decisionmaking, which can lead to an improved quality of life for all stakeholders connected to an enterprise, including shareholders, customers, suppliers, and the surrounding community.

\subsubsection{The art of government}

For Foucault 'power' is a descriptive concept: it is everywhere, it is productive, it does not have a centre, and it is neither an agency nor a structure (Foucault, 1980). The power of governmentality is the way people are instructed to govern themselves; it shifts power from the centre of authority (government) and distributes it amongst the population (ibid). In Foucault's 1978-79 The birth of biopolitics lecture series, he was interested in the way neoliberalism taught people to govern themselves (Foucault, 2008). Governmentality defines willing participation of the governed, which is based on the active consent of the general public. Where there is power there can also be resistance, and only through a deep understanding of the origin and structure of these situations will people be able to understand the future possibilities for social change (McNay, 1994).

This research uses Foucault's conceptual discourse on governmentality (Foucault, 1980). Drawing on Foucault, power can increase peoples' awareness of how their way of 'thinking and acting' has been shaped, and increasing this awareness makes it possible for them to change their way of 'thinking and acting' (Lynch, 2011). This dissertation provides insight into how recipient countries respond to donor agencies requiring the application of Western 'good governance' concepts to SOEs, alongside the recipient country's local values and cultural practices. Foucault's governmentality lens would see that a recipient state which aligns with 
donors' view on good governance becomes more pliable to meeting donors' expectations, creating a dependence due to aid being tied to meeting good governance principles.

Foucault saw the potential for neoliberalism to offer individuals an opportunity for greater autonomy, with the potential for political and economic freedoms. This would be a move away from what he perceived to have occurred under the traditional system of governmentality - the restricting dominance of the post-war welfare state over the lives of its citizens (Harvey, 2005). He observed that neoliberalism was the next step in the history of government (Foucault, 2008), and that neoliberal governmentality would eventually subdue the state as a consequence of government policies.

According to Foucault this produced another kind of consensus - political power of the electoral community. This is the right of the political community to exchange seats and rearrange the relations of the change of 'government', which gives and protects legitimacy. This becomes political consensus, in that the 'economic partners' accept the economic game of freedom (Foucault, 2008).

In his lectures, Foucault's analysis of neoliberalism is that:

"There will not be the market game, which must be left free, and then the domain in which the state begins to intervene since the market, or rather pure competition, which is the essence of the market, can only appear if it is produced, and if it is produced by an active governmentality." (Foucault, 1979, [in Burchell et al., 2008, p. 121]).

As suggested by Foucault in his The birth of politics lectures, under neoliberal policies the state delegates some of its duties such as delivering public services to the market, which becomes the sovereign power, and the state holds less influence over its citizens (Weedon, 1987, p.185). Foucault accepted the effectiveness of liberalism as an art of government to restrain growing state interference in the lives of its citizens. Liberalism, according to Foucault, could limit power of a state and make it function according to its own capacity (Burchell et al., 2008; 
Foucault, 1991). As discussed at the start of this chapter, the first wave of public reform in the latter half of the twentieth century, through neoliberalism, sought to roll back the presence of the state in citizens' daily lives, and sought to promote markets, the contracting out of public services, and the use of state-owned enterprises.

It could also be argued that international development agencies such as the World Bank, ADB, and OECD defined what is good governance to wield a type of disciplinary power over funding recipients through the use of conditionality to influence and 'correct' recipient state behaviour (Degnbol-Martinussen \& Engberg-Pederson, 1999). As noted previously, Foucault's governmentality lens suggested that recipient states become more pliable to meeting donors' expectations, creating an 'inverse sovereignty effect' (Overton \& Murray, 2016). This again can be explained in part by Foucault's discourse on power (Foucault, 1980). When recipient states and their peoples' values and norms are reshaped in line with corporate and donor principles, the prospects for funding are increased.

The term 'good governance' can be seen as a form of donor control in which recipient countries are labelled non-compliant (or deviant) ${ }^{12}$ if they do not adhere to the framework of good governance promoted by donors. According to Foucault, societal discourse mediates its power and control through institutions and elites who are charged with saying what counts as true. A government uses political, economic, and social mechanisms to control and dominate (Talbani, 1996). For Foucault, these discourses are about what can be said and thought, and also about who can speak, when, and with what authority. They represent meaning and social relationships, and they comprise subjectivity and power relations (Ransom, 1997).

Good governance contains a strong normative content of what public life 'ought to be' (Klijn, et al., 2012). In locating 'good governance' in this discourse, through the reconstruction of the state, donors can use the changing boundaries between the state and civil society to

\footnotetext{
${ }^{12}$ Recent research on the concept of corporate governance deviance (Aguilera et al., 2018) proposes that adopting a deviant corporate governance practice is contingent on the governance regulatory environment and a firm's corporate governance capacity. Its new typology of corporate governance deviance is based on a firm's over- or under-conformity with the dominant national logic, as well as its entrepreneurial identity motives.
} 
shape conduct, such as requiring recipient countries to have a financial management performance system the donor can recognise (i.e. which looks like their own system). It suggests that political action embodies the meanings and beliefs that people reach as they draw on inherited traditions to respond to new problems (Bevir, 2012). This raised the question for Bevir of whether markets and networks fitted as well with representative democracy as the ideal of a responsible bureaucracy (ibid). Governance can be pulled in a technocratic direction such that a narrow conceptualisation of governance dominates and is framed in such a way that culture and gender equality struggle (Roberts et al., 2007).

Foucault thought that a new social order with more individual autonomy would emerge from neoliberalism and experimental ways of living (Bevir, 2013). That is not how things turned out. Foucault was not alive to see the rise of networks in the public sector. In the second wave, the state works in partnership with the private, voluntary, and NGO sectors to deliver public services, and uses models such as SOEs, PPP, and whole of government initiatives. However, coordination between stakeholders has also meant difficult partnerships, and there has not always been the intended policy gains and efficiencies that was envisaged under these reforms, with citizen participation and cultural identity being compromised (ibid).

\subsection{CHAPTER SUMMARY}

Modern governance conveys a growing awareness of the ways in which dispersed forms of power and authority can secure order even in the absence of state activity (Bevir, 2013). It works through "infiltrating regulation into the very interior of the experience of subjects" (Edwards citing Rose, 2008, p.26), creating a "speculative, creative or innovative attitude to see opportunities in a competitive environment" (Simons \& Masschelein, 2008, p.53).

This literature review provides an historical account of approaches taken to deal with governance and change management issues faced by large and small economies following the global financial crises in the latter half of the twentieth century, ongoing attempts in the early $21^{\text {st }}$ century to respond to changing global conditions, and growing demand for selfdetermination by developing countries. Issues discussed raise certain questions about the role of corporate governance as a system of rules, practices, and processes used by SOEs in 
responding to these issues. There has been a been a call for the pendulum to move away from the neoliberal approach to governance; not back to when the state held the majority of the power-base, but for more autonomy over some services. The call also includes broadening the diversity of good corporate governance tools, and to look beyond the Western concepts of good governance (Murray \& Overton, 2011a, 2011b).

The literature provides context to responses given by participants and helps explain approaches taken (or not taken) by their boards and government. Although reviews on performance have been undertaken, this chapter highlights how little research has been undertaken on insights from key stakeholders in Pacific Island countries on how the SOE model is embedded, and the challenges and solutions applied to fit the model within local conditions. It also highlights the issue that there is no 'one right way' for how core governance principles should be applied, that good governance is constantly evolving and adapting to local conditions.

Foucault offered an interpretation of neoliberalism's main concepts and ideas, and the active politics of market construction. He advocated for the need to stand back and question the whole narrative of governance and examine the issue of power. Essentially, governance is about power, influence, relationships, decision-making and accountability. It is about who has influence, who decides, and how decision-makers are held accountable. (Foucault, 1980; Foucault, in Rabinow 1991; Joseph, 2014). Foucault viewed neoliberalism as providing more individual autonomy, and this provides some insight into challenges faced by countries with people who are strongly connected to their community and to collective responsibility, trying to implement neoliberal reforms.

Foucault is used to give this research a critical lens through which to question how discourse is used in development policy with regard to governance. By applying this lens to the literature on governance allows me to frame my questions in a more critical way. Interrogating these ideas has shaped this research through enabling its aim to look deeper than just accepting the neoliberal rhetoric of 'what good corporate governance is' to 'what good corporate governance means in Pacific SOEs'. 


\section{CHAPTER 3 RESEARCH METHODOLOGY}

\subsection{INTRODUCTION}

This chapter summarises the research methodology adopted in this study to answer the principal research questions. Section 3.2 outlines the epistemological approach the research is positioned within, and provides a discussion on Pacific epistemologies. Section 3.3 discusses the qualitative methodology that was applied, which enabled the participants to share their insights, reflections, and learnings. Section 3.4 outlines two methods used for the study - indepth interviews, and analysis of relevant primary and secondary literature and data. The interview format was guided by the participants, with most suggesting a discussion approach. The section also summarises the process used for the recruitment of participants, the interview sample, data collection, and the analytical approach of the data. Section 3.5 discusses ethical issues associated with undertaking fieldwork in the Pacific, and Section 3.6 outlines the positionality of the researcher.

\subsection{EPISTEMOLOGY}

The research is positioned in knowledge which participants generate from their experiences, perceptions, and reflections. It focuses on participant language and social action in how participants construct their views of corporate governance and SOE board performance. Therefore, the research adopted a social constructivist epistemology whereby the knowledge is 'constructed' as a result of socialised experiences and worldviews (Berger \& Luckman, 1966). This links with the qualitative methodology approach used, rather than empirical measurable 'facts' and figures as used in positivism (Guba \& Lincoln, 1994). Through the interviews, I was able to gain insights into participants' experiences, understanding, and knowledge of SOEs and corporate governance, and their application of this knowledge (Denzin \& Lincoln, 1994; Guba \& Lincoln, 1994; 2005).

The study's position is strategic in nature and lends itself to social and policy issues. I observed patterns in the data which has contributed towards generating new (small) theory, and it is envisaged that the empirical grounding of findings will help to improve specific conditions 
through reciprocity of learnings about corporate governance of SOEs in small Pacific Island countries.

Although I applied a Western (or a metro-centrist) epistemological approach, it is important to acknowledge Pacific ways of knowing, doing, and being. This understanding helped me in my analysis of the interview data and gave me a better insight in participant knowledge and decision-making.

\subsubsection{Pacific epistemologies in research methodologies}

In the Pacific research paradigm there are multiple Pacific epistemologies in how cultures and societies construct knowledge. They are a way of encoding and decoding social reality as it is created and experienced in the Pacific (Gegeo \& Watson-Gegeo, 2001, 2002; Smith, 1999). Kabini Sanga suggested that Pacific research lies within its philosophical orientation (Sanga, 2004) and David Gegeo (1998) explained that an indigenous epistemology refers to a cultural group's way of thinking, creating, and reformulating knowledge using traditional discourses and media of communication, and so anchoring the truth of the discourse in culture. For example, what constitutes good governance within a Pacific epistemology is informed by Indigenous knowledge and social systems at community or village level. Here governance provides authority within a community or village, and supports Pacific values and the natural environment in the wider society (Hassall et al., 2011).

"The people themselves know that good governance does not start when members are in parliament, but it starts right in the village" (Guadalcanal Province, 2006) ${ }^{13}$

A distinct characteristic of Pacific Island countries is cultural/ethnic and linguistic diversity (Gegeo \& Watson-Gegeo, 2001, 2002). There are multiple ways in which groups in the Pacific theorise and construct knowledge (ibid). This epistemological pluralism means that the way knowledge is constructed is determined by culture and context. For example, David Gegeo described two epistemologies in the Solomon Islands - Tolo/Interior Epistemology and

\footnotetext{
${ }^{13}$ From Civic Education in the Pacific: Preparatory Workshop 25 - 27 October 2006 Case study: Solomon Islands village level civic education project 'eye blong mifala des open. In G. Hassall, et al., (2011).
} 
Asi/Coastal Epistemology. They highlight how groups theorise and construct knowledge based on where groups live. 'Tauhi vā' (Ka'ili, 2005), originally from Tonga, is used in general research. In this approach nurturing socio-spatial ties through geographical and genealogical connections are applied with concepts of 'reciprocity' and 'relational spaces' (Tualaulelei \& McFall-McCaffery, 2019). In Samoan epistemology, knowledge is embedded in oration and storytelling, reflecting the respect held for elders and the matai system. Other core values that guide Samoan life and are part of effective research approaches include caring for one another and a strong connection to the community (Anae et al., 2001).

Pacific research approaches can be context-specific (i.e. education, health) but their origins may not be country-specific. For example, a contemporary Pacific research approach in education - 'Vā' (Amituanai-Toloa, 2009; Reynolds, 2016; Tuagalu, 2008; Wendt, 1999) has its origins in Samoa, Tonga, Niue, Fiji, and Hawaii. While there are different Pacific research methodologies and methods (such as the talanoa, tivaevae, faafaletui, toktok) there are also commonalities within the different Pacific epistemologies. Research is seen as a collective process as knowledge is collectively owned (Airini, et al., 2010). Theoretical underpinnings in Pacific epistemologies emphasise common values such as a holistic or spiritual worldviews that validate non-sensory, religious, and supernatural phenomena (Gegeo \& Watson-Gegeo, 2001; Meyer, 1998; Tualaulelei \& McFall-McCaffery, 2019; Wood, 2006). People are strongly connected to their community or village, and as well as the spiritual world, they are strongly connected to their mental, physical, and emotional worlds, and values and beliefs (Anae, et al., 2001; Cardinal, 2001; Wilson, 2008).

With regard to this research, my participants are experienced and well-educated, and they know and use Western ways of knowing (alongside Pacific). The type of careers they have had, or still have, mean they sit in both Pacific and Western worlds. They speak English fluently, as this is a requirement for board directors. Therefore, as a Western researcher, I did need to use a Pacific epistemology, as the power is with the participants. I acknowledge that while Pacific epistemologies can make participants comfortable, Western epistemologies was not out of place, especially when talking about subjects such as concepts of Western corporate governance and SOEs. 
Although I have not applied a Pacific epistemological approach, I use quotations from participants throughout my dissertation, especially in the findings chapters (6-10) so the reader can 'hear' the participant's voice, not just a precis of responses to illustrate findings. In addition, I wanted to give an opportunity for this group to be heard, in light of concerns by Pasifika researchers over Western appropriation with aspects of Pacific culture and language (Tualaulelei \& McFall-McCaffery, 2019) ${ }^{14}$. It was also important for me as a researcher that although my research does not have an explicit Pacific theoretical underpinning, and I did not use a Pacific research methodology, I was aware that most of my participants come from this context of narrative knowledge and the use of imagery.

\subsection{QUALITATIVE RESEARCH}

The constructivist epistemological approach links to a qualitative methodology. Qualitative research is an exploratory scientific method of observation to gather non-numerical data, such as participant perceptions based on their experience with SOEs, and stories used in interviews to illustrate these experiences (Babbie, 2014). The study used two qualitative approaches for data gathering that best matched the research questions. Data was gathered through in-depth face-to-face interviews and a review of relevant literature, including an analysis of textual, media material and official websites. This was because the international corporate governance literature stems from the northern hemisphere, or is based on countries with larger populations and bigger economies. Drawing on Tongan or Samoan SOE and government websites and newspapers provided an opportunity to analyse information that may not be found elsewhere.

\subsubsection{Reliability and Validity}

Interviews are best applied when seeking to explain 'why' and 'how' questions, or to explore behaviour that occurs in a particular context (Denzin \& Lincoln, 2005). The qualitative approach in this research used interview responses in the analysis to provide context, and to explain why actions were taken or not taken by participants. Qualitative research is also a

\footnotetext{
${ }^{14}$ N. Tavana proposes that research practices which include Samoan ways of knowing could increase Western researchers understanding of processes that are involved in constructing knowledge that may otherwise be misunderstood (Tavana, 2002, p.20).
} 
strategy for systematic collection, organisation, and interpretation of textual information (Denzin \& Lincoln, 2005; Babbie, 2014). Analysing and citing primary and secondary data along with interview data is an important exercise in critical thinking and provides reliability and validity to the findings. As discussed above, much of the literature on SOE governance takes a Western or northern hemisphere perspective, and a mixed method approach offered an opportunity for the interview data to be analysed within the context of Tonga or Samoa, as well as within international current thinking. This also provided an opportunity to highlight any salient issues between the literature, media material, websites, and the interview responses.

\title{
3.3.2 Appreciative Inquiry
}

Appreciative Inquiry (Al) is an approach that is mainly used in organisational change, and can be used in research and evaluation. It focuses on strengths rather than on weaknesses.

\begin{abstract}
"Appreciative Inquiry is about the coevolutionary search for the best in people, their organizations, and the relevant world around them. In its broadest focus, it involves systematic discovery of what gives "life" to a living system when it is most alive, most effective, and most constructively capable in economic, ecological, and human terms. Al involves, in a central way, the art and practice of asking questions that strengthen a system's capacity to apprehend, anticipate, and heighten positive potential." (Cooperrider \& Whitney 2005, p.3)
\end{abstract}

The potential political and commercial sensitivities of the topic, as well as the countries' small population size within which the participants operate, supported an Al approach. This method allowed me to identify strengths, achievements, and learnings. Al taps into stories about what participants believe can be used to create new opportunities for their organisation or SOEs in general. This approach was expressed by Cooperrider (1990) as the "heliotropic hypothesis", the idea that organisations evolve towards the most positive images they hold and articulate about themselves (Bushe, 2001). As a form of action research it has the capacity to create a sense of creative possibility, ideas, and innovative action. 
Chapters 2, 4 and 5 discuss recent reviews which outlined the poor performance of SOEs in the Pacific. It is, therefore, not surprising that during recruitment for participants, the emphasis was on what people were doing, or thought needed to be done, to deal with underperformance. As one participant said, "if you want to know what's wrong, read the [ADB] reports". However, several participants commented that they had not previously been asked by a researcher about their learnings and ideas for solutions, or whether they had something they could share more broadly, and so were happy to participate in this research.

As a process of inquiry that focuses on personal and organisational change, $\mathrm{Al}$ is based on the assumption that exploring dialogue about strengths and successes can be transformational for the individual and the organisation. It also focuses on how the future can be built on learnings from the past (Cooperrider \& Srivastva, 1987; Cooperrider et. al., 2003). It provides a strengths-based approach to understand what works best for programmes, people, institutions, and communities. Al is also a model that seeks to engage participants in selfdetermined change (Preskill \& Grindle, 2015). It creates opportunities for developing new relationships, networks, and communities of practice. It involves engaging with participants, and the process is adaptable to many cultures and contexts.

Ensuring participant requests were met with regard to how the interview would proceed, $\mathrm{Al}$ was applied to the framing of questions. Using an interview guide, the interviews took the form of a discussion, and invited the participant to draw on their life and work experiences, ending with any suggestions for positive action (Preskill \& Grindle, 2015). Although I have taken a constructivist epistemological approach, Al links well with Pacific research epistemologies with regard to the use of storytelling by participants to illustrate either what they mean, or to provide examples as part of their response.

\subsection{METHODS}

\subsubsection{Interviews}

There are many interview techniques, such as structured interviews, semi-structured interviews, and unstructured interviews. (Briggs, 1986; Denzin \& Lincoln, 1994; Lewis-Beck et al., 2004). Previous research I have undertaken with Tongan and Samoan participants has 
shown that for gathering data, face-to-face interviews, focus groups, or talanoa discussions are preferred approaches, with either a semi-structured interview questionnaire or an interview guide with topic areas or themes for exploration with the participant. My interview approach was to understand participants' perspectives, and to explore their experiences, attitudes, and reflections. The interviews were focused with my preference for depth, detail, and context, and this was reflected in the interview guide (Appendix E). It included exploratory open-ended questions which covered five broad themes, although most participants led the discussion around the themes.

Qualitative research is focused on capturing people's perspectives and insights, and in-depth interview responses are also able to provide background and context to the research (Denzin \& Lincoln, 1994, 2005; Babbie, 2014). Initial conversations with participants revealed that the preferred method was face-to-face interviews at a venue of their choice as this would provide the confidentiality they required. Focus groups were not used, as participants wanted to be able to speak candidly about their experiences, and focus groups would not have provided the confidentiality required. Many also responded that they were unlikely to complete an online or paper survey. Meeting in person helps build trust between the researcher and participant, and increases the likelihood that the participant will be more 'free and frank' and reflective with their responses (Gubrium \& Holstein, 2001; Kvale, 2007). With most of the participants having worked overseas and with tertiary qualifications, they were very familiar with the agreed interview approach, and academic obligations such as signed consent forms. One of the requirements for being a director or public servant in Tonga and Samoa is that they must be fluent in English as well as their own language, and all interviews were in English. Interviews were only digitally recorded if participants gave consent. Interviews took place either at their place of work or in a café/restaurant over a meal. One interview took place using an online platform. The in-depth interviews took about an hour, excluding the introductory and wrapping up periods. Board directors are busy people that also have other positions and limited time and so I was conscious of not taking up too much of their time. The reassurance of confidentiality and that their name or role would not appear in the dissertation contributed to a more relaxed atmosphere in which the interview took place. 
The interviews were undertaken between July and September 2019, with fieldwork starting in Tonga followed by Samoa.

\subsubsection{Talanoa}

While my interview approach appeared to align (for some participants) with an informal talanoa, I did not consciously apply this technique, based on the rationale outlined below.

I am aware how Pacific indigenous values influence the way Pacific peoples see their worlds, and talanoa is an appropriate method for the research. However, my previous research and evaluation fieldwork experience in the Aotearoa New Zealand context, and as a Pālangi/Pakeha, has led me to be very cautious about co-opting or appropriating indigenous research approaches. I did not apply talanoa as a research method as I did not see it as culturally appropriate for me as a pālagi/pālangi, and also because I do not speak the Tongan and Samoan languages.

However, some participants from both Tonga and Samoa suggested that the interview be an 'informal talanoa', where they would lead the discussion and share their ideas about corporate governance of SOEs based on their experiences either as a current or former board member, CEO, or government official. As a researcher, I recognise the power dynamic which is embedded in the relationship between my participants and me (Smith, 1992). My approach gave agency to participants to determine the style that they wanted to use. I was guided by my participants and much of it looked like talanoa, but I did not impose or deliberately seek to use a talanoa approach.

Participants led the way they wanted the interview to be conducted, which reflected the knowledge-making and knowledge-sharing approach of the participants. As they knew through the information sheet what I wanted to ask, they preferred to take the lead in the discussion with some participants starting the interview with "let's talanoa".

Talanoa is an oratory tradition which is found in many Pacific countries, including Samoa and Tonga. There are different forms of talanoa, with different protocols from formal to informal 
use, and as discussed in Section 3.2.1 there are differences between Pacific cultures and within Pacific countries (Wilson, 2001; Prescott, 2008). As a research methodology, talanoa is an Indigenous method and a culturally complex research process (Anae et al., 2001; Farrelly \& Nabobo-Baba, 2012). Unlike Western (or metro-centrist) methods of interviewing, talanoa research is undertaken in context with the understanding that it is a culturally and emotionally embedded reciprocal exchange between researcher and participant (Halapua, 2008; Farrelly \& Nabobo-Baba, 2012). Setsuo Otsuka (2006) explained that emotions and embodiment are important elements in talanoa research, and Timote Vaioleti (2006) described talanoa research as merging researchers' and participants' emotions, knowledge, experiences, and spirits in a holistic approach.

Farrelly and Nabobo-Baba $(2012$, p.4) contended that "talanoa research needs to deal with the deeper epistemological and ontological underpinnings of the lived realities of ... individual participants within their specific cultural contexts" and they advocated for the centrality of empathy to talanoa as a research methodology.

\subsubsection{Recruitment}

Recruitment for participant interviews was undertaken using a combination of approaches. For SOE board chairs and directors, there was a systematic use of lists from SOE and government ministry websites, and the Pacific Private Sector Development Initiative (PSDI) and companies register websites. From these websites, I developed a master-list of potential participants. If email addresses were available through this approach a letter of introduction email was sent. If there was only a contact phone number, I called the participant explaining the research, and requested an email address so that a letter of introduction and information sheet could be sent as a follow-up to the phone conversation. There were some challenges with this approach as not all sites provided email addresses or up-to-date contact details. Some SOEs did not display their current board of directors on their website, and some of those that did either did not provide contact details or only provided a generic SOE email address for contact. To overcome these challenges, I undertook other recruitment approaches, such as an email introduction by the SOE CEO to the board chair or other contact (as most SOE websites provided either a general email address or the contact details of its 
CEO and senior management). I also contacted some participants via the business and employment online service LinkedIn.

The recruitment approach for SOE board directors and senior management was appropriate as the interviews were focused on their professional experience and, as previously mentioned, most were familiar with the academic research process. The initial contact (either via email or phone call) was followed up with a further email containing more information about the research and including a letter of introduction from my supervisor, the information sheet and consent form. Other recruitment methods I undertook included snowballing during interviews, or assistance from the countries' Prime Minister's office or the public enterprise ministries. Most of the interview times were confirmed once I arrived in country.

While there was an attempt to contact all directors and chairs, SOE CEOs, and some senior public enterprise government officials, 30 responded and agreed to be interviewed. One participant withdrew due to a family bereavement, one withdrew due to being hospitalised, and two had to travel overseas at short notice. Other events such as the illness and subsequent death of Tonga's Prime Minister 'Akilisi Pōhiva meant that other possible interviews could not occur. The 2019 measles epidemic in Samoa was increasingly becoming an issue for some participants, and a further two participants who were contacted while I was in Samoa and who initially agreed to be interviewed were unable to meet due to the impending crisis, and this impacted on further interviews that could have taken place in Samoa. In addition, the research was undertaken at the time when SOE board applications in Samoa were underway, and this may have impacted on participant responses or willingness to participate. The COVID-19 pandemic meant that no further visits in 2020 could be considered, despite a desire to conduct follow-up meetings to report back with participants.

\section{Confidentiality}

Maintaining confidentiality was very important to participants. When developing the proposal, initial discussions with academics and other researchers raised the possibility that, although they might consider the research very useful, board directors, chairs, and government officials may not want to participate because of the sensitive nature of the 
subject, with recent international reviews critical of Tonga and Samoa SOE performance (ADB, $2009,2016 a)$. There was also a concern that the research may cover political or commercially sensitive issues. However, through reaching out very early by email and by phone I made it clear that the research is to learn from them about how they address challenges and other issues, so their insights and learnings could be shared wider within the community of SOEs. This helped to build a level of trust with the participants. Some participants were aware of my earlier work in Tonga and Samoa for New Zealand's Ministry of Foreign Affairs and Trade (MFAT), and this also helped with building trust.

\subsubsection{Interview sample and data collection}

The data collection was purposeful, with a focus on current and former chairs and directors of SOEs from different sectors (where possible). At the time of the 2019 interviews in Tonga, there were 12 SOEs that fell into five sectors with four sectors having a shared board; each shared board governs two or three SOEs - Transport, ICT, and Utility shared boards govern three SOEs each. The Property sector shared board governs two SOEs, and there is a standalone board for Tonga Cable Limited. The SOEs in Tonga are discussed in more detail in chapter 4. In Samoa, the 16 SOEs are each governed by a separate board. These are discussed in more detail in chapter 5.

Overall, 26 participants were interviewed about their involvement with either Tonga SOEs or/and Samoa SOEs. The sample provided enough rich data for the research as saturation was reached with the first ten interviews in each country; no new significant insights, perspectives, or new knowledge emerged from the data following the initial coding. The scope of study and nature of the research topic also determined that the sample was appropriate (Morse, 2000).

Table 3.1 below lists the SOEs in Tonga and Table 3.2 lists the SOEs in Samoa (at the time of the interviews in 2019). 
Table 3.1 Trading Bodies (SOEs) in Tonga (2019)

\begin{tabular}{|l|l|l|} 
No. & By shared board & \multicolumn{2}{l|}{ SOEs } \\
\hline $1-3$ & Transport Sector & $\begin{array}{l}\text { Ports Authority Tonga } \\
\text { Tonga Airports Limited } \\
\text { Friendly Islands Shipping Agency }\end{array}$ \\
\hline $4-6$ & $\begin{array}{l}\text { Information Communications } \\
\text { (ICT) Sector }\end{array}$ & $\begin{array}{l}\text { Tonga Communications Corporation } \\
\text { Tonga Post \& Tonga Fast Print Limited } \\
\text { Tonga Broadcasting Commission }\end{array}$ \\
\hline $7-9$ & Utility Sector & $\begin{array}{l}\text { Tonga Power Limited } \\
\text { Tonga Water Board } \\
\text { Waste Authority Limited }\end{array}$ \\
\hline $10-11$ & Property Sector & $\begin{array}{l}\text { Tonga Market Corporation Limited } \\
\text { Tonga Assets Manager and Association } \\
\text { Tonga Cable Limited }\end{array}$ \\
\hline 12 & Other Sector & \\
\hline
\end{tabular}

Table 3.2 Trading Bodies (SOEs) in Samoa (2019)

\begin{tabular}{|l|l|}
\hline No. & \\
\hline 1 & Development Bank of Samoa \\
\hline 2 & Electric Power Corporation \\
\hline 3 & Gambling Control Authority \\
\hline 4 & Land Transport Authority \\
\hline 5 & Polynesian Airline Ltd (Samoa Airways) \\
\hline 6 & Public Trust Office \\
\hline 7 & Samoa Airport Authority \\
\hline 8 & Samoa Housing Corporation \\
\hline 9 & Samoa Land Corporation \\
\hline 10 & Samoa Ports Authority \\
\hline 11 & Samoa Post Limited \\
\hline 12 & Samoa Shipping Corporation \\
\hline 13 & Samoa Shipping Services \\
\hline 14 & Samoa Trust Estates Corporation \\
\hline 15 & Samoa Water Authority \\
\hline 16 & Unit Trust of Samoa \\
\hline
\end{tabular}

Participants were given the choice for their interviews to be recorded or not. The recorded interviews were transcribed by me and these transcribed interview notes, along with the unrecorded interview notes, were sent to the participant for verification. Overall, 22 interviews were recorded and four interviews relied on notetaking. Only four participants responded with feedback on the shared interview notes, with feedback mainly minor and aimed at clarification of meaning. 
As discussed in Section 3.2.1, quotations were used extensively to give participants a voice. Research that involves participants (for example, interviews and participant-observation research) regularly make extensive use of quotations to illustrate the unique voices and perspectives of the participants. To ensure confidentiality an identification number was applied to each participant (e.g. Participant 003). Any more information (such as country, name of SOE, role, or sector) risked identifying the participant.

At the time the interviews took place, the sample included participants with multiple SOE roles or previous SOE roles. These are noted below in Table 3.3 footnotes. This highlights the ongoing challenge by government to appoint people to be a board director, chair, or CEO of an SOE from the small pool of people based in each country that have the necessary skills.

Table 3.3 below lists relevant past and present roles of participants at time the interview took place.

Table 3.3 Participant roles at time of interviews $(n=26)$

\begin{tabular}{|l|c|c|}
\hline Roles & Tonga( $\mathbf{n}=12)$ & Samoa $(\mathbf{n}=14)$ \\
\hline Current SOE chair/director & $4^{15}$ & $6^{16}$ \\
\hline Current SOE CEO/GM & $4^{17}$ & 3 \\
\hline Former SOE chair/director & $2^{18}$ & - \\
\hline Former SOE CEO/GM & 1 & - \\
\hline Current senior public servant & 1 & 3 \\
\hline Other & - & $2^{19}$ \\
\hline
\end{tabular}

\subsubsection{Data analysis}

Inductive reasoning starts with no preconceived ideas on findings, and is more open-ended and exploratory (Guest et al., 2012). A thematic systematic approach based on the five themes discussed in the interviews was preferred by the participants, and it also provided an opportunity to manually group responses by these themes.

\footnotetext{
15 Includes two chairs who had previously been SOE directors, and a director who is on two boards.

${ }^{16}$ Includes a chair who is also a senior public servant, a chair who is on a Tongan SOE board, and a director who also holds a senior corporate governance role.

17 Includes a former director.

18 Includes a former government minister.

${ }^{19}$ Includes subject matter person with insights for Tonga as well as Samoa.
} 
After I transcribed the recorded interviews, the scripts and notes went through systematic coding to identify big themes for each of the five themes discussed:

- Participant understanding of corporate governance principles.

- Whether participants consider local values and practices when implementing these principles. $^{20}$

- Challenges faced in implementing these principles.

- Approaches undertaken (or being considered) to address these issues.

- Learnings and reflections that can be shared with the SOE sector.

Participant responses were often insightful, reflective and memorable and they also confirmed the credibility of the analytic process for the interview data, providing not only useful insights but also building credibility of the researcher and the research. Systematic coding identifies key patterns, themes and issues in the data. It ensures confidence that the findings represent participant responses (ibid).

Not all participants were able to respond to every question, and where applicable, two participants were able to provide responses in reference to both Tonga and Samoa SOEs.

\section{Coding steps}

As an exploratory research project, I used an inductive coding method where the data is able to be coded and is able to form a narrative (Christians \& Carey, 1989).

I undertook four steps to the coding process, these were:

1. Initial coding. Manual colour coding for content analysis was undertaken using hard copies of transcripts and interview notes

2. Categorisation and determining themes. Identification and verification of initial key themes were then undertaken using Excel for further recoding and classification of the main themes within each five themes

\footnotetext{
${ }^{20}$ Current and former board members were asked this question, and other participants were asked whether they think the board takes into account local values and practices when implementing these principles. The same questioning approach applies to the challenges and solutions questions.
} 
3. Interpretation of findings. These main themes are listed in tables in the findings' chapters (6-10). This approach allowed me to compare the content of one interview with another on the same topic, making it easier to summarise the results of a number of interviews and frequency on the same topic

4. Triangulation. Where applicable, the literature review was used to inform and illuminate similar or differing perspectives from the interviews.

\subsubsection{Primary and Secondary data}

Tonga and Samoa Government websites and SOE websites hold a significant amount of information, although there was some degree of variability between SOE websites with annual reports and listing of current board members. The content analysis of this material was taken at a point in time, noting that website contents can change, and some websites at times were not always accessible. The Pacific Private Sector Development Initiative (PSDI) website which was used extensively in 2019 and 2020 was replaced in the latter half of 2020 with pages on the ADB website, but with none of the earlier country SOE information. Although gathering data from these websites could be seen as a novel approach, it provided information that would not necessarily be found in published material. The websites provided a snapshot of each SOE, and how they viewed their roles and obligations, and the policy position of each public enterprise ministry towards their appointment process and monitoring role. Chapters 4 and 5 largely draw on the analysis of material from these sites.

The literature review positions the research within the historical context of the late $20^{\text {th }}$ century and early $21^{\text {st }}$ century global financial crises which precipitated the growth of neoliberal policies and introduced corporate governance principles into the public service, along with SOE models. The literature review does not attempt to be exhaustive; rather a thematic structure was applied to the review, based on the ongoing discussion of 'good' governance, including corporate governance theories and models that attempt to explain the changing values in good governance, and to highlight that there is no one model for good corporate governance. 


\subsection{ETHICAL ISSUES}

Pacific societies and communities are varied, and Pacific values, ways of living, and beliefs are not uniform (University of Otago Pacific Research Protocols, 2011, p.7). While some values may be practiced differently in different communities as well as within respective Pacific groups, there are some commonly shared Pacific values, such as respect, reciprocity, family ties and obligations, and collective responsibility. Most cultures in the Pacific still hold their elders in great respect, and values such as humility, service to the community, and spirituality (most commonly associated with Christianity) are still actively practiced.

\subsubsection{Positionality}

Although I had previously undertaken fieldwork in Tonga and Samoa with community groups, government officials, and government ministers for evaluations for MFAT (see Section 1.3), as a pālagi/pālangi I do not have intimate knowledge of Samoan and Tongan cultures and practices. While I have been a governor on school boards, I have not worked for an SOE. Therefore, I positioned myself as part of the process, and took a 'sitting in the middle' approach (Smith, 1999).

As discussed in Section 3.2.1, there are different Pacific epistemologies, research tools, methodologies and theoretical frameworks, and there is an ongoing debate about whether a pālagi/pālangi researcher should undertake research in or on Pacific countries. However, the focus for this research is on a Western corporate governance model and how it is being adapted in two Pacific countries. I am conscious that some academics and researchers may be critical of a pālagi/pālangi undertaking this research. However, participants were pragmatic, and commented that so long as the research was being undertaken, and that the research findings could be shared with them, they did not worry about the ethnicity or cultural background of the researcher.

"I don't see any Tongan students doing this, and I don't think it really matters." (004)

"I was surprised, but it doesn't matter so long as it's being done." (021) 
"No-one has ever asked me if I had something to share with other boards here or overseas." (001)

Participants also considered that as the research is discussing a Western model, any discussions on how it is applied within their local values and practices could be explained by them to me. Previous work I had undertaken as a Research Fellow at Victoria University of Wellington on crime and justice also included interviews with Pasifika and Māori, and most preferred to be interviewed by someone not from their cultural/ethnic background as they felt they would be 'judged'; they preferred the anonymity of talking with me as they thought I would not hold any preconceptions of the interviewee. In these cases and in the current research, to ensure that I understood the nuance and context to participant responses, participants were invited to review their interview notes.

\subsubsection{Balance of power between researcher and participant}

With ethical principles in research, particularly research undertaken in the Pacific, balance is important (University of Otago Pacific Research Protocols, 2011). As previously noted, several participants commented that they had not previously been asked for their insights, and that only through completing the interview process were they able to reflect that there were some learnings they could share more broadly.

While there were five main themes in the guide, during the introductions, participants outlined how they would like the interview to proceed. They felt sufficiently briefed about what the research was exploring having received the information sheet before the interviews. All participants were senior people who were experienced either in the private sector or government (and some had political seniority). So the standard approach to ethics (with regard to researcher/participant power balance) was rather more complex in practice. The participants were confident and able to exercise control over their participation. Most participants wanted to influence how the interview would proceed, seeking to respond to the broad themes as a discussion between interviewer and interviewee. Confidentiality was a 
requirement for participation, with some agreeing to sign the consent form only after the interview had been completed.

\subsubsection{Reciprocity}

One of the aims of the research is for reciprocity and sharing of learnings, and the practice of reciprocity is also important in social science research and in Pacific cultures for strengthening relationships. Refreshments were offered during the interviews, and some interviews were undertaken in cafés and restaurants at the request of the participant. As part of the consent form participants were offered an opportunity to view and comment on interview notes taken, and asked if they would like to receive a summary of the research findings. Participants also expressed interest in attending a presentation if one took place in their country.

The original plan was to share findings in-person in Tonga and Samoa following the research analysis. However, the plans changed following the COVID-19 restrictions. A short presentation via YouTube will be used to share the research findings if travel is not possible. Some participants had referred to using YouTube as a cost-effective tool for training, so this would be a good alternative to presenting in person. Most participants also added that as they travel frequently, they are more likely to view a presentation via their mobile phone or laptop than read the dissertation or a research summary.

\subsubsection{Consent and Confidentiality}

Participation was voluntary and this was made clear in the letter of introduction, information sheet and consent form, and prior to commencing the interview. Any sensitive responses and quotations have remained confidential and have not been attributed to the participant. Participant numbers were assigned for each interview for confidentiality reasons, and because some participants held multiple roles (see Table 3.3), participants would be too easily identifiable if quotation references included role or sector. Participants were also reassured that issues deemed to be politically or commercially sensitive (or specific issues facing a particular SOE) would not be discussed, and instead more general examples would be used. 
The letter of introduction, information sheet, consent form, and interview guide went through the VUW Human Ethics process and received approval prior to fieldwork commencing (see Appendices).

\subsection{CHAPTER SUMMARY}

This chapter outlined the methodological approach taken with the qualitative data gathered. The following seven chapters discuss the findings from the analysis of this data. The next two chapters discuss SOE reforms in Tonga and Samoa, key public enterprise documents, and status of each SOE at the time of the 2019 fieldwork, as well as potential future policy changes. These chapters help provide context to participant responses, which are discussed in the interview findings' chapters (6-10). 


\section{CHAPTER 4 THE SOE MODEL IN THE KINGDOM OF TONGA}

\subsection{INTRODUCTION}

The first three chapters of this dissertation have set out the general issues and methodology for the research, and chapters 4 and 5 establish the context in which the participant interviews were conducted. This is to help provide better understanding of these responses with regard to implementing corporate governance principles in Tonga and Samoa SOEs.

Chapter 4 starts with a brief background of the Kingdom of Tonga (Tonga) including demography, cultural values and practices, political structure, and economy (Section 4.2). This is only a partial overview as there are much deeper issues and complexities than it is possible to go into here. Section 4.3 discusses SOE reforms in Tonga and documents three highlights from reforms and reviews of the SOE model in the last 20 years. These highlights were also discussed by participants in interviews, starting with the establishment of the Public Enterprises Act 2002 (PE Act), ${ }^{21}$ followed by the establishment of the Ministry of Public Enterprises (MPE) in 2006, and the introduction of the Shared Board model ten years later.

Section 4.4 documents the main functions of the twelve public trading enterprises, ${ }^{22}$ using information and statistical data retrieved from each SOE (if available), MPE, PSDI, ${ }^{23}$ and other Government of Tonga websites, interviews, relevant legislation, and other relevant documents. Section 4.5 provides a summary of the chapter.

\subsection{BACKGROUND}

\subsubsection{Demographics}

Tonga is an archipelago of about 170 islands in the South Pacific; only 45 of which are occupied (CIA Factbook, 2021). Figure 4.1 shows Tonga's spread of islands which are

\footnotetext{
${ }^{21}$ Referred to in the legislation as Public Enterprises but referred to by participants as SOEs.

22 At January 2020.

${ }^{23}$ PSDI is a regional technical assistance facility co-financed by the Government of Australia, the Government of New Zealand and the Asian Development Bank.
} 
scattered over 700,000 square kilometres, highlighting the difficulty of service provision by the Government of Tonga and SOEs.

Figure 4.1 Map of the Kingdom of Tonga's island group

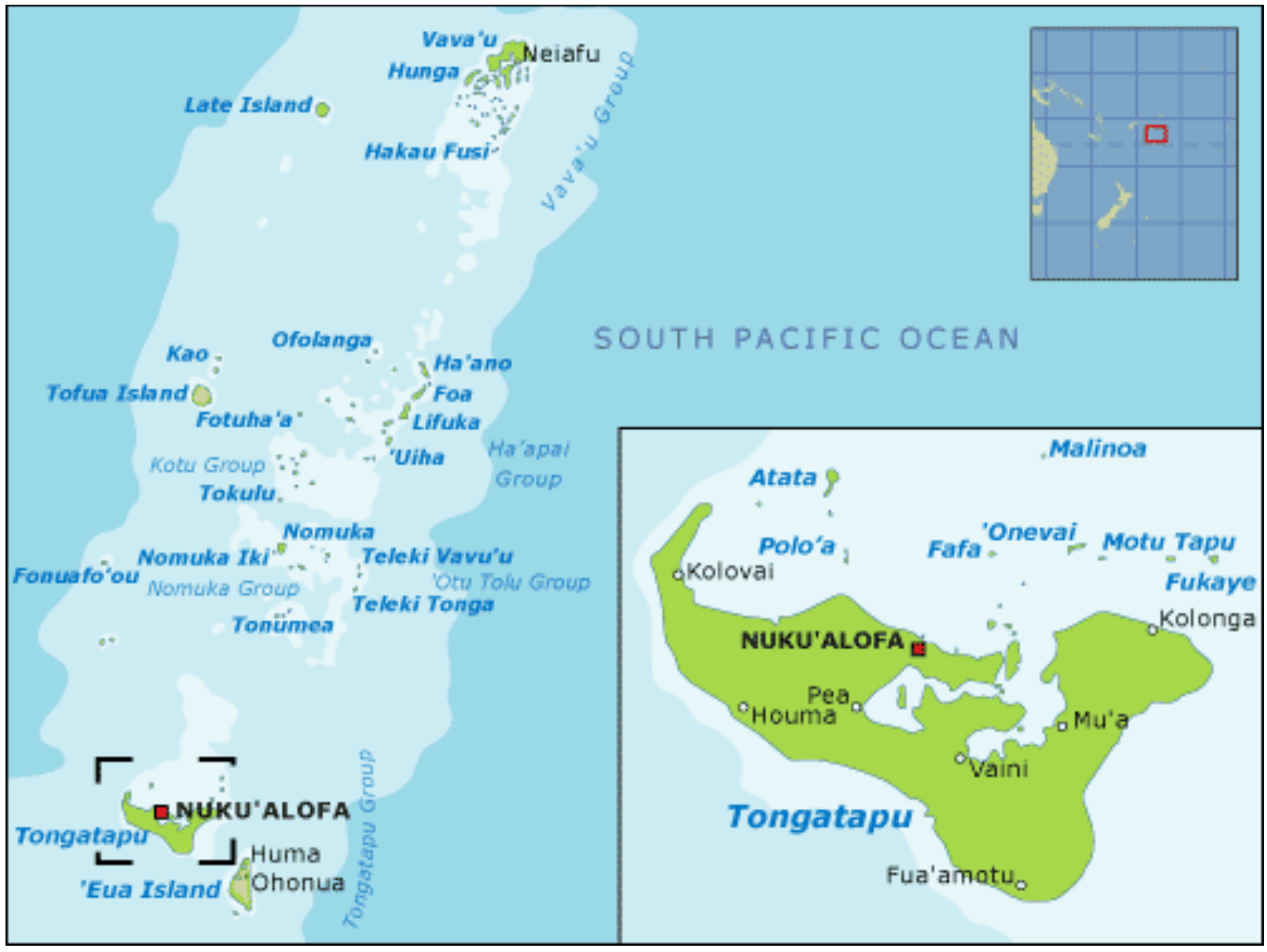

Source: Te Ara The Encyclopedia of New Zealand ${ }^{24}$

The population of Tonga in 2019 is estimated to be 104,494 (https://data.worldbank.org/country/tonga?view=chart, retrieved May 2021) and the capital, Nuku'alofa, is on the island of Tongatapu with over 70 percent of the population on this island (ibid). According to UNESCO, in contrast with other neighbouring states the literacy rate at 99 percent in Tonga is high (https://countryeconomy.com/demography/literacyrate/tonga, retrieved May 2021). The 2016 data census has school enrolment rates of 5-14 years old at 95 percent and 76 percent for secondary education with no difference between sex of student. The Human Capital Index $(\mathrm{HCl})$ measures the amount of human capital that a

${ }^{24}$ https://teara.govt.nz/en/map/1253/tonga 
child born today can expect to attain by the age of 18 . In Tonga today it will be 53 percent as productive. This is lower than the average for East Asia and Pacific region and upper middleincome countries (Human Capital Index, 2020).

\subsubsection{Cultural values and practices}

This research examines whether SOEs consider local values and practices in their implementation of corporate governance. This section provides a brief overview of Tonga's cultural values and practices. Like most cultures around the world, Tongan culture has not remained static, and in recent times with the introduction of the Internet, opportunities to work and travel overseas, ${ }^{25}$ and requirements for international trade and aid, most Tongans now operate anga fakatonga, the traditional Tongan way, and anga fakapālangi, the Western way (Metuamate, 2019; Morton, 1996).

Although an increasing number of Tongans have moved to the capital, Nuku'alofa, where Western and Indigenous cultural and living patterns have blended, village life and kinship ties continue to be important throughout the country. Everyday life is still influenced by Tongan traditions as well as Christianity. Tonga does not have an official state religion as the Constitution of Tonga (revised in 1998) provides for freedom of religion (Legislative Assembly of Tonga, Constitution of Tonga, Revised 1988). However, the Constitution declares Sunday to be a sacred day and all commerce and entertainment activities are stopped on that day (Advameg, 2016; Bennett, et al., 2017).

Tonga has strong Indigenous governance systems, and traditional Tongan culture is still stratified by rank: there are commoners, chiefs, nobles, and the Royal family. Nobles and chiefs are estate holders and still hold some influence, but do not hold absolute power within the government. Many of them are high ranking civil servants, and all other people are deemed 'commoners'. Rank and status are fixed from birth, and language is important when addressing people of different social standing. In practice, high rank and high status always go together (Campbell, 2015; Moimoi Steen \& Drescher, 2011).

\footnotetext{
25 Tongans have strong ties to overseas countries in New Zealand, Australia, and United States. Many Tongans now live overseas, in a Tongan diaspora, and send home remittances to family members who remain in Tonga.
} 
For many Tongans, relationships between people of differing social rank and class of authority are still governed by values such as respect for and obedience to traditional authority, or those of higher rank, and the corresponding value of reciprocity. Within a political framework constructed around such authority, there is a predisposition to accept it, so long as the reciprocal obligations of leadership are observed (Powles, 2014). The four values that form the pillars of Tongan society are faka'apa'apa (respect); lototo (humility); tauhi va (maintaining good relationships); and mamahi'i me'a (loyalty) (Thaman, 1997). Prior to democratic elections occurring, there were many women from noble families on SOE boards. At the time the fieldwork took place in 2019 , there were only two women on SOE boards. Some participants surmised that this may be due to stereotypes about women's roles in Tongan society, with women still being seen as more suited to community boards, yet there are women on private sector boards. At the time of writing, the Tongan Government is yet to ratify the Convention on the Elimination of All Forms of Discrimination Against Women (CEDAW).

\subsubsection{Political Structure}

Tonga's political system is more complex than can be covered in this section, and reforms are ongoing. However, this section aims to provide some background to better understand the perspectives from participants, such as why decisions are made (or not made) by SOE boards or government ministries.

Tonga is a constitutional monarchy and its written constitution dates back to 1875 . Unlike other Pacific nations, Tonga never completely lost its Indigenous governance and remains the only monarchy in the Pacific (CIA World Factbook, n.d.). The King is Head of State and Commander-in-Chief of His Majesty's Armed Forces. The King is advised by a Privy Council whose members he appoints (Australia Department of Foreign Affairs and Trade (DFAT), n.d.).

Prior to 2010, Tonga's Legislative Assembly comprised 12 cabinet ministers, two governors, nine noble representatives elected by 33 of their peers, and nine people's representatives elected by the people. The Executive consisted of the Privy Council and Cabinet, all of whose 
members were appointed by the Monarchy. Tonga's prime minister was appointed by the King from among the members of Parliament after having won the support of a majority of its members (Legislative Assembly of Tonga, n.d.).

In the 1990s, a call for constitutional reform was led by the pro-democracy movement over growing concern with the lack of accountability and transparency displayed by government ministers (Latukefu, 1993; Campbell, 1994) with regard to expense allowances, passport sales, land deals, and other financial mismanagement and royal scandals (Campbell, 2005; Powles, 2009). Guy Powles (2014) contended that the objective of the mainstream prodemocracy reformers was to transform the role and authority of the Monarch, but preserving certain elements of his power and influence to reflect a desire to retain traditions and values (Powles, 2014). I. Futa Helu, a supporter for greater democracy, saw reforms as moving Tonga from aristocracy to kingship rather than from kingship to democracy (Helu, 1992). Epeli Hau' ofa added that even with constitutional reforms, the royal and noble lineages would still be the focus of Tongan culture and Tongan identity as well as being the signposts of historical continuity for Tonga as a nation (Hau'ofa, 1992).

In 2006, King Tupou IV appointed a new prime minister, Dr Feleti Sevele, who was a non-noble in an attempt to placate pro-democracy supporters, slow down the reform process, and ensure the three pillars of Tongan society - the royal family, the nobility, and the people are preserved (Ward et al., 2009). Sevele was the first non-noble to hold the post since 1881, when the founder of the Free Church of Tonga, Reverend Shirley Waldemar Baker was made prime minister by King George Tupou I.

In November 2006, there were protests in the capital by pro-democracy supporters over the lack of action by the National Committee for Political Reform (NCPR) and Legislative Assembly to advance democracy in the government. The protests turned into riots which severely damaged property in much of Nuku'alofa. In 2008, King George Tupou V announced that there would be parliamentary elections in 2010 (Campbell, 2015; Powles, 2009; Ward et al., 2009). 
In 2010, major political reform occurred with the objective of a more inclusive and representative parliament and government. Political reform reflected public demands that both parliament and government be more accountable and transparent. The Constitution of Tonga was amended to shift most of the executive powers of the state from the Monarch to a Cabinet of elected leaders. For the first time in Tonga's history, the government was then elected (Powles, 2014) and in 2015, the country elected its first non-noble prime minister, pro-democracy campaigner 'Akalisi Pohiva.

From 2010 onwards, Tonga became a constitutional monarchy and a parliamentary democracy while still maintaining its indigenous governance. The governing structure comprises the Executive (Cabinet), Legislature, and Judiciary. The unicameral Legislative Assembly comprises 17 People's Representatives (on the basis of universal adult suffrage in a general election which takes place every four years), nine of whom are elected from Noble Representatives elected from among the holders of Tonga's 33 noble hereditary titles, and up to four additional members appointed by the King on the advice of the prime minister (DFAT, n.d.)

Executive power is vested in the Cabinet of ministers, legislative power is vested in the King in parliament, and judicial power is vested in the Supreme Court. The constitutional amendments in 2010 removed the King's royal privilege to appoint the prime minister and ministers of cabinet, and transferred that authority to the members of the Legislative Assembly. The King, however, appoints the prime minister on the recommendation of the Legislative Assembly (Legislative Assembly of Tonga, n.d.). Although the new constitution has reduced the King's power, which was devolved to the Cabinet and answers to the Legislative Assembly, the King retains the right to veto legislation (DFAT, n.d.). Like most emerging democracies, especially with a constitutional monarchy, there is still much political churn in Tonga. Kinyondo and Pelizzo (2013) contended that the monarch still has much control over the operations of parliament and that this is impacting on its effectiveness to deliver better legislative results. 


\subsubsection{Economy}

As a small open economy, Tonga is vulnerable to external economic shocks such as global financial crises, environmental disasters due to tropical cyclones and climate change, and global pandemics (World Bank, 2011, 2019, 2021) such as COVID-19 which has severely impacted Tonga's tourism.

In the 1980s Bertram and Watters (1985) termed the acronym MIRAB (Migration, Remittances, Aid, Bureaucracy) to describe remittance-dependent economies of small countries. Tonga's economy is dependent on migration, remittances and foreign aid, as its major sources of revenue (Bertram, 1993; Jimenez-Soto and Brown, 2012), and despite efforts to diversify, Tonga has a limited export sector, consisting of agricultural exports including squash, fish, root crops (yams), vanilla, and kava, and a fledging tourist industry. Since the 1960s, imports have exceeded exports, resulting in a consistent pattern of negative trade balances, therefore the economy remains dependent on external aid and remittances from Tongans living and working overseas to help bolster the economy and offset its trade deficit, accounting for nearly one-third of Gross Domestic Product (GDP) (Bertram, 1993; JimenezSoto \& Brown, 2012; Small \& Dixon, 2004).

Bertram has contended that as long as the 'rent' from remittances and international aid can be obtained for an indefinite period, it is a sustainable strategy (Bertram, 1986, 1993). As external resources, they represent revenue from 'invisible exports' to industrialised countries. However, this argument has not been popular with donor agencies (Poirine, 1998). One commentator argued that this increases dependency without any sign of efficiency and effectiveness (Hughes, 2003).

With regard to trade, agriculture is the leading productive sector. Agricultural exports, including fish, make up two-thirds of total exports (ADB, 2020). In 2018, Tonga's principal export destinations were Hong Kong (30\%), followed by New Zealand (15\%) and Australia and USA (both 14\%). Much of Tonga's food supplies are imported and cover the full range of consumer and industrial goods. In 2018, Tonga's principal import sources were New Zealand (39\%), followed by USA (13\%) and Australia (12\%) (DFAT, n.d.). In 2018, Tonga's product 
exports were USD12.9 million, making it the number 210 exporter of products in the world. Product imports in 2018 were USD146 million, ranking Tonga 202 of 221. Top exports are nonfilleted fresh fish (USD2.6m), vegetables (USD2.51m) and other processes (USD1.41m). During the last five reported years the exports of Tonga have changed by -USD3.48 million from USD16.4 million in 2013 to USD12.9 million in 2018 (Observatory of Economic Complexity, n.d.; CIA World Factbook, n.d.).

The manufacturing sector is very small, and tourism is modest and prior to COVID-19, had potential for expansion. Tonga has a sound basic infrastructure and well-developed social services. The government is trying to develop the private sector, encouraging investment opportunities in renewable energy and deep-sea mining, but it faces high unemployment among the young, moderate inflation, pressures for further democratic reform, and rising civil service expenditures (DFAT, n.d.).

Tonga is not collecting sufficient revenue to fund regular expenditures and to make investments that will support long-term economic growth. Tonga collects approximately 20 percent revenue to GDP, which is low by international and regional standards. The low level of revenue as a percentage of GDP can be explained by the reliance on remittances and grants. Both categories are hard to tax and in the case of remittances may be used mainly for consumption and not long-term income-producing investments (Adam Smith International (ASI), 2016)

Tonga's GDP growth averaged two percent annually between 2010 and 2014, which is below both the regional average (2.8\%) and global average (3.5\%) (Government of Tonga Ministry of Finance and National Planning, 2016). While there are several government initiatives that are designed to improve growth potential and macroeconomic stability in Tonga, growth will continue to be reliant on the New Zealand, Australian, and US economies through remittances (https://www.worldbank.org/en/topic/migrationremittancesdiasporaissues/brief/migration -remittances-data2021, retrieved May 2021). 
Table 4.1 below lists some economic data to provide insight into how much Tonga relies on personal remittances and aid as a percentage of its GDP.

Table 4.1 Economic statistics for Tonga

\begin{tabular}{|c|c|c|}
\hline 2019 & USD & $\%$ GDP \\
\hline Current GDP 26 & 512 million & 0.7 \\
\hline GDP per capita ${ }^{27}$ & 4,903 & - \\
\hline Exports of goods and services ${ }^{28}$ & 108 million & 21.1 \\
\hline Imports of goods and services ${ }^{29}$ & 341 million & 66.6 \\
\hline Trade balance and \% GDP & (199.1 million) & (42.11) \\
\hline Public expenditure and \% GDP ${ }^{30}$ & 90 million & 19 \\
\hline Foreign development assistance (Net ODA) $)^{31}$ & 108 million & $\%$ GNI 20 \\
\hline Personal remittance received ${ }^{32}$ & 190 million & 37.2 \\
\hline Received by country 2017 & - & - \\
\hline USA & 57.3 million & - \\
\hline NZ & 55.4 million & - \\
\hline \multirow[t]{2}{*}{ Australia } & 27.7 million & - \\
\hline & $\mathbf{N}$ & $\%$ \\
\hline Net Migration ${ }^{33}$ & $(3,999)$ & \\
\hline International Emigrant stock ${ }^{34}$ & 74,433 & - \\
\hline \multicolumn{3}{|l|}{ Destination Country } \\
\hline NZ & 23,940 & - \\
\hline USA & 21,221 & - \\
\hline Australia & 13,002 & - \\
\hline
\end{tabular}

\section{Migration}

Following World War Two, internal migration grew with Tongans from outer islands moving to Tongatapu for education and work opportunities. With a growing population in Tonga, differentials in wages and educational opportunities along with demand for labour, overseas migration followed mainly to New Zealand, Australia, and USA. (Small \& Dixon, 2004). In small populations, the loss of key skilled people can have a big impact on the country and remittances of cash and goods from migrants who live and work overseas help the Tongan economy (ibid).

\footnotetext{
${ }^{26}$ Source: https://data.worldbank.org/indicator/NY.GDP.MKTP.CD?locations=TO\&view=chart

27 Source: https://data.worldbank.org/indicator/NY.GDP.PCAP.CD?locations=TO

${ }^{28}$ Source: https://data.worldbank.org/indicator/NE.EXP.GNFS.CD?locations=TO

${ }^{29} \mathrm{https}$ ://data.worldbank.org/indicator/NE.IMP.GNFS.CD?locations=TO

${ }^{30}$ Source: Government of Tonga Statistics Department.

${ }^{31}$ Source: https://data.worldbank.org/indicator/DT.ODA.ODAT.CD?locations=TO

32 Source: https://data.worldbank.org/indicator/BX.TRF.PWKR.CD.DT?locations=TO

${ }^{33}$ Source: https://data.worldbank.org/indicator/SM.POP.NETM?locations=TO

${ }^{34}$ Source: https://countryeconomy.com/demography/migration/emigration/tonga
} 


\section{Remittances}

Table 4.1 above shows that remittances as percent of GDP is 37.16 percent. The average value for Tonga during the period 1975-2019 was 23.71 percent with a minimum of 12.22 percent in 1981 and a maximum of 37.49 percent in 2018. For comparison, the world average in 2019 based on 159 countries is 4.74 percent. ${ }^{35}$ The USA is the main source of remittances, followed by New Zealand and Australia. ${ }^{36}$ Whether this will be sustained (as ties decrease between Tongans born overseas and their parents or grandparents' homeland) will depend on how connections are maintained (Lee, 2007).

As discussed, in small populations the loss of key skilled people through migration can have a big impact on the country. Brown et al. (2013) conducted research on remittances in Fiji and Tonga and how remittances perform the function of poverty and social protection. This research argued that remittances are more stable than other financial flows. In a 2012 study on the impact of permanent migrants' remittances in Tonga, Eliana Jimenez-Soto and Richard Brown argued that remittances reduce the incidence of poverty by 31 percent within households. The research findings suggested that remittances can make a positive impact on the daily lives of people in Tonga and that an increase in migration opportunities has the potential to positively impact development (Jimenez-Soto \& Brown, 2012).

In a systematic literature review of development impacts on labour mobility in the Pacific, Yvonne Underhill-Sem and Evelyn Marsters (2017) noted that some Pacific communities are nominating several workers for the Recognised Seasonal Employer (RSE) scheme and encouraging them to commit a portion of their wages for community development projects. Examples included Lapaha Town Council in Tonga (McLellan, 2008, p.51).

\section{Foreign development assistance}

As mentioned, foreign development assistance (ODA) in the form of loans, grants and direct aid is another important component of the Tongan economy, and globally, Tonga is the

\footnotetext{
35 https://data.worldbank.org/indicator/BX.TRF.PWKR.CD.DT?locations=TO\&view=chart, retrieved May 2021.

${ }^{36}$ https://countryeconomy.com/demography/migration/remittance/tonga, retrieved May 2021.
} 
fourth-largest recipient of aid in ODA per capita terms (ASI, 2016). Construction and infrastructure projects funded by donor grants and soft loans are sources of growth for Tonga (DFAT, n.d.). Fifty-nine percent of its 2014-2015 annual revenue relied on foreign aid (Bertram, 2015). Foreign development assistance (Net ODA) in 2019 was USD108 million, 20 percent of gross national income (GNI). ${ }^{37}$

New Zealand's key focus areas for development funding include support for: governance institutions such as the Tonga Electoral Commission, judiciary and policing; trade and economic growth (e.g. development of the vanilla industry); infrastructure (e.g. strengthening Nuku'alofa's electricity); the health and education sectors; and regional safety and security of the region (Ministry of Foreign Affairs and Trade, n.d.).

\subsection{SOE REFORMS}

Most SOE services impact the people of Tonga, such as power, water, waste, and telecommunications. The SOE model is aimed at improving these services, and providing net profits for the government, which is the majority or 100 percent shareholder, to use in other sectors such as education and health (Government of Tonga, Ministry of Public Enterprises, n.d.).

In the last 20 years, reforms of the SOE sector in Tonga aimed to improve efficiency in SOE operations to contribute to the government's revenue and improve its fiscal position. They also aimed to improve governance and board accountability, and to overcome capacity issues with board appointments. The 2016 ADB Finding balance study discussed that Tonga's SOEs had become fiscal burdens on the national economy, and that Tonga's economy was adversely impacted by the $2007 / 08$ GFC (ADB, 2016a). It maintained that although the SOE portfolio performance declined through the period 2002 to 2009, it had since partially recovered. The ADB study also emphasised that political commitment to reform is a key driver for commercial results, and argued that the partial recovery follows the government's implementation of a broad-based reform programme supported by the strengthened Public

\footnotetext{
${ }^{37}$ https://data.worldbank.org/indicator/DT.ODA.ODAT.CD?locations=TO, retrieved May 2021.
} 
Enterprise Act in 2010 (The Pacific Private Sector Development Initiative, n.d.; ADB, 2016a). ${ }^{38}$ The report noted Tonga's progress towards placing its SOEs on a more commercial footing from 2009 to 2015. These included: liquidating two SOEs; contracting out Tonga Water Board's plumbing services in 2015; awarding six community service obligations (CSO) contracts, of which two were awarded to the private sector; implementing skills-based SOE director selection in 2013; strengthening the SOE Act in 2010 by removing all government ministers from SOE boards; publishing SOE results in local newspapers from 2010; and adopting a SOE divestment and ownership policy in 2015 incorporating a privatisation and reform pipeline as some public enterprises were criticised for competing on an uneven playing field with the private sector. However, public expectations that SOEs should be providing more affordable services continue (participant interviews, 001, 011).

The following section highlights three changes in the SOE sector that research participants said contributed to both challenges and solutions to improve SOE corporate governance: the establishment of the 2002 Public Enterprises Act; the formation of the Ministry of Public Enterprises (MPE) in 2006; and the introduction of a shared board model in 2015/16. Previous and current governments support Public Private Partnerships (PPP) as a way to help SOEs improve performance and to finance projects and core activities, and some SOEs (such as Tonga Power) have introduced PPP to help deliver services. Note that while the Act and the ministry's name use the term 'public enterprises', 'SOE' and public enterprise (PE) are used interchangeably by participants, and some PE websites and reports, which may have led to differing expectations of level of service between the public and the state.

\subsubsection{The Public Enterprises Act}

The Public Enterprises Act (PE Act) 2002 (amended in 2006 and 2010) and the 2016 Revised Edition (the primary Act) outlines the scheme, formation and ownership of PEs (SOEs), roles of the PE (SOE) minister, chief executive officers (CEOs) and directors, and the powers and accountability of the board. It also sets out the principal objective of every SOE and subsidiary - that is, to be as profitable and efficient as comparable businesses that are not state-owned.

\footnotetext{
38 This information was retrieved March 2020 from http://www.pacificsoe.org/tonga/state-owned-enterprises which is no longer able to be accessed in 2021. PSDI has a new website, one of its focus areas is the reform of SOEs and public-private partnerships.
} 
The Act sets out how SOEs are formed and owned, government's interest in the SOEs, and powers of the minister relating to corporate intent. It outlines accountability expectations for boards, such as corporate planning and reporting obligations and roles of directors, as well as the appointment and termination process. The Act also outlines expectations for CEOs and their staff.

Previously, the King and Privy Council decided who sat on SOE boards, and the nobility or a government minister chaired the boards. Reform changes leading to the 2002 Act meant that government ministers and public officials had to vacate their positions on boards. In Part IV of the Act it states that:

"...no member of Cabinet or the Legislative Assembly shall be appointed or remain as a director of a public enterprise except in the case where a new public enterprise is established and Government sees the need to appoint Cabinet members for an interim period"' (Government of Tonga, Public Enterprises Act 2002).

The principal objective for all SOEs (as set out in the PE Act, Section 4) is to be profitable and provide the best service to the people. Public Enterprises are described on the Ministry's website as "dynamic, proactive and innovative public sector businesses that contribute to the objectives and goals of the stakeholders/shareholders and provide excellent services to its customer base" (Government of Tonga Ministry of Public Enterprises, n.d.).

\subsubsection{Government Policy Obligation (GPO)}

The Act also includes a requirement (inserted in 2010) for an SOE to undertake noncommercial activities under Part II Section 4A of the Act, whereby the Cabinet may instruct a SOE to provide a GPO. This is when the government requires a SOE to provide goods and/or services to any persons, at a certain price. The government and the SOE enter into an enforceable agreement and must comply with any government budget and procurement processes. The agreement must be in writing and must record the nature and quantity of the 
goods and/or services to be provided, and specify the total price paid for the goods and/or services.

The total price of the GPO is calculated as the total cost of provision of the goods or services by the SOE, plus a margin to allow the SOE to meet its targeted return on equity as set by the minister. Where user fees are insufficient to cover the full cost of the goods and/or services, the balance of the total price shall be paid by the government to the SOE.

One of the issues discussed in the interviews is the role of the director. In the Act it states that a director shall "act in good faith and in the best interests of the public enterprise" (Part IV, Section 13). Ten of the 12 participants interviewed on Tonga's SOE thought that although directors were aware of their obligations in the Act, sometimes they felt there was a grey area when it came to acting in the best interests of the SOE if it was contrary to directives from the government as the 100 percent shareholder. In particular, this is an issue for Cabinet directives to provide community service obligations (CSOs), which are described in the Act as a GPO. Part IV which discusses directors' roles, Section 13 (d) states that directors shall "not agree to the public enterprise and subsidiary incurring an obligation unless the director believes at the time on reasonable grounds that the public enterprise shall be able to perform the obligation when it is required to do so". Half of the participants spoke of the pressure to undertake a non-commercial activity through a GPO directive, even though it was not in the best financial interest of their enterprise. These participants commented that the government did not always meet its part of the obligation, and that there was an expectation that costs should be met by the enterprise. The obligation provision has also been used by government ministers as a CSO for their constituents and this issue is discussed further in the findings chapters (6 to 10$)$.

\subsubsection{Ministry of Public Enterprises}

The Ministry of Public Enterprises (MPE) was established in 2006. It is mandated under the Public Enterprises Act 2002 (the 2016 Revised Edition), in addition to the Companies Act 1995, and the National Strategic Development Plan (Government of Tonga Ministry of Public Enterprises, n.d.). The Ministry focuses on economic reforms to better use public resources 
in wealth creation and adding value to service provision. Its function is to integrate its policy with the government's emphasis on a private sector-led economy (Government of Tonga Ministry of Information and Communication, n.d.).

The Ministry's website outlines its mission, values, core functions, its core customers, and its organisational structure (incl. Monitoring and Compliance, Rationalisation, Corporate and Services, and Legal Divisions). Its mission is stated as to: assist all SOEs to become profitable and sustainable and contribute to the government revenue; ensure SOEs are servicing and meeting the needs of all Tongan people; prepare SOEs for eventual privatisation (when required); and ensure SOE outcomes and direction are in line with government plans and priorities (Government of Tonga Ministry of Public Enterprises, n.d.).

The Ministry states that its values are:

- 'positive values' (We need to think optimistically about the future direction of the organisation, and the overall client base of the organisation. We have to serve our clients and customers with a positive attitude);

- 'pride' (We have to be proud of ourselves and the Ministry we are working for); 'support and collaboration'. (We need to be supportive of our customers and to work collaboratively with our other stakeholders);

- 'Integrity and honesty' (This is a vital value for the operation. We must have a zero tolerance for dishonesty);

- 'empowerment' (We must empower our staff and our stakeholders and customers to achieve their goals and contribute to ours); and

- 'service and professionalism' (We must have a professional approach to our service provision and our work in general).

Core functions

The ministry has outlined (and underlined) its core functions on its website (https://mpe.gov.to, retrieved 8 April 2020) along with the main objectives of these core functions. These are to:

1. Provide advice: i) to the PE minister in strengthening the implementation of the Public Enterprises Act 2002, ii) to the minister and Secretary for Finance in regard to a SOE's 
financial position performance and prospects, recommending corrective actions where necessary, and iii) to the minister on the process for approval of appointment of the CEO and directors.

2. Undertake policy development in consultation with other departments for consideration by government, to improve the financial performance and management of government business investments.

3. Monitor PEs (SOEs) through:

- gathering non-financial and financial information on all SOEs, and monitoring the database of their financial performance

- reviewing SOE Statements of Corporate Intent, annual and half yearly reports, and making periodic reports on the financial performance of SOEs

- evaluating SOE requests for borrowing and loan guarantees, in coordination with the Ministry of Finance Debt Unit

- ensuring SOEs comply with the legislation, checking their operations against the PE Act, ensuring regulations are met by SOEs, and that SOEs are aware of GPOs.

4. Assist with corporatisation of government trading activities and manage privatisations as part of government's divestment programme.

5. Assist with the appointment process of directors and CEOs.

The main objectives of these functions are to add value to the government's investments, reduce losses in the SOEs, and contribute to the focus and the direction of the government's strategic development plans.

\section{Dividends}

The ministry also assists the PE (SOE) minister by advising on dividend targets. It assesses SOE figures, then discusses the minimum and maximum amount with the Cabinet. Its role then is to advise the minister, take recommendations to the AGM, and negotiate a dividend amount with the board (Participant, 009).

MPE ensures SOEs get audited every financial year and that they develop corporate plans each year for the coming years, and to estimate their budget. Corporate plans only allow for 
what is budgeted, and MPE asks SOE analysts to not only focus on net profit, but also on longterm strategies such as infrastructure upgrade, and to consider financial and non-financial costs in their analysis (Participant, 009).

\section{Core customers}

The Ministry's core customers as stated on its website are the: public enterprises (SOEs), Legislative Assembly (under the PE Act the Ministry is required to present certain information at a prescribed time), other government ministries (to help it carry out some of its functions, such as Ministry of Finance, Ministry of Infrastructure, Ministry of Agriculture, Food, Forestry and Fisheries, and Ministry of Labour and Commerce), and the Privy Council and Cabinet. The Cabinet and His Majesty's Privy Council, as indicated in the PE Act, confirm or authorise decisions regarding the future direction of the SOEs, or appointments to the leadership of the organisations.

\subsubsection{Shared Board Model}

The Shared Board Model is an initiative not seen elsewhere in the Pacific, aimed at overcoming the challenges of having a small population. The Ministry introduced shared boards in 2016 to overcome issues in finding directors with the skills and experience needed to govern a SOE. This reduces the number of directors required by grouping SOEs into shared sectors (utilities, transport, ICT, property). ${ }^{39}$ It is also aimed at improving systems and standards across the sector. For example, in the utility sector, Tonga Power Limited's (TPL) systems are more advanced in terms of policy, IT, HR, billing, and procurement than Tonga Water Board (TWB). By adopting TPL's system the Ministry hopes that TWB can accelerate improvement of its standards. The SOEs in the utility sector also share a building and service policy for joint billing (power and water) which is expected to cut the cost of operations as well as improve services for their customers. The Ministry also sees the model as a 'steppingstone' to rationalise some SOEs, with the Act allowing SOEs to move to Holding companies, or for SOEs within one building to become one company (Participant, 009). In September

\footnotetext{
${ }^{39}$ Cable (TCL) is separate as it provides wholesale service to all these providers, and the government is only a majority shareholder.
} 
2020, new directors for the 12 PEs were also appointed for a one-year term so performance can be considered before appointments are renewed.

\subsection{TONGA'S PUBLIC ENTERPRISES}

In 2020 there were 12 Public Enterprises in Tonga. The tables below outline these by sector, and their core functions. Information and data have been sourced from Public SOE and MPE websites, relevant legislation, and the former PSDI website. ${ }^{40}$

This research is not an evaluation of SOE websites, but it is interesting to see what information they hold about their function and purpose, with most focused on providing information about the services they provide. The websites varied in content, with four of the 12 SOEs having non-functioning websites in April 2020. Only three SOEs stated they are PEs or SOEs, that they are either wholly owned by the government, or that the government is a majority shareholder. Four websites listed their board of directors, although two of these were out of date. One website added directors' other roles, and this can be seen as a positive accountability response to avoid conflict of interest, or to show the level of expertise directors hold. Two other websites did not list their board or management, but their 'News' page included photos of board members with the minister and management. Four other websites listed their management teams or business structure. Only one enterprise published its annual reports, one listed other SOEs, and four SOEs outlined their mission/vision statements on their website.

Tables $4.2-4.6$ below list the 12 public enterprises in Tonga by sector and shared boards (in 2020).

\section{Transport sector}

Ports Authority Tonga (PAT)

The PAT website listed the shared board and management team, and has published its annual reports from 2011 to 2019. In 2014 PAT became responsible for the ports on the outer islands

\footnotetext{
${ }^{40} \mathrm{PSDI}$ is a regional technical assistance facility co-financed by the Government of Australia, the Government of New Zealand, and the Asian Development Bank (ADB) http://www.pacificsoe.org/tonga/source-of-data/.This site is no longer accessible but provided financial highlights for all public enterprises.
} 
of Ha'apai, Eua, and Vava'u, as well as Nuku'alofa. PAT is engaged in a significant redevelopment of the Vuna wharf which is being financed through a T\$32.5m loan from the Government of China (https://www.portsauthoritytonga.com/, retrieved September 2020).

PAT has paid dividends to the Government of Tonga since 2010. The 2015 dividend of T\$1m represents a 250 percent increase in dividend payments in the five years since 2010 . Its stated mission is: "Developing, promoting and sustaining superior gateway facilities at seaports of Tonga to enhance Tonga's economic prosperity". Its vision is: "To be a premier provider in the quality of port service for the people of Tonga and the world", and its values are: "professionalism; innovation; teamwork; corporate citizenship; employee wellbeing and diversity; and progressive leadership" (ibid). The Authority's power is to issue standing orders or codes of practice in respect of operating or managing the port as a commercial undertaking. For that purpose, it may levy such port charges, fees and rates whatsoever arising from the management and operation of the ports and may similarly increase, decrease or abolish any such charge, fee or rate, thirty days after publication (ibid).

Table 4.2 SOEs in the transport sector

\begin{tabular}{|l|l|l|}
\hline \multicolumn{2}{|c|}{ Transport sector } & Function \\
\hline 1 & $\begin{array}{l}\text { Ports Authority } \\
\text { Tonga (PAT) }\end{array}$ & $\begin{array}{l}\text { To promote, encourage and assist in the development of commercially } \\
\text { viable and efficient ports in Tonga. }\end{array}$ \\
\hline 2 & $\begin{array}{l}\text { Tonga Airports } \\
\text { Limited (TAL) }\end{array}$ & $\begin{array}{l}\text { To provide airport operator and air navigation operating services in } \\
\text { Tonga. }\end{array}$ \\
\hline 3 & $\begin{array}{l}\text { Friendly Islands } \\
\text { Shipping Agency } \\
\text { (FISA) }\end{array}$ & $\begin{array}{l}\text { To run and operate a passenger and cargo ferry to the outer islands of } \\
\text { Nomuka, Ha'afeva, Pangai, and Vava'u, and bi-monthly to the Niuas. }\end{array}$ \\
\hline
\end{tabular}

Tonga Airports Limited (TAL)

TAL is the sole airport operator and air navigation services operator in Tonga. It comprises six airports which account for 250,000 passenger movements each year. It is held accountable to the standards and regulations of the Civil Aviation Act 1990, to New Zealand Civil Aviation laws and International Civil Aviation Organization guidelines, and it is a member of the Airports Council International. The website lists the senior and executive management teams and the board (although the list is out of date). Its mission states that TAL is an invaluable asset to the Kingdom of Tonga and that it is: 


\begin{abstract}
"Tonga's 'gateway to the world'... all persons visiting and using the airports are our customers... businesses serving the airports are our partners... the safety of our customers and partners is our critical concern ... our staff are the key to our success [and] profitability is our business objective" (http://www.tongaairports.com/, retrieved September 2020).
\end{abstract}

Its purpose is to: build a commercial business that meets the needs of its customers and builds sustainable revenues; operate profitably in a manner that enables constant reinvestment in infrastructure while returning an acceptable dividend to shareholders; provide a safe, secure and competitive civil aviation environment that encourages airlines to service Tonga in increasing numbers; provide a pleasant, efficient, safe and friendly customer experience that is identifiably Tongan and that encourages growth in passenger numbers (ibid).

\title{
Friendly Islands Shipping Agency (FISA)
}

FISA operates as a viable commercial operation and it must pay sufficient compensation to allow for the replacement of a similar vessel in around 20 years' time (based on the economic life of the vessel). FISA's website provides a business structure diagram which includes where the board is positioned within the organisation, but does not name who is on the management team or on the board, or that it is a shared board for the transport sector (http://www.fisa.to, retrieved May 2020) ${ }^{41}$.

FISA was set up in 2010 to replace the debt-stricken Shipping Corporation of Polynesia, and following the 2009 MV Princess Ashika ferry sinking with a death toll of 87. The vessel was built in 1972 and sank a month after it arrived in Tonga, and Tonga's transportation minister, Paul Karalus, resigned six days after the tragedy (Royal Commission of Inquiry into the Sinking of the MV Princess Ashika, 2010). FISA runs the MV 'Otunga'ofa, a passenger and cargo ferry donated by the Government of Japan to Tonga in 2010. This service is run on a weekly basis to the outer islands of Nomuka, Ha'afeva, Pangai, and Vava'u, and bi-monthly to the Niuas, and can take up to 400 passengers and 30 crew members. Although FISA largely operates

\footnotetext{
${ }^{41}$ This website had been suspended for large portions of 2020-2021.
} 
within domestic waters, the purchase of the cargo ship MV Niuvakai in 2014 was aimed at providing shipping services within the region. However, the ship has been assessed as not suitable for operating in regional waters. FISA has created a new company called Tonga Exports Shipping Agency Limited (TESAL) to operate the MV Niuvakai. TESAL's sole shareholder is FISA.

FISA stated values are "Respect, Reliability, Performance, Honesty, Safety, Accountability, Innovation, and Customer focus". Its strategic goals are: 1 improve and maintain vessel and infrastructure; 2 . improve commercial viability, cashflow and profitability; 3 . improve customer experience; 4. formalise long-term planning and financing sources; 5 . maintain and nurture key relationships; 6 . add 'ships under management' to the portfolio; and 7. enhancing our people's and the organisation's capacity (ibid).

\section{ICT sector}

Table 4.3 SOEs in the information, communications, and technology (ICT) sector

\begin{tabular}{|l|l|l|}
\hline \multicolumn{2}{|c|}{ ICT Sector } & Purpose \\
\hline 4 & $\begin{array}{l}\text { Tonga } \\
\text { Communications } \\
\text { Corporation (TCC) }\end{array}$ & $\begin{array}{l}\text { To provide a service for ICT solutions, fixed telephone lines, dial up } \\
\text { and broadband internet, and mobile services (branded UCall } \\
\text { mobile) }\end{array}$ \\
\hline 5 & $\begin{array}{l}\text { Tonga Post Limited } \\
\text { (TPL) }\end{array}$ & $\begin{array}{l}\text { To provide postal services. TPL is the sole postal administrator, and } \\
\text { is responsible for the production and sale of stamps. }\end{array}$ \\
\hline 6 & $\begin{array}{l}\text { Tonga Broadcasting } \\
\text { Commission (TBC) }\end{array}$ & $\begin{array}{l}\text { To set up, commence, and maintain a broadcasting service as a } \\
\text { means of information, education, and entertainment, and to } \\
\text { develop the service to the best advantage and interests of the } \\
\text { Kingdom. }\end{array}$ \\
\hline
\end{tabular}

\section{Tonga Communications Corporation (TCC)}

TCC has 100 percent market share on fixed telephone lines, 70 percent market share on dialup and broadband internet, and over 50 percent market share of GSM mobile services (branded UCall mobile). TCC has the widest cellular network coverage in Tonga (https://www.tcc.to/, retrieved March 2020). TCC is excluded from specified provisions in the PE Act to facilitate the partial sale of the government's shareholding in TCC. It is listed as a priority privatisation candidate in MPE's 'SOE Ownership, Divestment and Performance Improvement' policy paper. The website does not list its vision or mission statements, management team, or its shared board of directors, but it does state that: "with branches in 
all the outer-island groups, TCC is actively involved in giving back to the community with its grassroot initiatives and programmes and seeks to continue into the future for a better Tonga" (ibid). TCC publishes press releases, one of which highlights its profit result for the 2017-18 financial year, with a photo of the Minister of Public Enterprises and board holding a cheque. The previous year it had recorded a loss. It also adds that TCC is expanding its range of services, in line with the minister's directive to provide affordable services to all (ibid). The PSDI website listed TCC's vision "to be Tonga's no. 1 service provider for information technology and communications technology (ICT) solutions". Its Mission is "to be customer centric and exceed their expectations; empower people to enjoy life to the fullest through the use of the latest technology and innovations; to be a good, honest, responsible corporate citizen; and empowerment of employees by providing them with the necessary skills in an enabling environment conducive to achieving their full potential". The former PSDI website also reported from the ADB's 2016 Finding balance report that TCC's value halved between 2012 and 2014, based on an earnings multiple valuation methodology. The decline is attributed to substantially increased debt, raised to fund network upgrades (ADB, 2016a).

\section{Tonga Post Limited (TPL)}

TPL was established under the Postal Services Act in 2007. Under this Act the Minister of Finance may designate Tonga Post, or any other postal operator, as postal administrator for the Kingdom or any part of the Kingdom. TPL was corporatised in 2008 as a SOE and is the sole postal administrator. In 2013 activities formally undertaken by Tonga Print Limited were merged with TPL and the non-commercial activities undertaken by Tonga Print were closed and that SOE was liquidated. Some printing functions were retained by TPL and it established a subsidiary, Tonga Fast Print Limited, consolidated on an equity basis. The SOE distributes mail to 3,270 mailboxes and delivers directly to rural villages in Tongatapu and Vava'u. The outer islands are serviced through postal agents. TPL is responsible for the production and sale of stamps, and it contracts out production and international marketing of new stamp issues. Ninety percent of TPL's mail business is international. As is the case with many postal operators around the world, TPL's inbound mail volumes are steadily declining (https://tongapost.to/, retrieved March 2020). 


\section{Tonga Broadcasting Commission (TBC)}

TBC provides AM and FM radio and one local TV station, all free to air. It also serves as the local agent for Sky Pacific, which is a paid TV service. TBC also retails electronic equipment such as transistor radios, music CDs, and local DVDs. The TBC, under the TBC Act (1988), allows for the minister responsible for Communications to require TBC to broadcast any programme that the minister may from time to time determine (http://www.pacificsoe.org/tonga/stateowned-enterprises/tonga-broadcasting-commission/, retrieved March 2020). The Tonga Communications Corporation Act 2000 establishes the regulatory and licencing regime under which the TBC operates. The TBC is required to have an individual licence under Section 16 of the Communications Act and failure to hold the proper licence exposes directors and managers to a fine or a term of imprisonment or both (ibid).

Table 4.4 SOEs in the utility sector

\begin{tabular}{|l|l|l|}
\multicolumn{2}{|c|}{ Utility Sector } & Purpose \\
\hline 7 & $\begin{array}{l}\text { Tonga Power } \\
\text { Limited (TPL) }\end{array}$ & $\begin{array}{l}\text { To reduce Tonga's vulnerability to oil price shocks, and achieve an } \\
\text { increase in quality access to modern energy services in an } \\
\text { environmentally sustainable manner and to be financially sustainable. }\end{array}$ \\
\hline 8 & $\begin{array}{l}\text { Tonga Water Board } \\
\text { (TWB) }\end{array}$ & $\begin{array}{l}\text { To provide: water on Tongatapu and parts of the Vava'u and Ha'apai } \\
\text { groups and on the island of 'Eua; a safe, reliable and sustainable and } \\
\text { affordable service to the people of Tonga; and water supply services } \\
\text { for domestic, stock, commercial, recreational, environmental and } \\
\text { other beneficial uses in any area which it may be appointed to in the } \\
\text { TWB Act (2000) or Regulations. }\end{array}$ \\
\hline 9 & $\begin{array}{l}\text { Waste Authority } \\
\text { Limited (WAL) }\end{array}$ & $\begin{array}{l}\text { To establish, improve, maintain, operate and manage the collection } \\
\text { and disposal of all the waste in Tongatapu. }\end{array}$ \\
\hline
\end{tabular}

\section{Utility sector}

\section{Tonga Power Limited (TPL)}

The Electricity Act 2007 grants TPL a concession to generate and supply power throughout Tonga. The concession is for an open period, but it can be terminated by the government on giving three to six months' notice prior to the 'reset date'. The first reset date was 2015 and the company successfully negotiated a new reset date, expiring in 2020. TPL has two operating subsidiaries, Home Gas Ltd and Tonga Gas Ltd. TPL is regulated by the Electricity Commission and the government had set a target of achieving 50 percent of electricity generation from renewable energy sources by 2020 . This has not been achieved 
(http://www.pacificsoe.org/tonga/state-owned-enterprises/tonga-power-limited/, retrieved March 2020)..$^{42}$

Residential and commercial connections on Tongatapu are metered. TPL serves approximately 21,000 customers, of which 3,963 are commercial customers (ibid). TPL's core purpose is to "reduce Tonga's vulnerability to oil price shocks, and achieve an increase in quality access to modern energy services in an environmentally sustainable manner via its strategies and business plan and to be financially sustainable". Its stated vision is to "provide safe, reliable, and affordable services to the people of Tonga", its value is "people and the environment", and it has multiple tariffs to offer low cost prices for low-consumption users and to maximize shareholder value. (www.tongapower.to, retrieved March 2021).

\section{Tonga Water Board (TWB)}

The TWB website is non-functioning, but the TWB Act requires the SOE to provide its services efficiently and economically and to exercise its powers in accordance with the economic, social, and environmental policies of the government. It must apply sound commercial practices, including the need to ensure that its revenues are sufficient to provide for all depreciation, repayment of interest costs for all operational and maintenance costs, and to provide a reasonable return on investment. TWB also has powers as a regulator set out in the TWB Act. Its vision is "to provide safe, reliable, and affordable services to the people of Tonga", and its mission is to "achieve the maximum satisfaction of customers through the services it provides and in accordance with the PE Act" (http://www.pacificsoe.org/tonga/state-ownedenterprises/tonga-water-board/, retrieved March 2020). ${ }^{43}$

\section{Waste Authority Limited (WAL)}

WAL provides: commercial, industrial, and residential waste collection; waste management facilities; management of waste dump site areas; waste treatment; waste management services to ships and aircraft and imposition of requirements to be observed by pilots and ship masters; recycling; monitoring the effects of waste on human health; the regulation of

\footnotetext{
42 This website is no longer available.

${ }^{43}$ This site can no longer be accessed.
} 
persons involved in the transportation, storage and disposal of waste; preparation, adoption and enforcement of rules regulating activities associated with the management of waste; litter and waste control measures; public awareness on the minimisation of waste; and any other approved function (www.pacificsoe.org/tonga/state-owned-enterprises/tonga-waterboard/, retrieved April 2020). The Waste Management Act 2005 states that WAL may undertake CSO as directed by the government, but will only be obliged to undertake the CSO if the government undertakes to pay the agreed costs. CSO are referred to as GPOs in the PE Act as amended in 2010. WAL can levy fees and charges for the services it provides, but only as stipulated in its establishing Act (ibid). The WAL website is non-functioning.

\section{Property sector}

\section{Tonga Market Corporation Limited (TMCL)}

There is no website for TMCL and the information below is from the PSDI website. TMCL started its operations as a Public Enterprise in 2007. The market is located in a prime site in central Nuku'alofa and products sold include fresh produce, local handmade craft goods, and clothes. As a single asset SOE its financial performance is dependent on rental revenue. Although TMCL has a protected monopoly around the Talamahu market it still faces competition from road-side stalls. Despite its protected position the company's returns are low, with an average return on assets of 2.8 percent in the five years to 2015 (http://www.pacificsoe.org/tonga/state-owned-enterprises/tonga-market-corporationlimited-2/, retrieved April 2020). ${ }^{44}$

Table 4.5 SOEs in the property sector

\begin{tabular}{|l|l|l|}
\hline \multicolumn{2}{|l|}{ Property Sector } & Purpose \\
\hline 10 & $\begin{array}{l}\text { Tonga Market } \\
\text { Corporation Limited } \\
\text { (TMCL) }\end{array}$ & $\begin{array}{l}\text { To establish the main market, Talamahu, as a prosperous market } \\
\text { satisfying customer's needs. }\end{array}$ \\
\hline 11 & $\begin{array}{l}\text { Tonga Assets } \\
\text { Manager and } \\
\text { Association (TAMA) }\end{array}$ & $\begin{array}{l}\text { To acquire the assets of the Small Industries Centre (SIC), originally } \\
\text { set up to provide factory and warehouse space for small to medium } \\
\text { businesses. }\end{array}$ \\
\hline
\end{tabular}

\footnotetext{
${ }^{44}$ This site is no longer accessible.
} 


\section{Tonga Assets Manager and Association (TAMA)}

There is no website for TAMA and the information below is from the PSDI website. TAMA was established in 2011 to acquire the assets of the Small Industries Centre (SIC), originally set up to provide factory and warehouse space for small to medium businesses. SIC was administered by the Ministry of Labour, Commerce and Industries and acted as landlord and manager for light industrial sites. At the time of establishment, the Government recognised that the provision of these services was primarily a commercial operation and could be improved if undertaken within the SOE framework. Financial and operational performance has improved since corporatisation, and the next phase will see TAMA progressively privatise its portfolio (http://www.pacificsoe.org/tonga/state-owned-enterprises/tonga-assetsmanagers-associates-limited/, retrieved April 2020)..$^{45}$

\section{Other sector}

Tonga Cable Limited (TCL)

TCL was formed in 2009 and it has three shareholders - the Government of Tonga as majority shareholder (66.6\%), Tonga Communications Corporation (TCC) (16.7\%), and Digicel Tonga Limited (DTL) (16.7\%). TCL lists three Directors on its website - one represents TCC, one represents Digicel, and the third is the chair, who represents the interests of the government.

In 2013 TCL was commissioned to connect Tonga to Fiji. This was financed partially by the World Bank and ADB, and the balance was provided by TCC and DTL. TCL is the only provider of fibre-optic services in Tonga, and it is looking at options to connect the Ha'apai and Vava'u groups to the cable. This will be reliant on donor funding. Its services include: web hosting, data backup, virtual private server, fibre connectivity and bandwidth capacity, and IP transits (https://www.tongacable.to/, retrieved March 2020).

\section{Table 4.6 SOEs in the other sector}

\begin{tabular}{|c|c|c|}
\hline & Other Sector & Purpose \\
\hline 12 & $\begin{array}{l}\text { Tonga Cable } \\
\text { Limited (TCL) }\end{array}$ & $\begin{array}{l}\text { To build and manage a submarine fibre optic cable to connect Tonga } \\
\text { to an international network service. To provide quality, reliable, and } \\
\text { affordable broadband connectivity and innovative data services in the } \\
\text { region. }\end{array}$ \\
\hline
\end{tabular}

\footnotetext{
45 This site is no longer accessible.
} 


\subsection{CHAPTER SUMMARY}

This chapter provided a brief overview of Tonga which highlighted that its small economy is still reliant on remittances and ODA support. SOE reforms have been aimed at wealth creation and efficiencies, and have contributed to improved accountability with government ministers no longer eligible to be appointed to SOE boards. However, despite being clearly outlined in the legislation, it appears that boards still have to negotiate 'grey areas' balancing what is best for the enterprise with what is wanted by the government, such as with GPOs. The Ministry has applied innovative approaches to overcome capacity and capability issues with board appointments and budget restraints by using shared boards. This chapter used a wealth of information from SOE websites as they provided up-to-date information on the SOEs. However, revisiting these sites throughout this research has highlighted access issues that could be related to budgetary issues, consolidation of boards, non-payment of internet fees, sites taken down temporarily to refresh information leading to long delays, or that the website is no longer in operation. 


\section{CHAPTER 5 THE SOE MODEL IN THE STATE OF SAMOA}

\subsection{INTRODUCTION}

This chapter examines SOEs in the Independent State of Samoa (Samoa) to provide context for the responses made by participants about how and why Samoa adapts and localises Western principles of corporate governance in its SOEs. The chapter begins with an overview of the demography, cultural values and practices, political structure, and economy of Samoa (Section 5.2). As stated in the previous chapter, this is only a partial overview as there are much deeper issues and complexities than can be discussed here.

Section 5.3 documents four changes from reforms and reviews undertaken in the last 20 years aimed at improving SOE performance and board governance in Samoa. These were identified in participant interviews as both challenges and solutions to implementing corporate governance principles in Samoa's SOEs. Chronologically they are the: Public Bodies (Performance and Accountability) Act 2001; Community Service Obligations (CSOs), which are outlined in the Act and are part of a recent Ministry for Public Enterprises review; establishment of the Ministry for Public Enterprises (MPE) in 2015; and the development in 2019 of new criteria for board composition, as part of the recent appointment round.

Section 5.4 lists and outlines the main purpose and functions of the current 16 public trading enterprises, ${ }^{46}$ using information and statistical data retrieved from SOE, MPE, and PSDI ${ }^{47}$ websites, relevant legislation, other relative documents, and interviews.

\subsection{BACKGROUND}

\subsubsection{Demographics}

Samoa is made up of two main islands, Savai'i and Upolu, with eight smaller inhabited islands (Apolima, Manono, Fanuatapu, Namu'a, Nu'utele, Nu'ulua, Nu'ulopa, and Nu'usafe'e). Samoa's population is approximately 197,000 (World Bank, n.d.) with about 80 percent of the

\footnotetext{
${ }^{46}$ As at January 2020.

${ }^{47} \mathrm{PSDI}$ is a regional technical assistance facility co-financed by the Government of Australia, the Government of New Zealand and the Asian Development Bank. This website is no longer accessible.
} 
population living in rural centres (Samoa Bureau of Statistics, n.d.).There are approximately 340 villages for administrative purposes, and these are divided into 43 districts. The capital of Samoa is Apia, which is situated on the island of Upolu. About 77 percent of the total population resides on Upolu. Twenty-two percent of the population is on the island of Savai'i, and the remaining population is spread across the other islands. (ibid). Diagram 5.1 provides a visual image of the two main islands and proximity to American Samoa.

Figure 5.1 Map of Samoa

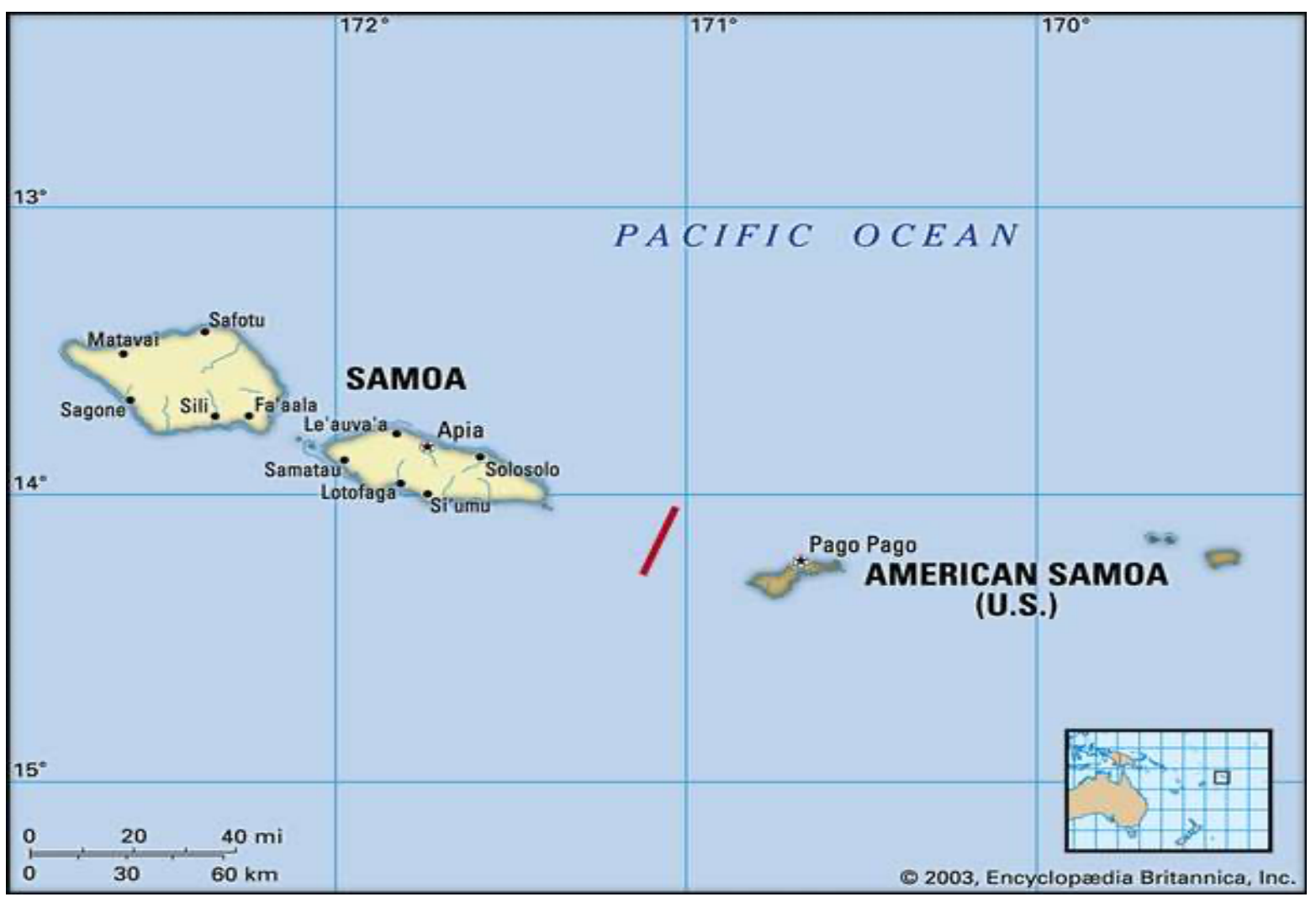

Source: Encyclopaedia Britannica

The adult literacy rate in Samoa is at 99 percent (https://countryeconomy.com/demography/literacy-rate/samoa, retrieved May 2021). Samoa's 2019 Ministry of Education net enrolment rates for primary education is 103 percent (Samoa Bureau of Statistics, 2019a). and progression rate to year 13 in secondary education is 75 percent, with females at 81 percent and males at 68 percent (Samoa Bureau of Statistics, 2019b). The Human Capital Index ( $\mathrm{HCl}$ ) measures the amount of human capital that a child born today can expect to attain by the age of 18. In Samoa today it will be 55 percent as 
productive. This is lower than the average for East Asia and Pacific region and upper middleincome countries (World Bank, 2020b).

\subsubsection{Cultural values and practices}

There have been many substantive books written about Samoa's cultural values and practices, and this section only provides a brief overview to help the reader better understand participant responses on whether they consider local values and practices when implementing corporate governance principles.

Fa'aSamoa, Fa'amatai, and Christianity are important customs, values, and practices in Samoan society, both in daily domestic life and in political settings (lati, 2000; Macpherson, 1999; Malielegaoi, 2017; Meleisea, 2000; Meleisea et al., 2012; Samoa Census of Population and Housing, 2016). Participant responses highlight how SOE governance is applied within these values and practices.

Fa'aSamoa is a traditional governance system and is used to describe many aspects of Samoan life, serving social, economic, and political functions (ibid). The fa'aSamoa system assigns traditional roles with specific functions within parliament and within the village council (Breda, 2019; lati, 2000). At the village level, the council represents legislative, judiciary and executing power in political, economic as well as moral matters (Macpherson \& Macpherson, 2009). Although some Samoan values and customs have changed since contact with the West, the concept of fa'aSamoa is seen by most Samoans as essential to their identity. It has been described as the 'Samoan way' or 'to act according to Samoan custom' by Pratt (1984, p.131). Fa'aSamoa can also be seen as a 'communal way of life' placing greater importance on the dignity and achievement of the group rather than its individual members. Meleisea (1988, p.21) described fa'aSamoa as a socio-economic and political framework based on the social structure of the aiga (communal and extended family relationships), and the $n u^{\prime} u$ (village) under the authority of the matai (chief) and fono ole nu'u (village council).

Fa'aSamoa is connected to the fa'amatai system (Fairbairn-Dunlop, 2003; Malielegaoi, 2017; Siauane, 2004). Central to the system are the matai, who hold family chief titles appointed by 
the consensus of the aiga. The matai can be male or female (Huffer \& So'o, 2000). The matai are responsible for the well-being of the extended family and the protection of family property, especially customary land, with about 80 percent of Samoa (229,457 hectares) under customary ownership (Fana'afi, 1986; White \& Lindstrom, 1997; Anae et al., 2017). Fa'amatai has been impacted by Western influence (Macpherson \& Macpherson, 2009) and is discussed further in Section 5.2.3 in relation to the current political structure in Samoa.

Missionaries from the 1830 s onwards extended their influence as 'agents of change' within Samoan society by introducing Christianity (Thornton et al., 2010). Today, approximately 98 percent of the population identify themselves as Christian (Samoa Census of Population and Housing, 2016). There is a close link between Samoan society and Christianity, and this is symbolised in the national motto 'Samoa is founded on God Fa'avae ile Atua Samoa' (Government of Samoa, https://www.samoagovt.ws/, retrieved April 2020).

Christianity plays a dominant role in the social, political, and economic life of Samoa at both a village and national level (Evile, 2007; Latai, 2015; Macpherson \& Macpherson, 2011; Thornton et al., 2010). The close relationship between village leadership and church is one of carefully balanced power and respect (Macpherson \& Macpherson, 2009). According to Kerslake (2004) this relationship ensures that church interests are closely considered in village politics.

This close relationship seems to have been the catalyst for amendments to the constitution in 2017, where Parliament amended Article 1 of the Samoan Constitution, converting the country from a secular to a Christian state and making Christianity the state religion, giving the text in the Constitution the potential to be used in legal processes. (Feagaimaali'iLuamanu, 2017; Wyeth, 2017). "Whereas the Leaders of Samoa have declared that Samoa should be an Independent State based on Christian principles and Samoan custom and tradition" (Samoan Constitution, p7). 


\subsubsection{Political structure}

SOEs in Samoa are either 100 percent owned or majority-owned by the Samoan Government. One participant described Samoa's governance system as "bi-cultural" - a constitutional republic based on a Western federal system, and an Indigenous village matai governance system. ${ }^{48}$ This section aims to assist the reader to better understand why participants spoke of the challenges they face with political interference by government ministers in board governance decisions.

Samoa is a parliamentary democracy, and its constitution and political system take account of Samoan traditions and culture (DFAT, n.d.; Breda, 2019). The 1960 Constitution came into force with independence from New Zealand in 1962 and includes a combination of principles based on the Westminster system including universal rights, and a recognition of customary rules. Only matai can be elected to Parliament and attend fono ole nu'u. (Anae et al., 2017; Huffer \& So'o, 2000).

Vito Breda (2019) commented that constitutionally Samoa acts as the custodian of the land and sea resources that are under the current constitutional system. Samoa's system of governance is distinctively structured, with the Constitution providing for an indirect parliamentary democracy including a combination of principles inspired by the Westminster system, a set of universal rights, and the recognition of customary rules (Breda, 2019). Samoa has a fono (unicameral legislative assembly), consisting of 49 members elected by citizens aged 21 years and over, serving five-year terms. Every Samoan member of parliament is also a matai, performing dual roles as a chief as well as duties in the Samoan Parliament (Drage, 1994). Most Samoans in positions of public responsibility also hold matai titles.

Universal suffrage was extended in 1990 but, as stated above, only matai are able to stand for election to Samoan seats. According to the 2016 Samoan Census, 14,335 males and 1,594 females are eligible to stand for election. Forty-seven candidates are elected from territorial districts by ethnic Samoans, with the remaining two chosen by non-Samoans with no chiefly

\footnotetext{
48 The participant provided an example that regardless of legal decisions, it is the matai who make the final decisions for the village.
} 
affiliation on separate electoral rolls. The prime minister is chosen by a majority in the Fono and is appointed by le Ao o le Malo (the Head of State) to form a government (https://www.palemene.ws/, retrieved March 2020). At the time the Constitution was adopted, it was anticipated that future Heads of State would be chosen from among the four Tama a 'Aiga paramount chiefs. However, this is not required by the Constitution, so Samoa can be considered a republic rather than a constitutional monarchy (ibid).

At Samoa's election in 2016, the Human Rights Protection Party (HRPP), which governed Samoa from 1982 to 2021, was returned to power under Prime Minister Tuilaepa Lupesoliai Sailele Malielegaoi. Until 2021, he had been in office since 1998. This election reserved five seats, or 10 percent, of the 49 parliamentary seats for women electoral candidates. The reform legislation was passed in 2013 and Samoa was the first Pacific Island country to introduce this type of reform. Article 44 of the Constitution requires that if fewer than five existing seats are won by women, additional seats (to a maximum total of 54 seats) are added to be held by women candidates with the highest number of outright votes. Four women candidates were successful in the 2016 election, and a fifth was appointed under the legislation, bringing the total number of MPs to 50 in 2016 (Parliament of Samoa https://www.palemene.ws/, information, retrieved March 2020). The interpretation of this reform legislation was at the centre of the initial political stalemate over the 2021 election results. The final outcome saw the Fa'atuatua i le Atua Samoa ua Tasi (FAST) Party become the new government. The new Prime Minister Fiame Naomi Mata'afa, is the daughter of Samoa's first prime minister, and becomes the country's first woman in the role.

Alongside Samoa's Western styled political system, the fa'amatai system (discussed in Section 5.2.2) is central to understanding Samoa's political system. This reflects Samoa's unique parliamentary system that incorporates significant elements of Samoan culture and tradition while retaining the principles of democracy (Meleisea, 1987; Meleisea et al, 2012; (http://www.samoagovt.ws, retrieved March 2020). The Constitution blends traditional and democratic institutions and processes, and recognises the separation of powers (legislature, judiciary, and executive) (ibid). 
The fono unicameral legislature is at the centre of Samoa's system of the roles of O le Ao o le Malo (Head of State), the Executive Government (to propose and implement laws) the Parliament (the Head of State and the Legislative Assembly which decides whether to pass the laws), and the Judiciary (to interpret laws). The Executive (prime minister, ministers) are accountable to parliament and the people. The core function of the Assembly is to make laws for Samoa and to monitor and challenge the work of the government (Parliament of Samoa, https://www.palemene.ws/, retrieved April 2020). The independent judiciary and separate court also resolve disputes over land and traditional titles (DFAT, n.d.).

Samoa is made up of 11 itumalo (political districts) which are based on the traditional 11 districts that were established before European arrival. Each district has its own faavae (constitutional foundations) based on the traditional order of title antecedence found in each district's faalupega (traditional salutations) (https://www.samoagovt.ws/about-samoa/, retrieved May 2020).

\subsubsection{Economy}

Nearly thirty years since Bertram and Watters (1985) coined the MIRAB model term, elements are still found in Samoa's economy. Samoa still relies on migration, remittances, and international aid to sustain the economic welfare of its population. Remittances are important in supporting the current account, and are a major source of external income and a key driver of economic growth (ADB, 2009; DFAT, n.d.; Macpherson \& Macpherson, 2011). Table 5.1 below shows that personal remittance received in 2018 was USD142 million, 17.2 percent of GDP.

Tourism is an expanding sector, accounting for 25 percent of GDP. However, it is experiencing significant impacts from the COVID-19 pandemic due to the suspension of international tourism (DFAT, n.d.). Prior to the pandemic, Samoa had started to diversify its economic base, with the manufacturing and service sectors now becoming contributors to GDP. Samoa's GDP for 2018 was approximately \$2 billion Tala. The major industries contributing to GDP in 2018 were commerce, agriculture, electricity and water, accommodation and restaurant, and communication (Samoa International Finance Authority, https://www.sifa.ws/about- 
us/overview-of-samoa/, retrieved April 2020). In 2017, Samoa exported \$119.2 million Tala of merchandise and imported $\$ 939$ million Tala of merchandise (ibid). Samoa's major trading partners are New Zealand, Australia, American Samoa, and Fiji (MFAT, n.d.).

Table 5.1 below lists some economic data to provide insight into how much Samoa relies on personal remittances and aid as a percentage of its GDP.

Table 5.1 Economic statistics for Samoa

\begin{tabular}{|c|c|c|}
\hline 2019 & USD & $\%$ of GDP \\
\hline Annual GDP 49 & 852 million & - \\
\hline GDP per capita ${ }^{50}$ & 4,323 & - \\
\hline Exports of goods and services ${ }^{51}$ & 316 million & 37.1 \\
\hline Imports of goods and services ${ }^{52}$ & 441 million & 51.7 \\
\hline Trade balance ${ }^{53}$ & (339.2 million) & $(40.07)$ \\
\hline Public expenditure \% GDP $2013^{54}$ & & 29.8 \\
\hline Foreign development assistance (Net ODA) ${ }^{55}$ & 124 million & $\%$ of GNI 15.2 \\
\hline Personal remittance received $2018^{56}$ & 142 million & 17.2 \\
\hline Received by country $2017^{57}$ & - & - \\
\hline $\mathrm{NZ}$ & 65 million & - \\
\hline Australia & 27 million & - \\
\hline \multirow[t]{2}{*}{ USA } & 18 million & - \\
\hline & $\mathrm{N}$ & - \\
\hline Net Migration ${ }^{58}$ & $(14,013)$ & - \\
\hline International emigrant stock ${ }^{59}$ & 124,403 & - \\
\hline \multicolumn{3}{|l|}{ Destination Country } \\
\hline NZ & 54,108 & - \\
\hline Australia & 32,173 & - \\
\hline USA & 20,201 & - \\
\hline
\end{tabular}

Agriculture and fishing make up 90 percent of exports, but their proportion of GDP has declined in recent decades. In 2018, Samoa's principal export destinations were American

\footnotetext{
${ }^{49}$ Source: https://data.worldbank.org/country/samoa?view=chart

${ }^{50}$ Source: https://data.worldbank.org/indicator/NY.GDP.PCAP.CD?locations=WS\&view=chart

${ }^{51}$ Source: https://data.worldbank.org/indicator/NE.EXP.GNFS.CD?locations=WS

52 Source: https://data.worldbank.org/indicator/NE.EXP.GNFS.ZS?locations=WS

53 Source: https://countryeconomy.com/trade/balance/samoa

${ }^{54}$ Source: Expense is cash payments for operating activities of the government in providing goods and services. https://data.worldbank.org/indicator/GC.XPN.TOTL.GD.ZS?locations=WS

${ }^{55}$ Source: https://www.theglobaleconomy.com/Samoa/foreign_aid/

${ }^{56}$ Source: https://data.worldbank.org/indicator/BX.TRF.PWKR.CD.DT?locations=WS

57 Source: https://countryeconomy.com/demography/migration/remittance/samoa

58 Source: https://data.worldbank.org/indicator/SM.POP.NETM?locations=WS\&view=chart

${ }^{59}$ Source: https://countryeconomy.com/demography/migration/emigration/samoa
} 
Samoa (27\%) followed by New Zealand (18\%) and Tokelau (14\%) (https://www.cia.gov/theworld-factbook/countries/samoa/\#economy, retrieved March 2020). Samoa is reliant on imports and has a large trade deficit. The main imports in 2018 were food, machinery and vehicles, manufactured goods, and petroleum products (Samoa Bureau of Statistics, n.d.). In 2018, its principal import sources were New Zealand (25\%) followed by Singapore (18\%) and China (12\%) (ibid).

The public sector accounts for a large portion of overall expenditure in Samoa, with government spending equivalent to 34 percent of GDP in 2016. The government supplies most infrastructure services and has a large role in agriculture, and SOEs employ 10 percent of the workforce (ibid).

\section{Migration}

After Samoa's independence, it signed a Treaty of Friendship with New Zealand which included special migration arrangements with Samoa, and has led to a significant diaspora, with more than half of Samoa's tertiary-qualified citizens living outside their country. Sizeable migration in the second half of the twentieth century from Samoa to New Zealand means that culturally the links between Samoa and New Zealand are very strong. Approximately 140,000 people of Samoan heritage live in New Zealand; this represents about 50 percent of New Zealand's Pacific Island population. New Zealanders, particularly those of Samoan heritage, constitute approximately 40 percent of tourist arrivals to Samoa each year, and many Samoans are dual citizens and travel freely between both countries (ASI, 2015).

Samoa is also one of the eligible Pacific countries for New Zealand's RSE scheme (Bedford \& Hugo, 2012). The scheme provides important employment opportunities for hundreds of seasonal workers from Samoa each year, while providing a valued labour source for New Zealand's primary producers (MFAT, https://www.mfat.govt.nz/en/countries-andregions/pacific/samoa, retrieved March 2020). The Government of Samoa is eager to gain more opportunities for their working-age populations to access temporary work in New Zealand, including applying pressure for work that matches its workers' skills, with the aim 
(on their return to Samoa) to enhance these skills in the workforce in Samoa (Bedford \& Hugo, 2012).

\section{Remittances}

As with Tonga, remittances make an important contribution to the economic functioning of Samoa, largely a function of permanent overseas migration of family members to New Zealand, Australia, and USA. In 2018, personal remittances received was USD142 million accounting for 17.2 percent of Samoa's GDP, which is among the highest ratios observed in the world, with more Samoans residing abroad than in Samoa, and with the majority of personal remittances coming from New Zealand.

In the mid-1990s, Appleyard and Stahl (1995) classified Pacific Island nations by how much their economies relied on remittances from migrants working overseas. Tonga and Samoa were identified as 'partly furnished' because of their reliance on remittances, but they were seen to have the potential to achieve higher domestic output if development aid and remittances were properly harnessed.

\section{International Development Aid}

Table 5.1 above shows that foreign development assistance (Net ODA) for 2019 was USD124 million, and 15.2 percent of gross national income (GNI). The ratio of aid to GNI provides a measure of recipient country's dependency on aid. This shows that direct aid remains important to the Samoan economy (https://stats.oecd.org/qwids/e, retrieved May 2021). Samoa is subject to economic and environmental volatility and continues to rely on foreign development assistance (ODA) in the form of loans and grants to support economic and human development.

Samoa receives aid from a large number of donors, primarily from New Zealand and Australia, and increasingly China, which has funded large infrastructure projects in the country. Samoa is also a member of the ADB and the World Bank and receives funding from those institutions for infrastructure activities (ASI, 2015). 
Australia is Samoa's largest bilateral donor, supporting economic growth, health, education, and governance (DFAT, n.d.). Australia's development partnership with Samoa aims to: strengthen the preparedness and responsiveness of Samoa's health system; maintain stability; promote social cohesion and ensure vulnerable people have access to essential goods, services and opportunities; mitigate and recover from COVID-19's economic impacts; and enhance its resilience to future shocks (ibid).

An important feature of the development context is also the historical, cultural, and economic relationship that exists between Samoa and New Zealand (ASI, 2015). New Zealand's Ministry of Foreign Affairs and Trade (MFAT) leverages off its close relationship with Samoa through its Treaty of Friendship, "friendship, confidence, and a mutual endeavour to obtain for their peoples fuller opportunities for social progress" (Treaty of Friendship, 1962) and because about half of New Zealand's Pasifika population are of Samoan heritage. New Zealand's development cooperation with Samoa provides general budget support to Samoa linked to improvements in Public Financial Management (PFM), and other activities to improve governance and public sector administration (ASI, 2015). New Zealand is also working on policy reforms, and the health, education, tourism and private sectors (MFAT, n.d.).

\subsection{SOE REFORMS}

Samoa was the first developing country in the South Pacific to implement a public sector reform programme with the introduction of a two-year Statement of Economic Strategy. It initiated SOE reforms in 1998, including the privatisation of several SOEs, and the deregulation of the financial sector. Samoa's reform process was seen as relatively successful because of the government's determination to lead the process (Saldanha, 2004; Pacific Islands Forum Secretariat (PIF), 2014).

In Samoa, SOE reforms and reviews undertaken in the last 20 years have been aimed at improving financial performance and board governance. The 2016 ADB report noted that despite initial reforms, including adopting the 2001 Public Bodies (Performance Accountabilities) Act and implementing SOE policy, there had been poor performance since 2003 and that implementation of the Act and policy has been weak. The report added that 
"Samoa is one of only two countries in the benchmarking sample to show no material improvement in portfolio ROE for 2002-2014, despite subsidized credit" (ADB, 2016a, p.24). However, the report noted that reform momentum had increased since 2008 to include the: adoption of a competition policy in 2013; enactment of the Competition and Consumer Act in 2016; privatising SamoaTel in 2010; establishing the Independent Selection Committee for directors in 2010; adopting the Composition Act in 2012 to remove all politicians from SOE boards; adopting a SOE divestment and ownership policy in 2015; preparing the privatisation of Agricultural Stores Corporation and announcing the intent to privatise the Public Trustee and Samoa Post Limited; and establishing a new SOE ministry under a minister of SOEs (ADB, 2016a). ${ }^{60}$

In the participant interviews, the 2001 Public Bodies Act, Community Service Obligations, establishment of the Ministry for Public Enterprises, and the development in 2019 of new criteria for board composition, were identified as both challenges and solutions to implementing corporate governance principles in Samoa's SOEs. Samoa's public trading bodies were often referred to as SOEs by participants and some SOE websites.

\subsubsection{Public Bodies (Performance and Accountability) Act 2001}

The Public Bodies (Performance and Accountability) Act 2001 (PB Act) is the principal legislation governing all Public Bodies. ${ }^{61}$ The main objective of a public trading body, as outlined in the Act, is to operate as a successful business and be as profitable and efficient as comparable businesses that are not owned by the state.

The PB Act also included the removal of politicians, ex officio posts (including SOE CEOs), and public servants from boards. It does, however, allow for government ministers and public servants to be on boards if deemed by the government that they have experience or qualifications needed on the board and this cannot be found elsewhere:

\footnotetext{
60 The Electric Power Corporation, Samoa Airport Authority, Samoa Ports Authority, Samoa Shipping Corporation, and Samoa Water Authority are considered strategic SOEs.

${ }^{61}$ The Public Bodies Act has a provision for Trading Bodies and Beneficial Bodies.
} 
"No Member of Parliament, Public Servant or a Constitutional Officer shall be a director or be re-appointed as a director unless Cabinet has certified that such appointment or reappointment, as the case may be, is necessary; and (i) in the national interest; and (ii) that the Member of Parliament, Public Servant or Constitutional Officer, as the case may be, has particular qualifications or business experience which the public trading body requires on its board of Directors and such qualifications or business experience cannot be found elsewhere; and (h) Any other additional criteria drafted by the Committee established under subclause 3.2.1 in consultation with Ministry and the existing board of the public trading body concerned and in accordance with international best practice, which is necessary for scrutinising a particular appointment or re-appointment of a director of a public trading body" (Public Bodies Act Schedule 4, 3.1.1 (g)).

Pressure to follow through with the reforms increased following the $2007 / 08$ GFC with some SOEs defaulting on loans which the government had to underwrite under the guarantee framework. Despite being a requirement in the 2001 Act, most SOEs also had no corporate plans or updated audits, partly due to a lack of understanding by most boards and CEOs of their roles and responsibilities, and partly due to a lack of monitoring by the Ministry of Finance (participant interviews, 015, 016, 017, 026).

Following the Leaders' Summit in Auckland 2008/09, the Prime Minister of Samoa withdrew from being a chair on SOE boards, and over the last 10 years there has been a gradual phasing out of government ministers as chairs of most boards (participant interviews, 015, 016, 017, 026). The enforcement of corporate governance principles for SOEs can be seen as a condition of international funding support (participant interview, 026).

Section 5 of the PB Act has a provision to transfer trading bodies to the Companies Act, but this had yet to be implemented at the time of the research fieldwork in August 2019. All public trading bodies are supposed to be registered on the companies registry and are expected to comply with the provisions of the Companies Act 2001. The intention of a transfer is to 
improve efficiency, good governance, board independence, and autonomy in delivering services (participant interviews, 015, 016, 017).

\subsubsection{Community Service Obligations (CSOs)}

As well as operating as a successful business, the PB Act also states that each SOE must meet any specified CSOs, and be an organisation that exhibits a sense of social responsibility by having regard to the interests of the community in which it operates. The policy on CSOs has recently been reviewed and changes were approved, but there is still discussion and debate on its definition due to confusion in meaning between Section 9.1 and Section 9.2 in the Public Bodies Act (participant interviews, 015, 016, 017).

Section 9.1 states that: "A Community Service Obligation shall be made solely for the objective of alleviating hardship in Samoa and according to the policies set out by the Ministry under section $28^{\prime \prime}$.

Section 9.2 states that: "For the purposes of this Act a Community Service Obligation means: (a) the provision of a good or service by a public trading body to a consumer or user on any terms other than normal commercial terms applying from time to time; or (b) the entering into an agreement by a public trading body on any terms other than normal commercial terms applying from time to time" (Public Bodies Act).

The ambiguity means that an SOE can undertake a non-commercial activity that may not alleviate hardship. This means the revised policies still need to assess the difference between Sections 9.1 and 9.2 to ensure clarity of CSO objectives for SOEs.

If an SOE receives a Cabinet directive for a non-commercial activity, it has to fund it from within its own budget, which impacts on the SOE's performance. If an SOE receives a Cabinet directive for an activity to alleviate hardship, there is special CSO funding which sits with the Ministry of Finance. The government's annual budget for this was \$4 million Tala (in 2019 it was $\$ 2$ million Tala due to the government having other priorities). The Ministry of Finance 
assesses if the CSO directive should be fully costed or not, and any shortfalls are met by the SOE (participant interviews, 015, 016, 017, 026).

A non-commercial activity could be, for example, when the minister directs the Airport Authority to deliver water to nearby villages. This is outside the SOE's core business and impacts on cost recovery, which affects their profitability. But if costed clearly in the SOE's annual report, the ministry will see why profit decreased, such as a seven percent drop because of the non-commercial activity (participant interviews, 014, 016).

Since 2001, only Electric Power Corporation (EPC) and Samoa Water Authority (SWA) have received funding for a CSO. The recent review by MPE showed the CSO process had not been effectively implemented and that it should apply to all trading bodies. MPE is working with SOEs on this policy to clarify CSOs and how they are funded (participant interview 016).

"CSOs need to be seen in the context that SOEs in Samoa operate to provide a service. Although public trading bodies are supposed to trade and make a profit and operate similar to a private company, they are still expected to provide a service." (017)

Corporate Social Responsibility (CSR) and CSO are applied differently. A CSR is what trading bodies are mandated to do. For example, EPC's CSR is to provide electricity to the public, and its CSO is street lighting where currently it is expected to cover the cost. Development Bank of Samoa (DBS) sometimes lends at a concessional rate that is lower than the market rate. This is a CSO (participant interview, 016).

\subsubsection{Ministry for Public Enterprises}

The Public Bodies (Performance and Accountability) Amendment Act 2015 included the roles of a new Minister for Public Enterprises and the Ministry for Public Enterprises (MPE). The ministry's website states that its focus is to improve financial performance and compliance of all public bodies, to improve and enhance services to the public. 
Samoa's MPE function was originally a division of the Ministry of Finance. The move to a separate ministry was to separate fiscal responsibilities from ownership monitoring/oversight. Although the 2001 Act outlined expectations for directors with regard to accountability for corporate plans, reporting, and financial statements, many boards were not undertaking these obligations (participant interviews, 015, 016, 017, 026).

In 2014, the MPE was established following the appointment of the Minister for Public Enterprises and it started as a team of five staff. At this time most SOEs were not performing to expectations, and increased monitoring and active oversight was required (participant interviews $015,016,017)$. The data that previously was collected by the Ministry of Finance for monitoring, and financial statements, had also become out-dated (participant interviews 015, 016, 017; MPE, https://www.mpe.gov.ws/, retrieved March 2020).

Once established, the ministry reviewed international lessons learned, and lessons from previous Samoa SOE privatisation programmes, about full or partial divestments by governments.

"[The ministry] uses international best practice benchmarks. It also contextualises corporate governance principles because Samoa is different from big economies that the frameworks have been developed for" (016).

It developed the 'SOE Ownership Performance and Divestment' policy to demarcate strategic and non-strategic assets of government. This forms the basis for developing the Government's divestment programme where the ministry identifies non-core activities. Other policies developed included the CSO and dividend policies (participant interviews, 015, 016, 017).

Having a sole minister responsible for SOEs is one advantage of a standalone ministry identified by participants interviewed (participant interviews, $014,015,016,017,021$ ). This sends a message of acceptance of the ministry's mandate to chairs, boards, and CEOs. Under the Ministry of Finance, it was hard for officials to have a close relationship with CEOs and 
boards, as there was a perception that the Monitoring division at the Ministry of Finance was only interested in the fiscal position and the budget. MPE is seen to have a broader and more active role in ensuring SOEs perform and meet their obligations to the government under the Act.

Perhaps not surprisingly, the new ministry faced challenges to implement reforms. These included an initial lack of resources, particularly in human resources, as most who started at MPE were new graduates. This meant there was no institutional memory and staff had to learn how to review required skills for boards. The lack of capacity meant it was difficult to work with the board, chairs, and CEOs to help them develop corporate plans. However, subsequent support from Cabinet and the prime minister meant that MPE eventually received technical assistance and was able (more recently) to drive reforms.

In the last five years there has been a coordinated effort by the ministry to work with boards on their governance obligations, and ownership of their SOE performance and results. It has focused on implementing regional and global grounded corporate governance principles into its policies, such as board structure, as numbers of directors on boards were not consistent and could range from 7 to 11 directors. In 2016, MPE asked Cabinet for a directive that boards must meet once a month. Previously, remuneration was based on how many meetings directors attended in a year. One participant added:

"The ministry is focusing on ensuring directors have the right skill set for each SOE; to explain to the public and aspiring directors, that it's the skill set, not their connection with government ministers; to explain it's not a free ride, if your skills are not matched to the SOE, you will be a dead log and we don't want that cost to be carried by the SOE. We want people to add value to decision-making and [understand] that the SOE is managed by the management." (015)

Although implementing reforms started slowly, MPE is now seeing positive changes in SOE performance and an acceptance of its mandate. Reforms have also promoted SOEs looking at how they are linked to other sectors (previously SOEs were more project focused) and MPE is 
encouraging more SOEs to practice sector-wide approaches to ensure holistic implementation, rather than piecemeal implementation of initiatives. SOEs are part of nine government sectors for broader issues in terms of service delivery at a sectoral level. SOEs are also part of the public administration sector plan, which includes dealing with climate change and other cross cutting issues (participant interviews, 013, 014, 015).

The reviewed policies have been implemented since 2018. Officials interviewed think that more positive changes will start to be seen from SOEs in the next five to ten years in terms of corporate governance practice, and a boost in profits. This would require CSO and ROE policies to be fully implemented. The ministry is looking at implementing further recent policy reviews, and exploring how to develop a space for SOE governance and management to be innovative when they are doing their strategic planning and at their normal board and management meetings, and to start looking at the big picture rather than being silo-ed (participant interviews, 015, 016, 017).

\subsubsection{Composition of new board of directors}

The Public Bodies Legislation is twenty years old, and the ministry is continuing to review policies, including on ROE and dividends, and making changes to the Public Bodies Act. One of the changes includes reinforcing the provisions that there will be no public servants (as ex officio posts) or members of parliament on SOE boards, to align with the revised policy. During the field work, there were still government CEOs on some of the boards, but the ministry expects these will be replaced in future appointment rounds. These changes had been prompted by issues such as conflict of interest, and non-attendance at board meetings (or just sending representatives), as well as international literature on good corporate practice for SOEs (OECD, 2015b; participant interview 017).

In December 2019, Cabinet appointed 92 people as directors to Public Bodies (trading, mutual and beneficial). This included 38 new directors, and there was also a reduction in the number of directors serving on Public Body boards (Ministry for Public Enterprises website https://www.mpe.gov.ws/new-directors-appointment/, retrieved April 2020). In January 2020 parliament passed the Miscellaneous (Boards of Public Bodies) Amendment Act 2020 
which saw a reduction in the number of directors on boards; from seven to a minimum of three and not more than five. This followed a review of the composition of boards that resulted in changes to the technical competencies and experience required by board directors. Most boards (trading, mutual and beneficial) will have at least one director with cultural leadership experience, a director who is a chartered accountant, and a director with subject matter experience that is specific to the SOE (participant interview, 017; https://www.mpe.gov.ws/new-directors-appointment/, retrieved April 2020). There was a slight increase in the appointment of women in director roles across all public bodies $(n=34$; 26\% compared to 24\%) (https://www.mpe.gov.ws/new-directors-appointment/, retrieved April 2020).

Thirteen trading bodies experienced changes to their boards, including two with new chairs. ${ }^{62}$ The director application information for 11 of these trading bodies outlined skills and experience for five directors. One of the remaining two (Samoa Post Limited (SPL)) required three directors for its board, and the other (EPC) required six, the sixth being the GM for EPC as an ex officio (Ministry of Public Enterprises, https://www.mpe.gov.ws/wpcontent/uploads/2019/08/IscDirNewBoardCmpositn20190808.pdf, retrieved April 2020).

With regard to the requirement for one director to be a cultural leader for 12 boards:

- Four had the requirement for one of the directors to have cultural leadership experience and strong understanding of government policies with solid background in rural development and community engagement (DBS, EPC, LTA, PTO). ${ }^{63}$

- Three sought a director with cultural leadership experience and a strong understanding of government policies with a solid background in community development and engagement (SSC, SSS, SWA). ${ }^{64}$

- Two stated in their director application information that they wanted a director who is a matai with cultural leadership experience and a strong understanding of

\footnotetext{
62 Gambling Control Authority, Polynesian Limited/Samoa Airways, and Samoa Ports Authority.

63 Development Bank of Samoa (DBS), Land Transport Agency (LTA), Public Trust Office (PTO).

${ }^{64}$ Samoa Shipping Corporation (SSC), Samoa Shipping Services (SSS).
} 
government policies with a solid background in public consultations and negotiations with village communities in relation to land use/issues (STEC, SLC). ${ }^{65}$

- One wanted a director with cultural leadership experience with sound investment knowledge and a strong understanding of government policies (Unit Trust of Samoa (UTOS)).

- One wanted an SOE director with cultural leadership experience and proven business entrepreneur skills and strong commercial background in revenue generating activities (Samoa Housing Corporation (SHC)).

- One did not specify cultural leadership experience, but wanted a director able to engage with the community, and advertised for a director with high level leadership experience and a strong understanding of Government policies with a solid background in rural development and community engagement (SPL) (MPE, New Board of Directors Composition, 2019, p. 3, https://www.mpe.gov.ws/wpcontent/uploads/2019/08/IscDirNewBoardCmpositn20190808.pdf, retrieved April 2020).

One of the recurring discussion points at an induction seminar held for first time directors of Public Bodies in March 2020 was on a director's 'Duty of Care', and some of the practical challenges they would face when it comes to 'acting in good faith' and 'acting in the best interest' of the public body. This issue had been discussed in the interviews by participants who commented on the challenges boards face between making decisions in the best interest of the SOE and directives they receive from Cabinet, which may not be in the best interest of the SOE. Manua Dr Cam Wendt from MPE discussed this issue at the induction seminar, noting:

"Yes there will be times when the Board will be instructed by Cabinet to do something that will have financial implications for your organisations. While the Act requires you to comply with policy directives issued on behalf of the Shareholding Ministers, your duty of care is to inform Cabinet of the implications this decision will have on the corporation. At the end of the day Cabinet has the

\footnotetext{
${ }^{65}$ Samoa Trust Estates Corporation (STEC)=land use; Samoa Land Corporation (SLC)=land issues.
} 
final say but you have acted in the best interest of the public body by bringing to their attention the impact it will have" (Ministry for Public Enterprises, https://www.mpe.gov.ws/induction-seminar-for-all-first-time-directors/, retrieved April 2020).

\subsection{SAMOA'S PUBLIC TRADING BODIES}

In 2020 there were 16 Public Trading Bodies, ${ }^{66}$ three Public Mutual Bodies, and nine Public Beneficial Bodies (Ministry for Public Enterprises, https://www.mpe.gov.ws/, retrieved April 2020). As of April 2020, the MPE website had not updated changes to the status of the Public Bodies. This research focused on the Public Trading Bodies, described on their websites as SOEs.

Tables 5.2- 5.5 below outline current SOEs (as of March 2020) and their functions. Some SOE websites did not have updated information, so this section includes information retrieved from interviews and from the MPE and PSDI websites.

\section{Transport sector}

Table 5.2 SOEs in the transport sector

\begin{tabular}{|c|c|c|}
\hline & Transport Sector & Function \\
\hline 1 & $\begin{array}{l}\text { Land Transport } \\
\text { Authority (LTA) }\end{array}$ & $\begin{array}{l}\text { To provide a safe national road network for Samoa, and an } \\
\text { acceptable standard of land transport infrastructure. }\end{array}$ \\
\hline 2 & $\begin{array}{l}\text { Polynesian Airline Ltd } \\
\text { (Samoa Airways) }\end{array}$ & $\begin{array}{l}\text { To provide air services between Samoa and America Samoa, aircraft } \\
\text { ground and cargo handling services for Air New Zealand and Fiji } \\
\text { Airways, and general sales activities. }\end{array}$ \\
\hline 3 & $\begin{array}{l}\text { Samoa Airport } \\
\text { Authority (SAA) }\end{array}$ & To manage Samoa's airports. \\
\hline 4 & $\begin{array}{l}\text { Samoa Ports Authority } \\
\text { (SPA) }\end{array}$ & $\begin{array}{l}\text { To manage the operations of the Apia International Port, as well as } \\
\text { maintenance and services of the Asau Wharf, Aleipata and Slipway. }\end{array}$ \\
\hline 5 & $\begin{array}{l}\text { Samoa Shipping } \\
\text { Corporation (SSC) }\end{array}$ & $\begin{array}{l}\text { To provide sea transportation services for domestic and inter-island } \\
\text { markets, as well as other neighbouring islands in the Pacific. }\end{array}$ \\
\hline 6 & $\begin{array}{l}\text { Samoa Shipping } \\
\text { Services (SSS) }\end{array}$ & $\begin{array}{l}\text { To provide Samoan seafarer crewing services for international } \\
\text { shipping agencies, shipping agency and stevedoring services, and } \\
\text { cargo handling for sea and air freighted cargos. }\end{array}$ \\
\hline
\end{tabular}

\footnotetext{
${ }^{66}$ As of 2017, the Samoa International Finance Authority (SIFA) moved from being a Public Trading Body to a Public Beneficial Body. However, the MPE website still states there are 17 trading bodies as at September 2020 as it had not been updated to reflect the SIFA changes.
} 


\section{Land Transport Authority (LTA)}

LTA was established in 2008 to consolidate road asset and road use management functions previously managed by the Ministry of Works, Transport and Infrastructure, and the Transport Control Board. Its mission is to sustain 'national road networks' by achieving acceptable standards of roads and land transport infrastructure, and meeting road use management standards to achieve quality of life. Its vision is to sustain the provision of a safe national road network for Samoa (Land Transport Authority, https://lta.gov.ws/, retrieved March 2020).

\section{Polynesian Airline Ltd (Samoa Airways)}

Samoa Airways' mission is to provide a safe airline operation and to deliver a competitive and reliable customer service (https://www.mpe.gov.ws/links/public-bodies/trading/polynesianairlines-limited/, retrieved April 2020). Its vision is to commit to providing a safe domestic and international air service that is competitive, reliable, and excellent for customers, and to supporting the economic development of Samoa. Samoa Airways' website (https://samoaairways.com/) provides only service information for its customers, and does not include information on its governance or management structure.

\section{Samoa Airport Authority (SAA)}

SAA manages three airports: Faleolo International Airport on Upolu, and Maota Airport and Asau Airport on Savai'i. ${ }^{67}$ SAA was established to improve, maintain and operate airports, and provide services in accordance with the Civil Aviation Act 1998 and the SAA Act which relate to the operation of aircraft or aviation related services. Its mission is to comply fully with all applicable legislation, standards, and practices to enhance safety and sustain profitable service delivery, and its vision is to be the leading hub of air travel in the Pacific region and globally. SAA does not receive CSO funding to operate the two non-commercial airports on Savai'i but subsidises these operations from profits at Faleolo (https://www.samoaairports.com/, retrieved March 2020).

\footnotetext{
${ }^{67}$ Flight services to American Samoa out of Fagalii Airport discontinued 31st December 2019. Flights to American Samoa on Samoa Airways are out of Faleolo International Airport.
} 


\section{Samoa Ports Authority (SPA)}

SPA was established under the SPA Act 1998 to operate as a self-funding, commercially viable organisation, required to ensure that the ports and maritime needs of the nation are met in an effective, efficient and timely manner. It manages two ports at Apia (Upolu) and Asau (Savai'i) (https://www.spasamoa.ws/home-spa/about-spa/mandate, retrieved March 2020; http://www.pacificsoe.org/samoa/state-owned-enterprises/samoa-ports-authority/; https://www.mpe.gov.ws/links/public-bodies/trading/samoa-ports-authority/). Its mission is to: develop and maintain Samoa's port infrastructure; be in line with its economic and social requirements (ESR); provide safe, secure, efficient, reliable, and profitable port services; and to meet international port standards (https://www.spasamoa.ws/home-spa/aboutspa/contact-us, retrieved March 2020). Its vision is to aspire to be the best provider of efficient port services. Its values are to provide professional, efficient services to its clients and stakeholders. It states on its website that "it is paramount that these services are engulfed and guided by the following values of: Professionalism; Efficiency; Honesty; Fairness; Promptness; Courteous; Transparency; Accountability" (https://www.spasamoa.ws/homespa/corporate-governance, retrieved March 2020). SPA did not receive CSO funding to operate its non-commercial port at Asau in 2014, but did receive a \$3 million Tala government grant (http://www.pacificsoe.org/samoa/state-owned-enterprises/samoa-ports-authority/, retrieved March 2020). ${ }^{68}$

\section{Samoa Shipping Corporation (SSC)}

SSC provides passenger and cargo shipping services between Upolu and Savai'i, and international services by charter. It operates six vessels. As well as the PB Act, SSC is subject to the Shipping Act 1998. Its mission is to provide seagoing transportation and shipping related services that are safe and reliable, environmentally friendly and climate resilient, cost effective, and profitable in providing high returns to shareholders. Its vision is to be recognised as the premiere Shipping Company in Samoa, and to be active in a number of specialised shipping related services. SSC does not provide any CSO. Its website provides

\footnotetext{
${ }^{68}$ This website is no longer accessible. It has been replaced by http://www.adbpsdi.org/. It is unclear what the grant was for.
} 
service information aimed at clients, but no information on its governance structure or mission statement (https://www.samoashipping.com/, retrieved April 2020).

\section{Samoa Shipping Services (SSS)}

SSS mission is to provide superior crewing and shipping services in accordance with international maritime standards (https://sssltd.ws/, retrieved March 2020). Its vision is sustainable service through quality performance. SSS works with the Samoa Maritime School at the National University of Samoa to register all graduate seafarers into its system and ensure they have all documents required for employment. SSS does not provide any CSO (http://www.pacificsoe.org/samoa/state-owned-enterprises/samoa-shipping-services-

limited/, retrieved March 2020). ${ }^{69}$ The SSS website lists the board of directors, management team, and publishes its annual plans.

\section{Utilities sector}

Table 5.3 SOEs in the utilities sector

\begin{tabular}{|l|l|l|}
\multicolumn{2}{|l}{ Utilities Sector } & Purpose \\
\hline 7 & $\begin{array}{l}\text { Electric Power } \\
\text { Corporation (EPC) }\end{array}$ & $\begin{array}{l}\text { EPC is responsible for the generation, transmission, distribution, } \\
\text { and selling of electricity in Samoa. It is also required to provide } \\
\text { quality advice on the provision and supply of sustainable and } \\
\text { quality electricity services. }\end{array}$ \\
\hline 8 & $\begin{array}{l}\text { Samoa Water Authority } \\
\text { (SWA) }\end{array}$ & $\begin{array}{l}\text { To provide water supply, wastewater services and other services } \\
\text { mandated under the Act for all the people of Samoa. }\end{array}$ \\
\hline
\end{tabular}

Electric Power Corporation (EPC)

EPC provides electricity to 98 percent of the population. It is responsible for the generation, transmission, distribution, and selling of electricity in Samoa. EPC plays a role in the energy sector alongside other government bodies, aiming to provide efficient, affordable, and reliable electricity to achieve the sector goal of 'sustainable energy supply'. EPC is also required to provide advice on the provision and supply of sustainable and quality electricity services. Tariffs are set by the electricity regulator in compliance with the Electricity Act 2010.

\footnotetext{
${ }^{69}$ This website is no longer accessible.
} 
Its mission is to provide and maintain quality electricity services through innovative, sustainable, and environmentally sound practices in developing renewable energy sources, generation and distribution infrastructure network, in partnership with customers and stakeholders to support the development of Samoa. Its vision is clean energy sources for affordable and sustainable electricity supply for Samoa. Its values 'spell out' PRIDE:

$\mathrm{P}$ - Passion for excellent customer service

$\mathrm{R}$ - Respect for all stakeholders (customers, staff, government, community, and the environment)

I-Integrity. Absolute and honesty in everything we do

I-Innovation. Always looking for better and cheaper ways of doing things

D - Delivery. Do everything with enthusiasm and determination. Meet the highest standards in everything we do

E - Empowerment. Encourage all staff to take responsibility for what they do and encourage them to make decisions that are in the best interest of EPC.

With regard to CSO, the government paid $\$ 3,807$ million Tala for the provision of transmission lines in rural areas, and installation and maintenance of streetlights (EPC, www.epc.ws; MPE, https://www.mpe.gov.ws/links/public-bodies/trading/electric-power-corporation/, retrieved April 2020).

\section{Samoa Water Authority (SWA)}

SWA delivers water services to approximately 85 percent of Samoa's population. The remaining population receives water from independent village water schemes run by district water committees. SWA is working towards replacing Samoa's aged reticulated water infrastructure, and has also built a wastewater treatment plant to treat and dispose of sewage from the Apia town area and the national hospital.

Samoa has had national drinking water standards since 2008 and SWA has established laboratory facilities and a testing regime to ensure it meets those. SWA's number of metered customers has increased to about 29,000 in 2017. The SWA 2017-2020 corporate plan's 
objectives include: improved customer satisfaction and community engagement; improved service delivery; financial sustainability; integrated water management; and robust organisational capability. Its mission is to effectively manage the provision of safe, reliable, and sustainable water services to customers (https://www.samoawaterauthority.ws/vision, retrieved March 2020). Its vision is to promote access to reliable, clean, and affordable water services for all people in Samoa within mandated service areas. The board of directors is listed on the MPE website, and includes the CEO of the Ministry of Health and the CEO of the Ministry of Natural Resources \& Environment (https://www.mpe.gov.ws/links/publicbodies/trading/samoa-water-authority/, retrieved 23 April 2020).

\section{Development sector}

Table 5.4 SOEs in the development sector

\begin{tabular}{|l|l|l|}
\hline \multicolumn{2}{|c|}{ Development Sector } & Purpose \\
\hline 9 & $\begin{array}{l}\text { Development Bank of } \\
\text { Samoa (DBS) }\end{array}$ & $\begin{array}{l}\text { To provide credit financing to viable development projects to } \\
\text { stimulate economic growth and social development. }\end{array}$ \\
\hline 10 & $\begin{array}{l}\text { Samoa Land Corporation } \\
\text { (SLC) }\end{array}$ & $\begin{array}{l}\text { To divest SLC assets on a commercial basis, and to assist with the } \\
\text { promotion of socio-economic development opportunities for } \\
\text { the people of Samoa. }\end{array}$ \\
\hline 11 & $\begin{array}{l}\text { Unit Trust of Samoa } \\
\text { (UTOS) / Unit Trust of } \\
\text { Samoa (Management) Ltd } \\
\text { To provide opportunities for small investors to access a range of } \\
\text { investments, spreading the risks and leaving the management of } \\
\text { their savings with the Trust. }\end{array}$ \\
\hline 12 & $\begin{array}{l}\text { Samoa Trust Estates } \\
\text { Corporation (STEC) }\end{array}$ & $\begin{array}{l}\text { To ensure efficient and prudent agricultural, industrial, } \\
\text { commercial or other development of land, assets and other } \\
\text { business enterprises. }\end{array}$ \\
\hline
\end{tabular}

\section{Development Bank of Samoa (DBS)}

DBS' primary objective is to provide financing for agricultural projects. It recognises the key priorities set out in the Government's Strategy for the development of Samoa 2017-2020. Its mission is to provide affordable credit financing services to support sustainable development in Samoa (https://www.dbsamoa.ws/corporate-profile/, retrieved March 2020). Its vision is to be a sustainable and successful financial institution meeting stakeholders' expectations. DBS delivers CSOs in the form of concessionary credit facilities as directed by government, but does not receive direct compensation for them (http://www.pacificsoe.org/samoa/stateowned-enterprises/development-bank-of-samoa/, retrieved March 2020). ${ }^{70}$ Until the 2019

\footnotetext{
70 This website is no longer accessible.
} 
board appointment process, the chair was also the Ministry of Finance CEO (MPE, https://www.mpe.gov.ws/links/public-bodies/trading/development-bank-of-samoa/; https://www.dbsamoa.ws/, retrieved March 2020).

\section{Samoa Land Corporation (SLC)}

SLC was set up following the reconstruction of WSTEC (Western Samoa Trust Estates Corporation) in 1990 which resulted in the government settling all of WSTEC's debt, and the government took control of about 9,712 hectares of WSTEC. SLC was mandated to divest the land, and recover the funds used to pay off WSTEC's debt, as well as to generate revenue for the government's developments. Its goal is also to generate revenue for government (https://www.samoaland.gov.ws/about-us/, retrieved March 2020). Its mission is to promote social and economic development opportunities for the people of Samoa, through the efficient and effective use of all SLC assets (ibid). Its vision is to ensure current and future generations of Samoa benefit from the sustainable management of all SLC assets. The SLC website is bilingual and makes available its annual reports, corporate plans, policies and manuals (https://www.samoaland.gov.ws/publications/, retrieved March 2020). SLC does not provide any CSOs (http://www.pacificsoe.org/samoa/state-owned-enterprises/samoaland-corporation/, retrieved March 2020). ${ }^{71}$

\section{Unit Trust of Samoa (UTOS) / Unit Trust of Samoa (Management) Ltd}

UTOS' goal is to provide an investment vehicle for local and overseas based Samoans and Samoan businesses. The establishment of the Trust was approved by the Minister of Finance in 2009 as required by Section 3 of the UT Act. It was also set up by Trust Deed, and is managed by UTOS (Management) Ltd. The shareholding ministers of UTOS (Management) Ltd are the prime minister and Minister of Finance. The UT Act provides for one company to manage the Trust, and a separate and independent trustee company to hold title to all investments of the Trust. Since its beginning, UTOS has invested in one privatised SOE, taking a 25 percent stake in Bluesky. ${ }^{72}$ As of 2016, the majority of UTOS investments are in short-term loans to SOEs,

\footnotetext{
71 This website is no longer accessible.

72 Bluesky Samoa Ltd is a Pacific regional telecommunications company. In Samoa, it offers mobile, fixed line, IP TV and Internet services. While UTOS owns $25 \%$ of Bluesky Samoa, the other $75 \%$ is owned by local and overseas investors in American Samoa, Samoa and Fiji.
} 
which are guaranteed by the government (http://www.pacificsoe.org/samoa/state-ownedenterprises/unit-trust-of-samoa-management-Itd/, retrieved March 2020). ${ }^{73}$

The principal purpose of the Unit Trust of Samoa Management Company Ltd is to operate and manage the investment fund, the UTOS. It provides opportunities for Samoans and businesses to invest in shares of privatised public bodies. Its mission statement is to attract a broad base of investors and stakeholders and continue to hold a diversified investment portfolio that generates maximum returns to funds under management. Its vision statement is to be the 'leading fund manager' in Samoa of investment vehicles that provides opportunities for a better future (https://www.utos.ws/about-utos retrieved March 2020). UTOS and Unit Trust of Samoa (Management) Ltd share the same website which publishes relevant Acts and reports, and names its trustees, board of directors, and CEO. MPE's website lists both financial and non-financial KPIs and outlines the purpose of the Unit Trust of Samoa (Management) Ltd.

\section{Samoa Trust Estates Corporation (STEC)}

STEC was established under the STEC Act 1977 to develop and maintain plantations on Upolu, wholesale and retail cattle, and produce and sell coconuts, copra, vegetables, firewood, and livestock. STEC was restructured in 1990 under the STEC Reconstruction Act, which requires it to carry on its operations "with a view to the privatisation of its enterprise by disposal or otherwise". STEC does not provide any CSO (http://www.pacificsoe.org/samoa/state-ownedenterprises/samoa-trust-estates-corporation/ 2 retrieved March 2020). ${ }^{74}$ STEC does not have its own website but MPE's website stated that the core functions of STEC are to control, manage, and develop the following as trustee for and on behalf of the people of Samoa. These are vested assets of STEC and any other assets that it acquires. Its vision is to achieve excellence in the management and development of estates for income generation and improvement of livelihoods, the sustainable development of resources to improve income, and the provision of quality services (MPE, https://www.mpe.gov.ws/links/publicbodies/trading/samoa-trust-estates-corporation/, retrieved March 2020).

\footnotetext{
73 This website is no longer accessible.

74 This site is no longer accessible.
} 


\section{Services sector}

Table 5.5 SOEs in the services sector

\begin{tabular}{|l|l|l|}
\hline \multicolumn{2}{|c|}{ Services Sector } & Purpose \\
\hline 13 & $\begin{array}{l}\text { Public Trust Office } \\
\text { (PTO) }\end{array}$ & $\begin{array}{l}\text { To provide an affordable service for those seeking executorship or } \\
\text { trusteeship assistance in estate matters, and to manage and } \\
\text { administer estates. }\end{array}$ \\
\hline 14 & $\begin{array}{l}\text { Samoa Housing } \\
\text { Corporation (SHC) }\end{array}$ & $\begin{array}{l}\text { To provide access to financial services and to provide affordable } \\
\text { homes for those on modest incomes. }\end{array}$ \\
\hline 15 & $\begin{array}{l}\text { Samoa Post Limited } \\
\text { (SPL) }\end{array}$ & $\begin{array}{l}\text { To provide a universal postal service within Samoa and have the } \\
\text { exclusive right to provide a reserved postal service within Samoa. }\end{array}$ \\
\hline 16 & $\begin{array}{l}\text { Gambling Control } \\
\text { Authority (GCA) }\end{array}$ & $\begin{array}{l}\text { To license casinos, manage their operations, and to better control } \\
\text { and enhance monitoring of the gambling sector. }\end{array}$ \\
\hline
\end{tabular}

Public Trust Office (PTO)

PTO's mission is to offer professional and independent estate and trustee services to the Samoan community, and its vision is to be the first-choice provider of such (https://publictrust.ws/who-we-are\#1552439008398-81eaf6c0-bd21, retrieved March 2020).

\section{Samoa Housing Corporation (SHC)}

The main purpose of SHC is to improve housing and living conditions of lower-to-moderate income persons and families, by lending monies to assist to build, extend, renovate, or purchase land for the purpose of building a home. It also administers housing for rent to the public. Most of its clients are middle to low income earners who are unable to qualify for credit facilities from commercial financial institutions, as they do not meet the collateral requirements and/or repayment schedules (https://www.samoahousing.ws/aboutcompany/, retrieved March 2020). Its mission is to provide affordable housing finance by being professional and profitable to satisfy stakeholders. Its vision is to be the active leader in the provision of finance for housing and land property for residential purposes. SHC does not apply for nor receive CSO funding (ibid). 


\section{Samoa Post Limited (SPL)}

SPL was established under the Postal Services Act 2010 (PS Act). It may provide such commercial postal services as it considers appropriate in accordance with Section 8 of the Public Bodies Act 2001, and as are consistent with the Companies Act (MPE, https://www.mpe.gov.ws/links/public-bodies/trading/samoa-post-limited/, retrieved March 2020). Its mission is to be the 'best' in physical distribution of parcels and paper communication, meeting international delivery standards, with capacity and capabilities to become an essential partner for the business community (https://www.samoapost.ws/, retrieved March 2020). Its vision is that SPL will achieve excellence through the provision of profitable, affordable, reliable, and accessible postal services to its domestic and international clients. With regard to CSO, SPL undertakes several non-commercial services, some of which it is required by the PS Act to provide. These services include the operation of district post offices in Savai'i and the delivery of mail throughout Samoa at a flat, regulated fee. SPL does not receive any direct compensation from the government for the provision of these services (http://www.pacificsoe.org/samoa/state-owned-enterprises/samoa-post/, retrieved March 2020). ${ }^{75}$ The SPL website provides service information aimed at customers. Information on its governance or management structures are not on its website (https://www.samoapost.ws/, retrieved March 2020).

\section{Gambling Control Authority (GCA)}

The objective of GCA is to: promote probity and integrity in gambling; to maintain the probity and integrity of persons engaged in gambling in Samoa; promote fairness, integrity and efficiency in the operations of persons engaged in gambling in Samoa; reduce any adverse social impact of gambling; and to promote a balanced contribution by the gambling industry to tourism and general community benefit and amenity (http://www.gca.gov.ws/about-us/; https://www.mpe.gov.ws/links/public-bodies/trading/gambling-control-authority/ retrieved March 2020). Its vision is to be the trusted casino and gambling regulator using international best practices, and advancing its mission with 'pride and integrity for a safe Samoa' (https://www.mpe.gov.ws/links/public-bodies/trading/gambling-control-authority/,

\footnotetext{
75 This website is no longer accessible.
} 
retrieved March 2020). GCA may be reclassified in the future as a National Mutual or Beneficial Body.

\subsection{CHAPTER SUMMARY}

This chapter provided a brief overview of Samoa, it highlighted that its economy is still reliant on remittances and ODA support, and it outlined how cultural values and practices are embedded in Samoa's constitution and legislation. Although Samoa has been impacted by Western influences, $f a^{\prime} a S a m o a$ and the fa'amatai governance system still play a dominant role in the social and economic life of Samoa, at a village and national level. They are also central to understanding Samoa's political system, and feature strongly in responses from participants. SOE reforms and reviews undertaken in the last 20 years have been aimed at improving financial performance and board governance, there have been ongoing reviews by MPE, including in 2019 developing new criteria for board composition.

Chapters 4 and 5 illustrate that both Samoa and Tonga have strong communal and kinship social structures, existing cultural protocols regarding authority, and strong notions of wellbeing and values. In addition, as mentioned in chapter 1 , Tonga and Samoa have a similar number of SOEs as in New Zealand, yet with very different population sizes. In the interviews, participants spoke of different approaches being taken to overcome challenges implementing corporate governance, and these are discussed further in the findings' (insights) chapters 610. 


\section{CHAPTER 6 INSIGHTS FROM PARTICIPANTS}

\subsection{INTRODUCTION}

The previous two chapters have set out the purpose and function of SOEs in Tonga and Samoa (chapters 4 and 5). This chapter and the following four chapters (7-10) use the findings from participant interviews to address the following key topics: chapter 6 (6.1-6.3) relates to participant understanding of corporate governance principles and whether they reflect the discussion in the literature review; chapter 7 discusses whether participants consider local values and practices when implementing these principles; chapter 8 outlines challenges participants face in implementing these corporate governance principles; chapter 9 examines approaches undertaken (or being considered) by participants or their SOEs to address these issues; and chapter 10 provides participants' reflections on their responses from the interviews, and whether they have lessons that can be shared with the wider SOE sector.

As mentioned in the Introduction (chapter 1), although this research is not a comparison of governance in Tonga and Samoa SOEs, it gathers insights from each country. Some findings may be similar or have small differences, however, this is not central to the thesis.

Participants provided multiple responses to each interview question, and so total responses in each table below may not equal the total number of participants. Quotations are used to tell the participants' narrative, to illustrate a theme, and to fit with the methodological approach of giving voice to participants.

\subsection{TONGA - UNDERSTANDING OF CORPORATE GOVERNANCE PRINCIPLES}

As discussed in chapter 4, Tonga's SOEs are designated into five sectors, and four sectors use shared boards. Participants had connections with four of these sectors. Responses from participant interviews on their understanding of corporate governance principles were analysed and collated into three broad themes. Table 6.1 (below) summarises these themes by those most commonly discussed, and this section discusses these themes. 
Corporate governance principles involve:

- Performance and efficiency ( $n=9)$, and these are achieved through:

○ Directors, CEO, and government knowing their roles, and directors having appropriate skills to implement the SOE's mandate $(n=9)$

- Applying business principles for wealth and value creation $(n=6)$

- Ensuring there are measurable performance tools in place $(n=4)$

- Applying international learnings $(n=4)$.

- Board accountability and transparency to the public and government $(n=6)$ through:

- Alignment with government's vision for the country $(n=6)$

- Transparency in reporting and procedures $(n=3)$.

- Corporate stewardship ( $n=6)$, practiced by the board through:

○ Long-term decision-making $(n=6)$

○ Developing and applying corporate governance policy and procedures $(n=6)$

- Implementing corporate social responsibility (CSR) as part of its mandate for efficiency, along with delivering dividends to the government $(n=5)$.

\subsubsection{Performance and efficiency $(n=9)$}

Participants commented that corporate governance principles involve knowing one's roles and having the appropriate skills to undertake those roles. Participants provided the following examples as being vital for SOE performance and efficiency: board directors knowing their roles and responsibilities; directors understanding the purpose and function of the SOE they are governing; directors knowing the difference between management and governance of an SOE; and directors knowing how to make their SOE profitable while providing and improving essential services to all members of society.

"Everyone from board level to staff level knows their roles ... There's a clear understanding between management and governance roles." (011)

\footnotetext{
${ }^{76}$ As discussed at the beginning of this chapter, participants provided multiple responses, and so total number of responses may be more than the total number of participants.
} 
Types of skills participants said that directors needed ranged from having financial literacy and competency, to honesty and trustworthiness.

"It's important for directors to understand financial accounts ... to understand the commercial world ... to understand the nature of the work of the enterprise ... need chair and CEO to have strong leadership qualities to avoid conflicts of interest from [government] ministers. Otherwise it could compromise [the SOE's] mandate of efficiency, profit making, transparency and accountability." (006)

Leadership qualities were also deemed important for the chair and CEO.

"Values contribute to how directors perform their duties and tasks ... a chair needs to hold Tongan values as well as have experience operating in the business arena." (009)

Participants viewed technical expertise in the SOE's sector as an important component for at least one director on the board, especially to be able to discuss technical issues with the SOE management. As discussed in the literature review, diversity in thinking and skills is now seen as part of 'good' corporate governance (Page, 2007; Conley et al, 2012; Lipton, 2016, 2018), and participants agreed that having a board made up of different skillsets (not just accountants and lawyers), as well as directors with experience in the private and public sectors, should be part of corporate governance principles. They considered this diversity would help improve SOE performance.

"Board should be diverse, with law, economics, finance, and community experience ... but they [directors] need to be able to read the financial papers." (012)

"Government is open to having directors on boards from different walks of life, not just with high qualifications, or technical skills or academics, but more diversity on boards." (011) 
Participants spoke of corporate governance supporting competitive and business principles in value and wealth creation. Participants referred to SOEs being mandated to be efficient and effective, such as providing dividends to the government while also providing affordable services to the people. They explained that board decision-making should consider both profit and service standards, and this would be achieved by using a business model to earn revenue for the shareholder and to control costs, and operating in ways that enable private sector growth.

Participants also referred to corporate principles such as relevant benchmarking for sustainable performance and use of international best practice standards. Examples provided include the suggestion that that there is a system to assess performance which can be measured with independent auditing and corporate plans, that boards are able to assess CEO performance, and more recent approaches to assessing board performance through board evaluations.

"Board evaluations are new to Tonga ... holding boards to account." (006)

As the quote above highlights, the enforcement of accountability is relatively new to SOE board directors. Tonga's Public Enterprises Act in 2010 was strengthened to improve accountability and enhance governance (http://www.pacificsoe.org/tonga/, retrieved October 2020). Part V of the Act is headed 'Accountability' and this is discussed further in Section 8.2.3. As noted in the literature review, Sir Adrian Cadbury (author of the Cadbury Report, 1992) would have like to have included recommendations in that Report for board self-evaluations on how the board is working and to identify areas for improvement. This is because while corporate governance frameworks have been developed to help improve regulatory design and curtail agency problems, such as between management and shareholders, board evaluations are a monitoring tool to better understand factors that impact the effectiveness of boards, and to assess board performance (Nordberg \& Booth, 2019; OECD, 2015a, 2015b, 2018a; Lipton, 2016; World Economic Forum, 2016). 
Within performance and efficiency, participants also identified the importance of applying international best practice standards as an example of their understanding of corporate governance principles in Tonga, such as for accounting and human resources. They considered it an important part of good governance for boards and management to take learnings from other international SOEs (including across the Pacific), as they saw Tonga as part of the global community.

\subsubsection{Accountability and transparency $(n=6)$}

Participants discussed the importance of board accountability and transparency to the public and government. While these factors don't automatically lead to good financial performance, they are seen in the literature as good corporate governance principles (Berle \& Means, 1932; Cadbury Committee, 1992; OECD, 2015a,2015b).

Participants referred to how the government now follows a more transparent appointment process to ensure directors with appropriate skills are selected - not just because of their affiliation with the government. The PE Act outlines the appointment and termination process of directors to boards, whereby no member of Cabinet or the Legislative Assembly shall be appointed as a director (Tonga Public Enterprises Act, 2016 Revised Edition, Part IV). Positions are advertised on Tonga's Ministry of Information \& Communications website (http://www.mic.gov.to/public-notices/6777-vacancy--public-enterprises-directors, retrieved October 2020) and are announced in the media and local newspapers (https://matangitonga.to/2020/09/03/new-board-directors-public-enterprises, retrieved October 2020).

Part V of Tonga's PE Act is headed 'Accountability' and includes: the board chair's obligations such as delivering to the PE minister a draft business plan, half-yearly reports, and an annual report and accounts; how the SOE can receive funding from the government; the board's obligation to pay dividends to the government; presenting information to the Legislative Assembly; and the obligation for the SOE to audit its financial statements (Tonga Public Enterprises Act, 2016 Revised Edition). As well as government accountability, participants also spoke of board accountability and that it is important that a board's decision-making is 
transparent. This helps to prevent corruption where directors have conflicts of interest, or 'rubber stamping' recommendations made by the management. Participants suggested that corporate governance principles ensure the board is held accountable for the performance of the SOE through a code of conduct outlined in the legislation.

"Comply with policy and procedures, good processes to ensure accountability. Ensure reporting outlines any requests from [government] ministers. Use the legis/ation." (010)

Participants explained that good processes and procedures help to ensure accountability and transparency by the board through its reporting, and this can help to avoid political influence on operational matters. They also noted the importance of a professional relationship between management and the board, and that the board should be at arm's length from management.

All participants understood that the Government of Tonga, as the majority or 100 percent shareholder, sets the direction through the Ministry of Public Enterprises. The board then sets the direction for management on how to follow government policy intentions.

A few participants also reflected that the principles of accountability and transparency are still being embedded, with one participant commenting that it "wasn't until the 1990s that accountability meant anything, before that people were on boards because of position and status" (005). Another participant tied this to the introduction of democratic elections: "Tonga is getting more into good governance. Government can be voted in, and can be voted out" (003).

It's interesting to note that embedding Government Public Obligations (GPO) into legislation and the adoption of the shared board model were not initially provided by participants as examples of good corporate governance practice. The use of the shared board model was identified by the Ministry of Public Enterprises as a solution to board resourcing and capacity 
issues faced by the Government of Tonga. GPO was not specifically discussed until participants talked about challenges that boards faced in balancing the dual functions of SOEs.

\subsubsection{Corporate stewardship $(n=6)$}

As part of corporate governance, participants referred to the importance of longterm/strategic decision-making, and planning for economic and social growth and development. They stressed the importance of developing and implementing policies and procedures for corporate social responsibility (CSR), to reflect what they see as the dual function of SOEs in providing sustainable economic growth and access to affordable core services to the public. The concept of a forward master plan developed by the board and management was provided as an example, to help overcome short-term decision-making which can be driven by ministerial directives. A master plan could aim to grow the business, maintain infrastructure, or prepare the SOE for privatisation.

"Setting clear strategic direction and targets are part of good [corporate] governance. The new chair has emphasised a need for a forward master plan." (002)

Providing an affordable and accessible service to the public was noted by participants as an important part of Tonga's SOEs' mandate, and that long-term decision-making needed to include economic, social, and environmental wellbeing. Participants spoke of the importance of board decision-making being 'holistic' - that board planning should consider social, financial, and environmental wellbeing, and wider stakeholder (the taxpayers') needs as well as shareholder (government) needs.

"The board's decision-making should be holistic ... good governance has to fit the country and fit the company... There needs to be a good line of sight between government's vision and the SOE's business plan." (001)

These participants viewed corporate governance principles as having to balance a number of factors - efficiency and profit with affordable service, care for the environment, as well as the 
impact of globalisation and digital security. In addition, the SOE corporate plan needs to align with government's strategic vision for the country.

"The corporate governance focus is for the company to be profitable, and at the same time putting through CSR [corporate social responsibility] to customers. From the directors' perspective that has always been the focus, as well as developing a sustainable economy for Tonga as a whole." (008)

Board chair leadership qualities were identified as critical in board decision-making and ensuring the SOE has good systems. Examples provided included ensuring there is good dialogue between government, the board, and CEO, or controlling overseas travel by directors to prevent excessive spending. If there is an issue with a Cabinet directive, it is the responsibility of the chair to meet with ministers to talk through consequences if the directive is followed, such as a reduction to dividends for the government. The outcome from these discussions are then documented and tabled at the next board meeting. Participants also stressed the importance of the board and management applying the legislation, and that SOE staff comply with board policy and procedures developed by management.

Overall, responses in this section reflect the Stakeholder theory premise of the importance of business ethics and CSR in corporate governance principles, and of giving attention to all stakeholders' needs (Freeman, 1984).

\subsubsection{Section summary}

Overall, participants had a good understanding of corporate governance principles and the role these play in Tonga's SOE board performance. In particular, they identified the importance of directors having the appropriate skills and knowing their roles. They understood the link between performance and long-term decision-making, and alignment with the government's vision for the country. While they saw that applying business principles for wealth and value creation was critical to the board's role, along with delivering dividends to the government, they recognised that CSR is also part of a board's mandate of providing an affordable service to the Tongan people. 


\subsection{SAMOA - UNDERSTANDING OF CORPORATE GOVERNANCE PRINCIPLES}

Responses from participant interviews on their understanding of corporate governance principles in relation to SOEs in Samoa were analysed and collated into three broad themes. This section discusses these themes and includes examples provided by participants along with quotations from the interviews. Participants provided multiple responses and Table 6.2 (below) summarises these themes by those most commonly discussed.

Table 6.2 Understanding of corporate governance principles in Samoa ( $N=14)$

\section{Corporate governance principles involve:}

- Performance and efficiency ( $n=10)$, and are achieved through:

- Applying business principles for wealth and value creation $(n=10)$

- Directors, CEO, and government knowing their roles, and directors having appropriate skills to implement SOE mandates $(n=8)$

- Ensuring there are measurable performance tools in place $(n=6)$

- Applying international learnings $(n=3)$.

- Board accountability and transparency to the public and government $(n=6)$ through SOE:

- Alignment with its government's vision for the country $(n=6)$

- Transparency in reporting and procedures $(n=3)$.

- Corporate stewardship $(n=6)$, practiced by boards through:

- Long-term decision-making $(n=6)$

- Implementing corporate social responsibility (CSR) as part of the SOE mandate for efficiency along with providing dividends to the government $(n=6)$

$\circ$ Developing and applying corporate governance policy and procedures $(n=3)$.

It is interesting to highlight that although there were broad similarities in the general factors towards understanding of corporate governance principles, some of these were expressed quite differently in the two countries. Examples provided for performance and efficiency for Tonga's SOE's mainly focused on directors, CEO, and government knowing their roles, and directors having appropriate skills to implement the SOE's mandate. Whereas for Samoa's SOE's, participants spoke of the importance of applying business principles for wealth and value creation. 


\subsubsection{Performance and Efficiency $(n=10)$}

Business principles for wealth and value creation

As discussed above, in Samoa, participant understanding of corporate governance principles mainly focused on applying business principles for wealth and value creation. Participants spoke of the importance of performance and efficiency through: SOEs operating profitably and sustainably; keeping tariffs low; servicing debt; maintaining infrastructure; delivering an efficient service; undertaking corporate planning processes; and not being a burden on the state. Participants spoke of a board's obligation to ensure its SOE is run profitably as revenue is primarily gathered from user charges. They added that working under the company model balanced with service has pushed the SOE to perform better and improve services; better than they would if they were part of a department or ministry.

"If an SOE can operate profitably and sustainably, keep tariffs low, not lose money, service debt, maintain infrastructure, not be a burden on the state ... it's operating in the best interest of the public and government." (026)

"Boards should display similar continuous improvement and entrepreneurial attributes [to private sector boards], and decisions should be underpinned by a strong business case." (018)

"A board ensures management carries out the work according to the plan. Board priorities are profit and staff; work is carried out with integrity and management is accountable; profit is a core function for dividends to government." (022)

However, one participant reflected that sometimes improved performance does not always mean improved cost efficiency.

"While there's been an improvement when [the enterprise] moved to the SOE model, there have also been increases in expenses and costs in running the company." (013) 
Directors, CEO, and government knowing their roles, and directors having appropriate skills to implement SOE mandates

Participants aligned performance and efficiency in corporate governance with directors, CEOs, and government knowing their roles, including understanding the differences between governance and management roles, and directors having the appropriate skills to implement their SOE mandate.

"MPE has to explain to the public and aspiring directors that it's the skillset [being sought], not their connection with government ministers." (015)

"An important role of board chairs is to ensure good governance processes are in place. There's been an evolution in board roles, responsibilities, and expectations. Before boards just looked at the financials to see if the organisation is covering costs and making money and the board considered they had then done their job." (018)

They added that it was important that corporate governance principles are embedded in the leadership skills that chairs and CEOs should hold, to steer SOEs towards profitability and sustainability. As in Section 6.1.1, participants reflected that corporate governance best practice also means that boards should have directors with broader skills than those previously thought necessary for strategic planning. The Cadbury Report (1992) and more recent writers (Lipton, 2016, 2018) discussed the importance of boards with a range of skills. Lipton called for diversity of thinking on corporate boards, and for decision-making to be holistic and include more environmental and social responsibility to ensure a board has the social licence to operate (ibid).

Ensuring there are measurable performance tools in place

Participants commented on the importance of ensuring there are measurable performance tools in place, such as applying international benchmarks to measure performance, and having a separate ministry to monitor performance and advise on privatisation. Participants 
gave examples such as board evaluations and performance frameworks that are applied, and that there is monitoring of SOE performance through quarterly and annual reporting. A few participants commented that performance should be assessed using both financial and nonfinancial measures.

"There are financial and non-financial indicators to measure SOE performance, [for example] number of vessels, tonnage etc. ... The chair undertakes the board evaluation survey and sees that the current process will help with recruitment of the next round of board directors." (025)

\section{Applying international learnings}

Participants considered that applying international learnings and adapting these for Samoa should be part of 'good' corporate governance.

"Leaders do need to look out to see international trends ... in this space. Leadership and flexibility of the model are important to look at." (020)

"Samoa is doing all it can to comply with world standards. It needs to react, respond, and behave [well] in a larger corporate sense because these are standards that are necessary to follow in the way the world is today. There is a system of requirements in the handling of expenditure and monetary assistance and Samoa understands that to be in today's world it needs to comply with international standards." (024)

This last quote reflects an overall awareness of where Samoa sits globally, and what it needs to do if it wishes to engage with other larger economies, aid agencies, and development banks, such as use of internationally recognised accounting systems. As commented on elsewhere, Samoa is experienced with applying and adapting Western models. This is reflected in the pragmatic responses held by participants, and also responses from stakeholders interviewed for evaluations of New Zealand's aid programmes in the Pacific (ASI, 2015, 2016; McGillivray et al., 2017, 2018). 


\subsubsection{Accountability and Transparency $(n=6)$}

Alignment with its government's vision for the country

Participants thought that having a separate ministry to ensure SOE corporate plans align with government's vision for the country, being responsible for appointments, monitoring of board performance, divestment policy, and that there are regulatory bodies to set tariffs, were important systems for accountability.

"The ministry's role is to represent government's interests, assist the government to achieve its objectives, and to help an SOE improve its service and make it more efficient." (014)

Boards being held to account, restrictions on government ministers or officials being appointed to boards, and requirements for boards to undertake three-year corporate planning to ensure they are operating in the best interests of the public and the SOE, were other examples of ways provided by participants to improve transparency and accountability. This lay principally with having systems in place to avoid conflicts of interest or corrupt decision-making by directors or government ministers, especially with regard to issues such as village interest versus national interest. Participants explained that there has always been governance in Samoa but that governance of SOEs has a national and international lens rather than a local/village emphasis.

"So long as the board provides information to Cabinet, it can make an informed decision about the implications the directive will have for the SOE. That's good corporate governance, and as government is 100\% shareholder, they [Cabinet directives] will continue to happen, and the board must comply." (017)

\section{Transparency in reporting and procedures}

Participants spoke of the importance of transparency in corporate governance, which is undertaken through: regular and transparent reporting; a merit-based appointment process for board selection; and planning and budgets being outlined in annual reporting. 
"In reporting, [the SOE] uses an RPT [Related Party Transactions category] for disclosure during budgeting estimates, to allow for ministerial assistance requests and Cabinet directives." (025)

Good procedures discussed include boards having monthly meetings structured along best practice guidelines preparing for the meeting in advance, sending out an agenda in advance so that directors can read the papers and be fully prepared, mutual respect for all attendees, and minutes and decisions being recorded (e.g. https://www.iod.org.nz/resources-andinsights/guides-and-resources/board-meeting-resources/\#, retrieved October 2020).

\subsubsection{Corporate Stewardship ( $n=6)$}

Participants saw long-term decision-making $(n=6)$ and corporate social responsibility (CSR) $(n=6)$ as part of good corporate governance. A few identified boards setting policies and strategies, and ensuring management delivers on corporate business plans $(n=3)$. With regard to CSR, participants referred to developing business cases to alleviate hardship, and better balancing of the commercial agenda and return for the government with ensuring efficient, accessible, and affordable services to the public. Participants referred to the Community Service Obligation (CSO) in the legislation as one example of how Samoa's SOEs implement CSR.

"The principal function is to be profitable and efficient, but we are aware of the CSO function. These are outlined in the annual plan and budgeted to make sure they are accounted for. In Samoa, community service obligations and corporate social responsibility are important." (025)

Only a few participants explicitly commented on the importance of applying corporate governance principles to SOE policies and procedures. Those that did spoke of policies being developed and implemented to strengthen achievement of their enterprise's objectives. 


\subsubsection{Section summary}

Overall, participants had a good understanding of corporate governance principles and the role these play in Samoa's SOE board performance. In particular, they identified the importance of wealth and value creation, and the contribution of director skills, performance tools, and long-term strategic thinking to achieving this.

\subsection{CHAPTER SUMMARY}

All participants were able to identify a range of factors that make up corporate governance principles, and most participants used terms found in Western models and frameworks, such as accountability, efficiency, performance, and transparency, to describe their understanding of corporate governance principles. Some referred to the OECD guidelines on corporate governance of SOEs (OECD, 2015b). Their views were that knowledge of good corporate principles alone is not sufficient to improve performance, but that it will garner support for further funding from aid agencies and development banks.

There also appeared to be a perception by almost half of the participants of blurred lines between alignment with the government's strategic vision for the country and political interference in SOE operations. Although the separation of political and commercial objectives is seen as best practice (Daiser et al., 2017; OECD, 2015b, 2016; Wong, 2018), the view in Samoa that as the 100 percent shareholder, the MPE minister on behalf of the government, should legitimately be involved if SOE decision-making could have a detrimental impact on the government's strategic plan for the country. In Tonga, participants understood the link between performance and alignment with the government's vision for the country. They saw that applying business principles for wealth and value creation was critical to the board's role, along with delivering dividends to the government, however, they recognised that CSR is also part of a board's mandate.

The term 'fairness' referred to in reports such as The Cadbury Report (1992) as one of the principles of corporate governance was not discussed in this section, but was raised by participants in the next two chapters when referring to local values and practices, and challenges faced in balancing the requirements to provide dividends to the shareholders and 
an affordable service to the community. This could be because the training of some participants was based on shareholder primacy rather than stakeholder theory.

While participants had a good understanding of the core principles, what the findings show is that the emphasis varied on what participants deemed the 'more important' principles and how they should be applied, or that this changes depending on what the government wants SOEs to focus on: either improving service (sometimes at the cost of dividends to the government); or improving the amount of dividends (sometimes at a cost to services or SOE infrastructure). This discussion on changing priorities supports recent debate on paradigm shifts within corporate governance to be holistic and factor in diversity, environmental and social responsibilities (Lipton, 2016).

Another overriding perspective from participants was that Western frameworks or models do not always factor in the context where the principles are applied, such as the scale and culture of a country. This is commented on further in chapter 7.

Overall, responses reflect that knowledge of corporate governance principles do not necessarily lead to application of those principles, and that there are other factors that need to be taken into consideration when discussing performance of a board's governance role. This was raised in an ADB report, which commented that some Pacific countries have comprehensive governance frameworks but that they are not necessarily implemented (ADB, 2009). 


\section{CHAPTER 7 APPLYING LOCAL VALUES AND PRACTICES}

\subsection{INTRODUCTION}

Having established what participants consider to be the principles of 'good' corporate governance, this chapter aims to answer the research question, Do SOE boards in Samoa and Tonga take local values into account in defining and practicing good corporate governance? It examines whether SOE boards in Tonga and Samoa apply local values and practices, and whether this is done to achieve social improvements. Current and former board members were asked this question, and other participants were asked whether they think the board takes local values and practices into account when implementing these principles. The same questioning approach applies to the challenges and solutions questions.

The literature review (chapter 2) highlighted the discussion on the influence by donors and aid agencies to reconstruct governance frameworks in their own image, rather than on the basis of local values (Larmour, 2012; Overton \& Murray, 2016). While the notion of culture is not static, maintaining custom and tradition can be seen as part of one's identity, for example, 'what makes us Samoan or Tongan', and is part of social cohesion, especially within the vast social diversity in the Pacific region. This research highlights the tension between externallydriven notions of good governance and democracy, and local values in Pacific societies (McLeod, 2008), and contributes to the discussion of the paradigm shift that is occurring globally within corporate governance (Lipton, 2016).

Participant responses are outlined below by country, and unlike the other findings' chapters, the findings from this chapter are discussed not by themes but by participant perception of whether they consider local values and principles, and whether they think local values and principles enhance or compromise governance and the performance of SOEs in their countries.

\subsection{TONGA}

Participants did not at first explicitly comment that their boards applied local values and practices to their governance of SOEs. However, following further discussion and reflection, 
seven $(n=7)$ of these participants qualified their responses: in considering both profit and affordability of service in decision-making, with the emphasis of service over dividends (to the principal or sole shareholder, the Government of Tonga), they do apply local values and practices to their decision-making.

These participants added that perhaps SOEs in Tonga apply a hybrid model: that is, they apply the Western model in which SOEs apply corporate governance principles, and they also provide an accessible and affordable service to the Tongan public as part of CSR through Tonga's Government Public Obligations (GPO). They factored in demography, size of the country, and location in their decision-making, but did not consider actions they took such as consultation with the public, a director providing a community perspective for the board, or developing policy to ensure price stability, to be uniquely Tongan.

Participants considered that Tonga's SOEs' dual function of providing both profit and affordability of service was 'good' corporate governance. The following quotations illustrate this dual aspect, and participant perceptions that corporate governance principles need to be adapted and contextualised for Pacific nations.

"The principles need to have a direct relationship with the local context, factor in demography and location such as the Pacific Islands instead of the West or Asia. Priority is the stakeholders which are the Tongan people, the taxpayers. Government is voted in by the people, and government has to deliver what the people want, which is an affordable service." (001)

"Its mandate is to deliver dividends to the government and an affordable service to the people of Tonga. It's good to be more creative in the SOE business plan making sure it achieves both goals. If it focuses on the service, it's easier to justify the lower dividend even if it doesn't deliver on the government expectations; keeping people happier is more important. Tonga is moving towards being more democratic, so the people will decide at the end of the day." (002) 
Participants also spoke of SOE performance indicators, and that they should consider nonfinancial indicators such as social and cultural wellbeing.

"Key indicator is happy Tonga." (004)

"Tongan culture is very important. Key values are love and care for Tongan people and Tonga itself. The ministry always considers what's in the best interests of the government. It also advises the [PE] minister that there are other things which need to be considered along with dividends." (009)

Participants did agree that Christian principles and Tongan culture can affect SOE performance. They explained that the public expects SOEs to be paternalistic and to look after them through 'in-kind dividends'; they see SOEs belonging to them through their taxes, so SOEs should provide flexible charges or discounts for cultural services under the GPO.

"Christianity and Tongan culture makes them more dependent ... In Tonga you still get people coming to us about attending a funeral on an island, so we have to stop the ferry on an island which is not part of the schedule ... It will change, but the board is aware of flexibility when it comes to these cultural services. .... people who cannot afford to have their cargo shipped ... will come to us because culturally they see the service belongs to them." (007)

Three $(n=3)$ other participants responded that they did not support taking local values and practices into account in corporate governance principles. They thought that the international model of corporate governance for SOEs is the best model for Tonga, as it ensures boards are held accountable and that their decision-making is transparent.

They were wary that applying local governance principles could prevent or interfere with the board delivering services to all citizens. One participant thought that it would take Tonga a long time to develop a Tongan model, and that it would be better for Tonga to link up with other countries to share experiences or lessons learned. 
"I don't want to get bogged down in something that stops me reaching out to the people. My role is delivering a service to the people; I am cautious of the cultural aspect if it interferes with the intention of the company. Government's attitude is 'Don't talk to me about cultural issues if it's going to interfere with my ability to deliver a good service to the people."' (003)

This participant was also concerned that their enterprise was already negatively affected by local values and culture through having a small population. They added that local politics already puts pressure on the board in deciding what is best for the SOE, and for the country's economic, social, and environmental wellbeing. They felt that the changing landscape from a monarchical hierarchical system to a more democratic form of government is placing pressure on the board with regard to influencing aspects of decision-making by businesses and by government. As a board's role is to ensure an SOE delivers a service, this participant was cautious of the cultural aspect to the extent that it could interfere with the intention of the company to make a profit and deliver dividends to the government.

"Tonga needs a longer time to evolve before SOEs adopt local values or practices, and time is needed to understand what corporate governance best practice is and what it means for Tonga. Tongan practices and values are already changing with the impact of technology on Tongan culture." (003)

One participant was more strident, because of what they perceived as the negative aspects of local customs on SOE governance, leading to corrupt behaviour from some directors, or decisions made that were not in the best interest of the SOE.

"We're exposed enough to know what can be applicable in our context and what cannot work in our culture ... I do not support 'Tonganising' SOE corporate governance principles because of issues such as rent seeking behaviours, paying for favours, and corruption. Boards have to be strong to say 'no' to government ministers; once they say 'yes' they will be asked again and again. It's important to 
get everything [ministerial or Cabinet directives] in writing, and that they go to the board for discussion. Boards need to stick to it and will be respected and survive." (006)

The third participant thought that the lack of women on boards was a reflection of Tonga's culture and values towards women in governance, because traditionally women's roles in governance remained within the family and community. This participant did concede that there were women on private sector and community boards, but the government was not enabling more women to be appointed to SOE boards.

At the time of this interview there were only two women on the five SOE boards which each had five to seven directors, including chairs. Previously there were more women, but they tended to be from the nobility and some participants doubted they had the appropriate skills to be on an SOE board.

"It's our culture, how we're raised ... it's hard for a woman to stand up and be a director. Women feel held back, that they won't get on a board, so won't apply ... I think the Tongan culture is behind the lack of women on SOE boards, but I'm hopeful for the next generation. It's up to parents to discuss that there are no limitations to being a girl ... We've been brought up that men are meant to lead. What's happening on boards is a reflection of this - that we think men do it better."

Two $(n=2)$ further participants did not think local values and practices are applied, but did suggest that SOEs tap into traditional roles to improve performance. They thought that SOEs would be more effective if local practices and values are taken into consideration.

"Tonga's perspective is different, and it can tap into the traditional roles to improve performance ... It's important for outsiders to be aware that traditionally women were the custodians of society, custodian of the mores, of ways of behaviour. The male was custodian of providing a living. Usurping one over the other could cause 
conflict over the roles ... The SOE model is not incorporating traditional roles into the corporate governance model." (005)

"There should be the need to contextualise things; of course it's business, but there are ways to look at it with a Tongan lens, the way we give to our families and relatives but in the way of business. ... We're used to picking up Western ideas, [but these] need to be married with Tongan and church culture." (012)

\subsubsection{Section summary}

Participants held mixed views whether SOEs in Tonga applied local values and customs in their governance and, if they did, whether this would be useful or detrimental to SOE performance. One group added that if considering the community's wellbeing in decision-making meant they were applying local values, then they considered that they did. A small group was opposed to any "Tonganising" of SOE governance as they thought it implied poor governance practice. A smaller group again thought SOEs in Tonga didn't apply local values and customs, but that perhaps if they did, it may help SOE performance.

\subsection{SAMOA}

Most (12 of 13) participants who responded about Samoa SOEs believe that Samoa localises the Western principles of corporate governance for its SOEs. They explained that Samoa is used to adapting Western models and they see that Samoa's SOE model aims to deliver both profit and CSR. They acknowledged that at times it seems the two are competing with each other, but they contend that in Samoa SOEs cannot be purely profit-focused, and this is acknowledged in the legislation.

"There are elements of Samoan culture involved, but good governance is good governance regardless of the country." (018)

Participants spoke of the importance to contextualise (as opposed to changing) the principles, so they can be applied more effectively in countries like Samoa, as no one model fits all contexts. 
Participants commented that while understanding of corporate governance principles has increased in recent times, the challenge is in implementation, and that it would take time to change the attitudes and behaviours of stakeholders. ${ }^{77}$ There was general acknowledgement that corporate governance is a Western model, but that Samoa leans to cultural leadership so corporate governance in Samoa is very much a merger of Western and local principles and values.

"Corporate governance best practice principles are the same for any country; the difference is how they are adapted to fit the Samoan cultural context." (023)

There was also a view that the cultural element of hierarchy will change over time, and situations such as an example provided by a participant of a chair with a matai title getting the CEO to do the work the chair should be undertaking themselves, will become less common.

"There's been a history of the importance of cultural leadership and ensuring that fa'a Samoa customs and tradition are maintained. But it's important to remember that these are always evolving." (020)

While most agree that corporate governance principles are helping SOEs to become more efficient and are leading towards sustainable profit-making, they feel that international donor agencies have set standard criteria that often do not attempt to incorporate the governance situation already in existence. The SOE model in Samoa is not purely commercial, and this view can put it on a collision path with international donor expectations. Another participant added that adapting corporate governance principles needs to be managed in the context of international politics.

"It's complex. Samoa's company's legislation is based on the New Zealand model, and Samoa out of habit and history has followed New Zealand practice and

\footnotetext{
${ }^{77}$ This challenge and others are discussed further in chapter 8 Challenges implementing corporate governance.
} 
legislation. From the regional point of view, it helps to understand these corporate governance standards and concentrate on local implementation. ... Western standards such as the OECD Standards are developed by powerful countries, and control what the World Bank, $A D B$, and IMF do. It's a lot more complicated, and you can't expect Samoa to change these standards overnight." (024)

Participants acknowledged that Samoa is used to adapting Western frameworks, and were aware the SOE governance structure, Samoa's constitution, and PE Act are based on New Zealand models. Overall, they viewed governance 'best' practice for SOEs as a blend of local governance and Western principles of corporate governance.

"[MPE] always considers cultural values, especially in governance. Governance has always been in Samoa in a cultural sense before implementation of the SOE model. There's always been a form of governance in the villages and it's central to the organisation of Samoan society. It just requires tweaking to incorporate commercial sensitivity, but basic principles of good governance, good practices have always happened in the villages before implementing the SOE model." (015)

"The board acknowledges that the priority is the language and following cultural protocols, especially when doing presentations to elders in the community. From a cultural perspective, all written documentation and resolutions are in English and Samoan. There's a director on the board representing the community. ... Community engagement is in Samoan." (019)

One participant spoke of the importance for boards to be aware of their role with ensuring Samoan heritage is recognised where possible, such as ensuring Samoan values are part of the decision-making. An example provided by another participant with regard to their board's appointment of the CEO was that the successful applicant was required to speak both English and Samoan, and be knowledgeable of cultural protocols such as the Samoan social structure and role of the matai as chief of the village. They added that this is particularly important when consulting on such issues as land when the SOE needs community support for projects. 
"The SOE model in Samoa is not purely commercial, as it needs to strike a balance where social obligations and responsibilities are served." (015)

As well as taking culture and customs into consideration, participants spoke of ensuring the provided service is affordable, as one of Samoa's cultural values is service to the community. One participant added that Samoan culture and customs feature in directors' decisionmaking, and that there is always an element of ensuring the SOE provides an affordable service to the people of Samoa. However, as there has always been governance in traditional Samoan culture, some participants commented that sometimes it is a balancing challenge for directors when trying to implement corporate governance principles in their decision-making with what is best for the country as a whole, instead of their own village or community.

"This is where Samoan culture and customs come in, they understand that there's always an element of providing an affordable service to the people ... continuing to refine the PE model and adapting to Samoa's context will be good for Samoa." (017)

"A model that's half profit and half CSO-CSR. These two are always competing ... In Samoa, SOEs can't be just purely profit only. In Samoa there are people who are trying to survive, and this should determine the model." (023)

The two main examples provided by participants about how Samoa takes into local values and practices consideration were the Community Service Obligation (CSO) and board composition, where most SOE boards require one director in the role of cultural leader. Both elements are in legislation and policy.

\section{Community Service Obligations}

As discussed in chapter 5, there is a provision in Samoa's Public Bodies (Performance and Accountability) Act 2001 for SOEs to exhibit a sense of corporate social responsibility (CSR) (Part 2 (d)) and to implement Community Service Obligations (CSO) to alleviate hardship (Part 
3). The main function of CSO is to alleviate the hardship of low-income earners. CSO is approved by government and funded under the CSO budget of the government. However, there have been issues with a lack of provision in Treasury's budget to deliver CSO. This has meant additional funds have to come from the SOE dividends, which are not supposed to be used to fund CSOs. If a board receives a directive from the PE minister for a CSO, then the board must ensure this is carried out, even if there is no guarantee of receiving funds from the government to implement the CSO.

"They [CSO] are unique to Samoa and reflects the government's concern for the community, especially those in remote areas who also tend to be from the poorer communities ... In Nadi or Suva you will not see streetlights in some areas, but the Government of Samoa has made a commitment that the community has access to water and electricity. It sees it has obligations to the more vulnerable sectors of the community." (014)

"CSOs need to be seen in the context that SOEs in Samoa operate to provide a service. Although public trading bodies are supposed to trade and make a profit and operate similar to a private company, they are still expected to provide a service." (017)

Chapter 5 discussed the recent review of the CSO provisions by the MPE Monitoring division, and the revised guidelines designed to help determine whether a proposed activity fits within the government's policy on CSOs. The Budget division of the Ministry of Finance will allocate a pool of funds for CSOs every financial year and the MPE will review the CSO proposals in accordance with the register, prioritisation guidelines, and the budget allocation. It also outlines how SOEs should respond to a direction from the PE minister, as well as tightening the definition of CSOs to make it clear that an approved CSO must demonstrate how it will contribute to the government's target 'Alleviate hardship in Samoa' (Ministry of Public Enterprises Guidelines on Community Service Obligations). 


\section{Board composition}

Participants spoke about the importance of boards respecting the culture, noting that most chairs have matai titles, and many directors do as well. Participants noted the recent (June 2019) Cabinet-approved changes to board selection and composition, which includes ensuring that for most SOE boards there is a director that has cultural leadership experience. This person must also have experience and credibility within the community. The changes mix the skills of a community representative with a person with leadership qualities.

"In Samoa it's very important for a director with cultural leadership experience to have a matai title, achieving both the cultural element and leadership element." (017)

"Many boards link back to villages and their community, so there's a struggle for directors between community obligations and national obligations. Samoa is a status conscious society because of the hierarchical structure in its society. The current application [process to be a director] infers matai for cultural leadership." (020)

One participant added that the director role is one of Tautua ${ }^{78}$ stewardship, that as a leader within the community their role is to serve that community, which is embedded in Samoan culture.

"Stewardship or Tautua, leadership and service - the path to leadership is service. Leadership should have a servant-hood heart. It's part of the role of being a public servant." (022)

This reflects the argument that an holistic governance approach can offer powerful insights into how Indigenous stewardship of resources can be merged with commerce to transform both organisations and societies (Nicholson et al., 2019).

\footnotetext{
${ }^{78}$ In the role of SOE director, Tautua conveys the cultural tradition of service of an individual to a greater cause. Tautua is reflected in the Samoan proverb-o le ala i le pule o le tautua-the road to leadership is through service (Milner, 1966, p.145).
} 
Another participant added that although directors are politically appointed, it was important for these cultural leaders to also have the right skills to govern, such as financial literacy, technical expertise, and business knowledge.

"If government needs to have, for example, a pastor or a matai planter from a village on the board, then it needs to make sure they know about business and how to contribute to a moneymaking enterprise ... these cultural leader directors need to be able to read and design a budget, understand auditing systems, read monthly operational accounts, and to analyse banking saving reserves accounts as well." (024)

This participant understood why the government would want a culturally qualified person who is politically sensitive to the government, but did not think a board needs a cultural expert, unless the SOE was dealing with land issues. In that situation the board and management would need to have a high level of cultural sensitivity towards the affected community.

Other examples provided by participants of how Samoa takes local values and practices into account in corporate governance included adapting Western director training programmes, and performance monitoring tools. Director training material has been from New Zealand, but it has been adapted in parts to fit Samoan culture. For example, some material is in Samoan, and localised scenarios are used in the training. MPE also adapts international best practice benchmarks for monitoring/oversight and board performance frameworks, to suit Samoa's culture, environment, and economic conditions.

"The ministry contextualises corporate governance principles because Samoa is different from big economies that the frameworks have been developed for. No one size fits all for SOEs." (016) 
One $(n=1)$ participant thought the governance of SOEs in Samoa does not take into account local values and practices, but thought SOE governance should be customised for Samoa and that this would be good for the economic and social wellbeing of Samoa and SOE performance.

\begin{abstract}
"Unsure what it might look like ... Ultimately it will depend on the government, and what government wants. There should be clear guidelines on how to improve the service to people and make it affordable. MPE wants the SOE to run as a private company to make money, but there needs to be a clear model on what the government wants. The SOE can make a profit if it is run as a private company, but at the end of the day, you have to take that profit back to the government, unlike in the private sector. ... if the SOE can prove to the government that people will enjoy the benefit, government will be happy." (013)
\end{abstract}

The participant appeared to be referring to the political environment in which SOEs sit. On one hand they are expected to operate as if in the private sector, but if there is a risk that board decision-making could impact negatively on the government it may try to intervene. On the other hand, if the people of Samoa are happy if the SOE lowers fees, the government will benefit from any positive feedback from the community.

The participant who thought it was important for cultural leaders to also have other skills to sit on an SOE board also commented that standards of good corporate governance are now international and should not be adapted by Samoa to allow for the cultural system of Samoa. This participant added that SOEs should not undertake any customary behaviour that does not benefit all of Samoa, or contravenes the corporate behaviour 'rulebook'. While the participant agreed with adapting SOE governance, the participant was opposed to seeking a distinctive Samoan corporate governance model:

"It would be a futile exercise to seek to develop a distinctive or culturally Samoan model of corporate governance. If it's perceived there's a problem of bad behaviour such as dishonesty, then focus on that. Samoa is part of the system of 
internationalised corporate standards and practices. There is Samoan corporate experience from New Zealand-based legislation and standards/practice and Samoan representation on many relevant international bodies, WTO, etc. So the effective corporate model is not and should not be totally foreign to Samoa. Samoa needs to accept it and use the current frameworks, not have a separate model. Samoa needs to focus on the lack of implementation and on corruption sometimes countries hide around cultural considerations, that's rubbish." (024)

Although this participant would not support Samoa developing its own corporate governance model at least in the short-term, it was not because he thought it would somehow be inferior to the Western model. Rather he believed it was unnecessary as Samoa is very familiar with contextualising Western models, and if Samoa is to work globally, it needs to work within the model used by larger economies. The participant rejected the inference that Samoan culture risks 'contaminating' corporate governance principles, ${ }^{79}$ and saw the problem was with individual self-serving behaviour, which is found globally in many governance situations and not just in small Pacific countries.

"If people think that expectations of Samoan culture will contaminate corporate behaviour, they are wrong. There are strong cultural rules and expectations, some of it stretched wrongly. ... Misusing someone else's money, or just benefiting your own family, that's not Samoan custom or culture. It does not mean paying off a minister or allowing in the budget money to go to the villages for a customary donation. ... There are laws against corruption in Samoa. It's not Samoan customary or cultural behaviour, but individual behaviour in the guise of customary behaviour." (024)

The participant acknowledged that it has been challenging in the past for SOE chairs, directors, and government ministers for decision-making to be in the best interest of all Samoans, not just those within their village community.

\footnotetext{
${ }^{79}$ A few participants in Tonga rejected what they termed 'Tonganising' SOE governance as they thought some of the corrupting behaviours that people argue is 'cultural' could impact on SOE's accountability and transparency of its performance.
} 
"Samoan cultural practices are open to be judged according to broader standards, especially behaviour in the corporate world. SOEs are not village organisations."

\subsubsection{Section summary}

Most responses highlight the conscious contextualisation of Western corporate governance principles within Samoa's culture and local values. This is reflected in Samoa's CSO policy and the designation of one director as a cultural leader (although most if not all board members are matai). This role would advise the board on such matters as compensation for injury or death of an employee, or about land that may be impacted by SOE plans. Only one participant thought SOEs don't localise the Western principles of corporate governance, and a further participant spoke strongly that although boards adapt the Western model for Samoa conditions, he was opposed to developing a Samoan corporate governance framework in the short term. This participant thought it was unnecessary and could impede Samoa's ability to operate in the corporate global scene.

\subsection{CHAPTER SUMMARY}

This chapter examined whether Western corporate governance could be enhanced by knowledge of how cultural values and principles are applied to this model, and whether there are learnings that could be applied more broadly. The findings from this chapter highlight the mixed views participants hold about whether SOE boards in Tonga and Samoa apply local values in practicing corporate governance, and whether this was good for SOE performance, benefited the nation, and reflected a desire for self-determination. Due to years of adapting Western models to gain financial support participants said that they have become used to adaptation. There have also been years of being exposed to dialogue that Western models such as NPM are 'gold standard' or 'best practice' for reform (Farazmand \& Pinkowski, 2006; Osborne, 2006), or that neoliberal corporate governance is 'good governance' (Kaufmann et al., 1999, 2009; World Bank, 1989). 
The cultural values recounted by participants, for example service to the community, Christianity, and the collective culture, are consistent with the views of Pacific scholars (Amosa, 2012; Helu-Thaman, 1997)

Tongan society still places a high value on families, paying respect to those of seniority and maintaining oral traditions of storytelling. Konai Helu-Thaman (1997) defines culture as a way of life of a group of people, which includes their language and a body of accumulated knowledge, understandings, beliefs, skills and values. Helu-Thaman's Kakala Pacific research model represents a garland made of flowers and leaves, and is a metaphor to describe a the collective nature of Tongan society, and that the society and its people are 'woven together'.

Desmond Amosa $(2010,2012)$ describes Samoa's cultural values as underpinned by its collective culture and fa'a Samoa. Samoa's traditional social structure, including village life, highlights the respective authority and roles of various institutions in Samoan society. Christianity is central to Samoan culture, and contributes to the traditional social protection system. It has a large influence on village life and larger-scale policy and social protection interventions. The main Christian churches are closely linked to the state and the matai system. Leaders often perform multiple roles as matai, church leaders, and government ministers.

Overall, participant perceptions are that corporate governance principles need to be adapted and contextualised for Pacific nations if SOEs are to be successful. However, with regard to SOEs in Tonga, a few participants were concerned that applying local practices and culture could compromise the integrity of SOEs to perform and provide dividends to the government. They did not support taking local values and practices into account in corporate governance principles and thought that the international model ensures boards are held accountable and that their decision-making is transparent. They were wary that the hierarchical system in Tonga could prevent or interfere with the board delivering services to all citizens, or interfere with the intention of the enterprise to make a profit. There were concerns that some in power may abuse their position for personal gain, leading to a lack of transparency and corrupt behaviour where decisions are made that are not in the best interest of the SOE. 
Most participants interviewed about Samoa SOEs believe that governance 'best' practice for SOEs is a blend of Indigenous governance and Western principles of corporate governance. They explained that Samoa is used to adapting Western models and they considered that Samoa's SOE model aims to deliver both profit and CSR. They contended that in Samoa SOES cannot be purely profit-focused and this is acknowledged in the legislation; the two main examples are the CSO and board composition, where most SOE boards require one director with the role of cultural leader. One participant added that SOEs should not undertake any customary behaviour that does not benefit all of Samoa or contravenes the corporate behaviour 'rulebook', and was opposed to development of a distinctive Samoan corporate governance model.

All participants acknowledged that their country already has Indigenous governance principles, but that to be able to operate in the global economy their country needs to apply international models of governance to their SOEs. However, they emphasised how they apply them and what priority they place on each element of corporate governance, should be determined by each country if the SOE model is to operate successfully.

Although participants understood the principles of corporate governance, priority was placed on 'fairness' to stakeholders over profits for the shareholder. This is reflected in a view that the director role is one of 'stewardship' (not to be confused with Stewardship theory which is briefly discussed in the literature review). This shows that while participants were pragmatic about using Western models, through time they have become more comfortable with adapting those models to fit their countries' values and practices. While most agree that corporate governance principles are helping SOEs to become more efficient and are leading towards sustainable profit making, they feel that international donor agencies have set standard criteria that often do not attempt to incorporate the governance situation already in existence. As the SOE models in Samoa and Tonga are not purely commercial, this view can put them on a collision path with international donor expectations. 
Participants also referred to a hybrid model where SOEs have a dual function - applying principles of efficiency and profitability for the enterprise, along with ensuring accessibility and affordability of the service to the public. CSR is in the legislation of both countries, through GPO or CSO. This hybrid view supports a growing international discussion that corporations should employ a hybrid approach to corporate governance - encouraging corporations to maximise profits but only to the extent that the economic objectives are not detrimental to the environment and society (Barreca, 2019; Gountoumas, 2016). The hybrid corporate governance system is derived from country-specific culture, including values and 'ideology characteristics' such as stewardship, CSR, and partnerships between the corporate and community sectors (Thyil \& Young, 2010). It tends to be a hybridisation of the AngloAmerican (single-tier model) and German (two-tier model) systems. As discussed in the literature review, the 2017 study on 'ambicultural' corporate governance practices argued that Indigenous businesses are harmonising Indigenous and Western corporate practices and worldviews to create and enhance economic and cultural well-being through a flexible corporate governance model (Nicholson et al., 2019). This appears to be occurring in Tonga and Samoa SOEs. 


\section{CHAPTER 8 CHALLENGES DELIVERING CORPORATE GOVERNANCE}

\subsection{INTRODUCTION}

The literature review (section 2.9.3) noted that the 2016 ADB review of SOEs in island countries, which included Tonga and Samoa, argued that weak governance and regulatory frameworks make it hard for SOEs in the long-term to function on purely commercial principles, and stressed that political commitment to reform would be a key driver for commercial results (ADB, 2016a). However, this is a tricky balance for governments to "avoid the pitfalls of both passive ownership and excessive state intervention" (OECD, 2015b, p.3). There are also other examinations of SOE models which have highlighted challenges from larger economies (Bernier et al., 2020; Ginting \& Naqvi, 2020; Musacchio \& Ayerbe, 2019) such as ineffective monitoring or lack of incentives to improve performance.

Chapter 8 outlines the main responses from participants on their challenges in delivering corporate governance. It notes participants' views about issues that obstruct SOE boards from implementing corporate governance principles and governing effectively. Participants provided multiple responses, and these have been analysed and synthesised into common themes and in order of the most common unprompted responses. Overall, political influence by government in SOE operational decision-making and poor director performance were the most common issues discussed by participants. It is unclear whether these two are linked and reflect a lack of trust in government-appointed directors, which was suggested by some participants. The following sections will discuss these challenges and others further.

\subsection{TONGA}

The themes outlined below in Table 8.1 highlight challenges participants identified as factors boards face that affect their ability to govern effectively. 
Table 8.1 Challenges implementing SOE corporate governance in Tonga $(n=14)$

- Government role in SOE decision-making $(n=10)$

- Shared Board model $(n=6)$

- PE Ministry $(n=6)$

- Ineffective board evaluations $(n=4)$

- Lack of diversity on boards $(n=2)$

- Board skills, performance, and behaviour $(n=9)$

- Conflict of interest by $(n=8)$

- Balancing SOE dual function $(n=4)$

- SOE staff skills and SOE performance $(n=5)$

- Lack of public understanding of SOE function $(n=4)$

- Impact on the local private sector $(n=2)$

\subsubsection{Government role in SOE decision-making $(n=10)$}

Government's influence in operational matters is seen by most participants $(n=10)$ as a major challenge for boards, along with finding a balance between government's short-term priorities and the long-term sustainability of the SOE, followed by capacity building ( $n=9)$. This supports recent research on anticorruption and integrity in SOEs, which reported that SOES can be subject to undue interventions by senior public officials or other third parties (OECD, 2018b). One reason for political influence or interference in operational matters could be due to past poor board governance and CEO performance.

\section{"Sometimes Cabinet or government ministers want to influence commercial operations, and the ministry has to look at these requests and how to convey these to the board. Satisfying customer expectations are important to ministers; if the public are unhappy they will tell their government representative." (009)}

In Tonga, with its small population, participants referred to everybody knowing everybody', and they commented on the hierarchical system in Tonga and how it affects CEO, board, government, and public behaviour. There are also challenges in coming to terms with what it means to operate within a new democracy. Participants also mentioned the reluctance of people to be on a board because of perceived government interference, and the impact this 
has on MPE's ability to attract Tongan people with the appropriate skills who are working or studying overseas, back to Tonga. Participants commented that government ministers were aware of and understood good corporate governance principles, but at a political level they might be interpreted differently if they don't align with the government's agenda.

Participants also spoke of pressure from government for short-term decisions to cater for voter demand over the need for the board and management to make long-term decisions for the sustainability of the SOE, such as increasing charges to increase revenue to improve SOE infrastructure, maintenance, future use of technology, and ability to provide higher dividends to the shareholder/s.

"I didn't have the guts to challenge and push back at requests from the minister ... I allowed the government minister's requests as instructions [and] decisions were not made in the best interest of [the SOE]. I saw my role to maximise the revenue, but very hard to say 'no' to a government minister. I felt board and management was not totally independent from government influence. ... there were challenges with ministers' pressure from local politics over what's best in the national interest." (010)

Government ministers wanting to keep tariffs low to placate their constituents was identified as a challenge for boards, as reduced profits decreased dividends and reduced funds for maintenance or reinvestment in the SOE. Participants stated that while SOE corporate plans should align with the government's strategic vision for the country, the concern is that boards do not always follow proper process when they receive a request from the government. This could be due to traditional cultural practice treating requests as instructions from those in power or who have seniority (either in government or from the monarchy).

The following quote reflects these blurred lines between political interference for personal or constituent gain, and ensuring SOE decision-making is in-line with the government's strategic vision for the country. 
"Political interference has been raised by boards, but government of the day is the government of the day and they have their vision and what they want, we follow through what they want. So long as the board follows proper process, we can implement their vision. If we follow due process and that tells us not to go ahead, we don't go ahead. If the board receives a direction from the PM, other board members often want to implement straight away, but I would argue that the board needs to go through due process and put together a sub-committee to get more information and consult with the community. That's our job, not just to say "yes yes". If we get a direction, we'll say yes we'll work on it, and do our homework, then present our findings and if the minister still wants to go ahead with it, we say well this is our recommendation. One time it took two months to consult and do research, then board presented findings to the PM, he then changed his mind." (011)

One participant explained it is important for boards to maintain a functional relationship with the government, and although ministers are not supposed to get involved with operational matters directors understand that in a small country any perceived or real loss in service or increase in costs can negatively impact a minister's constituency. This places pressure on boards to find profits elsewhere through improved performance or rationalising staff levels.

"With the first board, the government was trying to dictate the terms via their rep on the board - a government minister - and the board wanted to maintain a relationship at the time with the government ... the government is not supposed to get involved in the operations of the board and should leave it to the board to make the decisions. Our purpose is to maximise profit, but also is service-oriented. Government struggles with the balance." (003)

Another participant thought that one way to overcome the public or government demands is for boards to raise awareness of the role of the government in SOEs as well as the function of an SOE. However, one participant was less optimistic and thought that the public is only interested in maintaining or improving the level of service at no or little additional cost. The 
public is more interested in receiving a service, and less interested in which organisation is providing the service. Even if the government is supposed to be at arm's length, the enterprise is still state-owned and is seen by the public and ministers to have a duty of care to its people.

SOEs are seen as a 'double-edged' sword for government ministers. Improving services or an increase in dividends can be good public relations opportunities, but poor SOE performance, increases in costs, or reductions in services can mean unwanted media attention for ministers.

"For SOEs the emphasis is on dividends, but they also have to manage what the public wants. We have to balance complaints from the public on affordable and accessible service, with complaints from the government over dividends. Staff and public level of understanding is that they think government sets thresholds. We need to work on raising awareness of the SOE function and arm's length role of government with public and staff." (006)

While participants thought that government ministers understood the importance of applying corporate governance principles, they believed they would overlook these when it was perceived that they risked compromising the government's agenda. One participant, however, thought that perhaps some ministers don't understand the function of an SOE.

"Don't think government understands the function of a PE. There is a lot of political interference. It makes things unstable and not good for SOEs. We already offer a lot of discounts to parliamentarians - if I don't do that, there will be a lot of complaining." (007)

As well as the challenges of domestic political interference, some participants commented on international donor influence where there is an expectation to apply the model with no or little consideration to the conditions in Tonga. 


\section{Shared board model}

Recruiting directors, especially chairs, with the right skills for shared boards is seen as a challenge. Participants spoke of the required leadership qualities for governing shared boards, that relevant skills were more critical for a shared board, and without these there is a risk that it would be too easy for the PE minister to influence operational matters.

"The challenge for the ministry is to find the right chair that will be a strong leader if further reform is needed." (009)

The rationale behind a shared board is to help overcome capacity issues on boards and reduce costs in terms of directorship fees. While participants saw the use of shared boards as a pragmatic approach to resourcing and capacity issues, half the participants interviewed commented that this model came with its own challenges. These included increased workloads for directors, especially those on several shared boards. Each shared board covers three SOEs and the workload for directors does not reduce for each SOE. There is also a concern that decisions made by a shared board in the interest of one SOE could negatively impact another SOE within the same sector.

"Directors shouldn't be on multiple boards as workload is too heavy, especially for shared boards. ... directors struggle to read all the board papers. Only benefit I can see in having directors on multiple boards is that they can bring in good practices from other boards, like sharing policy documents." (002)

"I think there is too much risk with a shared board as it's too easy for a government minister to influence operational decisions. There's also a risk to directors wearing multiple hats." (010)

There can also be conflicts of interest from one enterprise that can affect another enterprise. Participants spoke of an expectation that if one SOE is failing, the other two SOEs need to help the one that is failing. They expressed concern that this increases the likelihood of the board 
getting involved in operational matters, for example if CEOs who have the same shared board disagree over resolving an issue, the board could be approached for resolution.

Different interpretation of corporate governance best practice has also led to teething problems in implementing the shared board model. As previously mentioned, attracting Tongan citizens back to Tonga is seen as a challenge, not just because of government's role, but also because of the remuneration of CEO and board roles. As board roles are not fulltime, there is little incentive for potential directors based overseas to return to Tonga.

The shared board came in 2015 and is still in a transitioning period. Some boards still have separate meetings for each SOE, and no shared meeting, which would help board and CEOs be on the same page. Participants thought that MPE needs to be more involved, especially with direction if the next step is amalgamating three SOEs into one SOE.

"Shared board - good initial idea to share costs, standardise HR, IT, lower costs. But hasn't worked. Boards are more 'hands on', have not got buy-in from all the CEOs and management. MPE should take the lead to standardise HR, not the board." (007)

As discussed in chapter 4, the shared board model is an innovative and pragmatic approach not seen elsewhere in the Pacific, aimed at overcoming the challenges of having a small population with resourcing and capacity issues. However, like any new approach it can take time to establish, get buy-in from management and boards, improve systems and standards across the sector, and ensure directors have the skills to govern three boards rather than just one.

\section{Ministry of Public Enterprises}

Half of the participants interviewed spoke of issues they had with MPE. This included its role as a regulator, monitoring board performance, and that it should be more proactive in getting women onto SOE boards. With regard to its role as a regulator, participants raised issues associated with MPE and the skills required for public officials to understand business 
processes and the corporate world, provide appropriate advice to the minister, and how a regulator should function with regard to setting sustainable dividend rates.

"There are always challenges. [The SOE] believes the regulator should play a more active role in making sure there is a direct relationship between the wholesale price and the retail price, and not just giving it away to the service providers ... to do whatever they want to do with it. Because at the end of the day, the infrastructure is for the taxpayer." (001)

SOEs are required to submit their Statement of Corporate Intent to MPE to review the plan and decide what the dividend should be for the next financial year. Participants spoke of the challenge when the ministry sets high targets and expectations for dividends, but the SOE wants to keep some dividend back, they then have to submit a proposal.

"I don't agree with the approach if they have already sent the business plan, dividends should reflect what's in the plan." (002)

One participant suggested that if an SOE cannot operate and govern under a corporate model, then perhaps the SOE should be absorbed back within a government ministry. The participant does not agree with MPE assessing the dividend as it does not take into consideration other factors such as maintenance and the long-term sustainability of the organisation.

"If we are running the board like a mini-ministry, then we should hand it back to the government. But we are here to run it like a business and make money. If we can't do that then we are defeating the purpose of a public enterprise, and the government will need to get other people to do it. So, we need to look at the tariffs and what's the optimum that people can afford, and keep the politicians happy with it ... To me the dividend to the government is the last result. Need to maintain $H R$, asset first. Government is trying to understand this. I want the board to dictate what the dividend should be, [but] currently this is done by MPE." (004) 
Ineffective board evaluations

Participants also raised the issue with MPE setting unmeasurable performance indicators as part of board evaluations, and that it should provide measurable assessments that are contextual and appropriate for Tonga as part of these evaluations. They also queried the appropriateness of self-evaluations for director performance, and instead one participant suggested that users of the service should be surveyed.

"I have received from the ministry a self-review survey, a Likert scale, but no base line. It's hopeless, 1-6 competence. Need a benchmark to assess yourself [against]. Assessments need to be measurable and contextual. That's why we need a JD to spell out what [directors] need to do and a timeline. That's an indicator for assessment. Check list is the JD. Need to have concrete evidence. Performance is comparative. Sometimes you set up competent people to [look] incompetent because there's no benchmark." (004)

One participant was critical of board self-evaluations adding that it was not appropriate to assess their own "successes". Rather, that it should come from the stakeholders, in particular the public, surveyed by the ministry on service satisfaction and the level of dividends to the government. Another participant queried the applicability of international benchmarks and whether they should be adapted to the geographical context of the SOE.

"If something went wrong, it wasn't your fault, it was someone else's fault. Now there is supposed to be accountability, but the measures for that fall down. The ministry uses return on assets but that's not always a good measure." (005)

\section{Lack of diversity on boards}

Two participants thought a challenge for MPE is how to encourage more women to apply to be a director, and for the ministry to proactively recommend women identified as suitable for selection to Cabinet for approval. The issue is partially seen as a cultural issue but also seen as a lack of commitment by government to actively encourage women to apply. 
"There should be women on boards. The issue is with Tongan culture; women can participate in discussions but get told to shut up. You need to be a very strong woman to be on a PE board. I think in time it will change. In Tongan culture women are not supposed to ask questions in front of men." (010)

"The government has a role to play in changing attitudes. It should actively encourage women to apply, and should be shoulder-tapping for now. There should be one or two women on each SOE board." (011)

The role of MPE is to advise the PE minister about dividends and appointments to boards, and to monitor board performance. However, as discussed by participants they are aware how quickly public enterprise results can deteriorate when political commitment to commercial outcomes weakens. Despite these challenges, attempts have been made by MPE to improve accountability. It was the first public enterprise ministry in the Pacific to publish detailed SOE performance results on its website (PSDI, 2017; RNZ, 2017). Information included profiles of each SOE, including financial performance and the names of board members, as well as the performance of the overall SOE portfolio. ${ }^{80}$

\subsubsection{Board skills, performance, and behaviour $(n=9)$}

Director skills and behaviours affecting performance were raised as a concern by participants $(n=9)$, in particular directors' level of understanding of their role on an SOE board, or not understanding the difference between governance and management. Participants spoke of directors from the corporate sector not understanding the SOE role of profit and service, directors lacking business sector experience, and the board being focused on short-term profit making and not long-term decision-making for sustainability.

Other challenges boards were facing which were having long-term effects on SOE performance included the lack of ongoing training for directors, a lack of diversity in skills, directors not having skills required to govern a particular SOE, and the impact of a previous board's poor decision-making.

\footnotetext{
${ }^{80}$ Unfortunately for this research, the ministry's website was down for much of 2020.
} 
"I'm concerned with the current board's lack of entrepreneurialism, [but] entrepreneurs could be in conflict with the current government vision." (005)

Participants commented that sometimes the challenge is not lack of understanding of corporate governance principles, but lack of application - that directors don't practice governance principles in their decision-making, such as decisions being made by directors outside of board meetings. Or that other factors are taken into consideration, such as the political nature of SOEs. Although SOEs are supposed to operate at arm's length from the government, this is difficult in practice. The government can remove a board if it feels the board's corporate plan does not reflect the government's vision for the enterprise.

"Board and government understand the difference. But the issue is how it's implemented ... decisions should have board resolutions, not [be made] outside the meeting." (010)

\section{Conflicts of interest}

Participants raised the issue of conflicts of interest for directors, that some directors may have different objectives to that of their government and are not aligned with government's vision for the enterprise. Some directors (especially from the corporate world) are only interested in profit and may directly or indirectly benefit if they represent, for example, a retailer on the board. When government is not the 100 percent shareholder, it is difficult to get consensus from the board for decisions to be made.

"It's also complicated with having two directors on the board [representing two other companies]. They have $16.7 \%$ each of shares in the SOE. This can prove problematic, as there can be a conflict of interest with other retailers wanting to enter the market, and with decisions having to be unanimous. To change this, the CEO will have to put a paper up to Cabinet to recommend a change in legislation where the government can buy back the shares through compulsory legislation or create a new Act." (001) 
Participants described how it is hard to make progress if the board is dysfunctional and no agreement can be made at meetings, While the government and government representative on the board may want to deliver to the public, other board members from the private sector want to deliver profit to the SOE. If they are representing other shareholders, then they are looking to ensure maximum profit to these shareholders.

In addition, participants referred to conflicts of interest occurring in situations such as directors wanting reappointment, and directors being too close to management. They commented that the sustainability of the enterprise had in the past been compromised when government focused on profit and dividends, with boards competing to provide the biggest dividends.

"The problem is that a one-year appointment, with option for renewal, encourages short-term decisions as they want to make an impact and get reappointed." (007)

There are examples of photo opportunities on some SOE websites, that show the board, chair, and CEO handing a large cheque (literally and figuratively) to the PE minister or prime minister.

"Some board members in the past used dividends to secure their position on the board. They provide a big cheque of $\$ 5$ million - a photo op with the ministers, and then increase the tariffs to cover this." (004)

Much of this was brought about by directors wanting to show they were performing to support reappointment. Participants commented that the hierarchical nature of Tongan culture meant that some directors' priority is to please government by providing dividends, even if this meant not maintaining the entity's infrastructure, improving staff development, and growing the business. 


\section{Balancing SOE dual function}

As discussed in chapter 5, Tonga's Public Enterprise 2002 Act includes allowance for noncommercial activities, where the government and a public enterprise enter into a written agreement under which the SOE provides goods or services in return for payment by government of the whole or part of the agreed price.

While few referred specifically to the legislation, participants commented that there was an expectation by government for SOEs to provide these non-commercial activities within their current corporate and operating plans, and not be paid either in full or in part by government for these activities. Participants referred to directors from the private sector struggling with government's social service expectations of SOEs and the need to balance profit with service objectives, especially government's non-payment for these non-commercial activities.

Participants added that it depended on whether the focus is dividends for the government or a cheaper service for the public. In the past, the casualty has been the maintenance and longterm sustainability of the SOE, especially if the long-term aim by the government is to privatise some SOEs.

"It's not sustainable and only meets part of the brief, which is providing an affordable service to the people. We should be able to run the business efficiently within the resources, then any remainder can go to the government." (004)

"The challenge for any PE is finding the balance between service and profit. With a change of minister comes a change in focus. Previous minister wanted [the SOE] to focus on service ... because once they have the service, the profit will come. This year the minister wants the PE to focus on profit ." (007)

Participants were very clear that a board's focus is on the performance of the SOE, that it performs well and produces dividends for the shareholder/s. However, when there is a SOE with multiple shareholders, this can result in challenges for the board if the government does 
not compensate the SOE for GPOs and expects the SOE to absorb the cost, meaning fewer dividends for the private sector shareholders.

\subsubsection{SOE staff skills and SOE performance $(n=5)$}

Participants spoke of the lack of appropriate staff skills impacting on SOE performance, the lack of appropriate training, lack of leadership from the CEO, and challenges for boards to measure CEO performance. Capacity issues in Tonga mean CEOs need to have a range of skills including people manager, strategist, expert technician, with an understanding of legal and accounting responsibilities. However it was reported that previous terms of reference struggled to hold CEOs accountable due to performance measures being too generic in job descriptions and not appropriately measurable.

"The challenge for SOE boards is finding a CEO in Tonga that is both a good technician, but also knows how to manage staff and the SOE accounts." (006)

Participants added that they thought that one of the struggles is changing staff mindset from working for the government to working for an SOE where customer service and profit-making are the priorities. Some referred to staff struggling to request payment from some members of the public, especially from their elders, the nobility, or senior members of the government.

"Before, performance didn't matter, staff still got paid. Under the SOE model performance matters. The whole SOE relies on the productivity of its staff to survive." (009)

Participants referred to a lack of staff capability to provide accurate and timely information, and remarked that internal reporting is often poor, that most staff don't have an academic background, and the impact this was having on board decision-making.

\subsubsection{Lack of public understanding of SOE function $(n=4)$}

Some participants spoke of a lack of public understanding of the SOE model and that this lack of understanding is impacting on customer willingness to pay the fees set by the board. There 
is a concern that the service will suffer if fees are not paid. It was explained by these participants that the public still see these enterprises as providing a public service, and that as taxpayers they should not have to 'pay twice' for these services. SOEs provide essential public services and participants added that the public are vocal and use the media to voice concerns over charges and service, with some approaching their government representative to complain and argue for reduced tariffs and user charges.

"I don't feel the community understands what a SOE is, they're just interested if it provides a good service. There's feedback through social media if the service is poor ... all the public care about is service." (011)

Although not raised in this research by participants as an issue, the effects of misallocated resources by SOEs can undermine the public's trust in public institutions (OECD, 2019). Participants think the public views the cost to the public purse as bearable so long as cost and service provision do not impact negatively on their day-to-day lives.

\subsubsection{Impact on the local private sector $(n=2)$}

Only two participants raised a concern that there was a challenge to ensure private sector businesses can compete with SOEs, and that governments don't use their regulatory powers to make it an uneven playing field. However, they considered it was more likely that it would be international companies or a conglomerate of smaller Tongan-based businesses that could offer some of the services currently provided by SOEs. The challenge in these circumstances is provision of sustainable services - international firms may exit and local firms may fail. Either scenario reduces services to the public.

\subsubsection{Section summary}

The Government of Tonga's influence on operational matters is seen by most participants as a major challenge for boards, along with a conflict of interest between SOE performance and government's priorities, and the task of finding a balance between government's short-term priorities and the long-term sustainability of the SOE. The solution to capacity issues through the use of shared boards was also seen as creating new challenges. Participants commented 
that shared boards have a greater need for more experienced chairs and directors with the required skillsets and leadership qualities, but that government's influence may be deterring suitable people from applying.

\subsection{SAMOA}

The themes outlined below in Table 8.2 highlight the challenges or issues faced by SOE boards in Samoa that were identified by participants. The lack of relevant director skills, and poor director decision-making and behaviour, were the most commonly discussed issues by participants, along with government's role in SOE operational decision-making.

These were also seen by participants as the two main challenges SOEs face in Tonga. As with Tonga, it is unclear whether they are linked and reflect government's lack of trust in its directors as was suggested by participants. Participants provided multiple responses, and these have been analysed and synthesised into common themes.

Table 8.2 Challenges implementing SOE corporate governance in Samoa $(n=12)$

- Government role in SOE decision-making $(n=12)$

○ PE Ministry $(n=5)$

- Board skills, performance, and behaviour $(n=12)$

- Balancing SOE dual function $(n=9)$

○ Conflict of interest $(n=4)$

- SOE staff skills and SOE performance $(n=8)$

- Lack of public understanding of SOE function $(n=4)$

\subsubsection{Government role in SOE decision-making $(n=12)$}

All participants commented on government's influence in SOE operational decision-making. This may be due to poor performance prior to the latest reform initiatives prompting the government to intervene, or concerns with staff and director leadership skills in the management and governance of SOEs. 
"The political nature of SOEs. Samoa is not achieving efficiency because it does not have enough people, skills, interaction, not enough regulatory mechanisms, and not enough educated leaders in the public service." (024)

Participants added that the mindset of staff has not transitioned from when the enterprise was a government department, and that SOEs are still struggling with staff behaviour over efficiency and improved service.

Participants perceived government's role in SOE decision-making as political interference, for example, with government influencing tariff rates or charges due to community complaints, or applying Cabinet directives for CSOs that are either not in SOE corporate plans or do not come with government backing to fund these projects.

"If someone wants to make a major complaint [about charges] they see the PM." (018)

"ROI can be compromised by ministerial directives." (016)

Participants saw these directives as assisting government ministers' constituencies, and compromising the SOE's ability to provide sustainable dividends, ensure there are funds to maintain the SOE infrastructure, and future-proof the enterprise, including by training staff. Corporate governance principles consider fairness to all stakeholders, and there was a concern that political interference in board or management decision-making could compromise or override the interests of some stakeholders.

"Political interference can override 'fairness to all'." (021)

"Government is wanting patronage to be extended to their constituencies." (026)

An issue often seen in countries with small populations is the pressure senior government or SOE officials face to be available at short notice to Cabinet. The 'domino' effect is the 
cancellation of clashing meetings including board meetings. This can impact board director availability as they too have competing obligations.

"It's a challenge to attend board meetings when set meeting times are changed at short notice [because] the CEO is called to a Cabinet Committee meeting which is rescheduled at the same time as the board meeting. This makes it difficult for directors to attend the rescheduled meetings." (019)

Corporate governance approaches can be influenced by external forces. International donor agencies have set standard criteria for their projects in various countries including Samoa, and participants perceive that these criteria often do not attempt to incorporate the governance situation already in existence, and to implement projects accordingly.

\section{Ministry of Public Enterprises (MPE)}

Participants discussed issues with MPE, but acknowledge that these are largely due to the ministry only being in existence for the last few years. When the ministry was first established, there was limited consultation with SOEs to inform policy. There had been issues resourcing the ministry and it was believed these will be resolved as recommendations from recent reforms and reviews are implemented, such as consistency over the number of directors on boards, skills required for directors, board evaluations, and CSOs.

"The ministry is seen by some as playing a more controlling and enforcement role, which encroaches on the management role. There is perceived lack of meaningful consultation and mentoring which causes resistance from some SOEs. There needs to be a more balanced approach to foster more transparency and more effective consultations, allowing for mutual understanding between the ministry and the boards and management. A successful and profitable SOE, the ultimate objective, will benefit all ... MPE needs to be more strategic, as it can be too parochial, and it should be consulting more with chairs." (024) 
"At that time there was a lack of understanding by most boards and CEOs of corporate governance, no clear transparency or accountability. MPE focused on grounded corporate governance principles amongst the reforms, which were aligned regionally and globally." (015)

One participant noted that leading up to the GFC, the ministry could see SOEs struggling and that most with loans had defaulted, which fell back to government under the guarantee framework. At the time most SOEs had no corporate plans and no updated audits, so the message to boards was to step up ownership of performance and results. MPE started looking at governance, how boards were structured (number of directors on boards ranged from 7 to 11), and undertook a review of director fees. It also looked at required skills for directors on a corporate board.

"It's a big step for some directors, and the ministry has to constantly remind board and management of their roles. Although it wants people on the board with a business mind-set, it doesn't want their self-interest to be blurred or influence their decisions on the board. If the ministry thinks that's happening then it will start to have a conversation to get them back on track." (017)

\subsubsection{Board skills, performance, and behaviour $(n=12)$}

All participants raised issues with directors not having the relevant governance skills required, along with poor board performance and director behaviour. In particular, directors' level of understanding of their role on an SOE board could be poor, with most highlighting the need to have people that can think innovatively to overcome challenges faced by SOEs, or with strategic planning.

They also added that despite the introduction of director training there is still a lack of directors with strategic planning and commercial experience. Literacy level and the capacity of those on boards are still seen as issues, such as some directors not having email or internet knowledge to access information. Participants spoke of directors getting involved in the 
management and operational side of their SOE, instead of focusing on their governance role of setting the strategic direction of the enterprise.

Participants referred to the appointment process which they said had previously been an issue, with government ministers and officials appointed to boards to ensure government interests were maintained. However, recent changes to policy means that they can no longer be appointed to most SOEs. While directors are government-appointed, corporate governance guidelines recommend that government ministers and officials should not sit on SOE boards to avoid conflict of interest issues.

"The board should think more strategically but is more involved in the day-to-day operations of the SOE ... a lack of clear expectation for the board member who is the community representative." (013)

"Some directors lack the appropriate skill set for an SOE. This would be the same elsewhere in other countries. It doesn't mean they're not following good corporate behaviour. If it were a private company some directors would not be there, but as an SOE, there's a political element to who is on boards." (024)

Participants raised the issue of holding boards to account for their lack of compliance, transparency, and accountability. Participants spoke of boards: not respecting or complying with corporate governance principles and legislation; lack of reporting; poor communication with MPE or management; not having corporate plans or no internal or independent audits; not endorsing quarterly reports before these are submitted to MPE; and not having monthly meetings. Participants suggested that a lack of 'hard' strategic decision-making could be tied to directors wishing to be reappointed, or pressure from their community. Other issues raised included a board's current performance being impacted by previous board decisions, and chairs having different goals to the directors.

"For a long time SOEs and boards were left to their own. So the challenge has been to get them to understand that they have certain accountabilities. Some incumbent 
directors are from the 'old school' and have resisted training, as they don't think they need it. Training has been in the legislation, but until recently it has not been monitored. Over the last three years, the ministry has identified who has received training and has informed the minister which boards have been difficult about attending training." (017)

Prior to changes in the appointment process implemented in the $2019 / 20$ round, participants spoke of issues such as a lack of accountability, with some boards not reporting on Cabinet directives in the board minutes. Participants explained that they were not always noted because of the cultural values placed on the status of government ministers by Samoan society including by directors, where some (at the time) were also government ministers or officials. This caused problems such as annual reports and corporate plans not being submitted.

As noted earlier, one participant questioned the need for a cultural leader to be appointed on SOE boards as most directors, especially the chairs, have matai titles and so felt the board does not need a separate person who may or may not be able to read a budget.

\section{Balancing SOE dual function}

As discussed in chapter 5 , the principal objective of a public trading body (SOE) in Samoa is to operate as a successful business, be as profitable and efficient as a business in the private sector, meet any CSOs, and exhibit a sense of social responsibility by having regard to the interests of the community in which it operates (Samoa Public Bodies (Performance and Accountability) Act 2001).

However, participants spoke of the difficulty balancing profit-seeking with long-term strategic interest and social responsibility, and that the government is not always clear about what it wants regarding the level of service, profit, and dividends it expects; or who is to pay for CSOs which are not part of the SOE's corporate plan. The PE Act (2001) allows for the compensation by the government for losses incurred by the SOE from the provision of goods and services if the shareholding ministers (acting on the advice of Cabinet) direct a public trading body to 
provide a CSO if the performance of the obligation is necessary. Nonetheless, participants spoke of instances in which an SOE is not compensated by the government.

"[The SOE] has to wear the cost not met by government's CSO budget." (018)

The different expectations for SOEs between the prime minister and the MP minister, and between the prime minister and SOE boards was discussed by participants. Some speculated this could be because the prime minister's ultimate objective is to ensure that SOEs provide a more efficient and better service than when they were government departments. Other government ministers are conscious that their electorates can vote them out if they are unhappy with increased SOE charges for services.

"The prime minister wants prices to be reasonable and that the corporation is financially sustainable. But the Minister for Public Enterprises wants prices as low as possible, as that's the platform he came into parliament on. Sometimes there's conflicting objectives. The board wants to provide more dividends for the government, but the prime minister wants profit to be used for a better service, and to look after the SOE first." (013)

"Operating in two different worlds. Some organisations have struggled with the development into an SOE, balancing the commercial agenda and returns for the government with ensuring efficient, accessible, and affordable services to the public." (014)

The confusion has led MPE to work on amending the legislation. This is discussed further in the following chapter. Participants also spoke of balancing expectations in Samoan culture to provide an affordable service, and directors' obligations to the SOE and the shareholding ministers to ensure they govern through a commercial lens. The quotations below reflect the general awareness by participants that the SOE model needs to evolve if it's to be successfully embedded into Samoan culture. 
"This is where Samoan culture and customs come in, they understand that there's always an element of providing an affordable service to the people. There are directors who are more commercial - they are normally the wealthy businesspeople who think like that. That's why the model has government selecting a mixture of people with different backgrounds. Law, financial, cultural leader, church minister is a good mixture, gives a balance of views in decisionmaking. Early boards were made up of all corporate or finance people and focused on profit." (021)

"Only challenge is the commercial mind set into the decision-making, because sometimes those cultural values may have negative impacts on decision-making. For example, because the ministry gives board chairs respect [because of their positions/chiefly titles], it gives them more time when in arrears, more leniency. However, the ministry always stresses to the board and CEO that they are there in the best interest of the SOE, not themselves or who they may be representing." (017)

\section{Conflicts of interest}

Participants discussed the issue with conflicts of interest for directors who may face pressure from their village or community. These directors may be experienced in dealing with traditional governance matters but find governance of an SOE at a national level a challenge that requires a 'macro' national mindset. Participants spoke of board decisions being affected by some directors' concerns that they may not be re-appointed.

"Close family and village ties increase the risk of conflict of interest for board directors. Government ministers and village chiefs can exert pressure on directors in their decision-making." (026)

"There's a struggle between community or village and national obligations. CSOs can compete between these, depending on the political agenda." (020) 


\subsubsection{SOE staff skills and SOE performance $(n=8)$}

Participants saw that lack of SOE commercial maturity, and management and staff capacity and capability, are issues for boards in implementing corporate governance principles. This can prevent an SOE from performing to its full capacity.

"There was no training for staff to prepare them for working for an SOE. The GM wants to budget for staff training." (013)

Participants spoke of SOEs still having too many staff; CEO skills not being sufficient for SOE work; and that management team skills needed to be strengthened. Participants commented that developing a good corporate culture within SOEs has been a challenge, and thought there could be a number of factors, such as staff moving from a government department to an SOE with no training to prepare staff for a change in their roles.

"Some SOEs are still bloated with staff despite them having limited resources."

One participant commented that their board spent much time replacing the whole management team as it did not have the appropriate skills, experience, or qualifications to make the SOE profitable. The management team had been with the organisation when it was a government department but struggled with the organisation's change in focus as an SOE. Another participant said that some staff still have the mentality that they work for government and therefore did not have to focus on improving services or organisational efficiency.

"There had been the same management for the last 25 years, and by looking at the accounts the previous board saw that management was struggling, and that there needed to be a change in the make-up of management. The workforce and management didn't have the right skills to make [the SOE] profitable." (022) 


\subsubsection{Lack of public understanding of SOE function $(n=4)$}

Participants thought a lack of understanding by the public about the functions of SOEs, and the reasons for service charges, affects the board in implementing corporate governance principles. Participants spoke of how the public will complain to the media, or would approach the PE minister or the prime minister directly to complain that charges are too high. This would then lead to government interference with the SOE's corporate plan objectives.

\subsubsection{Section summary}

All participants addressed challenges with board skillset, performance, and behaviour, in particular that some directors grapple with what they saw as balancing SOE dual function of profit and providing dividends to the government, and providing an affordable service to Samoan citizens. They saw this being exacerbated by the government's involvement in SOE operational decision-making.

\subsection{CHAPTER SUMMARY}

Participants identified several factors that challenged boards' ability to govern effectively. Sometimes the challenge is not lack of understanding of corporate governance principles, but lack of application. Some of the issues identified are also experienced by SOEs globally, such as the ability for boards to govern at 'arms-length' to the government, or dealing with 'political appointments' to some SOE boards. The challenge for SOE boards is to find a balance between government's short-term priorities and the long-term sustainability of the SOE. Challenges identified in proceedings for the 2016 Global knowledge sharing network on corporate governance of state-owned enterprises report included obtaining a high degree of professionalism and ensuring that ownership is conducted at arm's-length from other government functions such as regulation. It also commented that the public needs assurance that the ownership rights are exercised in the public interest and not for the benefit of public officials or political constituencies (OECD, 2016).

Despite Tonga's GPO, participants spoke of the difficulty balancing the obligation to deliver a profit to the government and an affordable service to the public. Local cultural practices along with the hierarchical system in Tonga (as well as being a relatively new democracy) contribute 
in part to government's involvement in operational matters. A lack of women on boards could be seen as a cultural issue rather than a lack of skill, as there are many women in Tonga on private sector and community boards, and prior to the recent reforms, women from nobility were on SOE boards.

While participants saw the use of shared boards as a practical approach to resourcing and capacity issues, it has increased the workload for directors, with an increased risk of conflicts of interest. Chairs of shared boards require great leadership qualities, and without the necessary skills there is a risk that it would be too easy for government to influence operational matters.

Skills required for public officials to understand business processes and the corporate world, and a lack of directors with appropriate governance skills, has led to concerns that boards and Cabinet may not be receiving the appropriate information needed for decision-making. Added to these challenges is the international donor influence on government, which participants perceived is applied without consideration to conditions in Tonga. These include measures of success or performance for SOEs, and whether international benchmarks should be adapted to the geographical context of the SOE.

Challenges identified by participants with regard to SOEs in Samoa reflect internal and external pressures, from poor director performance and behaviour, to government's involvement in SOE operational decision-making. It is unclear whether these are linked to past board performance before recent reforms were implemented.

Lack of compliance, transparency and accountability with corporate governance principles and legislation would imply a lack of understanding of these principles, however, cultural values placed on the status of government ministers by Samoan society is impacting on directors' governance decisions. This means that local values at times can inhibit performance, although some participants would argue that it depends on whether there is more value placed on dividends or on services to the community. Directors may be experienced in dealing with traditional governance matters but find governance of an SOE at 
a national level a challenge. Participants spoke of the difficulty balancing profit-seeking with long-term strategic interest and social responsibility.

Internal challenges such as lack of commercial maturity, director skills, and staff capacity are also seen as issues that can prevent SOEs from performing to full capacity. With regard to external factors, an SOE may have good processes to improve efficiency and performance but fails to deliver on its goals, and good policy for transparency and accountability but fails to deliver its corporate plan. Participants identified government involvement in operational matters such as with tariffs or charges, and dividend targets that don't factor the cost of noncommercial activities, as challenges that lead to boards' non-performance.

Overall, the challenges that are faced in Tonga and Samoa with delivering effective governance of SOEs reflect frustrations held elsewhere with the nature of the model. While some issues are faced elsewhere, they appear to be accentuated in smaller countries. While the SOE model helps former government departments to improve processes, pressure to achieve profit for its principal shareholder is at the expense at future proofing the enterprise.

Participant responses reflect their understanding of what is required to govern SOEs effectively, but that navigating the political environment, as elsewhere, is factored in the decision-making whether that relates to board appointments, or whether dividends are disbursed. 


\section{CHAPTER 9 OVERCOMING CHALLENGES IMPLEMENTING}

\section{CORPORATE GOVERNANCE}

\subsection{INTRODUCTION}

Chapter 9 outlines the main responses from participants on how they are overcoming the challenges in implementing the corporate governance principles discussed in chapter 8 , or how they think some of the issues could be addressed. The main challenges that participants spoke of involved the different perspectives that key stakeholders have about how SOEs should be governed. This is largely seen as a combination of lack of skills or understanding of their roles, or the consequence of politics in small countries.

The responses are listed thematically and in order of the most common unprompted responses. While these do not necessarily align directly with the challenges discussed, they reflect a pragmatic awareness that while they cannot change the challenges of operating in a country with a small economy and population, their responses focus on minimising or managing the challenges, such as through innovatively implementing good corporate governance principles of accountability, transparency, and board performance.

\subsection{TONGA}

The themes outlined below in Table 9.1 highlight the main themes discussed by participants and approaches taken (or potential solutions) to overcome challenges that SOEs in Tonga face in implementing good corporate governance. This chapter elaborates on these responses, with examples provided, along with quotations from participants.

\subsubsection{Accountability and transparency $(n=8)$}

Participants considered improving board accountability and transparency would help solve some challenges faced by SOEs in Tonga. These include better processes in reporting, increasing community awareness, and regular and constructive dialogue between key stakeholders. While these responses can be grouped under 'performance', having good processes does not necessarily increase dividends for shareholders. However, better 
reporting, increased community awareness of SOE functions, and more constructive dialogue between stakeholders, can improve board performance with regard to accountability to shareholders, and transparency in its decision-making.

Table 9.1 Overcoming challenges implementing corporate governance by SOEs in Tonga ( $n=14)$

- Improve accountability and transparency $(n=8)$ through:

- Improved reporting $(n=8)$

- Increasing community awareness $(n=7)$

- Regular and constructive dialogue between government, board, and management $(n=4)$

- Improve board performance (6) through:

- Reforms and reviews $(n=6)$

○ Directors appointed on merit,

- Professional training $(n=5)$

○ Shared board model $(n=5)$

$\circ \quad$ Long-term planning $(n=5)$

- Staff development and organisational culture $(n=5)$

- International support $(n=3)$

- MPE monitoring, advisory, and policy role $(n=4)$

"We overcome conflict of interest using sub-committees ... and we ensure correct procurement process." (011)

"Remain clean when asked to do a favour by government ministers ... refer to the legislation and regulations, and ask that requests are put in writing so they can be tabled at board meetings. ... When the board is too close to management it's 'scratch my back' decision-making, you risk not operating for the good of the SOE but operating to your own devices ... [The chair] stopped overseas travel by directors and management to overcome unnecessary spending and travel." (006)

These quotations reflect the importance of applying good processes to protect the board from corruptive behaviour or conflict of interest issues by government ministers, and between 
board directors and management; thereby indirectly improving performance, although that may not necessarily mean increased dividends to shareholders.

Improved reporting

Participants knew that reporting requirements are set in the legislation, but until recently they had not always been implemented by boards. Participants associated improvements in reporting with chairs being appointed on merit, and with improvements in MPE's monitoring programme. They spoke of ensuring there is quarterly and annual reporting; publishing annual reports on the enterprise's website; adopting paperless reporting for board meetings so that all documentation can be provided to directors securely and in line with the move towards e-government; and that board decisions and actions are documented.

"All reports are published on the SOE website. The board agenda and documents are emailed to the board, and the board only uses e-copies for the meeting. They are put on a projector at the meeting to reduce paper waste. Decision-making is made at the meetings, not outside of meetings." (001)

"We're paperless - all financial papers are provided at least two-three days before meeting. It's a modern requirement, and we encourage management to use technology. Directors have iPads. [The chair] can have all board papers, legislation, structure of [the SOE], staffing and salaries info when meeting with the minister. It's more secure as e-docs are all passworded." (006)

When it comes to auditing the SOE or monitoring it by the MPE, participants spoke of the importance of documenting decisions made at board meetings. This paper trail helps inform the shareholder, for example, why dividends are lower or non-existent due to a GPO request by the minister or prime minister but not funded by the government.

"[The PE] legislation ... helped reinforce accountability and overcome risk to the CEO's position by making sure we [the board] document all decisions and actions ... including actions made based on requests from government ministers. We made 
sure in board minutes, actions such as waiving charges are documented ... the CEO can waive or provide a discount but must report to the board and record everything." (010)

Only CEOs or CFOs can make decisions to reduce rates on a case by case basis and must present detailed audited accounts to the board that include 'in kind' dividends.

\section{Increasing community awareness}

Participants said they relied on social media to gather feedback from service users. Although customer satisfaction surveys were part of some SOE corporate plans, they were either seldom carried out or not carried out at all. Participants spoke of finding out what taxpayers want through reading social media as people are very vocal on this platform when they want to complain to the retailers. Participants thought that increasing public awareness about SOEs and their functions could prevent lobbying by constituents to government ministers to reduce charges, and reduce pressure from government to intervene in the operations of the SOE. Regular community engagement through consultation visits by management and board directors, and through social media, is also seen as an opportunity to improve service delivery and instil trust with the community.

"[The SOE] has an Awareness Programme - going out to the community. This is about being more accountable to the public, explaining how dividends are being used, trying to fix the miscommunication about RE [renewable energy], explaining that RE won't necessarily be cheaper for customers, and explain that the SOE still needs to maintain infrastructure, generators etc.... We also raise awareness about climate change, how it will affect communities and the environment ..." (008)

"The board now has technical and working sub-committees; decisions are put on hold until there's been consultation with the community and research done to deal with issues such as how climate change will impact on the ICT business plan. Then the committee takes the information to the board for decision-making ... the board and the ministry can go to the churches and town councils to get feedback from 
the public. If they want to get anything across to the community, these are the best ways." (011)

Regular and constructive dialogue between government, board, and management As well as improving communication with the public, participants spoke of improving communication and information between government and the board, between CEO and board, and with other SOEs that are part of the shared board model. Participants stressed the importance of regular dialogue between:

- Government (ministers and MPE) and the SOE to discuss any issues and to prevent issues escalating, and to provide necessary information for a constructive discussion.

- SOE CEO and chair.

- SOEs with shared boards having a monthly meeting for each SOE, and a joint meeting as a shared board every two months.

"We have to give very accurate information to the [government] ministers and have a constructive discussion with them." (009)

With regard to transparency, one participant added that it requires strong leadership to follow corporate governance principles, and that early dialogue by the chair with the minister is important. This can prevent issues escalating and help the minister to have confidence in the board.

\subsubsection{Board performance $(n=6)$}

Participants identified ways to improve board performance, including: implementing recommendations from recent reforms and reviews, or undertaking further reforms; ensuring directors are appointed on merit, that they have the right skills and receive professional training; using a shared board model; implementing long-term planning; improve staff development and organisational culture; and use of international support. 


\section{Reforms and reviews}

Participants suggested that either implementing recommendations from recent reforms and reviews, or undertaking further reforms and reviews of policies and legislation for the SOE model in Tonga, are required to improve board performance and SOE performance.

Participants thought the government should explore the use of models such as Public-Private Partnerships (PPP) (but ensuring that government is the majority decision-maker on boards), or fully privatising some enterprises with the rationale that it would lead to better services, and help SOEs finance projects. It was suggested that any further reviews should include whether SOE core functions of providing both an affordable service and dividends to their shareholders need to be rebalanced, with the priority being placed on providing efficient, affordable, and accessible services to the community.

Participants also noted that the last set of reforms have helped to overcome director performance issues, with director appointments now being based on merit, and that boards are better balanced with directors who have different skillsets. They also added that director contracts are renewed annually to ensure directors attend board meetings and contribute to board discussions, with performance now being assessed with the introduction of board evaluations undertaken by MPE. Reforms also meant that government ministers and public officials were no longer eligible to sit on SOE boards.

"Previously, the King and Privy Council decided who sat on SOE boards, and the nobility or a government minister chaired the boards. Policy changes in the 2000s meant that government ministers and public officials had to vacate their positions on boards. Now the ministry puts up recommendations for directors to the Cabinet ... Current board members' backgrounds include business, former civil servants, technicians, former politicians, former government ministers, farmers, academics, and some with noble connections." (005)

One participant added that the increasing use of technology will help overcome challenges with board performance, and that those on boards unable to adapt will not be reappointed. 
"Whatever the future reforms are, the government will find it difficult to work with the current make-up of the board ... Using technology is going to rule the way we do things in the future, [and the SOE] is one of the key drivers ..." (003)

\section{Directors appointed on merit}

To overcome previous challenges with board composition, MPE is moving to skill and meritbased selection. Reforms have meant that government ministers can no longer be appointed to SOE boards, and that appointments are now based on appropriate skills for the role. Boards previously had two to seven directors, but are now moving to five for each board. Directors need the required skills relevant to the SOE, and to operate in the best interest of the SOE and stakeholders rather than a constituency or a private business.

"The ministry makes sure that directors chosen have the applicable skills and experience to help the CEO lead the SOE i.e. financial, business, legal, community experience, and technical expertise ... Board term is up to three years. The ministry reviews each director's performance every year. The first year is a probation year, then the ministry considers whether they contribute at board meetings - do they read the papers, or just turn up at the meeting? Are they using the skills they've been appointed for?" (009)

\section{Professional training}

Participants, however, thought that more in-depth training for new directors, including compulsory inductions (on board behaviour, roles of directors, and understanding of the legislation), and refresher training for current directors (with training fitting the local context) were still required to help improve board performance, especially as reappointment is reviewed annually. This was seen as helping build trust with the government. Appointing chairs with strong leadership skills was perceived as very important, especially for dealing with requests from ministers, or managing inappropriate relationships between directors and management. 
"SOE training for new directors and refresher training for current directors ... Strong leadership by board chairs who know their roles and the PE legislation. It's all common sense." (006)

While participants agreed that boards are becoming better balanced with directors who have different skillsets, one participant thought that MPE should be applying more strategies to encourage appointment of women to boards. As previously discussed, it's thought that change will come but it will take time as board composition changes slowly.

\section{Shared board model}

Although the shared board model was seen by some participants as a challenge (as discussed in the previous chapter) because it relies on directors and especially chairs with strong corporate governance experience, the model was also identified by the government as a way to help with resourcing issues, and as a way to standardise policies and safeguard the board.

Shared boards are also seen by participants as a practical way for countries with small populations and with capacity issues to overcome the shortage of directors with the necessary skills to govern an SOE. They saw it leading to better connections with SOEs from the same sector, and providing an opportunity to share resources and synergies with accounting practices and systems, IT processes, and policy development. Some participants spoke of cost cutting opportunities to share facilities such as having the board meetings in one place but each SOE takes turns with catering, and they can organise and share training for the SOEs' staff.

The three SOEs in the utility sector are in a shared building and have a service policy for joint billing (power and water), with the aim of cutting the cost of operations and improving services. They also share the loan for a new shared building.

"Having three SOEs as part of the shared board helps to standardise policies and safeguard the board, which must make sure it is on top of policies. I can see that the standard of skills at each SOE are different and the shared board is trying to 
bring them up to the same level ... There's a monthly meeting for each SOE, and a joint meeting every two months." (006)

"As a small country, shared boards can help overcome resourcing issues through not having to fund three separate boards. It helps to have better connections with other SOEs from the same sector. Before having shared boards, [the SOE] did not have any dealings with other same sector SOEs. Now they work more closely if there are work-related issues, they can just call up and arrange a meeting. It's like one company now. If we have an issue with our financial reports, we can call up a CFO from one of the other SOEs to discuss the issue. One SOE who had experience with IT helped another SOE, instead of having to spend resources." (002)

While the initiative has yet to be evaluated and is viewed cautiously by some international aid agencies and other Pacific governments, one participant asked, "Do we have to follow, or do we lead on what we believe?". This participant saw the shared board model as a mechanism for efficiency in small states, rather than a one-off issue for Tonga.

"This model has not previously been used in the Pacific before ... the Cabinet wanted recent reforms to consider how to reduce costs and improve performance through efficiencies and productivity for all SOEs." (009)

The participant also saw it as a 'stepping-stone' to a more developed model, and thinks that there are three options for next steps:

1. turn each shared board and the associated SOEs into a holding company. The Act allows SOEs to move to holding companies, and under the existing Act there can be the same directors for each SOE and the same directors for the shared board, or

2. turn each shared board and the associated SOEs into one big company, or

3. keep the status quo. 
Whatever reforms to the shared board model are taken will rely on the government's willingness to further explore models such as holding companies, or be encouraged by aid agencies to undertake PPP. Whatever approach is taken, MPE will need the approval of its minister, and the government will want to exert influence over the board to be seen by their constituents as responding to their service demands. This would mean either remaining as the 100 percent shareholder or as a majority owner having the final veto, or be able to sanction decisions even if there is not 100 percent support from the other shareholders.

\section{Long-term planning}

Long-term planning is seen by participants as an important part of board decision-making for SOEs, and that if 'locked in', this would reduce pressure from government to make short-term decisions to placate the voting public. Suspending dividends for some SOEs so that revenue can be used to improve infrastructure and services is seen as a tool to help make enterprises more sustainable and resilient. Participants also saw that long-term planning would help SOEs remain relevant and keep pace with changes in the sector. They felt that three year business plans are not enough and that SOEs need to plan further ahead.

"I would like the master plan to have a five to twenty-year break from providing a dividend in order to improve the service long-term. To develop a master plan, we need to work with government's Ministry of Infrastructure, who is working on urban planning. The SOE master plan then can become part of the national plan as the SOE needs to align with government's plan. Make sure they're connected ... Once approved in the national plan, it can't be touched." (002)

\section{Staff development and organisational culture}

Participants link the lack of staff professionalism and poor corporate culture to poor customer service and lack of leadership, and consider staff development important to ensure boards receive appropriate advice and information. They spoke of the importance of training and that SOE's need to be more proactive and innovative with how to use limited training resources, such as using training clips on YouTube. Participants added that to achieve SOE 
objectives, management need to work with staff, motivate them, and send the message when reviewing performance that they will do well and can be promoted if they undertake training.

Other approaches currently taken and identified by participants include building a learning culture within the organisation, staff satisfaction surveys, setting up social committees, redesigning job descriptions and terms of references, restructuring, starting staff meetings with a prayer, improving work conditions, implementing compliment and complaint boxes for SOEs, and running CEO forums.

"In the business plan there's been a commitment to carry out a customer service satisfaction survey, but until now they have not been undertaken. Now they'll be done on a monthly basis. We need feedback and evidence from the survey to justify certain actions to government." (002)

\section{International support}

Participants understood part of the solution to some of the performance issues SOE boards are facing could be found elsewhere, including learnings from other Pacific SOEs, and applying international standards in accounting, human resources, and corporate governance. Participants spoke of not needing to 'reinvent the wheel', especially as Tonga had limited resources, and the internet was an affordable opportunity to access professional refresher training and documented material of best practice standards from wealthier countries. They commented that SOEs in the Pacific face similar challenges, and sharing and learning from their neighbours was a pragmatic approach to dealing with gaps in internal support from MPE.

\subsubsection{MPE monitoring, and policy role $(n=4)$}

Four participants thought that MPE needs to:

- ensure government operates within the Act

- provide good advice on board appointments

- understand each SOE's core business in its role as a regulator, and

- through its monitoring function, ensure SOEs keep within the legislation. 
They see MPE's role as improving performance, and that its monitoring function could be strengthened by MPE ensuring SOEs use international standardised accounting systems, and using different measures to assess board performance in board evaluations. Although they thought it was important for the ministry to be at 'arm's length' with SOEs, they did see the ministry's role was to ensure the regulator understood its role within a small country with limited resources.

"Ensure there is a strong regulator to help balance the need for [the SOE] to run as a business and provide dividends to the shareholders." (001)

"The ministry should keep distance from the board, but still make sure it keeps within the jurisdiction of the government." (004)

One of the roles the ministry plays is to ensure government ministers stay within Public Enterprise guidelines and operate within the Act and policies. If ministerial directives are not within the boundary of the SOE's corporate plan, it is the responsibility of MPE's CEO to meet with the minister and explain the consequences of the directive.

"Sometimes I think [the minister] understands but they've been given wrong information ... When I come and explain that these are the boundaries you play in as a government minister, and these are the boundaries the ministry has to play within, and we can only play within these policies, they say "OK don't worry, go back and don't carry them out". (009)

Regular communication, improved policies and advice between the ministry and the minister, and the ministry and boards, may help improve accountability and transparency. But boards may still be instructed by the government to take a contrary position, and the government may not agree with the ministry's advice. This is not unique to Pacific SOEs and is a common criticism of officials internationally, such as with scientists from the health sector advising UK and USA governments over the best approach to manage the global 2019-2021 Coronavirus outbreak (Pollock et. al., 2020). 


\subsubsection{Section summary}

Improved accountability and transparency through improved reporting and increasing community awareness, and improving board performance through further reforms and reviews, directors being appointed on merit, and use of different models such as shared boards, are all seen as approaches to deal with issues boards face to improve corporate governance. These appear to be ways to work within the system, rather than approaches to changing the system.

\subsection{SAMOA}

The themes outlined above in Table 9.2 highlight the main ideas discussed by participants to overcome challenges that SOEs face in Samoa in implementing good corporate governance practices This section elaborates on these responses, with examples provided along with quotations from participants

Table 9.2 Overcoming challenges implementing corporate governance by SOEs in Samoa ( $N=12$ )

- Improve board performance $(n=7)$ through:

- Directors appointed on merit $(n=7)$

- Cultural leadership $(n=7)$

- Professional training $(n=7)$

- Staff development and organisational culture $(n=6)$

- Reforms and reviews $(n=6)$

- International support $(\mathrm{n}=2)$

- Improve accountability and transparency $(n=6)$ though:

- Improved reporting $(n=6)$

- Regular and constructive dialogue between government, board, and management $(n=6)$

- Increasing community awareness $(n=2)$

- MPE monitoring, advisory, and policy role $(n=5)$ 


\subsubsection{Board performance $(n=7)$}

Participants spoke of the importance to continue improving board performance. They identified several ways this could be achieved: through the board appointment process with ensuring directors are appointed based on merit, the right skills, and experience; that there is a designated cultural leader on each board; increasing professional training in corporate governance; staff development and improving organisational culture; implementing recommendations from recent reforms and reviews or undertaking further reforms or reviews; and the use of international support.

\section{Directors appointed on merit}

As discussed in chapter 5 , at the time of the interviews, Cabinet had recently approved a reduction in the number of directors on a board, reducing to a minimum of three directors and maximum of five. Directors are now expected to be appointed on merit, with boards having a director with cultural leadership experience, a chartered accountant, and a director with subject matter experience specific to the SOE. Participants thought the current reforms will improve SOE performance in the long-term.

\footnotetext{
"Here's an example of overcoming challenges: the previous Samoa Airways Board did not think 'outside the box', was using the old mentality, and not building the IT infrastructure. The problem had been not finding the right people in Samoa with the best possible minds in the aviation industry. The board was recently replaced and since July there's been progress; it's a direct relation to having a new board and implementing strategic reforms, such as adopting new technology so people can book online, and partnering with travel agents from Australia to target Samoans living in Australia and New Zealand. These people have strong ties to their culture, are patriotic, and want to keep their connection to Samoa." (014)
}

One participant noted that the SOE reforms were part of conditions placed by international funding agencies, rather than initiatives promoted from within Samoa by the prime minister. Perhaps because the reforms were driven by players outside Samoa rather than within 
Samoa, this has contributed to ongoing performance issues due to a lack of enforcement of policy changes.

"Despite the rhetoric, the PM was pressured to undertake reforms and enforce corporate governance principles for SOEs [including] removal of politicians and public servants from boards. Mainly a condition of international funding grants, and establishment of Public Enterprise legislation. The issue is with the lack of enforcement." (026)

Participants commented that the reforms should mean that fewer directors are appointed based on their close connection with government ministers, which will reduce conflicts of interest in decision-making. Participants also suggested that there was still a need to strengthen board diversity through MPE 'shoulder tapping' potential suitable candidates, including women and Samoans living overseas, and encouraging them to apply to be a director. Participants also noted that the reduction in the number of directors on boards was a positive approach to improve the efficiency of the board.

"I still think 'shoulder tapping' is needed as part of getting the right people. This may include Samoans residing overseas who are qualified, know the culture, and can add value to Samoa SOEs. They would still need to apply and go through the process." (014)

These comments align with international discussion on improving diversity on boards. Diversity doesn't guarantee a better performing board, but great diversity plus a strong positive culture are key factors in a high performing board (Creary et al., 2019).

Determining the right size of an SOE board is an important issue with respect to promoting board efficiency. Large boards can result in unwieldy processes and lack clear direction, whereas boards which are too small may not fully reflect the needs of the enterprise. Cost savings can be a key motivator in reducing the size of boards. The Working party on state ownership and privatisation practices. Board of directors of state-owned enterprises: An 
overview of national practice noted that SOEs should follow best practices adhered to in the private sector and be limited in size:

"As a general rule, board size should be developed taking into consideration factors such as an entity's size, complexity, risk of operations and the needs of the board.... over time the optimal board size may vary in line with changes in its functions or the needs of the board. ... a large number of OECD economies identify the optimum board size as somewhere between 5 and 8 members" (OECD, 2015c, p.45).

\section{Cultural leadership}

There were mixed views on whether there was a need for a cultural leader on SOE boards. More participants thought that having a designated director with a cultural leader role was a positive move, as it represented the importance of Samoan culture in board decision-making when it came to use of land, improving services, and increasing charges.

"They must have experience and credibility with community. In Samoa it's very important for a director with cultural leadership experience to have a matai titleachieving both the cultural element and leadership element. This director is not necessarily the chair, but they must have an understanding of government." (017)

"It's good to have a cultural leader on the board; they come from the village, they know the struggles the people are facing." (021)

SOE board directors need to remain independent from different interest groups as well as from ad hoc political intervention (OECD, 2013). Some participants query the need for a cultural leader role on boards. They feel that other directors with matai titles can represent the interests of the community, and with fewer directors on boards they would prefer to have a director with business skills. They are sceptical that a cultural leader will represent the interests of all sectors of society, and not just certain communities where they are known. While understanding local values is seen as important for directors, these participants do not think that a cultural leader role on SOE boards is necessary, as most chairs are also matai. 
"I have reservations with the board structure, but weaknesses of some directors are overcome by others on the board. I'm not convinced that SOE boards need a director who is solely responsible for the cultural aspects, as most directors on SOE boards are matai. What can the cultural member do that the other directors can't do? All speak Samoan and the board would consult village communities with management." (024)

\section{Professional training}

Over the last decade the Samoan government has sought to professionalise SOE boards, ensuring that training for new directors is in the legislation and is compulsory. However, this has only been monitored more recently since the ministry received additional resourcing to monitor attendance and ensure directors comply. Participants referred to The Samoa Institute of Directors (SIOD) training. The five-day Directors Executive Development course is targeted at new directors and those interested in becoming directors. It covers the role of a director, strategic planning, relationships between the CEO and the board, and financial information in the context of SOEs (not private sector firms or NGOs).

SIOD undertakes refresher training for reappointed directors, which the prime minister and the PE minister expect the directors to attend. The ministry also undertakes induction sessions for new directors. This covers expectations of their board role, the difference between their governance role and management's role in the SOE, and that they are appointed for particular skills but also need to contribute to the whole of the board's work. SIOD is funded by the United Nations Development Programme (UNDP) for women to attend its governance training. However, participants are unsure whether these women were putting themselves forward for SOE boards. Some participants are concerned that male directors feel they do not need to attend training although they appear to be struggling to understand their role on SOE boards.

"The UNDP provides funds for women to attend [S]/oD training for free, but I'm unsure how many applied in the current round for directors, or how many will be 
successful. ... the international donor agencies have set standard criteria for their projects in various countries inclusive of Samoa [such as governance training for women] and these criteria often do not attempt to incorporate the governance situation already in existence ..." (023)

While training and inductions are currently provided, participants identify the need for more in-depth professional training on the SOE model that is tailored for Samoan conditions, to help directors solve issues they may face. In particular, further clarity is needed about roles and responsibilities and how these should be carried out within Samoa's hierarchical cultural customs. Training for directors to think innovatively and strategically to improve long-term performance is also suggested, along with how to deal with Cabinet directives that could potentially compromise SOE resilience and long-term sustainability.

"Training on clarity of roles for boards to help build trust by government that the board will deliver for government ... To have clear expectations and guidelines for a board, such as when and where boards should meet, and who is responsible for the day-to-day operations of the SOE." (013)

"A key component is capacity building of boards. The more they know about their roles and responsibilities that will help deal with the cultural aspect ... This cultural element will change, so long as government refines recruitment selection of boards ... I always encourage the board to look at the macro economic benefit, the outcome, the big picture, not just what we do." (021)

\section{Staff development and organisational culture}

Participants thought that staff development and improving the organisation's culture will help board performance through being provided with accurate information from staff to help the board with decision-making. They also think improving organisational culture will help the SOE with improved performance. Participants spoke of leadership training for CEOs and their management team, and thought it is important for the board to focus on inspiring CEOs to become effective leaders, to create space for CEOs to take ownership, and to 'think like a 
leader', not a day-to-day manager. Participants also spoke of the importance of clear guidelines to improve internal performance.

To overcome resourcing issues to fund staff development, participants suggest using a range of affordable options to improve capacity and professionalism, such as: online digital resources (e.g. YouTube); resources through organisations such as the Chamber of Commerce; tapping into similar entities and networks that are Pacific-based to share training opportunities.

"Staff need a corporate mind-set and need to adopt a work ethos. Staff need to see the end result and get a big buzz if they see people benefiting." (018)

One participant added that their board has approved new equipment for their staff to respond to climate change, and that directors, management and staff are undertaking a team building exercise involving tree planting. This SOE is also looking to attract qualified and experienced Samoans who have studied overseas and are returning to Samoa, to replace poor-performing staff.

"The new CEO focuses on quality of work, standards, integrity, transparency, and professionalism. By bringing in qualified people into some of the key management roles, the board has seen a difference, and the SOE is beginning to make a profit. Standards across the SOE needed to be raised if it was going to be internationally recognised. Once standards are raised, it makes people work harder, they feel more involved, and they can see the results." (022)

Participants also thought the government can facilitate training of staff on procurement guidelines.

"To improve efficiency, government needs to work on procurement processes and the capacity of its employees, that the procurement process does not have unnecessary red tape. Management should have knowledge, [but] if it doesn't 
make sense in the private sector why would it make sense in the government [sector]?" (018)

Procurement issues are not new and were raised in evaluations of New Zealand's aid investment in the Pacific (ASI, 2015, 2016; McGillivray et al., 2017, 2018), with MFAT leading the procurement process on behalf of Pacific governments. This was largely due to capacity issues in-country. The previous quote reflects a level of frustration that SOEs should be able to follow private sector procurement processes, rather than government procurement processes for public departments.

\section{Reforms and reviews}

With Public Enterprise legislation nearly twenty years old, participants think it is time to review the legislation, SOE classification, and how dividend rates are calculated. The Ministry for Public Enterprises had undertaken a recent review which aims to clarify what is meant by CSO in the Act. The ambiguity in the current text means that an SOE can undertake a noncommercial activity, but this is not necessarily aimed at alleviating hardship. The review has assessed the difference between Sections 9.1 and 9.2 in the Act to ensure clarity for SOEs, and the process is currently being directed by the minister on advice from Cabinet.

Participants are hopeful that recent reforms and reviews will re-examine Samoa's SOE classifications to rebalance the SOE function to not just focusing on profit, but allowing a more even balance of efficiency, profit, and affordable service, and recalculation of the dividend rate to achieve this. Participants hope that the reviews will clarify how CSOs will be funded, and how they will be assessed. They suggest that future reviews consider the privatisation of some SOEs, and use of different models such as a mixed ownership model (PPP) or a sectoral shared board model. Participants would like the government to review how the SOE model can better deliver its dual function, and spoke of wanting the government to put in a framework that will ensure a balance between delivering government profit dividends with providing the best possible service for the community. 
"Recent reforms are focusing on better balancing the commercial agenda and returns for the government with ensuring efficient, accessible and affordable services to the public. ... there are challenges operating in 'two different worlds' but boards try to implement good corporate governance principles. For example, if a SOE fails, it's the board of directors that take responsibility and are held accountable. And regular reporting to ensure transparency. Previously, some organisations have struggled with the development into a SOE. But now following reforms, SOEs are making progress, with some moving to be privatised." (014)

Participants reflected that although implementing reforms has started slowly, in the last ten years they are beginning to see the fruits of those reforms. Previously SOEs were more project focused and silo-ed, and the reforms have allowed SOEs to become more sectoral-focused, which they hope will lead to more strategic, innovative, and holistic decision-making,

\section{International support}

Participants thought that SOE performance should be compared to the right benchmarks, such as with other Pacific nations. They believed boards should be looking to international advice and learnings for solutions to issues SOEs are facing in Samoa, such as international standards in accounting, maritime, and aviation. These participants did acknowledge that they had received international support with implementing the SOE model, but as it is evolving internationally, they would like more recent learnings to be shared, to help with development in Samoa.

\subsubsection{Accountability and transparency $(n=6)$}

With regard to improving SOE accountability and transparency, participants identified better reporting, regular and constructive dialogue between stakeholders, and increasing community awareness.

\section{Improved reporting}

Participants commented that although it has always been a requirement for the board to provide quarterly and annual reports to the ministry, it is only in recent times that most SOEs 
are complying. This is largely due to increased monitoring by MPE and the recent change in the composition of boards. Participants note that boards are encouraged to outline the costs of ministerial directives in the Annual Report. One participant added that their board was overcoming the challenges of the SOE's dual function through annual reporting of Cabinet directives, and outlining the economic and social costs and benefits in business cases. Participants discussed the corporate planning process, that board chairs are encouraging their CEOs to develop good business cases which include financial and non-financial benefits to Samoa, and of the importance of three-year corporate planning to ensure the board is operating in the best interests of the public and government.

"Trading bodies have an obligation to be profitable. If Cabinet provides a noncommercial activity directive, SOEs are still expected to make a profit. Reporting these activities help SOEs to balance or justify the impact [directives] may have on profit." (016)

"Samoa's SOE dual function doesn't need to be challenging. .... Initiatives still have to be underwritten by a good business case. There's a way to make a case based on actual return, but also on social outcome. It's important that when preparing the case, you need to be able to articulate what those outcomes are. The solution the SOE is designing should be based on many criteria and factors based on the population the SOE is trying to serve." (018)

A board has a duty to provide information and to advise Cabinet of the financial implications of directives, how they will affect income revenue, service, and targets set for that year etc. This is to enable Cabinet to make an informed decision and be aware of the implications the directive will have on the SOE. If Cabinet says continue, the board has met its duty of care as a board.

Regular and constructive dialogue between government, board, and management Participants thought that communication between the government, boards, and management is improving but more could be done, such as the board regularly 
communicating its expectations with its management team, and regular communication between the chair and MPE minister. They spoke of the importance for correct reporting lines, regular and early discussions, and providing good information to stakeholders, including affected communities, to avoid issues escalating.

"Every year the board has a meeting with management to set expectations." (019)

\section{Increasing community awareness}

Participants considered that increasing community awareness may help with some of the issues that SOEs are facing, especially with regard to use of land, types of services that are available, the cost of services, and lobbying the government over these issues. One participant added that in Samoa, consultation with the community is an ongoing process, not a 'one off'. It is seen as important to have the community on board with SOE decisions or plans, as this will reduce government interference.

"People complain when they don't understand or know what's behind the decisions. In Samoa you need to consult, consult, consult; one consultation is not enough. Some milestones in projects need to continue to consult until the community understands ... undertake consistent dialogue and consult and engage with communities ... Get public support-if they're happy then they tell the minister and the minister will be happy." (021)

To overcome the community's lack of awareness over the role of SOEs, an education programme about SOE functions was suggested, which could include government ministers and the business community, as well as communities.

\subsubsection{MPE monitoring, advisory, and policy role $(n=5)$}

The ministry's role is to ensure SOEs are operating efficiently and sustainably, and chapter 5 outlined in detail what MPE is currently doing to improve SOE performance, accountability, and transparency. MPE's role is also discussed by participants in this chapter under Reforms and reviews. However, five participants also saw MPE as having a facilitator role between the 
SOE and government ministers, as well as providing advice to the minister on appropriate level of dividends.

"The ministry takes a consultative approach with the SOEs. It doesn't strictly enforce ROE [return on equity]." (016)

Participants thought the ministry is focusing correctly on ensuring directors have the right skills for each SOE, rather than having connections with government ministers. They referred to positive changes such as revamped board evaluations, three-year performance summary, and monitoring of quarterly and annual reporting. They also added that with additional resources MPE can hold boards to account.

"The ministry has to explain it's not a free ride; if your skills are not matched to the SOE, you will be a dead log and we don't want that cost to be carried by the SOE. We want people to add value to decision-making." (015)

As previously discussed, MPE has been working on reviewing its policies, working on amending the PE Act and, with increased resources, has been able to take a more active monitoring role. Participants generally supported MPE's involvement with providing advice on appointments to the selection committee it is seen as providing increased rigour to the process, and is based on internationally agreed criteria for board appointments. They commented that before the review, the process was ad hoc, but now the ministry has set up policy and procedures for the committee to follow.

\subsubsection{Section summary}

Improved board appointment processes, with directors appointed on merit, including a director with cultural leadership along with professional training were raised most often by participants to help overcome challenges implementing good corporate governance by the board. Participants added that improved reporting would help ensure boards meet their reporting obligations to improve accountability and transparency. Although Samoa has a 
small population, regular communication between stakeholders is also seen as key to help overcome issues with political involvement in the operational decision-making of SOEs.

\subsection{CHAPTER SUMMARY}

Participants identified several ways SOEs are using, or could use, to overcome challenges with implementing corporate governance principles. These ranged from changes to policy or legislation, to improving capability within the organisation through increased training for boards and SOE staff, and improved reporting and communication between stakeholders. While some of the approaches are used elsewhere such as adopting paperless reporting for board meetings, there are some initiatives that appear to be tailored for the Pacific and small island nations, such as use of shared boards, the appointment of a designated cultural leader on some boards, and corporate social responsibility being enshrined in the public enterprise legislation with GPO and CSO.

Participants from both countries spoke of similar initiatives such as regular community engagement, improved reporting, and implementing long-term planning. Participants commented on the importance of accessing learnings from other Pacific SOEs, and applying international standards in accounting and corporate governance. On-going community engagement appears to be more emphasised as an important approach than perhaps it is with countries outside the Pacific, and in bigger economies.

Participants also saw MPE having roles in implementing strategies that encourage board diversity and the appointment of women, and acting as a facilitator between SOEs and Cabinet. This would depend on whether the ministry has enough resourcing to provide policy and monitoring, but also support from the minister to provide 'free and frank' advice and to proactively look at improving the diversity on boards.

Further reforms and reviews of policies and legislation are suggested to explore other models, and how GPOs should be funded and assessed. Participants spoke of the need to rebalance the SOE function to not just focus on profit, but on a more even balance of efficiency, profit, and affordable service, and recalculation of the dividend rate to achieve this to reflect the 
particular needs of its citizens. Whether future reforms include changing the designations of SOEs to either a public private partnership model (if the enterprises have potential for profit making), or they are reabsorbed into a government department, or made NGOs because the priority is delivering an affordable service rather than profit-making, is an ongoing discussion globally with regard to the future of SOEs in the post COVID-19 era.

The shared board model, and moving towards e-government with paperless reporting for board meetings so that all documentation can be securely provided to directors, were two initiatives used in Tonga but not in Samoa. Evaluation of the shared model may encourage other countries to consider the model if the benefits outweigh any shortcomings.

In Samoa, participants identified two initiatives that they perceive as unique to Samoa - that there is a director position for a cultural leader on most SOE boards, and that this cultural leader would still need to represent the interests of all citizens and be able to participate fully with other aspects of board business. In Samoa's PE legislation, there is a statement that one of the principal objectives is to be a successful business that exhibits a sense of corporate social responsibility through the CSO. As discussed in the literature review (chapter 2) on ambicultural governance, Samoa's innovations in corporate governance in its SOEs combines the best of disparate cultures, and opens new ways of thinking (Chen \& Miller, 2010). The aim of Samoa's approaches appears to create and enhance economic and cultural well-being through creative governance (ibid). Indigenous governance can offer powerful insights into how Indigenous stewardship of resources can be merged with Western approaches to commerce to transform organisations and societies (Nicholson et al., 2019).

Overall, with regard to the SOE model, participants do not seek to 'throw the baby out with the bath water'. Rather, there is a recognition by participants that the model does come with challenges. For it to function effectively and move beyond its neoliberal roots the core principles of governance for SOEs need to be adapted to fit local conditions.

Tonga and Samoa appear to be peeling back the layers to create an environment to use their culture to find solutions to challenges faced governing SOEs 


\section{CHAPTER 10 REFLECTIONS AND LEARNINGS}

\subsection{INTRODUCTION}

The process of reflection during the course of the interviews shows the importance of learning not just from experience with working through the challenges in the SOE sector, but also the interview process itself. For example, initial responses from most participants that Tonga's SOEs do not consider local values and practices when implementing corporate governance changed. They initially didn't consider approaches were uniquely Tongan largely because of negative connotations of applying Tongan values to Western systems of governance.

There is not often the chance to express learning - or the space to identify things that worked. International reviews (ADB: 2009; 2011; 2014; 2016a) have reported negatively on SOE performance and have not covered innovative approaches adopted by boards, CEOs, or governments to overcome challenges implementing corporate governance principles. However, countries in the Pacific are experienced in adapting Western models and the SOE model is no different.

This research focuses on whether SOEs in Tonga and Samoa take local values and practices into account in using Western corporate governance principles. Participants were asked whether there are learnings from how their SOEs apply these models, and whether these lessons learned can be used elsewhere. Overall, participants were surprised to be asked if they had learnings which could be shared more broadly. This could be explained by a number of things; that apart from the former directors or CEOs, they are currently deeply involved in SOE governance and have not had a chance to reflect on any learnings, or a post-colonial perception that a small country in the Pacific could not be doing anything that is worthy of sharing.

This chapter results from giving participants an open-ended opportunity to reflect on their experience and give voice to their views. The findings below show a mix of reflections on lessons learned that participants were willing to share, and views on the future of SOEs in Tonga and Samoa. 


\subsection{TONGA}

The themes outlined below in Table 10.1 highlight the main themes discussed by participants regarding reflections on the SOE model in Tonga. This chapter elaborates on these responses with examples provided, along with quotations from participants. Participants provided multiple unprompted responses.

\section{Table 10.1 Reflections and Learnings on SOEs in Tonga ( $n=14)$}

- The SOE model is good for Tonga, and it is evolving with a Pacific flavour $(n=7)$

- Further reviews and reforms are needed $(n=7)$

\subsubsection{The SOE model is good for Tonga and it is evolving with a Pacific flavour $(n=7)$}

While most participants thought the Western model is good for Tonga, participants added that for a corporate governance model to be implemented effectively by SOE boards it needs to be adapted to fit a country's priorities, culture, and values. There is an acknowledgement that in a small country it is easy to discuss and negotiate with the relevant minister, such as on appropriate dividends. However, participants acknowledged that it is taking longer for Tonga to adapt to the SOE model and that Tonga is still working out what components of the model work best for Tonga. Participants spoke of Tonga needing to work through how to sustain development of the model while maintaining its culture.

"There may be international corporate governance best practice frameworks, but these wouldn't necessarily work in the Pacific, or in Tonga because they don't take into account the local context. I don't believe one size fits all. Good governance has to fit the country and fit the company. It also needs to be reflected in the corporate culture of the organisation, 'good soup'." (001)

Tonga's culture and values place service to one's community as an important part of Tongan life, and one participant reflected that the role of a director in Tonga aligns closely to a community role. 
"Being a director is a way of giving back to the community; success should be measured by the community." (011)

However, participants added that a change in attitude and behaviour towards the purpose of SOEs and corporate governance (as opposed to traditional governance) can take time and needs resources to implement and embed, especially if there's a perceived conflict with local values and practices. Participants feared that Tonga may lose some aspects of its culture, and recognise that globalisation will change how they view traditional governance. Tailored training for directors is seen as a way of ensuring the principles of corporate governance are met and at the same time respect the values that underpin Tongan culture.

"I recommend training for new directors and refreshers for directors. Orientation, then annual refresher training to change behaviour. Training should be held in Tonga, with a mix of both Western and Tongan trainers. Yes, experts from overseas but tailoring it to what's the best method for Tonga. Trainers need to have good understanding of Tonga, its values and culture." (011)

Participants were pragmatic that international funding is tied to reform, and that Tonga is familiar with adapting Western models. The issue largely lies with how to embed this with Tongan values.

"Technology exposure to Internet will change ... society and culture, it's going to happen. Technology has no interest in culture, but it's how you use technology to retain and promote your culture. If you try to stop it, it will make it worse." (003)

Although there have been performance issues with SOEs in Tonga, there were mixed views about where the fault lies. It was generally agreed that it was not Tonga's cultural values that were the problem, rather the manipulation of these values for individual gain. One participant saw the Tongan political model changing, and only then would SOE governance become more effective. 
"Political change is based on individual behaviours, not the system itself - the future is a hybrid of monarchical and democratic rule." (005)

Participants stressed the importance of communication for working relationships, and that this is a positive attribute of SOEs in Tonga where chairs and CEOs had ready access to the PE minister (who is often the prime minister) and the King. One participant reflected that any change to the SOE model would be dependent on changes to the political structure in Tonga. Participants considered that the government will need to manage expectations with the international community on how corporate governance principles are applied in Tongan SOEs.

Until recently, media would publish photos of boards and management handing over a large dividend cheque to the minister, and there have been issues with competition between SOEs on who would give the most dividends to the government. The government's view was that the healthiest SOE was the one that provided the most dividends. However, participants spoke of a change of focus by government and SOEs towards service. Government ministers are not necessarily altruistic and the change in focus is linked to improved chances for reelection. SOE boards and management also know that to be able to implement reforms or new projects they need government support, and this can be helped through linking these to improved customer service and satisfaction.

\subsubsection{Further reviews and reforms required $(n=7)$}

Participants also acknowledged that priorities for SOEs change over time and that further reviews and reforms will be required to meet the changing demands from customers, advances in new technology, and resourcing challenges. Some participants noted approaches such as further developing the shared board model and improving the appointment process for directors. Participants reflected that the SOE model needs to adapt to meet the changing world, noting it is important for Tonga to take learnings from other countries, such as the impact that privatising some SOEs had on New Zealand, and the wish not to make similar mistakes. 
Participants discussed the emphasis on providing an efficient and affordable service to all its citizens, and that Tonga may need to explore a different model for some of its SOEs and apply innovations to overcome capacity issues. Although the PPP model is seen by some participants as a solution to overcoming resourcing issues, one participant said that the government should be 100 percent shareholder for SOEs that are critical to the infrastructure of the country, such as cable, water, and power. Another added that SOEs need to have more creative business plans to meet both profit and service expectations.

Participants suggested the way of the future for Tonga is for the government to explore models that might fit Tonga's economy and society better, including whether a service can be offered by the private sector more efficiently. This is because the SOE model is not supposed to discourage private sector provision. One participant added that other Pacific islands are moving towards PPP, and donors are encouraging governments to support private sector investment so that local or international businesses can come into Tonga with lower prices for customers. Another participant proposed that in order to manage risk, the government should try the PPP model over the next 10 years to see if it works, before fully privatising SOES.

"The PPP model may be suitable for some SOEs. However, the private sector would argue that they could provide a better service." (002)

"The government can sell SOEs if the service can be offered by the private sector, but the role of government is to maintain core services, so some should stay. See how PPP works over next 10 years." (010)

Participants believed that it is important to implement international best practice, to use learnings from the Pacific and internationally, and that research into how SOEs in other countries are overcoming governance and performance issues should be part of any review of the model in Tonga. 
"It's the future ... to link up with other countries in order for us to share experiences or lessons learned." (003)

One participant thought that the government should look within Tonga to the private sector for a model that would suit Tonga's SOEs better than the current models.

\footnotetext{
"I suggest that the airport's terminal service is a good model whereby a consortium of companies come together, rather than one business benefiting over others. It's a private sector model but can be used for SOEs, with land staying in government ownership." (005)
}

Participants also recognised that for SOEs to be sustainable, Tonga should embrace technology and new innovations. They also noted that it should be the responsibility of the SOE boards and management to increase public awareness of the effects of climate change and the need to future-proof important services.

"Boards also need to understand and take into account other issues such as climate change, and shareholders also need to understand it may impact on dividends." (009)

With regard to diversity on boards, participants acknowledged that women bring different skills to a board and that women can and do make a difference by bringing the family and community perspective to the board.

"The government has a role to play in changing attitudes ... it should actively encourage women to apply, and should be shoulder tapping for now." (011)

As part of their learnings, three participants repeated their concern that while the model can be better adapted to suit Tongan conditions, they warn against "Tonganising" SOE governance. This is due to experience with director conflicts of interest in relation to their community, and involvement in SOE operations by some government ministers. They 
emphasised that Tonga's move to SOEs shows a commitment to a more transparent and profitable way of governing.

"There's no place in corporate governance for Tongan culture.... There should only be one standard. If you allow local context, there's a risk of some less desirable behaviours to creep in and affect decision-making. It's important to implement international best practice." (006)

"Strong values are already being compromised. Strong hierarchical culture is changing, changing the landscape. I can relate to some of the concerns of those that supported the monarchical system, but Tonga is not going back, and they will have to accept it ..." (003)

Participants saw that applying corporate governance principles can help avoid individuals using their position within Tongan society to influence board decision-making to benefit themselves or their village.

\subsubsection{Section summary}

Although participants were initially slow to recognise that the SOE model in Tonga is evolving with a Pacific flavour, they were quick to comment that they think the model is good for Tonga. However, some thought that the SOE model needs to be adapted to fit a country's priorities, culture, and values for it to be implemented effectively. They acknowledged that it can take time for changes in attitude and behaviour towards the model in Tonga, especially if conflict is perceived with local values and practices, and this needs to be realised by the international community.

\subsection{SAMOA}

Table 10.2 below highlights the main themes discussed by participants regarding their reflections on the SOE model in Samoa. This chapter elaborates on these responses with examples provided along with quotations from participants. As with Tonga, participants saw the need for more structural changes to the SOE model in Samoa, that further reforms are 
needed, and for any changes to fit better within local values and practice. Participants provided multiple unprompted responses.

Table 10.2 Reflections and Learnings on SOEs in Samoa $(n=14)$

- Further reviews and reforms required $(n=9)$

- The SOE model is good for Samoa and it is evolving with a Pacific flavour $(n=8)$

\subsubsection{Further reviews and reforms required $(n=9)$}

At the time of these interviews Samoa's MPE had been undertaking policy reviews, which included the re-classification of some SOEs. However, the majority of participants interviewed were unaware that reviews were underway and thought that it was time to review the classification of SOEs with some being re-assigned, either being absorbed back into government, becoming mutual bodies, or becoming PPPs. In the long-term, participants agreed that some SOEs could be privatised, and that competition could enable the public to benefit from more affordable services offered by other businesses, but at the same time not destroy the fabric of Samoan society.

"The ministry is currently undertaking policy reviews, which includes reviewing literature from around the world and assessing what will work well in Samoa ... Other considerations include whether some trading bodies will be privatised, or some will be reclassified to criteria that will work in today's world." (015)

With regard to Samoa's private sector, participants commented that they don't want changes to SOEs to have a negative impact on the community, for example, if a business discontinues due to SOE reforms. Consultation with the private sector and the public would need to be undertaken about which SOEs are retained and which should be privatised.

"In the last few years the private sector is having a greater voice in the types of projects, including those for non-trading SOEs ... I think a review of public enterprise models is required. Leaders do need to look out to see what international trends 
are doing in this space. Leadership and flexibility of the model is important to look at." (020)

\section{Different models}

Participants were pragmatic that to be part of the global economy, as well as being fiscally responsible, the government will need to explore changes to the SOE model, noting that the income earning capacity of most of Samoa's population will determine what these models will look like. Participants saw that SOEs are evolving, and that some may need to be reclassified to become mutual bodies, or that the local private sector has a role in some mixed-ownership model approach.

"Other SOEs could be privatised including Samoa Post, Public Trust. Some SOEs may return to the government, such as with the National Health, which was an SOE and is now merged with the Ministry of Health. Some SOEs may stay as SOES and remain non-commercial, such as SQA [Samoa Qualification Authority] and NUS [National University of Samoa]. The wharves and ports could become PPP in the future." (014)

"It's a myth that there isn't a suitable local private sector to work within a mixedownership model in Samoa and Tonga. There are fiscal risks when politicians control these assets, with the temptation to use for patronage. Mixed-ownership models can help keep government honest - transparency, efficiency - and reduce risk of political meddling in the operation of SOEs ... Governments also need to avoid pressure from vested interests within their country and be open to mixedmodel with the private sector/companies outside their country. ... Privatisation is not incompatible with continuing to subsidise tariffs, if the government wishes to do so." (026)

The above quotes reflect participants' expectations that there will be change to the SOE model over time to support the local private sector, attract international private sector investment, and increase shareholder accountability and transparency. 
Participants spoke of PPP as a way to ensure government remains accountable and transparent in its decision-making. This could reduce the risk of political interference in the operation of SOEs with lowering of tariffs, or with the tendering procurement process. Mixedownership models could help bring investment into an SOE, help the enterprise to become more efficient, and could be used as a step before it is considered for complete privatisation.

"PPP is a good approach before an SOE is $100 \%$ privatised." (013)

The ministry is also looking at the PPP model to help bring in investment into SOEs." (015)

However, some participants were more cautious about moving to a PPP model: it may not bring about more affordable services, and the current SOE model should be able to provide an affordable service and dividends to the government to use in the education or health sectors. The SOE model could be a long-term solution rather than a step towards privatisation or PPP.

"Moving to privatisation or PPP model is complex. Samoa is a small economy with a small private sector ... people still expect affordable service from a public body." (016)

One participant queried why a government would privatise an enterprise which is providing dividends. If the government wants to move Samoa towards more self-determination, they think that SOEs can play a role by investing their reserves into other Samoan initiatives, rather than relying so much on international investment.

"As a government-owned enterprise dividends go to government, but as part of good corporate behaviour, some SOEs who are cash heavy and have no debt should build reserves for a rainy day and look to find investment strategies within Samoa. If SOEs are making profits, then there's an untapped reservoir of homemade 
revenue. SOEs have the legislative mandate, there's a huge potential for the country if they are efficient, display good corporate behaviour, and deliver profit for benefit of the country. Why should some SOEs be privatised if they're providing the government revenue? The issue in developing countries is that governments use international donor money over its own money. Donors have an incentive as a way of control. Samoa should own its own destiny and reinvest SOE revenue rather than look to overseas donors." (024)

Participants stressed the need for the government to protect Samoa's water and power services in light of changing environmental conditions. One participant spoke of the impact that climate change is having on some coastal communities, with families having to relocate to higher areas which have traditionally been unoccupied, and which do not have water supplies.

Sustainability of water supply, eliminating losses of treated water and water conservation, as well as financial sustainability, remains a challenge for Samoa. ${ }^{81}$ There were mixed responses about what model would best protect communities' access to water supply - from government being the 100 percent shareholder, to privatisation of the water utilities, either through a management contract, lease, or partial privatisation of segments of the water supply (e.g. water/wastewater treatment).

"Most PEs will be privatised if the government wants the business to grow. But certain services the government needs to retain include water and electricity. They are necessities - all about accessibility and affordability to the people." (021)

Some participants saw the use of CSOs as one way where SOEs could still operate as a business but where the government maintains its responsibility to ensure affordable services are maintained to small remote and rural communities.

${ }^{81}$ https://www.samoawaterauthority.ws/history 
"CSOs need to be seen in the context that SOEs in Samoa operate - to provide a service. Although public trading bodies are supposed to trade and make a profit and operate similar to a private company, they are still expected to provide [an accessible and affordable] service. Samoa is a small place, I wouldn't leave the provision of water and electricity to the private sector because it's a political football, the market is so small ... [these] are services that have to be provided so it's a government obligation." (017)

\subsubsection{SOE is a good model for Samoa and is evolving with a Pacific flavour $(n=8)$}

Participants talked of the willingness of the government, ministry, SOE managements and boards to make the SOE model work in Samoa, and that despite some challenges they think overall it is a good model for Samoa, particularly as some enterprises are being pushed to perform better and to improve services. Samoa, like many other Pacific nations, is familiar with adopting and adapting Western models and frameworks, and the SOE model is no different. Participants spoke of the benefits of corporate governance of enterprises such as improving efficiency and quality of service, although producing sustainable profits and dividends has remained elusive for some of the enterprises. Participants saw multiple reasons for this, and these are discussed in the earlier findings' chapters.

"The SOE model is good for Samoa - balances cost recovery, provides accessible and affordable service to the community, and provides a 'reasonable' profit back to the government." (021)

"The SOE model is the least worst option for Samoa and Tonga. If an SOE can operate profitably and sustainably, keep tariffs low, not lose money, service debt, maintain infrastructure, not be a burden on the state, undertake three-year corporate planning, it's operating in the best interest of the public and government." (026)

Participants commented that SOE governance has substantially improved compared to 10 years ago, and add that other Pacific Islands are following Samoa's model. They thought that 
Samoa will continue to refine the SOE model and continue to adapt it to Samoa's cultural context, as no one model fits all contexts.

Participants acknowledged that adaptation will involve the balance between delivering government dividends and providing the best possible service for the community, which will require balancing profit-seeking with long-term strategic interest and social responsibility. Participants commented that for wealthier nations it would be harder to strike this balance. Directors also see their role on an SOE board as contributing to the betterment of their community.

\footnotetext{
"Governance best practice for Samoa SOEs is a blend of local Samoan governance and Western principles of corporate governance. A contributing factor leading to good governance practice is a stable government, and leaders who understand the function of SOEs." (014)
}

While participants felt that corporate governance is a good model for Samoa, they had more to learn from international experiences with SOEs (including learnings about what not to do). Some participants suggest that Samoa's SOEs response to CSR was more emphasised than in Western countries.

Participants pointed to the legislation and suggest this was because of the importance placed by government on the level of essential services provided to Samoans. This reflects the premise in Stakeholder Theory (Freeman, 1984) of the importance of business ethics and corporate social responsibility in good corporate governance principles. As discussed in the literature review, the theory views corporations in terms of their relationships to a broad set of stakeholders, where board decision-making is holistic, with board planning considering social, financial, and environmental wellbeing, and wider stakeholder needs as well as shareholder needs.

Some participants talked of the future of SOEs in Samoa and that Samoa will continue to look to the New Zealand model for learnings and lessons, OECD benchmarks for SOEs, and 
reviewing literature from around the world to assess what will work well in Samoa. Other considerations raised include whether some trading bodies will be privatised, or some will be reclassified to criteria that will work in today's world, and how any changes made will impact Samoa's private sector, as they don't want changes to have a negative impact on the community if a business discontinues.

\subsubsection{Section summary}

As with Tonga, participants viewed the SOE model as evolving with a Pacific flavour, and that further reviews and reforms will be required to respond to changing demands on these enterprises. Participants also agreed that a stable government with government ministers understanding the function of SOEs is key to good corporate governance.

\subsection{CHAPTER SUMMARY}

Indigenous cultural values in both Tonga and Samoa place service to one's community as an important part of people's lives, and despite being on a corporate board, the role of a director aligns closely to that of a community role.

Overall, participants interviewed about SOEs in Tonga initially struggled to provide learnings to share. However, throughout the interviews, three stood out:

- the shared board model,

- that the community is paramount in board decision-making, and

- the importance of regular communication between stakeholders.

Participants reflected that the SOE model is good for Tonga, despite the struggle to provide sustainable dividends. They acknowledge that the SOE model is evolving with a Pacific flavour to fit the country's priorities, culture, and values, and this is crucial if the model is to be implemented effectively. This will take a change in attitude and behaviour from government and the community, including reviews to explore other models. 
For SOEs in Samoa, participants think it is time to review the 2001 Public Bodies Act. Although there have been recent reviews to policies and a new separate ministry set up, participants think it is time for further reforms and to explore other models. Changes have been occurring internationally in the SOE space as well as in the corporate governance area, and participants want to take advantage of these new learnings, especially looking at learnings on 'what not to do', such as selling SOEs and then governments having to buy them back.

Overall, participants thought that the SOE model is good for Samoa and speak of the benefits of corporate governance such as improving efficiency and quality of service, although producing sustainable profit and dividends has remained elusive for most of the enterprises. But participants added that the model needs to continue to evolve with a Samoan flavour.

Some aspects have already occurred, such as policy for board selection with the requirement for a cultural leader on most boards, and with corporate social responsibility enshrined in the Act. This reflects the importance of community welfare in Samoan culture, with participants surmising that perhaps CSR is more emphasised in the Pacific than in the West and is something that the West can learn from their Pacific neighbours.

While participants were not initially aware that Tonga had learnings to share about how they have applied innovative ways to overcome challenges of being a small country with capacity issues, on reflection there was a realisation that they were actively taking an agile iterative approach to challenges and learnings. Whereas for Samoa, participants added that they were experienced with adapting Western models and had learnings they could share on how to adapt and implement Western models. Overall, there are important signs of an assertive reshaping of governance narratives at local levels. 


\section{CHAPTER 11 CONCLUSIONS}

\subsection{INTRODUCTION}

This chapter firstly provides a summary overview of the research (11.2), and briefly discusses any limitations (11.2.1). Section 11.3 addresses the research questions and provides a summary of the answers based on findings from the literature and interviews. The chapter concludes with how the research relates to the wider global literature on good corporate governance (11.4).

\subsection{SUMMARY OF THESIS}

This thesis is a study of how state-owned enterprises (SOEs) in Tonga and Samoa approach their governance roles in a context where concepts of good corporate governance are changing internationally (World Economic Forum, 2016). Since the 1980s the term 'good governance' has been worked and re-worked by those in the international development sector, and in 2009 Kofi Annan called for the adoption of a values-based system of governance (Annan, 2009). This research considered whether corporate governance practice in SOEs can be enhanced by the application of local cultural values and principles, and whether there are lessons learned from these two countries that could be shared more broadly.

There is much research on what constitutes good or effective governance but most of the corporate governance literature is from Western economies. Previous aid investment evaluations that I have been involved with have highlighted a lack of recognition of local conditions and values when examining Western models of governance in Pacific Island countries. This raises the question of whether there are different approaches to corporate governance that the global community can learn from. SOEs are a useful area to study as a defined sector as they play an important role in the Pacific to ensure the public has access to essential services that support social and economic wellbeing. This research examined the role of SOE boards in two Pacific countries, and how they implement notions of 'good' corporate governance principles within local settings. 
The three key research questions are: 1) How does the international discourse on 'good' corporate governance affect the way SOE boards work in Samoa and Tonga? 2) Do SOE boards in Samoa and Tonga take local values into account in defining and practicing good corporate governance? 3) Can their approaches and learnings be applied to other parts of the Pacific and outside of the Pacific? The answers to these questions are summarised in Section 11.3. The overarching research question asks, What does 'good' corporate governance mean in Pacific SOEs? This is discussed in the concluding section (11.4).

This study involved interviews in Tonga and Samoa, and examined insights from 26 current and former SOE board chairs, directors, CEOs and senior public officials from Tonga and Samoa, and subject matter experts, who discussed their knowledge of corporate governance, and their own experiences and approaches to corporate governance. The interviews were undertaken between July and September 2019, firstly with 12 participants who were interviewed about Tonga's SOEs, then 12 participants interviewed about Samoa's SOEs, and two participants were interviewed about both countries' SOEs. The potential political and commercial sensitivities of the topic, as well as the countries' small population size within which the participants operate, required that names and roles remained confidential and therefore are not named in the thesis. Interview responses went through systematic coding and then thematic analysis on five themes discussed: participant understanding of corporate governance principles; whether participants consider local values and practices when implementing these principles; challenges faced in implementing these principles; approaches undertaken (or being considered) to address these issues; and learnings and reflections that can be shared with the wider SOE sector.

The research adopted a social constructivist epistemology whereby knowledge is 'constructed' as a result of socialised experiences and worldviews (Berger \& Luckman, 1966). This links with the qualitative methodology approach used, rather than empirical measurable 'facts' and figures as used in positivism (Guba \& Lincoln, 1994). The research is positioned in knowledge which participants generate from their experiences, perceptions, and reflections. It focused on participant language and social action in how participants construct their views on corporate governance and SOE board performance. 
The research also examined the global literature on the rationale for the concept of 'good governance' which emerged in the latter half of the twentieth century, and corporate governance principles that support SOE models, to provide context for participant responses, along with global issues facing corporate governance.

Previous studies or reviews of governance (e.g. ADB's Finding balance series) adopt an approach which focuses on weakness and shortcomings, and this can lead to 'disciplining' and the imposition of a prescriptive approach to global models. My research seeks to understand how Pacific Island agents negotiate global and local models of governance to find positive outcomes. The research supported an Appreciative Inquiry (AI) approach as this method allowed the research to identify strengths, achievements, and learnings. Al taps into stories about what participants believe can be used to create new opportunities for their organisation or SOEs in general. This approach was expressed by Cooperrider (1990) as the "heliotropic hypothesis", the idea that organisations evolve towards the most positive images they hold and articulate about themselves (Bushe, 2001). As a form of action research it has the capacity to create a sense of creative possibility, ideas, and innovative action.

\subsubsection{Research limitations}

The main aim of the study was to examine whether two Pacific countries with different cultural values and practices apply them in the governance of their SOEs, and whether this could lead to learnings that could be shared more widely with the SOE sector. The qualitative research design was aimed at exploring in-depth views and different perspectives held by those experienced and closely involved in the governance of SOEs in Tonga and Samoa. Qualitative research allows for a systematic collection of participant knowledge, attitudes, insights, and behaviours, to identify themes, patterns, and relationships. It uses smaller, targeted and focused samples, and findings are not aimed at providing generalisations and external validity of the findings.

Although the study achieved saturation with main themes from the interviews, there were certain limitations with in-country primary documentation of SOEs. Relevant websites would 
frequently be inaccessible, and information on SOEs and their boards was not always up-todate, such as the list of current board directors. However, the social world is constantly changing, and this research needs to be read as a 'point in time'. This exploratory research is also not intended to provide conclusive evidence but is intended to help the reader have a better understanding of the responses to the research questions.

\subsection{ADDRESSING THE RESEARCH QUESTIONS}

This section returns to the research questions and provides a summary of the answers to each question drawing on the literature and interview responses.

\subsubsection{How does the international discourse on 'good' corporate governance affect the way SOE boards work in Samoa and Tonga?}

The international discourse on 'good' corporate governance relates to the early rhetoric of good governance as a singular prescriptive model (World Bank, 1981, 1989, 1992). It is based on the neoliberal concept of good governance with a minimal state, leaving other agencies (the private sector, NGOs, community groups) to better deliver public services (Bevir, 2009; Gregory, 2013).

The terms 'good' or 'best' (which have been used to suggest there is only one way of applying corporate governance) are being questioned. Each organisation, company, or enterprise is different in terms of its history, culture and other qualities (Epstein et al., 2021), and practices that work for larger, more mature enterprises, may not work well, or at all, for younger, smaller enterprises. This research supports the assertion that boards need to adjust their practices and procedures to achieve their goals (ibid). Recent discussion on corporate governance relates to the need for a paradigm shift, and for principles to be holistic and factor in diversity, environmental and social responsibilities, and long-term wellbeing of all stakeholders and the enterprise (Lipton, 2016; OECD, 2016; World Economic Forum, 2016).

Responses from participants indicate that Tonga and Samoa SOEs are engaged with this discourse. Participants were aware of the importance of keeping abreast of the global 
discussion on corporate governance principles and practices from the ADB, OECD, World Bank, Institute of Directors, and New Zealand.

"Leaders do need to look out to see international trends ... in this space. Leadership and flexibility of the model are important to look at." (020)

They showed support for SOE board chairs and directors to attend directorship training, including regular refreshers, as they saw a link between implementing internationally recognised corporate governance principles and SOE performance. Participants acknowledged this had not always been the case, but there is a growing acceptance for the need for governance training and board evaluations.

"Board evaluations are new to Tonga... holding boards to account." (006)

However, participants did comment that training needs to be adapted to fit the country, for example, that case studies are based on scenarios directors are likely to face in their country.

While all participants had a good understanding of the core principles of governance and referred to OECD and IOD handbooks, an overriding perspective was that Western frameworks or models do not always factor in the context of where they are applied, such as the scale and culture of a country, or size of a country's economy. Participants spoke of the priority they placed on 'fairness' (which was discussed in the 1992 Cadbury Report) to stakeholders over profits for the shareholder.

"Values contribute to how directors perform their duties and tasks, a chair needs to hold Tongan values as well as have experience operating in the business arena." (009)

The Tongan and Samoan legislations are clear about the purpose of public enterprises (SOEs), as well as roles and obligations of key stakeholders. Despite being clearly outlined in the legislation, it appears that boards still have to negotiate 'grey areas', balancing what is best 
for the enterprise with what is wanted by the government. Overall, responses reflect that knowledge of corporate governance principles does not necessarily lead to application of those principles, and that there are other factors such as ensuring the wellbeing of all citizens, in particular the most vulnerable. One example was being instructed by government ministers to divert a ferry to allow mourners access to a funeral on an island that is not usually covered by the ferry service. Generally, participants maintained that governance frameworks need to ensure other factors are taken into consideration when discussing performance of a board's governance role, and that these impacts should be included in annual reporting.

"Political interference has been raised by boards, but government of the day is the government of the day and they have their vision and what they want, we follow through what they want. So long as the board follows proper process, we can implement their vision." (011)

Participants were pragmatic about using Western models, and through time they have become more comfortable with adapting those models to fit their countries' values and practices.

"The SOE model is the least worst option for Samoa and Tonga." (026)

The application of corporate governance principles is also seen by participants as a valid approach to help overcome inefficient governance, cronyism, and corruption. However, they agreed that it would be naïve to suggest that this alone will improve organisational performance and economic growth. What is evident in the responses from participants was that there is a good understanding of corporate governance, and that it provides a coherent system, principles, and processes by which organisations are directed and controlled. Most participants used terms from Western models and frameworks to describe their understanding of corporate governance principles, such as accountability, responsibility, efficiency, performance, and transparency. These are all terms found in corporate governance handbooks (e.g. Financial Markets Authority (FMA), 2018; Financial Reporting 
Council (FRC), 2018, 2019; OECD, 2015a, 2015b). The difference, however, may be with how these terms are applied in the local context especially with overcoming challenges.

\section{Challenges with the SOE model}

The challenge for governments with the SOE model is to avoid the pitfalls of both passive ownership and excessive state intervention (OECD, 2015b). Some of the issues identified by participants are also experienced by SOEs globally, such as the ability for boards to govern at 'arms-length' to the government, lack of diversity of thought, and politically appointed directors (Conley et al., 2012; Creary et al., 2019; Mbele, 2015; OECD, 2015b).

Participants spoke of the challenge for SOE boards to find a balance between government's short-term priorities and ensuring the long-term viability of the SOE, although this does not appear to be a consideration if an SOE is being prepared for privatisation. Participants from both Tonga and Samoa commented on their government's involvement in SOE operational decision-making. It is unclear whether this involvement was driven by past board performance before recent reforms were implemented, or because the government is the majority or 100 percent shareholder, and feels it should have more control over the operation of SOEs. SOE effectiveness can be dependent on how it is directed and controlled, and implementing elements of effective governance can be undermined when political interference compromises the performance of the enterprise (Mbele, 2015; OECD, 2015b).

"There is a lot of political interference. It makes things unstable and not good for SOEs." (007)

This has led the international donor community to introduce the good governance conversation as a way to influence policies in a recipient country (Currie-Alder, 2014; Nederveen Pieterse, 2004). The 2020 briefing for the incoming New Zealand Minister of Foreign Affairs outlines the importance of leading, strengthening, and leveraging connections to influence other countries in ways that are advantageous to New Zealand's interests, and to project New Zealand's values (MFAT, 2020). Embedding accountability and transparency principles and financial management systems as part of public sector governance support can 
also have a broader impact with exposing poor government ministerial behaviour, such as with political board appointments rather than appointments based on merit.

The neoliberal reforms, including the SOE model, were used to implement policies to control the role the hierarchic state plays in the lives of its citizens. However, Tonga and Samoa both have hierarchical structures in their societies.

The status of government ministers and the power they hold within each country was also raised by participants as possibly contributing to challenges board chairs and SOE management were facing, rather than the lack of knowledge of good corporate governance by ministers. These are cultural values placed on the status of government ministers by Tongan and Samoan society and mean that local values at times can appear to inhibit performance. Directors may be experienced in dealing with traditional governance matters but find governance of an SOE at a national level a challenge.

"I didn't have the guts to challenge and push back at requests from the minister." (010)

Participants spoke of the difficulty balancing the obligation to deliver a profit to the government and an affordable service to the public, especially when the government does not compensate the SOE for a Government Policy Obligation (GPO) or Community Service Obligation (CSO). However, some participants maintained that it depends on whether there is more value placed on dividends or on services to the community. While it could be argued that government interference in Tonga and Samoa SOEs is due to strong cultural influences, the same argument cannot be used by SOEs elsewhere such as in New Zealand for similar government behaviour. Therefore, it could be misleading to refer to cultural influences challenging SOE governance in the Pacific; rather it could be the model itself.

The 2016 ADB report stated that SOE reform has been ongoing for decades, and global policymakers are aware of SOEs' performance issues, fiscal costs, and negative impact on growth and poverty alleviation. It argued that chronic SOE portfolio underperformance 
highlights a fundamental flaw in the SOE model, and considered that it is not an effective long-term ownership structure.

"This is the fundamental flaw in the SOE model: politicians always find difficulty with commercial decisions that have political costs. These costs include job losses, closing down loss-making businesses, or disallowing power and water utilities from charging true service costs." (ADB, 2016a, p.38)

That review also maintained that the model cannot replicate private ownership market disciplines, and so long as SOEs remain under majority public ownership, politicians will avoid commercial decisions with potential short-term political costs. While some development agencies would like a greater emphasis on boosting the private sector or encouraging a PPP model over the SOE model, the risk is that countries primarily dependent on remittances and foreign aid will struggle if some SOEs are privatised. Participants from both countries spoke of similar initiatives to overcome challenges in implementing corporate governance principles, including either nationalising or applying a PPP model to some SOEs. However, privatisation was seen as a big risk, especially to core public services. Participants referred to where governments have had to buy back enterprises, such as in New Zealand with Kiwirail.

In summary, the international discourse on 'good' corporate governance affects the way SOE boards work in Tonga and Samoa. SOEs are overcoming challenges by adapting the core principles to fit within the values and constraints of each country. Recent global debate on the need for a paradigm shift reflect the constraints SOEs and the private sector are facing globally with the model. In Tonga, shared boards are being used to overcome the lack of directors with corporate governance experience willing to be appointed onto SOE boards. In Samoa, most boards must have a director as a designated cultural leader to ensure board decisions consider any impact to Samoa's culture and values. 


\subsubsection{Do SOE boards in Samoa and Tonga take local values into account in defining and practicing good corporate governance?}

The above question is critical to this thesis. This section examines whether SOE boards in Tonga and Samoa are part of the movement for a paradigm shift to broaden concepts of good corporate governance to include recognition of local conditions and values when implementing Western models of governance (political and corporate).

\section{There is growing support for values-based corporate governance}

Integrity and fairness (referred to in international codes and guidelines (e.g. Cadbury Report, 1992; OECD, 2015a)) was not initially part of the good governance discussion with participants, but this was discussed by participants in Tonga and Samoa when referring to local values and practices, and challenges faced in balancing the requirements to provide dividends to the shareholders and an affordable service to the community. Overall, participant perceptions were that corporate governance principles need to be adapted and contextualised for Pacific nations if SOEs are to be successful in these countries. Although participants understood the principles of commercial corporate governance, priority was placed on 'fairness' to stakeholders over profits for the shareholder.

Participants spoke of the importance of board decision-making being 'holistic' - that board planning should consider social, financial, and environmental wellbeing, and wider stakeholder (citizen and taxpayer) needs as well as shareholder (government) needs. This reflects the Stakeholder theory (Freeman, 1984) premise of the importance of business ethics and corporate social responsibility (CSR) in good corporate governance principles, and considering all stakeholders' needs. This theory, which views corporations in terms of their relationships to a broad set of partners or stakeholders, has drawn increasing attention within the debate on good corporate governance practice. Larry Fink, founder, chair and CEO of BlackRock ${ }^{82}$ argued that society is increasingly asking that companies respond to broader societal challenges, and serve both a public and private social service (Fink, 2018). Fink maintained that to deliver financial performance long-term, an enterprise needs to also make

\footnotetext{
82 BlackRock, Inc. is an American multinational investment management corporation and the world's largest asset manager.
} 
a positive contribution to society, and that stakeholders are demanding that companies exercise leadership on a broader range of issues:

\author{
"Companies must benefit all their stakeholders, including shareholders, \\ employees, customers, and the communities in which they operate. Without a \\ sense of purpose, no company, either public or private, can achieve its full \\ potential" (Fink, 2018, p.1).
}

Ten years after the call to action for the adoption of a values-based system of governance (Annan, 2009) the good governance debate continues, with measures of public and private sector success changing. The ongoing discussion is still calling for values-based corporate governance, and board diversity in corporate governance practice (DFID, 2017; Page, 2007; Conley et al., 2012; World Economic Forum, 2016). Good governance was seen as a 'cure all' by neoliberals who promoted 'less government' and 'more governance', condemning the hierarchic approach to the provision of public services as fundamentally inefficient. They argued that the state should not itself deliver services but rather develop an entrepreneurial system based on competition and markets (Kjaer, 2004). However, results from subsequent public sector reforms are challenging the neoliberal view of good governance practice in both the public and private sectors (Grindle, 2007; Lipton, 2016). The World Bank overestimated the impact of governance reform on economic growth, and the focus on governance reform has not proved as effective as promised in fostering development (Sundaram, 2015). Its use of indicators has failed to take into account country-specific challenges and conditions, with statistical analysis selection bias and a lack of consideration of the interlinkages among the array of variables (Sundaram, 2015; Gregory, 2013; Grindle, 2010).

Integrating environmental and social issues was once considered the domain of public sector governance. However, the integration of ESG is also being encouraged as part of good corporate governance for the long-term wellbeing of organisations, including SOEs. Shareholders and other stakeholders are paying attention to the way enterprises behave and use environmental and social indicators as a test of how they would handle strategic and operational challenges (Lipton et al., 2016). 
The 2016 World Economic Forum's New paradigm report is seen as a road map and an emerging corporate governance framework, although it has its critics (Bebchuk \& Tallarita, 2020). The framework aspires to recalibrate the relationship between stakeholders and shareholders, and considers corporate governance as a collaboration among corporations, shareholders, and other stakeholders working together to achieve long-term value (Lipton, 2016; Lipton et al., 2016). The New paradigm aims to encourage corporations to incorporate relevant sustainability, the well-being of all stakeholders, and ESG and CSR considerations in developing their long-term strategies and operational planning (World Economic Forum, 2016).

Nicholson et al.'s, (2019) research goes further and proposes that Indigenous governance can offer powerful insights into how Indigenous stewardship of resources can be merged with commerce to transform both organisations and societies. They argued that to transform societies (including business institutions) into environmentally, spiritually, socially, and culturally sustainable societies, an Indigenous ambicultural governance approach is valuable (Nicholson et al., 2019). The researchers support previous academic assertions (Chen \& Miller, 2011) that the continuity of socially and culturally embedded knowledge handed down through Indigenous cultures has the potential to facilitate change in business. They argued that governance has an important role in the socioeconomic landscape, particularly when such a landscape seeks to recalibrate its activities by addressing collective well-being while maintaining financial viability (Nicholson et al., 2019). Although their research is focused on the private sector, much of the findings could also be applied to SOEs as both apply corporate governance principles.

Tonga and Samoa's SOEs take local values and practices into account and the SOE model is evolving with a Pacific flavour

Overall, participants held mixed views about whether SOE boards in Tonga and Samoa apply Indigenous and local values in practicing corporate governance. All participants acknowledged that their country has traditional governance principles, but that SOEs are not 
village organisations, and to be able to operate in the global economy their country needs to apply international models of governance to their SOEs.

Upon reflection, most participants referred to a hybrid model where SOEs have a dual function - applying principles of efficiency and profitability for the enterprise, along with ensuring accessibility and affordability of the service to the public. This is reflected in the legislation of both countries through GPOs or CSOs. Both Tonga and Samoa have used innovations to adapt Western models of corporate governance to fit with their values. This research shows that a country's value systems influence behaviour, and that SOE boards take local values into account in defining and practicing good corporate governance.

"The [corporate governance] principles need to have a direct relationship with the local context, and factor in demography and location such as the Pacific Islands instead of the West or Asia." (001)

Good governance contains a strong normative content of what public life 'ought to be' (Grindle, 2010). Participants interviewed spoke of SOEs serving the well-being of communities alongside creating profit for the shareholders. Participants referred to this as the dual function of SOEs or the hybrid nature of SOEs in their country. Their description appears to align more towards the relational stewardship model, or as one participant described it as Tautua stewardship, that as a leader within the community their role is to serve that community. Here, an SOE director is seen as a public servant.

"Stewardship or Tautua, leadership and service - the path to leadership is service. Leadership should have a servant-hood heart. It's part of the role of being a public servant." (022)

SOEs are an important feature of Pacific Island economies, and have formed part of the public sector reforms since the 1990s. This research finds that globally there is growing support for values-based corporate governance (Chen \& Miller, 2011; Nicholson et al., 2019; World Economic Forum, 2016). SOEs in Tonga and Samoa are applying their own Indigenous 
solutions to help them implement the corporate governance model. These innovations mean that the SOE model in Tonga and Samoa is evolving with a Pacific flavour.

\subsubsection{Can their approaches and learnings be applied to other parts of the Pacific and outside of the Pacific?}

While there may be good reason to promote a singular prescriptive template approach to implementing good corporate governance, it can leave little room institutionally and philosophically for sharing experiences. This was reflected during recruitment for interviewees to participate in this research, when some initial responses from participants were of surprise that they may having learnings or approaches worthy of sharing,

"No-one has ever asked me if I had something to share with other boards here or overseas." (001)

Although these countries are experienced in applying Western models, there appears to be little recognition of the innovation used to adapt these models to overcome the challenges of implementation. This research finds that Tonga and Samoa's approaches and lessons could be applied elsewhere. Indigenous cultural values in both Tonga and Samoa place service to one's community as an important part of people's lives. Despite being on a corporate board, the role of a SOE director aligns closely to that of a community role, governing for the longterm wellbeing of both the community and the enterprise. Participant interviews also highlighted the high level of public expectation that SOEs go beyond legal requirements, and press boards and policymakers to address broader welfare issues.

In international development, corporate governance aims to provide accountability to providers of capital. International discussion is also moving towards areas of stakeholder connection, long-term thinking, and a broader view of wellbeing (Freeman, 1984; World Economic Forum, 2016). Nearly thirty years on from the 1989 World Bank report, international development agencies have looked at the feasibility of achieving good governance, and are promoting 'good fit' solutions where appropriate, and 'effective governance' (DFID, 2017; World Bank, 2017). The G20/OECD principles of corporate 
governance (OECD, 2015a) emphasised long-term growth, and that for an organisation to prosper it needs to take into account country-specific economic, legal, and cultural differences.

Using capital to generate long-term wealth creation and economic prosperity is behind the World Economic Forum's New paradigm. This paradigm is consistent with a changing perspective on good corporate governance, with an expectation that even privately owned enterprises should consider the wellbeing of a wider range of stakeholders (Fink, 2018; Nestor, 2018; OECD, 2015a; O'Kelley et al., 2018). This includes a re-emphasis of the concept of CSR which encompasses business ethics, corporate philanthropy, corporate citizenship, sustainability, and environmental responsibility.

Pacific Island countries are used to adapting Western models and participants believe that governance 'best' practice for SOEs is a blend of local governance and Western principles of corporate governance. While some of the approaches are used elsewhere, such as moving towards e-government and adopting paperless reporting, there were some initiatives that appear to be tailored for the Pacific and small island nations, such as use of shared boards (in Tonga), the appointment of a designated cultural leader on some boards (in Samoa), and CSR being enshrined in Tonga's and Samoa's public enterprise legislation with government policy obligations (GPO) and community service obligations (CSO).

Participants were initially unsure whether corporate governance principles and practices internationally could be enhanced by knowledge of localised cultural values and principles. While not all participants were conscious of SOEs taking local values into account in defining and practicing good corporate governance, there was a general reflection that international corporate governance best practice frameworks also need to fit the culture of the organisation and the country. While good corporate governance principles were important for ensuring accountability and transparency, the community is seen as paramount in board decision-making, along with regular communication with stakeholders. Participants reflected that the SOE model is good, despite the struggle to provide sustainable dividends. They acknowledged that the SOE model is evolving with a Pacific flavour to fit the country's 
priorities, culture, and values, and this is crucial if the model is to be implemented effectively. They also acknowledged that this would take a change in attitude and behaviour from its government and the community, and the international development aid agencies.

\subsubsection{What good corporate governance means in Pacific SOEs}

This research aimed to identify what good corporate governance means in Pacific SOEs. The research found that SOEs do take local values and practices into account in their corporate governance approach. This dissertation also asserts that while there are core governance tenets that contribute to long-term sustainable success, they need to be considered within the context of where the organisation is located, and on how principles may be applied.

SOEs in New Zealand and most other Pacific countries use the shareholder model. However, what the research found is that boards in Tonga and Samoa view stakeholder engagement with the community as an important part of their governance role, which could be a reason for issues participants discussed regarding challenges in implementing 'good' corporate governance principles. The research highlights the challenge that despite these countries having corporate governance principles embedded in their legislation, and SOEs with frameworks for implementing corporate governance principles, they won't necessarily result in good performance outcomes. Participants do not seek to 'throw the baby out with the bath water' and get rid of the SOE model. There is, however, a recognition that the model comes with challenges, and for it to function effectively and move beyond its neoliberal roots the core principles of governance for SOEs need to be adapted to fit local conditions.

This could include changing the discourse from 'state-owned' enterprises back to 'public' enterprises. While legislation uses the terms 'public enterprises' or 'public bodies', and ministers and ministry titles use 'public enterprise/s', most participants and many of the enterprises' websites, and literature use the term 'state-owned enterprises' or 'SOEs'. Public expectations appear to be that these enterprises are publicly-owned rather than governmentowned, and should be focused on service to the community rather than making profit. This may be contributing to an underlying disconnect between stakeholders. 
Overall, the research finds that: adopting western corporate governance for SOEs requires an iterative learning process; SOEs are applying a hybrid or ambicultural approach to the corporate governance model; and engaging with all stakeholders is an essential part of good SOE governance in the Pacific. Good corporate governance means that Pacific SOEs can apply principles to protect the interests and wellbeing of all stakeholders, it can help protect against self-serving interest, and it means that Pacific SOEs can be part of the global discussion on what good corporate governance should look like and how it could be applied in certain conditions going forward.

The following concluding section considers how these findings might inform global literature on good corporate governance. In particular, whether the findings support Foucault's premise on knowledge and power; whether findings from international development agency reviews on SOE performance result from the model itself, or how it is applied in small island countries; and whether the way the model is being adapted could support better long-term performance. This chapter concludes with a comment on applying ambiculturalism to corporate governance in the SOEs.

\subsection{CONCLUDING DISCUSSION}

\subsubsection{Good corporate governance is dynamic and responsive, and can be modified to fit} local situations

Outside of the international development sector, there is a growing awareness of the need for changes in the corporate sector by governance reformers, shareholders, and investors who have come to understand the trade-offs between short-term returns and long-term social, environmental and economic prosperity (Sampford \& Connors, 2006; UN Global Contact, 2004). The changing perspective is focusing on an expectation that even privately owned enterprises should consider the wellbeing of a wider range of stakeholders (Fink, 2018; Nestor, 2018; O'Kelley et al., 2018). In larger economies, there has been a big drive for longterm sustainability, greater transparency, and governors having the skills and experience needed to support this (Lipton, 2016). This discussion is largely brought about by the $2007 / 08$ GFC and the growing interest in more environmental and social responsibility (i.e. social licence to operate), diversity of thinking on boards, and trust and integrity as core leadership 
qualities (Lipton, 2018). The discussion also includes broadening the range of corporate governance tools, and looking beyond Western concepts of good corporate governance (Chen \& Miller, 2011; Nicholson et al., 2019).

The value of corporate governance models is that they can improve processes, efficiencies, and accountability. International donor agencies, however, have set standard criteria that often do not attempt to incorporate the governance situation already in existence, and they may not be acknowledging that these models can take time to embed. In Foucauldian terms, good governance is used as a means by international aid agencies (under neoliberalism) to discipline and control local institutions (Bevir, 2013; Escobar, 1985; Foucault, 1972, 1979, 1980; Marglin \& Marglin, 1990; Nederveen Pieterse, 2010; Rabinow, 1991). In development studies, structural adjustment was seen as a radical break with the development tradition that societies must adjust to global economic imperatives (Murray \& Overton, 2011; Nederveen Pieterse, 2010). There are still signs of this as seen in responses by participants regarding 'falling into line,' accepting criticism etc. There has also been an almost Orwellian mantra that 'states are bad' and 'markets are good', of which 'good governance' was an ideology that was never going to succeed in a pure form, either in small countries or countries with large economies. Under structural adjustment, the discourse was that if the state is to be involved, it must be 'proper and behave'. However, the corporate governance model is a model that was never meant to be applied unmodified, but needs to be adapted to fit local conditions (Bevir, 2012). Theories such as neoliberalism and NPM cannot assure policy makers that these approaches will deliver efficient or effective governance, and this is possibly the reason why there have been successive waves of public sector reforms. There is never going to be a perfect function with an imperfect system.

For Foucault, knowledge is connected to power (Foucault, 1972), and in the early years of public sector reform, knowledge of the SOE model in the Pacific was limited. However, the research concludes that through an iterative learning process, knowledge of the model and of corporate governance principles has grown, and with that increased knowledge has come an increase in awareness of how these tools could be applied in different contexts. Drawing on Foucault, power can increase peoples' awareness of how their way of 'thinking and acting' has been shaped, and increasing this awareness makes it possible for them to change their 
way of 'thinking and acting'. Foucault's conceptual discourse on governmentality (Foucault, 1980) suggested that the research would find participants more pliable to meeting donors' expectations, creating a dependence due to aid being tied to meeting good governance principles. While this may have been the case in the past, increased knowledge of corporate governance practice has enabled directors and chairs to adapt the SOE model. Neoliberalism did not mean that people were free from constraints, rather being free to contest them, to negotiate them, and to transform (Foucault, 1979, [in Burchell et al., 2008]), and there are important signs of assertive reshaping of governance narratives at a local level. These are forms of emancipation, and even resistance. Small economies are stamping their brand of what good governance is for SOEs in more imaginative ways than may be seen in countries with larger economies. Responses show that people are thinking about how best to deal with the challenges. Instead of resisting or dismissing the corporate governance model, they are actively engaging with it, and adopting aspects that suit or fit with their local values and practices of social responsibility and wellbeing. This is good governance with a Pacific flavour.

What constitutes good corporate governance is constantly evolving as a response to changes to priorities in society and the economy. The discussion by participants on changing priorities supports recent discussion and debate on paradigm shifts within corporate governance, with greater attention being given to being holistic and to factor in diversity, environmental, and social responsibilities (World Economic Forum, 2016).

Overall, good corporate governance should be effective, dynamic and responsive; it should be modified to fit local situations, and (along with a responsive state) can promote long-term wellbeing for its society. Rather than resist, participants acknowledge that they are operating within this system but they cannot attain perfection, so they are applying an adaptive management approach with the resources they have.

In the development field where donors and lenders are looking for ways to assist emerging economies, this research can be relevant from the point of view of looking at local conditions already in place, and exploring what might need to be adapted to get local buy-in and ownership. Contextualising to local conditions will take time and require a strong 
understanding of why there is need for change, and what the benefits will be for all stakeholders.

11.4.2 The concept of scale and its influence on SOE structure and governance is an important issue for Pacific Island nations.

Scale is an important issue for SOEs in Pacific Island nations and the research gives insight into the SOE model over vastly different scales. The SOE model can be applied at a smaller scale but this raises particular issues, such as the small pool of people, the interconnectedness, and maintenance of SOE infrastructure from a smaller revenue base.

As discussed, SOEs in the Pacific play an important role providing essential services. However, small populations can mean a country has a small pool of people to choose from for SOE chair and director roles. Tonga has attempted to overcome this issue by using shared boards. Another issue may not be to do with capacity or capability, rather a lack of suitable people wanting to be on a SOE board because the government is the shareholder, or principal shareholder.

There are also economies of scale issues regarding trading SOEs. Tonga has 12 SOEs and five boards for a population of approximately 100,000; Samoa has 16 SOEs and boards for a population of approximately 200,000; and New Zealand has 12 SOE boards for a population of five million. Core infrastructure is needed regardless of population size. This means that many of the services provided by SOEs in the Pacific are likely to need additional support from government to make the charges affordable for its citizens, and further financial support to maintain the infrastructure.

\subsubsection{SOEs from small island nations are actively adapting and innovating the corporate} governance model to improve local performance

Directors and SOE officials are applying Appreciative Inquiry to work within the core principles of corporate governance. They are actively asking, 'how can these tools be applied in my country?' Pacific SOE directors are fully aware of issues and limitations, but also potential. Participants interviewed are engaged, critical, and skilled professionals; not passive, but 
active people working in a sector with many constraints. They are learning, reflecting, and innovating, such as using shared boards or appointing directors as cultural leaders. Responses show that participants recognise there are areas they don't know much about and need assistance with, either from other enterprises in the Pacific, or elsewhere. They acknowledge their country's SOEs are faced with many challenges, but the narrative should be that they are not a 'basket case'; they are actively applying a flexible iterative approach, using learnings on how best to adapt corporate governance tools. Therefore, rather than assessing whether an organisation has applied good corporate governance as set out as best practice by international aid agencies, future reviews or evaluations of SOE performance should assess how well an organisation has learnt and adapted it to local conditions. Evaluations can assess smart adaptation, flexibility, and imaginative approaches to overcome local constraints and to increase long-term prospects for success.

There have been critical reviews of SOEs in small countries (ADB, 2009, 2014, 2016a; World Bank, 2020a) that concluded there is chronic SOE portfolio underperformance which highlights a fundamental flaw in the SOE model. The 2016 ADB review suggested that it is weak governance that makes it difficult for Pacific SOEs to operate on strict commercial principles over the long term. It argued that long-term government ownership of SOEs often results in outcomes counter to the SOE model. However, the findings in this research show the problem is not the ownership model, but government behaviour. There are often unclear and sometimes conflicting expectations by the state, subverting the model to try and enhance political prospects. Most participants in this research considered that privatisation or partial privatisation of SOEs was not the right approach for countries with small economies. While some SOEs will be prepared for privatisation to foster private sector growth, others in strategic sectors such as agriculture, transport, water, ICT, and power, should not be privatised to ensure guarantee of supply of essential services.

Based on qualitative analysis of participant interviews and relevant literature, this research concludes that an ongoing learning process is required for a corporate governance model to be successfully adopted by SOEs, as opposed to applying a blueprint or 'off the shelf' model of SOE corporate governance and expecting this to be immediately effective. A country's 
value systems influence behaviour, and the adoption of Western approaches can take time, especially if the messages from the principal shareholder are mixed, and the rationale for adoption is unclear. Formal theories of governance should be seen as guides to activity, rather than as tools that can deliver promised efficient and effective governance.

Participants acknowledge that the world of corporate governance is dynamic, and they are responding and adapting it to fit their local situation. Participants in this research are not just doing what they are being told to do, nor are they resisting. They learn about the model and are adapting it to their own local situation. The model is also being used as a tool for accountability to help avoid corrupt or self-interested behaviour. These SOEs are asserting local agency over a global narrative. Globally, each SOE brings its own challenges for its country and government, and the public it is meant to serve. There appear to be no easy solutions to applying the SOE model, but there is a willingness to apply its features.

The world has changed dramatically since aid and development agencies began to address issues of governance in recipient countries. There has been a large increase in the number of countries pursuing electoral democracies, more countries are integrated into the global economy, and more are connected through technology. During and post-COVID-19, governments may look to rebalance the SOE function to not just focus on profit, but on a more even balance of efficiency, profit, affordable service, and protecting local selfsufficiency and resilience. This may lead to recalculating the dividend rate to reflect these changing priorities by government.

\subsubsection{Ambiculturalism is reshaping the good governance narrative at a local level}

Problems require theoretical reflection and practical activity if they are to be adequately addressed. Foucault (Foucault, 1980; Foucault, in Rabinow 1991) advocated for the need to stand back and question the whole narrative of governance and examine the issue of power, as governance is about power, influence, relationships, decision-making and accountability. It is about who has influence, who decides, and how decision-makers are held accountable. In responding to the recent call by academics for finding solutions using local culture and knowledge, this research has identified pointers towards different approaches to governance. 
The 2017 study on "ambicultural" corporate governance practices argued that indigenous businesses are harmonising Indigenous and Western corporate practices and worldviews to create and enhance economic and cultural well-being through a flexible corporate governance model (Nicholson et al., 2019).

Bevir (2012) and others (Chwalisz, 2017; OECD, 2020; Pateman, 1970) argued that as part of a healthy democracy, the most effective way to govern is through engaging citizens in participatory structures. As part of this process, countries are prioritising what values they place on certain public services, and how these services can be funded. The most effective way to govern is through engaging with all stakeholders, "you need to consult, consult, consult; one consultation is not enough." (021)

Ambiculturalism can provide diversity of thought and a more diverse avenue for public participation. Governance of SOEs can be a vehicle for community participation, and an ambicultural approach to governance can introduce novel forms of participation at various stages in the policy making process. This would empower disadvantaged groups to enter the policy process, and enable public sector workers to engage in more dialogue with the targets of their policies. Participants spoke of the importance of ongoing consultation with the community, reflecting the importance of community welfare within their cultures. For example, ambiculturalism recognises how local protocols, structures and processes can improve community participation using established cultural norms. Here, directors play a stewardship role which reflects Pacific values such as respect, reciprocity, family ties and obligations, and collective responsibility. Broader stakeholder engagement helps to ensure there is an on-going 'social licence' to operate, and provides a more 'hand in glove' approach to meet community environmental and social expectations, and workforce concerns.

An ambicultural approach could be added to the SOE governance model. Corporate governance theories cannot fully explain the complexity and diversity of corporations, and governance practice can differ from country to country due to cultural values, and political, economic, social, and historical contexts. It would be dangerous to assume that corporate governance theories can be applied without being adapted to local conditions, especially in 
small countries where 'everyone knows everyone'. SOE governance practices need to be tailored to the jurisdiction where they operate. This process can take time to embed, especially in countries struggling with many demands on their capacities to pursue change.

Expanding on research undertaken by Chen and Miller $(2010,2011)$ and Nicholson, Spiller, and Pio (2019) on ambicultural approaches, a hybrid or ambicultural corporate governance model for SOEs would blend Indigenous cultural governance values with Western models of corporate governance. This may increase the likelihood of ownership by stakeholders of SOEs in non-Western countries. Based on SOEs being governed using Western corporate governance models while remaining socially and culturally grounded, future reforms could include a recalibration of the role of SOEs in the economy. This could include considering an Indigenous worldview and knowledge base that can help deepen and develop Western governance practices and bring transformational value to both Indigenous governance and Western corporate governance. An Indigenous-Western connection to corporate governance leads to a recommendation to consider an ambicultural approach when reforming SOEs in countries where Indigenous values and practices are strongly embedded in society. An ambicultural approach could also rebalance the SOE model to support long-term financial performance as well as improving the wellbeing of a country's citizens.

An ambicultural approach should be part of future reforms. There will be a need to take an integrated approach to governance models rather than a single perspective to understand the elements and effects of good corporate governance. An ambicultural model of corporate governance would have different incentives, with directors playing a caretaker/steward role, focusing on the wellbeing of the community and the government. Board performance and informed decision-making could also be enhanced by Indigenous stewardship. It may be better suited for countries where a privatisation programme of SOEs is not deemed to be a feasible option. It may also provide an appropriate balance between the legitimate interests of different stakeholders, where performance measures could include adherence to a country's values, as well as providing revenue for other public services such as health and education. 


\section{REFERENCES}

Adam Smith International [ASI]. (2015). Evaluation of the Samoa country programme. Wellington: New Zealand Ministry of Foreign Affairs and Trade: Manatū Aorere.

Adam Smith International [ASI]. (2016). Evaluation of New Zealand's development cooperation in Tonga. Final report. Wellington: New Zealand Ministry of Foreign Affairs and Trade: Manatū Aorere.

Adler, P. (2001). Market, hierarchy, and trust: The knowledge economy and the future of capitalism. Organization Science, 12(2), 215-234.

Advameg Inc. [Forum]. (2016). Tonga. Countries and their cultures. http://www.everyculture.com/To-Z/Tonga.html

Aghion, P. \& Williamson, J. (1998). Growth, inequality and globalization. Cambridge: Cambridge University Press.

Aguilera, R., Judge, W. \& Terjesen, S. (2018). Corporate governance deviance. Academy of Management Review, 43(1), 1-23.

Aguilera, R. \& Haxhi, I. (2019). Comparative corporate governance in emerging markets. In R. Grosse \& K. Meyer (Eds.) Oxford Handbook on Management in Emerging Markets. Oxford, U.K.: Oxford University Press.

Agudelo, M., Jóhannsdóttir, L. \& Davídsdóttir, B. (2019). A literature review of the history and evolution of corporate social responsibility. International Journal of Corporate Social Responsibility, 4,(1).

Airini, [A]., Anae, M., Mila-Schaaf, K., Coxon, E., Mara, D. \& Sanga, K. (2010). Teu le vaRelationships across research and policy in Pasifika education: A collective approach to knowledge generation \& policy development for action towards Pasifika education success. Wellington, New Zealand: Ministry of Education.

Alkhafaji, A. (1989). A stakeholder approach to corporate governance: Managing in a dynamic environment. New York: Quorum Books.

Amico, A. (2020). Government ownership in the post virus world. Harvard Law School Forum on Corporate Governance. https://corpgov.law.harvard.edu/2020/04/12/governmentownership-in-the-post-virus-world/

Amituanai-Toloa, M. (2009). What is a Pasifika research methodology? The "tupua" in the winds of change. Pacific-Asian Education Journal, 21(2), 45-53.

Amosa, U. (2007). Public sector reform in Tonga: The show must go on. Pacific Economic Bulletin, 22(3), 183-190. 
Amosa, D. (2010). Local government and good governance: The case of Samoa. Commonwealth Journal of Local Governance, (7), 7-21.

Amosa, D. (2012). Social policies in Samoa. London: Commonwealth Secretariat and United Nations Research Institute for Social Development.

Anae, M., Coxon, E., Mara, D., Wendt-Samu, T. \& Finau, C. (2001). Pasifika education research guidelines: Final report. Wellington: Ministry of Education.

Anae, M., Tominiko, F., Fetui, V. \& Lima, I. (2017). Transnational Sāmoan chiefs: Views of the Fa'amatai (Chiefly System). The Journal of Sāmoan Studies, 7(1).

Annan, K. (2009). Governance and values. Speech at the Oslo Center for Peace and Human Rights. https://www.kofiannanfoundation.org/speeches/governance-and-values/.

Ansell, C. \& Torfing, J. (Eds.). (2016). Handbook on theories of governance. Northampton, MA: Edward Elgar Publishing, Inc.

Appleyard, R. \& Stahl, C. (1995). South Pacific migration: New Zealand experience and implications for Australia. Canberra: AusAID International Development, issue no. 2.

Asian Development Bank. [ADB]. 2004. State-Owned enterprise reforms and private sector participation. Manila: ADB.

Asian Development Bank. [ADB] (2009). Finding balance: Making state-owned enterprises work in Fiji, Samoa, and Tonga. NSW: Pacific Liaison and Coordination Office, ADB.

Asian Development Bank. [ADB]. (2011). Asian Development Bank's support for promoting good governance in Pacific developing member countries. Evaluation Study, SES:REG 201141.

Asian Development Bank. [ADB]. (2014). Finding balance 2014: Benchmarking the performance of state-owned enterprises in island countries. Manila: ADB.

Asian Development Bank. [ADB]. (2016a). Finding balance 2016. Benchmarking the performance of state-owned enterprises in island countries. Manila: ADB.

Asian Development Bank. [ADB]. (2016b). Sustained reform agenda can improve stateowned enterprises - ADB Report. https://adbpsdi.org/news-and-insights/newreleases/read/sustained-reform-agenda-can-improve-state-owned-enterprises-adb-report, retrieved March 2020.

Association of Chartered Certified Accountants. (2018). Tenets of good corporate governance. London: ACCA. 
AusAid. [2006]. Anti-corruption and good governance measures. In Inquiry into Australia's aid program in the Pacific, Chapter 5.

https://www.aph.gov.au/Parliamentary_Business/Committees/Joint/Completed_Inquiries/j fadt/pacificaid/report/chapter5.

AusAid. (2007). Approaches to anti-corruption through the Australian aid program lessons from PNG, Indonesia and Solomon Islands. Canberra: AusAid.

Australia Department of Foreign Affairs and Trade [DFAT]. (n.d.). Samoa country brief. https://www.dfat.gov.au/geo/samoa/Pages/samoa-country-brief,

Australia Department of Foreign Affairs and Trade [DFAT]. (n.d.) Tonga country brief. https://www.dfat.gov.au/geo/tonga/Pages/tonga-country-brief.

Ayeni, V. (2001). Public sector reform in developing countries: A handbook of commonwealth experiences. London: Commonwealth Secretariat.

Babbie, E. (2014). The basics of social research. (6th Ed.). Belmont, California: Wadsworth.

Baer, W. (1994). Privatisation in Latin America. In D. Greenway \& J. Whalley (Eds.) The World Economy, 17(4). Oxford, U.K. and Cambridge, U.S.A.

Ball, S. (2007). Education plc: Understanding private sector participation in public sector education. New York: Routledge.

Ball, S. (2011). Academies, policy networks and governance. In H. Gunter (Ed.) The state and education policy: The academies programme. London: Continuum.

Bárcena, A. \& Prado, A. (Eds.). (2016). Neostructuralism and heterodox thinking in Latin America and the Caribbean in the early twenty-first century. Santiago: UN/ECLAC.

Barreca, E. (2019). Accountable compensation: The progressive case for stakeholder-focused, board-empowering executive compensation laws. Yale Law School.

https://digitalcommons.law.yale.edu/cgi/viewcontent.cgi?article=1554\&context=yjreg.

Bebchuk, L. \& Tallarita, R. (2020). The illusory promise of stakeholder governance. Cornell Law Review, 106, 91-178.

Bedford, R. \& Hugo, G. (2012). Population movement in the Pacific: A perspective on future prospects. Wellington: New Zealand Department of Labour.

Benn, S. \& Dunphy, D. (2007). Corporate governance and sustainability: Challenges for theory and practice. UK: Routledge.

Bennett, S., Plant, H. \& Boekweg, M. (2017). Tongan culture.

http://freebooks.uvu.edu/polynesian_culture/05_Tongan_Culture.php. 
Berger, O. \& Luckman, T. (1966). The social construction of reality: A treatise in the sociology of knowledge. London: Penguin.

Berle, A. \& Means, G. (1932). The modern corporation and private property. New York: Commerce Clearing House.

Berle, A. \& Means, G. (1967). The modern corporation and private property. (2nd Ed.). New York: Harcourt, Brace and World.

Bernier, L. (2015). Public enterprises today: Missions, performance and governance. Brussels: Peter Lang S.A.

Bernier, L., Florio, M. \& Bance, P. (Eds.). (2020). The Routledge handbook of state-owned enterprises. Oxon and New York: Routledge.

Bertram, G. \& Watters, R. (1985). The MIRAB economy in South Pacific microstates. Pacific Viewpoint, 26(3), 497-519.

Bertram, G. (1986). Sustainable development in South Pacific micro-economies. World Development, 14, 809-822.

Bertram, G. (1993). Sustainability, aid, and material welfare in small Pacific island economies, 1900-1990. World Development, 21(2):247-258.

Bertram, G. (2015). Sovereignty and material welfare in small island jurisdictions. In A region in transition: Politics and power in the Pacific Islands, 391-435. Saarbrucken University Press.

Bevir, M. (2007). Encyclopedia of governance. Thousand Oaks, Calif.: Sage Publications.

Bevir, M. (2009). Key concepts in governance. Los Angeles, Calif.: Sage Publications.

Bevir, M. (2012). Governance: A very short introduction. Oxford: Oxford University Press.

Bevir, M. (2013). A theory of governance. UC Berkeley: Gaia Books.

Bowen, H. (1953). Social responsibilities of the businessman. New York: Harper.

Bowen, W. (2008). The board book: An insider's guide for directors and trustees. New York \& London: W.W. Norton \& Company.

Breda, V. (2019). Samoa: Constitutional governance and customary law. Comparative Law Journal of the Pacific, 23, 163-180.

Briggs, C. (1986). Learning how to ask: A sociolinguistic appraisal of the role of the interview in social science research. Cambridge: Cambridge University Press. 
Brown, R., Connell, J., \& Jimenez-Soto, E. (2013). Migrants' remittances, poverty and social protection in the South Pacific: Fiji and Tonga. Population, Space and Place, 20(5), 434-454.

Bruce, A., Buck, T. \& Main, B. (2005). Top executive remuneration: A view from Europe. Journal of Management Studies, 42(7), 1493-1506.

Bruton, G., Peng, M. \& Ahlstrom, D. (2015). State-owned enterprises around the world as hybrid organizations. Academy of Management Perspectives, 29(1), 92-114.

Burchell, G., Davidson, A. \& Foucault, M. (2008). The birth of biopolitics: Lectures at the Collège de France, 1978-1979. UK: Palgrave Macmillan.

Bushe, G. (2001). Meaning making in teams: Appreciative inquiry with pre-identity and postidentity groups. In R. Fry, F. Barrett, J. Seiling \& D. Whitney (Eds.) Appreciative inquiry and organizational transformation: Reports from the field, 39-63. Westport, CT: Quorum.

Cadbury Committee [Cadbury Report]. (1992). Report of the committee on the financial aspects of corporate governance. London: Gee.

Campbell, I. (1994). The doctrine of accountability and the unchanging locus of power in Tonga. The Journal of Pacific History, 29(1), 81-94.

Campbell, I. (2005). The quest for constitutional reform in Tonga. The Journal of Pacific History, 40(1), 91-104.

Campbell, I. (2015). Island kingdom: Tonga ancient and modern. ( $3^{\text {rd }}$ Ed.). Christchurch: Canterbury University Press.

Cardinal, L. (2001). What is an indigenous perspective? Canadian Journal of Native Education, 25(1), 180-182.

Carroll, A. (1979). A three-dimensional conceptual model of corporate social performance. Academy of Management Review, 4, 497-505.

Carroll, A. (1991). The pyramid of corporate social responsibility: Toward the moral management of organizational stakeholders. Business Horizons, 34(4), 39-48.

Carroll, A. (2015). Corporate social responsibility: The centerpiece of competing and complementary frameworks. Organizational Dynamics, 44(2), 87-96.

Carroll, A. (2016). Carroll's pyramid of CSR: taking another look. International Journal of Corporate Social Responsibility, 1(3).

Castells, M. (1996). The Rise of the network society. The information age. Economy, society and culture. Oxford: Blackwell. 
Celik, S. \& Blume, D. (2021). New OECD corporate governance reports and the G20/OECD principles of corporate governance. Harvard Law School Forum on Corporate Governance, July 15, 2021.

Center for International Private Enterprise. (2002). Instituting corporate governance in developing, emerging and transitional economies: $A$ handbook. Washington, DC: The Center for International Private Enterprise.

Chen, M.J. (2002). Transcending paradox: The Chinese "middle way" perspective. Asia Pacific Journal of Management, 19, 179-199.

Chen, M.J. (2008). Reconceptualizing the competition-cooperation relationship. A transparadox perspective. Journal of Management Inquiry, 17(4), 288-304.

Chen, M.J. \& Miller, D. (2010). West meets east: Toward an ambicultural approach to management. Academy of Management Perspectives, 24(4), 17-24.

Chen, M.J. \& Miller, D. (2011). The relational perspective as a business mindset: Managerial implications for East and West. Academy of Management Perspectives, 25, 6-18.

Christensen, T. \& Laegreid, P. (2007). The whole-of-government approach to public sector reform. PAR Public Administration Review, 67(6), 1059-1066.

Chwalisz, C. (2017). The people's verdict: Adding informed citizen voices to public decisionmaking. New York: Roman \& Littlefield.

CIA World Factbook. [n.d.]. Samoa. https://www.cia.gov/the-worldfactbook/countries/samoa/\#economy

CIA World Factbook. [n.d.]. Tonga. https://www.cia.gov/the-worldfactbook/countries/tonga/

Clark, G. (2007). Governing finance: Global imperatives and the challenge of reconciling community representation with expertise. Economic Geography, 84, 281-302.

Clark, G., Feldman, M., Gertler, M. \& Wójcik, D. (2018). The New Oxford Handbook of Economic Geography. Oxford, UK.: Oxford University Press.

Clarke, T. (2017). International corporate governance: A comparative approach. ( $2^{\text {nd }}$ Ed.). London; New York: Routledge.

Coffee, J. \& Palia, D. (2016). The wolf at the door: The impact of hedge fund activism on corporate governance. Annals of Corporate Governance, 1(1), 1-94.

Conley, J., Broome, L. \& Krawiec, K. (2012). Narratives of diversity in the corporate boardroom: What corporate insiders say about why diversity matters. In Discourse 
Perspectives on Organizational Communication. Maryland: Fairleigh Dickinson University Press.

Conteh, C. \& Huque, A. (Eds.). (2014). Public sector reforms in developing countries: Paradoxes and practices. London: Routledge.

Cooperrider, D. (1990). Positive image; positive action: The affirmative basis of organization. In S. Srivastva \& D. Cooperrider (Eds.) Appreciative management and leadership, 91-125. San Francisco: Jossey Bass.

Cooperrider, D. \& Srivastva, S. (1987). Appreciative inquiry in organizational life. In Research in organizational change and development, 1, 129-169. Stamford, CT: JAI Press.

Cooperrider, D. \& Whitney, D. (2005). Appreciative inquiry: A positive revolution in change. San Francisco, CA: Berrett-Koehler.

Cooperrider, D. Whitney, D. \& Stavros, J. (2003). Appreciative inquiry handbook. Bedford Heights, OH: Lakeshore Publishers.

Cornforth, C. \& Chambers, N. (2010). The role of corporate governance and boards in organizational performance. In K. Walshe, G. Harvey, \& P. Jas (Eds.) Connecting knowledge and performance in public services: From knowing to doing, 99-127. Cambridge: Cambridge University Press.

Crane, A., Matten, D., McWilliams, A., Moon, J. \& Siegel, D. (Eds.). (2008). The Oxford handbook of corporate social responsibility. Part VI. Oxford: Oxford University Press.

Creary, S., McDonnell, M., Ghai, S. \& Scruggs, J. (2019). When and why diversity improves your board's performance. Harvard Business Review, March 27, 2019.

Currie-Alder, B. (2014). International development: Ideas, experience, and prospects. Oxford: Oxford University Press.

Daiser, P., Ysa, T. \& Schmitt, D. (2017). Corporate governance of state-owned enterprises: A systematic analysis of empirical literature. International Journal of Public Sector Management, 30(5).

Dalton, D., Daily, C., Ellstrand, A. \& Johnson, J. (1998). Meta-Analytic reviews of board composition, leadership structure, and firm performance. Strategic Management Journal. In D. Larcker \& B. Tayan (2019) Loosey-goosey governance: Four misunderstood terms in corporate governance. Rock Center for Corporate Governance at Stanford University Closer Look Series: Topics, Issues and Controversies in Corporate Governance No. CGRP-79.

Das, A. (2019). New governance and neoliberalism. In A. Farazmand (Ed.) Global encyclopedia of public administration, public policy, and governance. Cham: Springer. 
Davis, J., Schoorman, F. \& Donaldson, L. (1997). Toward a stewardship theory of management. The Academy of Management Review, 22(1), 20-47.

Dawes, S. \& Lenormand, M. (Eds.). (2020). Neoliberalism in context governance, subjectivity and knowledge. Cham: Springer International Publishing: Imprint: Palgrave Macmillan.

Degnbol-Martinussen, J. \& Engberg-Pederson, P. (1999). Aid: Understanding international development cooperation. London; New York: Zed Books Ltd.

De La Cruz, A., Medina, A. \& Tang. Y. (2019). Owners of the world's listed companies. Paris: OECD Capital Market Series.

Denhardt, R. \& Denhardt, J. (2000). The new public service: Serving rather than steering. Public Administration Review, 60(6), 549-559.

Denhardt, J. \& Denhardt, R. (2011). (3 ${ }^{\text {rd }}$ Ed.). The new public service: Serving, not steering. Armonk, New York: M.E.

Denzin, N. \& Lincoln, Y. (Eds.). (1994). Handbook of qualitative research. Thousand Oaks, CA: Sage.

Denzin, N. \& Lincoln, Y. (2005). Introduction: The discipline and practice of qualitative research. In N. Denzin \& Y. Lincoln (Eds.) The Sage handbook of qualitative research, 1-33. (3rd Ed.) Thousand Oaks, CA: Sage Publications.

Department for International Development. [DFID]. (2011). Governance portfolio review summary. London, UK: DFID.

Department for International Development. [DFID]. (2017). Economic development strategy: Prosperity, poverty and meeting global challenges. London, UK: Department for International Development [DFID].

Donaldson, T. \& Preston, L. (1995). The stakeholder theory of the modern corporation: Concepts, evidence and implications. Academy of Management Review, 20, 65-91.

DuBois, M. (1991). The governance of the third world: A Foucauldian perspective on power relations in development. Alternatives, 16, 1-30.

Drage, J. (1994). New politics in the South Pacific. Institute of Pacific Studies, University of the South Pacific.

Duncan, R. (2005). A common currency for the Pacific Island economies. In S. Chand (Ed.) Pacific Islands regional integration and governance, 105-118. Canberra: Asia Pacific Press.

Duncan, R. \& Voigt-Graf, C. (2008). Labour market scenarios for the Asian decent work decade in the Pacific Island countries. International Labour Organization Asia-Pacific Working Paper Series. 
Dunleavy, P. \& Hood, C. (1994). From old public administration to new public management. Public Money and Management, 14(3), pp.9-16.

Eccles, R. \& Youmans, T. (2015). Materiality in corporate governance: The statement of significant audiences and materiality. Harvard Business School Working Paper, 16-23.

Edwards, R. (2008). Actively seeking subjects? In A. Fejes \& K. Nicoll (Eds.) Foucault and lifelong learning: Governing the subject. London; New York: Routledge.

Epstein, A., Parkin, J. \& Lamm, R. (2021). The small, young company board. Harvard Law School Forum on Corporate Governance. https://corpgov.law.harvard.edu/2021/07/30/thesmall-young-company-board/, retrieved August 2021.

Escobar, A. (1985). Discourse and power in development: Michel Foucault and the relevance of his work to the third world. Alternatives, 10(3), 377-400.

Evile, M. (2007). The inseparable partnership. In A. So'o (Ed.) Changes in the matai system. O Suiga i le Fa'amatai, 73-82. Apia: Centre for Samoan Studies, National University of Samoa.

Fairclough, A. (1991). Global environmental and natural resource problems - their economic, political and security implications. The Washington Quarterly 14, 81-98.

Fairbairn-Dunlop, P. (2003). Samoan women: Widening choices. Suva, Fiji: University of the South Pacific.

Fama, E. \& Jensen, M. (1983). Separation of ownership and control. Journal of Law and Economics, 26.

Fana'afi, A. (1986). Western Samoa: The sacred covenant, land rights of Pacific women. Suva, Fiji: Institute of Pacific Studies, University of the South Pacific, 103-109.

Farazmand, A. \& Pinkowski, J.(Eds). (2006). Handbook of globalization, governance, and public administration. New York: Routledge.

Farrelly, T. \& Nabobo-Baba, U. (2012). Talanoa as empathic research. Paper for presentation at the International Development Conference 2012 Auckland, New Zealand, 3-5 December, 2012.

Feagaimaali'i-Luamanu, J. (2017). Freedom of religion not threatened: A.G. Samoa Observer 9/6/2017.

Fernando, A. (2012). Business Ethics and Corporate Governance (2 ${ }^{\text {nd }}$ Ed.). India: Pearson.

Financial Markets Authority. (2018). Corporate governance in New Zealand: Principles and guidelines. Wellington; Auckland: FMA. 
Financial Reporting Council. (2018). The UK corporate governance code. London: The Financial Reporting Council Limited.

Financial Reporting Council. (2019). The UK stewardship code 2020. London: The Financial Reporting Council Limited.

Fink, L. (2018). A sense of purpose. Harvard Law School Forum Corporate Governance and Financial Regulation, https://corpgov.law.harvard.edu/2018/01/17/a-sense-of-purpose/

Florio, M. \& Fecher, F. (2011). The future of public enterprises: contributions to a new discourse. Annals of Public and Cooperative Economics, 82(4), 361-373.

Forum for Directors of Indigenous Organisations. (n.d.). Good governance better decisions stronger communities. https://fdio.com.au/.

Foucault, M. (1972). The archaeology of knowledge. (Trans. by A.M.S. Smith). New York: Pantheon Books.

Foucault, M. (1980). In C. Gordon (Ed.) Power/knowledge: Selected interviews and other writings 1972-1977. Brighton, Sussex: Harvester Press.

Foucault, M. (1991). Governmentality. In G. Burchell, C. Gordon, \& P. Miller (Eds.) The Foucault effect: Studies in governmentality, 87-104. Chicago: University of Chicago Press.

Foucault, M. (2008). The Birth of Biopolitics: Lectures at the Collège de France, 1978-79. Edited by M. Senellart; translated from the French by G. Burchell. UK: Palgrave Macmillan. (Originally published by Le Seuil, 2004).

Fréchette, L. (1999). Good governance crucial in global struggle for development and peace says Deputy Secretary-General to World Conference in Manila. UN Press Release. Deputy Secretary-General. Statement. New York: UN Dept. of Public Information, 28 May 1999 World Conference on Governance in Manila, Philippines, on 31 May 1999.

Freeman, R. (1984). Strategic management: A stakeholder approach. Boston: Pitman.

Freeman, R. (1997). A stakeholder theory of the modern corporation. In T. Beauchamp \& N. Bowie (Eds.) Ethical theory and business, 66-76. Prentice-Hall.

Freeman, R. \& Liedtka, J. (1991). Corporate social responsibility: A critical approach. Business Horizons, 34(4), 92-98.

Freeman, R., Harrison, J., Wicks, A., Parmar, B. \& de Colle, S. (2010). Stakeholder theory: The state of the art. Cambridge: Cambridge University Press.

Friedman, M. (1962). Capitalism and freedom. Chicago: University of Chicago Press. 
Friedman, M. (1970). A Friedman doctrine: The social responsibility of business is to increase its profits. The New York Times Magazine, Sept. 13, 1970, 17.

Gatti, M. \& Ondersma, C. (2021). Stakeholder syndrome: Does stakeholderism derail effective protections for weaker constituencies? North Carolina Law Review, forthcoming Rutgers Law School Research Paper No. forthcoming. https://papers.ssrn.com/sol3/papers.cfm?abstract_id=3793732

Gegeo, D. (1998). Indigenous knowledge and epistemology: Rural development examined from within. The Contemporary Pacific, 10(2), 289-315.

Gegeo, D. \& Watson-Gegeo, K. (2001). "How we know": Kwara'ae rural villagers doing indigenous epistemology. The Contemporary Pacific, 13(1), 55-88. http://doi.org/cn3jhz

Gegeo, D \& Watson-Gegeo, K. (2002). Whose knowledge? Epistemological collisions in Solomon Islands community development. The Contemporary Pacific, 14(2), 377-409.

Genesis Energy, (2011). Statement of Corporate Intent 2011/12-2014. Auckland: Genesis Energy Limited, 10. In S. Wong (2018). The state of governance at state-owned enterprises. Public Sector Opinion No. 40. International Finance Corporation, Washington, DC.: World Bank.

Ginting, E. \& Naqvi, K. (2020). Reforms, opportunities, and challenges for state-owned enterprises. Manila: ADB.

Gisselquist, R. (2012). Good governance as a concept, and why this matters for development policy. Working Paper, 30, UNU-WIDER.

Gomez-Mejia, L., Wiseman, R. \& Dykes, B. (2005). Agency problems in diverse contexts: A global perspective. Journal of Management Studies, 42(7), 1507-1517. Wiley Blackwell.

Gountoumas, R. (2016). The hybrid approach: Balancing a corporation's economic desires against its social responsibility. U.C. David Business Law Journal, 17, 197-198.

Government of Tonga. (2016). Budget statement 2016/17. Ministry of Finance and National Planning.

Government of Tonga Ministry of Public Enterprises. (n.d.). mpe.gov.to, retrieved October 2020.

Greany, T. \& Higham, R. (2018). Hierarchy, markets and networks: Analysing the 'selfimproving school-led system' agenda in England and the Implications for Schools. London: UCL IOE Press.

Greene, J. (2014). State-owned enterprises: Justifications, risks, and reform. Presentation at the IMF Fiscal Analysis and Forecasting Workshop Bangkok, Thailand, June 16 - 27, 2014. 
Gregory, R. (2013). Assessing 'good governance' and corruption in New Zealand: 'Scientific' measurement, political discourse, and historical narrative. Victoria University of Wellington Institute For Governance And Policy Studies Working Paper 13/03.

Grindle, M. (2004). Good enough governance: Poverty reduction and reform in developing countries. Governance: An International Journal of Policy, Administration, 17(4), 525-548.

Grindle, M, (2007). Good enough governance revisited. Development Policy Review, 25(5), 533-574.

Grindle, M. (2010). Good governance: The inflation of an idea. HKS Faculty Research Working Paper Series, RWP10-023, John F. Kennedy School of Government, Harvard University.

Grossi, G., Papenfuß, U. \& Tremblay, M. (2015). Corporate governance and accountability of state-owned enterprises. The International Journal of Public Sector Management,28(4/5), 274-285.

Grugel, J. \& Hammett, D. (2016). The Palgrave handbook of international development. London: Palgrave Macmillan UK.

Guba, E. \& Lincoln, Y. (1994). Competing paradigms in qualitative research. In N. Denzin \& Y. Lincoln (Eds.) Handbook of qualitative research, 105-117. London: Sage.

Guba, E. \& Lincoln, Y. (2005). Paradigmatic controversies, contradictions, and emerging confluences. In: N. Denzin \& Y. Lincoln (Eds.) The Sage handbook of qualitative research, 191-215. (3rd Ed.). Thousand Oaks: Sage.

Gubrium, J. \& Holstein, J. (2001). Handbook of interview research. Thousand Oaks: Sage.

Guest, G., MacQueen, K. \& Namey, E. (2012). Applied thematic analysis. Thousand Oaks: Sage.

Gupta, S. Schiller, C. \& Ma, H. (1999). Privatization, social impact, and social safety nets. IMF Working Paper No. 99/68.

Gurtner, B. (2010). The financial and economic crisis and developing countries. Translated by Jacqueline Gartmann. International Development Policy / Revue internationale de politique de développement, 1, 189-213.

Gwynne, R. \& Kay, C. (Eds.). (1999). Latin America transformed: Globalization and modernity. London: Arnold.

Halapua, S. (2008). Talanoa process: The case of Fiji. unpan1.un.org/intradoc/groups/public/documents/UN/UNPAN022610.pdf

Harvey, D. (2005). A brief history of neoliberalism. Oxford: Oxford University Press. 
Hassall, G., Kaitani, M., Mae, P., Tipu, F. \& Wainikesa, L. (2011). Comparative study on local government and traditional governance systems interaction in Pacific Island countries. Background Report on Local Government and Traditional Systems in Pacific Island Countries Governance Program. School of Governance and Development Studies, University of the South Pacific.

Hau'ofa, E. (1992). The social context of the pro-democracy movement in Tonga. Paper presented at the Convention on the Constitution and Democracy in Tonga, Nuku'alofa. planet-tonga.com/HRDMT/Articles/Convention_92/Epeli_Hauofa.shtml.

Helu, I. (1992). Democracy bug bites Tonga. In R. Crocombe, U. Neemia, A. Ravuvu \& W. Busch (Eds.) Culture and democracy in the South Pacific, 139-152. Suva, Fiji: Institute of Pacific Studies, University of the South Pacific.

Henry, K. \& Kiel, G. (2004). The role of the board in firm strategy: Integrating agency and organisational control perspectives. Corporate Governance, 12(4), 500-520.

Hood, C. (1991). A public management for all seasons? Public Administration, 69(1), 3-19.

Hood, C. \& Jackson, M. (1991). The new public management: A recipe for disaster. Canberra Bulletin of Public Administration, 64, 16-24.

Huffer, E. \& So'o, A. (2000) (Eds.). Governance in Samoa pulega i Samoa. Asia Pacific Press.

Huffer, E. \& So'o, A. (2005). Beyond governance in Samoa: Understanding Samoan political thought. The Contemporary Pacific, 17(2), 311-333. University of Hawai'I Press.

Hughes, H. (2003) Aid has failed the Pacific. Centre for Independent Studies. IA33.

lati, I. (2000). The good governance agenda for civil society: Implications for the fa'a Samoa. In E. Huffer \& A. So'o (Eds.) Governance in Samoa, 67-77. Asia Pacific Press.

Indreswari, M. (2006). Corporate governance in the Indonesian state-owned enterprises: A thesis presented in fulfilment of the requirements for the degree of Doctor of Philosophy in Development Studies at Massey University, Palmerston North, New Zealand.

Ireland, P. (2005). Shareholder primacy and the distribution of wealth. The Modern Law Review, 68(1), 49-81.

Jensen, M. \& Meckling, W. (1976). Theory of the firm: managerial behavior, agency costs and ownership structure. Journal of Financial Economics, 3(4), 305-360.

Jessop B. (2011). Metagovernance. In M. Bevir (Ed.) The Sage handbook of governance. Thousand Oaks, CA; London: Sage, 106-123. 
Jimenez-Soto, E. \& Brown, R. (2012). Assessing the poverty impacts of migrants' remittances using propensity score matching: The case of Tonga. Economic Record, 88(282), 425-439.

Jordana, J. \& Levi-Faur, D. (Eds.). (2004). The politics of regulation: Institutions and regulatory reforms for the governance age. Cheltenham: Edward Elgar.

Joseph, R. (2014). Indigenous peoples' good governance, human rights and selfdetermination in the second decade of the new millennium - A Māori perspective. Address to the United Nations Permanent Forum on Indigenous Issues, Thirteenth Session on Good Governance and Human Rights, New York, 12-23 May 2014. Māori Law Review, December 2014.

Ka'ili, T. (2005). Tauhi vä: Nurturing Tongan sociospatial ties in Maui and beyond. The Contemporary Pacific, 17(1), 83-114.

Karnani, A. (2019). The case against corporate social responsibility. Wall Street Journal, 23(14), 1-5.

Kaufmann, D., Kraay, A. \& Zoido-Lobaton, P. (1999). Governance matters. World Bank Policy Research Working Paper, 2196. Washington: The World Bank.

Kaufmann, D., Kraay, A. \& Mastruzzi, M. (2009). Governance matters VIII: Aggregate and individual governance indicators 1996-2008. Policy Research Working Paper 4978, World Bank.

Kay, J. \& Silberstone, A. (1995). Corporate governance. National Institute Economic Review, 153, 84-107. Cambridge: Cambridge University Press.

Keasey, K., Short, H. \& Wright, M. (2005). The development of corporate governance codes in the UK. In K. Keasey, S. Thompson \& M. Wright, Corporate governance: Accountability, enterprise and international comparisons, 21-45. New York: John Wiley and Sons.

Kennedy, A. (2000). The end of shareholder value. RSA Journal 148, 50-53.

Kerslake, M. (2004) Aspects which contribute to the creation of wealth and poverty within the family setting. Report to National University of Samoa Research Committee. [NUS]: Apia.

Klijn, E., Van Buuren, A. \& Edelenbos, J. (2012). The impact of governance: A normative and empirical discussion. In D. Levi-Faur (Ed.) The Oxford handbook of governance. Oxford: Oxford University of Press.

Kinyondo, A. \& Pelizzo, R. (2013). Strengthening legislatures: Some lessons from the Pacific region. Politics \& Policy, 41(3), 420-446.

KiwiRail. (2017). Compliance as a statutory corporation. In S. Wong (2018). The state of governance at state-owned enterprises, 11. Public Sector Opinion No. 40. International Finance Corporation, Washington, DC.: World Bank. 
Kjaer, A. (2004). Governance. Cambridge: Polity Press.

Knack, S. (2001). Aid dependence and the quality of governance: cross-country empirical tests. Southern Economic Journal, 68(2), 310-29.

Kooiman, J. \& Jentoft, S. (2009). Meta-governance: Values, norms and principles, and the making of hard choices. Public Administration, 87(4), 818-836.

Koslowski, P. (2000). The limits of shareholder value. Journal of Business Ethics, 27, 137-148

Krause, R., Semadeni, M. \& Cannella Jr, A. (2013). CEO duality: A review and research agenda. In D. Larcker \& B. Tayan. (2019). Loosey-goosey governance: Four misunderstood terms in corporate governance. Rock Center for Corporate Governance at Stanford University Closer Look Series: Topics, Issues and Controversies in Corporate Governance No. CGRP-79.

Kvale, S. (2007). Doing interviews. Thousand Oaks: Sage Publications.

Laking, R. (2012). State-owned enterprises. Te Ara: The Encyclopedia of New Zealand. http://www.TeAra.govt.nz/en/state-owned-enterprises.

Lange, D. (1990). Business biting hand of nanny govt. The National Business Review, 24.7 March.

Larcker, D. \& Tayan, B. (2019). Loosey-goosey governance: Four misunderstood terms in corporate governance. Rock Center for Corporate Governance at Stanford University Closer Look Series: Topics, Issues and Controversies in Corporate Governance No. CGRP-79.

Larmour, P. (1998). Making sense of good governance. In Research School of Pacific and Asian Studies (Ed.) State, society and governance in Melanesia Discussion Paper. Canberra: Australian National University.

Larmour, P. (2005). Foreign flower: Institutional transfer and good governance in the Pacific islands. Honolulu: University of Hawaii Press.

Larmour, P. (2012). Interpreting corruption: Culture and politics in the Pacific Islands. Honolulu: University of Hawaii Press.

Latai, L. (2015). Changing covenants in Samoa? From brothers and sisters to husbands and wives? Oceania, 85(1), 92-104.

Lateef, K. (2016). Evolution of the World Bank's thinking on governance. World Development Report Background Paper. Washington, DC.: World Bank.

Latukefu, S. (1993). The pro-democracy movement in Tonga. Journal of Pacific History, 28(3), 52. 
Lee H. (2007). Transforming transnationalism: Second generation Tongans overseas. Asian and Pacific Migration Journal, 16(2), 157-178.

Legislative Assembly of Tonga. (n.d.). About our parliament.

https://parliament.gov.to/about-our-parliament.

Leiva, F. (2008). Toward a critique of Latin American neostructuralism. Latin American Politics and Society, 50(4), 1-25.

Lessambo F. (2014). Corporate governance in Japan. In The international corporate governance system. Global financial markets series. London: Palgrave Macmillan.

Levi-Faur, D. (2012). From "big government" to "big governance"? In The Oxford handbook of governance, Oxford Handbooks Online.

DOI: 10.1093/oxfordhb/9780199560530.013.0001

Levy, D. \& Kaplan, R. (2008). Corporate social responsibility and theories of global governance: Strategic contestation in global issue arenas. In A. Crane, D. Matten, A. McWilliams, J. Moon, \& D. Siegel (Eds.), The Oxford Handbook of Corporate Social Responsibility. Part VI. Oxford: Oxford University Press.

Lewis-Beck, M., Bryman, A. \& Liao, T. (2004). (Eds.). The Sage encyclopedia of social science research. Thousand Oaks: Sage.

Licht, A. (2001). The mother of all path dependencies toward a cross-cultural theory of corporate governance systems. https://ssrn.com/abstract=266910.

Lieberman, I. (2018). In good times prepare for crisis: From the great depression to the great recession: Sovereign debt crises and their resolution. Washington, DC.: Brookings Institution Press.

Lipton, M. (2016). The new paradigm. A Roadmap for an implicit corporate governance partnership between corporations and investors to achieve sustainable long-term investment and growth. International Business Council of the World Economic Forum.

Lipton, M. (2017). Corporate governance: The new paradigm. Harvard Law School Forum on Corporate Governance. https://corpgov.law.harvard.edu/.

Lipton, M. (2018). Some thoughts for boards of directors in 2019. The Harvard Law School Forum. Friday, December 14, 2018. https://corpgov.law.harvard.edu/2018/12/14/somethoughts-for-boards-of-directors-in-2019/.

Lipton, M. \& Savitt, W. (2019). The new paradigm. Harvard Law School Forum on Corporate Governance. https://corpgov.law.harvard.edu/2019/10/28/the-new-paradigm/. 
Lipton, M. \& Steinberger, E. (1978). Takeovers and freezeouts. Law Journal Seminars Press, 1(1). New York.

Lipton, M., Rosenblum, S., Niles, S., Lewis, S. \& Watanabe, K. In coordination with M. Drexler, World Economic Forum. (2016). The new paradigm. A roadmap for an implicit corporate governance partnership between corporations and investors to achieve sustainable long-term investment and growth. International Business Council Of The World Economic Forum.

Lynch, R. (2011). Foucault's theory of power. London; New York: Routledge.

Lysandrou, P. (2011). Global inequality, wealth concentration and the subprime crisis: A Marxian commodity theory analysis. Development and Change, 42(1).

McLellan, N. (2008). Seasonal workers for Australia - Lessons from New Zealand. Farm Policy Journal, 5(3), 43-53.

McCourt, W. (2013). Models of public service reform: A problem-solving approach. Policy Research Working Paper, No. 6428. Washington D.C: The World Bank.

Macdonald, B. (1998). Good governance and Pacific Island states. In P. Larmour (Ed.) Governance and reform in the South Pacific, 21-53. Canberra: The Australian National University.

McGillivray, M., Poppelwell, E. Niemi, M., Salong, J. \& Vira, J. (2017). Evaluation of New Zealand's Aid Programme in Vanuatu. Report prepared for the NZ Ministry of Foreign Affairs and Trade. Wellington, NZ: Sapere Research Group.

McGillivray, M., Poppelwell, E., Cribbens, N., Kiddle, L. \& Taumoefolau, F. (2018). Evaluation of MFAT's Partnerships Fund. Report prepared for the NZ Ministry of Foreign Affairs and Trade. Wellington, NZ: Sapere Research Group.

McLeod, A. (2008). Leadership models in the Pacific. ANU Research School of Pacific and Asian Studies Discussion Paper 2008/6.

McNay, L. (1994). Foucault: A critical introduction. Cambridge: Polity Press.

Macpherson, C. (1999). Changing contours of kinship: The impacts of social and economic development on kinship organization in the South Pacific. Pacific Studies 22(2), 71-95.

Macpherson, C. \& Macpherson, L. (2009). The warm winds of change. Globalisation in contemporary Samoa. Auckland: Auckland University Press.

Macpherson, C. \& Macpherson, L. (2011). Churches and the economy of Sāmoa. The Contemporary Pacific, 23(2), 303-338. University of Hawaii Press. 
McWilliams, A. \& Siegel, D. (2001). Corporate social responsibility: A theory of the firm perspective. Academy of Management Review, 26, 117- 27.

Maldonado, N. (2010). The World Bank's evolving concept of good governance and its impact on human rights. Doctoral workshop on development and international organizations. Stockholm, Sweden, May 29-30, 2010.

Malielegaoi, T. (2017). Pālemia: Prime minister Tuila'epa Sa'ilele Malielegaoi of Samoa: A memoir. With P. Swain. Wellington: Victoria University Press.

Meyer, M. (1998). Native Hawaiian epistemology: Sites of empowerment and resistance. Equity \& Excellence in Education, 31(1), 22-28.

Mallin, C. (2011). Corporate governance developments in the UK. In C. Mallin (Ed.) Handbook on international corporate governance: Country analyses. Edward Elgar Publishing. (2 ${ }^{\text {nd }} E d$.).

Mallin, C. (2018). Corporate governance. Oxford: Oxford University Press. (6th Ed).

Mansbach, R. \& Taylor, K. (2018). Introduction to global politics. London: Routledge.

Marglin, F. \& Marglin, S. (Eds.). (1990). Dominating knowledge: Development, culture \& resistance. Oxford: Clarendon Press.

Mbele, N. (2015). Corporate governance in state-owned enterprises. Submitted in accordance with the requirement for degree of Doctor of Philosophy. University of the Witwatersrand, Johannesburg.

Meleisea, M. (1987). The making of modern Samoa: Traditional authority and colonial administration in the history of Western Samoa. [Suva, Fiji]: Institute of Pacific Studies of the University of the South Pacific.

Meleisea, M. (1988). Seeds of change: Political development in Western Samoa. Macmillan Brown Lectures, University of Canterbury, Christchurch.

Meleisea, M. (2000). Governance, development and leadership in Polynesia: A microstudy from Samoa. In E. Huffer \& A. So'o (Eds.) Governance in Samoa pulega i Samoa. Asia Pacific Press.

Meleisea, M., Schoeffel-Meleisea, P. \& Meleisea, E. (2012). Samoa's journey 1962-2012: Aspects of history. Wellington: Victoria University Press.

Mellor, T. \& Jabes, J. (2004). Governance in the Pacific: Focus for action 2005-2009. Manila: Asian Development Bank. 
Metuamate, A. (2019). Kingship and kinship: The house of Tupou, democracy and transnationalism in Tonga. A thesis submitted for the degree of Doctor of Philosophy of The Australian National University.

Meuleman, L. (2011). Metagovernance. In B. Badie, D. Berg-Schlosser \& L. Morlino (Eds.) International encyclopedia of political science, 1555-1557. Sage Publications Inc. 155https://www.doi.org/10.4135/9781412959636.n355

Miles, J. (2012). Management and organization theory: A Jossey-Bass reader. Hoboken: Jossey-Bass.

Milner, G. (1966). Samoan dictionary. New Zealand: Polynesian Press.

Ministry of Foreign Affairs and Trade [MFAT]. (n.d.). Samoa.

https://www.mfat.govt.nz/en/countries-and-regions/australia-and-pacific/samoa/, retrieved March 2020

Ministry of Foreign Affairs and Trade [MFAT]. (n.d.). Our development cooperation with Samoa. https://www.mfat.govt.nz/assets/Aid-Prog-docs/IATI-PDFs/PACPF/OurDevelopment-Cooperation-Samoa.pdf, retrieved May 2021.

Ministry of Foreign Affairs and Trade [MFAT]. (n.d.). Our development cooperation with Tonga.https://www.mfat.govt.nz/assets/Aid-Prog-docs/IATI-PDFs/PACPF/Tonga.pdf, retrieved May 2021.

Ministry of Foreign Affairs and Trade [MFAT]. (2020). Briefing for incoming Minister of Foreign Affairs. NZ MFAT.

Minogue, M., Polidano, C. \& Hulme, D. (1998). Beyond the new public management: Changing ideas and practices in governance. In New horizons in public policy. Cheltenham: Edward Elgar Publishing.

Moimoi Steen, T. \& Drescher, N. (2011). Tonga - Land, see, people. Tonga: Tonga Research Association.

Moir, L. (2001). What do we mean by corporate social responsibility? Corporate Governance, 1(2), 16-22.

Morck, R. (Ed.). (2005). A history of corporate governance around the world: Family business groups to professional managers. Chicago: The University of Chicago Press.

Morse, J. (2000). Determining sample size. Qualitative Health Research, 10(1), 3-5. Sage Publications, Inc.

Morton, H. (1996). Becoming Tongan: An ethnography of childhood. Honolulu: University of Hawaii Press. 
Murray, W. \& Overton, J. (2011a). Neoliberalism is dead, long live neoliberalism? Neostructuralism and the international aid regime of the 2000s. Progress in Development Studies, 11(4), 307-19.

Murray, W. \& Overton, J. (2011b). The inverse sovereignty effect: Aid, scale and neostructuralism in Oceania. Asia Pacific Viewpoint, 52(3).

Musacchio, A. \& Ayerbe, E. (Eds.). (2019). Fixing state-owned enterprises new policy solutions to old problems. Washington, D.C.: IDB.

Namoga, M. (2011). Corporate governance and board performance: Empirical evidence from Pacific Island countries. PhD thesis, James Cook University.

Nederveen Pieterse, J. (2004). Globalization or empire? London; New York: Routledge.

Nederveen Pieterse, J. (2010). Development theory: Deconstructions/reconstructions. (2 ${ }^{\text {nd }}$ Ed.). Los Angeles; London: Sage.

Nestor, S. (2018). Corporate governance 2030: Thoughts on the future of corporate governance. Harvard Law School Forum Corporate Governance and Financial Regulation.

Newman, J. \& Clarke, J. (2009). Public, politics and power: Remaking the public in public services. London: Sage.

New Zealand Law Commission. (2006). Waka Umanga: A proposed law for Māori governance entities. Wellington: New Zealand Law Commission.

New Zealand Office of the Auditor-General. (2014). Maintaining a future focus in governing crown-owned companies. Wellington: OAG.

Nguyen, P., Kecskés, A. \& Mansib, S. (2020). Does corporate social responsibility create shareholder value? The importance of long-term investors. Journal of Banking and Finance, 112.

Nicholson, A., Spiller, C. \& Pio, E. (2019). Ambicultural governance: Harmonizing indigenous and western approaches. Journal of Management Inquiry, 28(1) 31-47.

Nordberg, D. \& Booth, R. (2019). Evaluating the effectiveness of corporate boards. Corporate Governance, 19(2), 372-387.

Nunberg, B. \& Nellis, J. (1995). Civil service reform and the World Bank. World Bank Discussion Paper No. 161. World Bank.

Observatory of Economic Complexity. (n.d.) Tonga profile.

https://oec.world/en/profile/country/ton/.

Office of the Registrar of Indigenous Corporations. (n.d.). Corporate governance.

https://www.oric.gov.au/run-corporation/corporate-governance, retrieved October 2020. 
O'Kelley, R. \& Martin, M. (2017). Global and regional trends in corporate governance for 2018. Harvard Law School Forum on Corporate Governance.

https://corpgov.law.harvard.edu/2017/12/29/global-and-regional-trends-in-corporategovernance-for-2018/.

O'Kelley, R., Goodman, A. \& Martin, M. (2018). 2019 global and regional trends in corporate governance. Harvard Law School Forum Corporate Governance and Financial Regulation, https://corpgov.law.harvard.edu/2018/12/30/2019-global-regional-trends-in-corporategovernance/.

Organisation for Economic Co-operation and Development. (2005). Publication of public institutional reforms, OECD comparative report. Paris: OECD.

Organization of Economic Cooperation and Development. (2006). DAC guidelines and reference series applying strategic environmental assessment: Good practice guidance for development co-operation. Paris: OECD.

Organization of Economic Cooperation and Development. (2015a). The G20/OECD principles of corporate governance. Paris: OECD.

Organization of Economic Cooperation and Development. (2015b). OECD guidelines on corporate governance of state-owned enterprises. Paris: OECD.

Organization of Economic Cooperation and Development. (2015c). The Working Party on state ownership and privatisation practices. Board of directors of state-owned enterprises: An overview of national practice. Paris: OECD.

Organization of Economic Cooperation and Development. (2016). Global knowledge sharing network on corporate governance of state-owned enterprises. Paris: OECD.

Organization of Economic Cooperation and Development. (2018a). Board evaluation: Overview of international practices. Paris: OECD.

Organization of Economic Cooperation and Development. (2018b). State-owned enterprises and corruption: What are the risks and what can be done? Paris: OECD.

Organization of Economic Cooperation and Development. [2020]. Innovative citizen participation and new democratic institutions. Catching the deliberative wave: Highlights 2020. Paris: OECD.

Organization of Economic Cooperation and Development. (2021). The future of corporate governance in capital markets following the COVID-19 crisis. Paris: OECD.

Orlegge, W. (2005). Public enterprises in Papua New Guinea: The need for strategic management. Pacific Economic Bulletin, 20(1), 162-167. 
Osborne, S. (2006). The new public governance? Public Management Review, 8(3), 377-387.

Otsuka, S. (2006). Talanoa research: Culturally appropriate research design in Fiji. In the Proceedings of the Australian Association for Research in Education (AARE) 2005 International Education Research Conference: Creative Dissent-Constructive Solutions [OnLine]. Melbourne, Australia: AARE.

Overton, J. \& Murray, W. (2016). Aid and the 'circle of security'. In J. Grugel \& D. Hammett (Eds.) The Palgrave Handbook of International Development. London: Macmillan.

Page, S. (2007). The difference: How the power of diversity creates better groups, firms, schools and societies. Princeton, N.J.: Princeton University Press.

Pacific Islands Forum Secretariat. (2014). Samoa forum compact peer review report. Suva, Fiji: PIF.

Paine, L. (2020). Covid-19 is rewriting the rules of corporate governance. Harvard Business Review, 6 October, 2020.

Pande, S. (2011). The theoretical framework for corporate governance. SSRN Electronic Journal, http://ssrn.com/abstract=1949615

Pateman, C. (1970). Participation and democratic theory. Cambridge: Cambridge University Press.

Patterson, J. (2001). Corporate governance, the limits of rationality and proceduralisation. ESRC Centre for Business Research, University of Cambridge, Working Paper No. 198.

Pollitt, C. \& Bouckaert, G. (2004). Public management reform: A comparative analysis. Oxford: Oxford University Press.

Poirine, B. (1998). Should we hate or love MIRAB? The Contemporary Pacific, 10, 65-105. University of Hawai'i Press.

Pollock, A., Roderick, P., Cheng, K. \& Pankhania, B. (2020). Covid-19: Why is the UK government ignoring WHO's advice? BMJ [Internet], 368.

https://www.bmj.com/content/368/bmj.m1284.

Powles, G. (2009), Testing tradition in Tonga: Approaches to constitutional change. Victoria: Monash University.

Powles, G. (2014). The Tongan monarchy and the constitution: Political reform in a traditional context. Australian National University, SSGM Discussion paper 2014/9.

Pratt, R. (1984). Pratt's grammar and dictionary Samoan-English, English Samoan. Auckland: McMillan: 
Prescott, S. (2008). Using talanoa in Pacific business research in New Zealand: Experiences with Tongan entrepreneurs. AlterNative: An International Journal of Indigenous Peoples, 4(1), 127-148. Sage.

Preskill, H. \& Grindle, H. (2015). Guide to appreciative inquiry. FSG reimaging social change. www.click4it.org/images/f/f5/Guide_to_Appreciative_Inquiry_(003).pdf.

PricewaterhouseCoopers. [PWC]. (2015). State-owned enterprises: Catalysts for public value creation? www.psrc.pwc.com.

Pacific Private Sector Development Initiative (PSDI). (2017). Tonga becomes first Pacific country to publish detailed SOE performance results online. 19 May 2017. https://adbpsdi.org/news-and-insights/news/read/tonga-becomes-first-pacific-country-topublish-detailed-soe-performance-results-online.

Rabinow, P. (Ed.). (1991). The Foucault reader: An introduction to Foucault's thought. London: Penguin.

Radio New Zealand [RNZ]. (2016). State-owned-firms draining pacific economies: ADB. https://www.rnz.co.nz/international/pacific-news/308983/state-owned-firms-drainingpacific-economies-adb. [Interview with Christopher Russell].

Radio New Zealand [RNZ]. (2017). First Pacific Island to publish state-owned enterprises online.https://www.radionz.co.nz/international/programmes/datelinepacific/audio/201841 021/first-pacific-island-to-publish-state-owned-enterprises-online [interview with Christopher Russell, ASB].

Radio New Zealand [RNZ]. (2019). Marshall Islands step up state owned enterprise reform. https://www.rnz.co.nz/international/pacific-news/379535/marshall-islands-steps-up-stateowned-enterprise-reform.

Ransom, J. (1997). Foucault's discipline: The politics of subjectivity. Durham: Duke University Press.

Reynolds, M. (2016). Relating to Va: Re-viewing the concept of relationships in Pasifika education in Aotearoa New Zealand. AlterNative: An International Journal of Indigenous Peoples, 12(2), 190-202. http://doi.org/c6k9.

Rhodes, R. (1997). Understanding governance: Policy networks, governance, reflexivity and accountability. Buckingham: Open University Press.

Roberts, S., Wright, S. \& O'Neill, P. (2007). Good governance in the Pacific? Ambivalence and possibility. Geoforum, 38, 967-984.

Robinson, M. (2015). From old public administration to the new public service implications for public sector reform in developing countries. Singapore: UNDP Global Centre for Public Service Excellence. 
Roll, M. (Ed.). (2014). The politics of public sector performance: Pockets of effectiveness in developing countries. London: Routledge.

Rossouw, G. \& Sison, A. (Eds.). (2006). Global perspectives on ethics of corporate governance. New York: Palgrave Macmillan.

Saldanha, C. (2004). Strategies for good governance in the Pacific. Austral Foundation.

Samoa Bureau of Statistics. (n.d.). Economics. https://www.sbs.gov.ws/economics, retrieved September 2020.

Samoa Bureau of Statistics. (n.d.). Population and demography.

https://www.sbs.gov.ws/populationanddemography, retrieved September 2020.

Samoa Bureau of Statistics. (2019a). Primary education.

https://www.sbs.gov.ws/images/sbs-documents/social/education/Primary.pdf, retrieved September 2020.

Samoa Bureau of Statistics. (2019b). Secondary education.

https://www.sbs.gov.ws/images/sbs-documents/social/education/Secondary.pdf, retrieved May 2021.

Samoa Observer. (8 May 2015). Four state owned enterprises (S.O.E) are up for privatisation. http://www.pireport.org/articles/2015/05/12/state-owned-enterprises-samoa-slatedprivatization.htm.

Samoa Observer. (2 February 2016). Directors reminded about accountability. http://www.sobserver.ws/en/02_02_2016/local/1917/Directors-reminded-aboutaccountability.htm.

Samoa Observer. (10 June 2016). Leadership tackles good governance.

http://www.samoaobserver.ws/en/10_06_2016/local/7228/Leadership-tackles-goodgovernance.htm.

Samoa Observer. (12 May 2017). Airport G.M. says $\$ 22,500$ as chairman's fee "is peanuts". http://www.sobserver.ws/en/12_05_2017/local/19892/Airport-GM-says-\$22500-asChairman\%E2\%80\%99s-fee-\%E2\%80\%9Cis-peanuts\%E2\%80\%99\%E2\%80\%99.htm

Samoa Observer (13 May 2017). Letter to the editor http://www.samoaobserver.ws/en/13_05_2017/letterstotheeditor/19938/Boards-andtheir-payments.htm.

Samoa Observer (8 October 2017) Good governance in sight for future leaders. http://www.samoaobserver.ws/en/27_10_2017/local/25943/Good-governance-in-sight-forfuture-leaders.htm. 
Samoa Observer (12 February 2018). Directors reminded about accountability. http://www.samoaobserver.ws/en/02_02_2016/local/1917/Directors-reminded-aboutaccountability.htm.

Samoa Observer (10 July 2018). Board members' qualifications in spotlight http://www.samoaobserver.ws/en/10_07_2018/local/34872/Board-members\%E2\%80\%99qualifications-in-spotlight.htm.

Samoa Observer. (15 July 2018). Minister Lautafi defends board appointments. http://sobserver.ws/en/15_07_2018/local/35025/Minister-Lautafi-defends-Boardappointments.htm.

Samoa Observer (14 August 2018) Audit queries $\$ 25,000$ Christmas gifts. http://www.sobserver.ws/en/14_08_2018/local/35880/Audit-queries-\$25000-Christmasgifts.htm.

Sampford, C. \& Connors, C. (Eds.). (2006). World ethics forum conference proceedings. The Joint Conference of The International Institute for Public Ethics (IIPE) and The World Bank Leadership, Ethics and Integrity in Public Life 9-11 April 2006, Keble College, University of Oxford, UK.

Sanga, K. (2004). Making philosophical sense of indigenous Pacific research. In T. Baba, 'O. Mahina, \& Y. Williams. Researching Pacific and Indigenous peoples: Issues and perspectives. Auckland: University of Auckland.

Sarwar. L. (2016). Evolution of the World Bank's thinking on governance. World Development Report Background Paper. Washington, D.C.: World Bank.

Schwarting, G. (2013). Public corporate governance codes: Necessary but successful too? Administrative Culture, 14(1), 145-157.

Sen, A. (1987). On ethics and economics. Oxford, UK: Basil Blackwell.

Sen, A. (1999). Development as freedom. New York, NY: Alfred A. Knopf.

Shamir, R. (2010). Capitalism, governance, and authority: The case of corporate social responsibility. Annual Review of Law and Social Science, 18 May 2010.

Shleifer, A. \& Vishny, R. (1997). A survey of corporate governance. The Journal of Finance. Volume, 52(2), 737-783.

Siauane, L. (2004). Fa'aSamoa: A look at the evolution of the fa'aSamoa in Christchurch. A thesis submitted in fulfilment of the requirement for the degree of Masters of Arts in Pacific Studies at the University of Canterbury Christchurch New Zealand. 
Siems, M. \& Alvarez-Macotela, O. (2017). The G20/OECD principles of corporate governance 2015: a critical assessment of their operation and impact. Journal of Business Law, (4), 310328.

Simons, M. \& Masschelein, J. (2008). Our 'will to learn' and our assemblage of a learning apparatus. In A. Fejes and K. Nicoll (Eds.) Foucault and lifelong learning: Governing the subject, Chapter 4. London; New York: Routledge.

Small, C. \& Dixon, D. (2004). Country profiles - Tonga: Migration and the homeland. Washington, DC.: Migration Policy Institute.

Smith, L. (1999). Decolonizing methodologies: Research and indigenous peoples. London: Zed Books.

Spiller, C. \& Nicholson, A. (2017). Wakatu incorporation: Balancing kaitiaki stewardship and commerce. In SAGE business cases. Sage.

Stiglitz, J. (1998). Redefining the role of the state: What should it do? How should I do it? And how should these decisions be made? Presented on the Tenth Anniversary of MITI Research Institute (Tokyo, Japan) March 17, 1998.

Stiles, P. \& Taylor, B. (1993). Benchmarking corporate governance: The impact of the Cadbury Code. Long Range Planning, 26(5), 61-71.

Stiles, P. \& Taylor, B. (2001). Boards at work. Oxford: Oxford University Press.

Stout, L. (2012). The shareholder value myth: How putting shareholders first harms investors, corporations and the public. San Francisco: Berrett-Koehler.

Sundaram, J. (2015). Does good governance always boost development? World Economic Forum, 25 June 2015. https://www.weforum.org/agenda/2015/06/does-good-governancealways-boost-development/.

Syrett, S. \& Bertotti, M. (2012). Reconsidering private sector engagement in subnational economic governance. Environment and Planning A, 44(10), 2310-2326.

https://doi.org/10.1068/a44675

Talbani, A. (1996). Pedagogy, power and discourse: Transformation of Islamic education. Comparative Education Review, 40, 66-82.

Talesh, S. (2016). Public law and regulatory theory. In C. Ansell \& J. Torfing (Eds.) Handbook on theories of governance. Berkeley: University of California.

Tavana, N. (2002). Traditional knowledge is the key to sustainable development in Samoa: Examples of ecological, botanical and taxonomical knowledge. Proceedings of the 2001 National Environmental Forum. 3, 19-261. Apia: Ministry of Natural Resources and Environment. 
Thaman, K. (1997). Reclaiming a place: Towards a Pacific concept of education for cultural development. The Journal of the Polynesian Society, 106(2), 119-130.

Thornton, A., Kerslake, M. \& Binns. T. (2010). Alienation and obligation: Religion and social change in Samoa. Asia Pacific Viewpoint, 51(1), 1-16.

Thyil, V. \& Young, S. (2010). An empirical investigation of hybrid corporate governance systems in large firms: Evidence from India. In Proceedings of the International Federation of Scholarly Associations of Management World Congress: Justice and Sustainability in the Global Economy. [Paris, France]: IFSAM, 1-21.

Tricker, R. (2009). Corporate governance: Principles, policies, and practices. Oxford: Oxford University Press.

Tuagalu, I. (2008). Heuristics of the vä. AlterNative: An International Journal of Indigenous Peoples, 4(1), 107-126.

Tualaulelei, E. \& McFall-McCaffery, J. (2019). The pacific research paradigm: Opportunities and challenges. MAl Journal, A New Zealand Journal of Indigenous Scholarship, 8(2).

Turner, M. \& Hulme, D. (1997). Governance, administration and development. London: Macmillan.

Underhill-Sem, Y. \& Marsters, E. (2017). Labour mobility in the Pacific: A systematic literature review of development impacts. Auckland: New Zealand Institute for Pacific Research, [University of Auckland].

Ungureanu, M. (2012). Models and practices of corporate governance worldwide. CES Working Papers, Centre for European Studies, Alexandru loan Cuza University, 4(3), 625-635.

United Nations \& Economic Commission for Latin America and the Caribbean. [UNECLAC]. (1990). Changing production patterns with social equity: The prime task of Latin American and Caribbean development in the 1990s. Santiago: UN: Economic Commission for Latin America and the Caribbean.

United Nations Department of Economic and Social Affairs \& United Nations Development Programme. (2012). UN system task team on the post-2015 UN development agenda: Governance and development: Thematic think piece. [New York]: UNDESA, UNDP, UNESCO.

United Nations Development Programme [UNDP]. (1995). Public sector management, governance and sustainable human development. Discussion Paper. New York: UNDP.

United Nations Development Programme (UNDP). (2015). Old Public Administration to the New Public Service Implications for Public Sector Reform in Developing Countries. New York: UNDP. 
United Nations Economic and Social Commission for Asia and the Pacific. [2009]. What is good governance. Bangkok: UNESCAP.

United Nations Global Contact. (2004). Who cares wins: Connecting financial markets to a changing world. New York: United Nations.

United Nations Human Rights Council. (2016). UN Working Group on business and human rights' report to the UN Human Rights Council. New York: United Nations.

University of Otago. (2011). Pacific research protocols. Otago: University of Otago.

Vaioleti, T. (2006). Talanoa research methodology: A developing position on Pacific research. Waikato Journal of Education, 12, 21-34.

Verhoest, K., Thiel, S., Bouckaert, G., Lægreid, P. \& Van Thiel, S. (Eds.). (2012). Government agencies practices and Lessons from 30 countries. UK: Palgrave Macmillan.

Ward, G., Vaea, E., Halapua, S., Taufe'ulungaki, A. \& Fonua, S. (2009). Final Report. Naku'aLofa: Constitutional and Electoral Commission. The Kingdom of Tonga.

Weedon, C. (1987). Feminist practice and post-structuralist theory. Oxford: Basil Blackwell.

Wendt, A. (1999). Afterword: Tatauing the postcolonial body. In V. Hereniko \& R. Wilson (Eds.) Inside out: Literature, cultural politics, and identity in the new Pacific, 399-412. Lanham, MD: Rowman \& Littlefield.

West, A. (2009). Corporate governance convergence and moral relativism. Corporate Governance: An International Review, 17(1), 107-119.

Whincop, M. (2005). Corporate governance in government corporations. Aldershot: Ashgate.

White, G. \& Lindstrom, L. (1997). Chiefs today: Traditional Pacific leadership and the postcolonial state. Stanford: Stanford University Press.

Wilcox, J., Schneider, L. \& Bernal, A. (2012). The importance of corporate governance in state-owned enterprises. White Paper. http://gc.caf.com/upload/pubs/White\% 20Paper\%20Corporate\%20Governance\%20(english).pdf.

Williamson, O. (1964). The economics of discretionary behavior: Managerial objectives in a theory of the firm. Englewood Cliffs, NJ: Prentice-Hall.

Wilson, C. (2001). Review of Decolonizing methodologies: Research and indigenous peoples by Linda Tuhiwai Smith. Social Policy Journal of New Zealand, 17, 214-217.

Wilson, S. (2008). Research is ceremony. Indigenous research methods. Black Point, Nova Scotia, Canada: Fernwood Publishing. 
Wood, H. (2006). Three competing research perspectives for Oceania. The Contemporary Pacific,18(1), 33-55.

Woods, P. \& Simkins, T. (2014). Structural reform in England: Emerging configurations of governance and leadership in the new 'local'." Educational Management Administration \& Leadership 42(3), 321-323.

Wong, S. (2018). The state of governance at state-owned enterprises. Public Sector Opinion No. 40. International Finance Corporation, Washington, DC.: World Bank.

World Bank. (n.d.). Samoa. https://data.worldbank.org/country/samoa?view=chart, retrieved May 2021

World Bank. (1981). Accelerated development in Sub-Saharan Africa: A plan for action. [The Berg Report]. Washington, D.C.: World Bank.

World Bank. (1989). Sub-Saharan Africa. From crisis to sustainable growth. A long term perspective study. Washington, D.C.: World Bank.

World Bank. (1992). Governance and development. Washington, D.C.: World Bank.

World Bank. (1994). Governance, the World Bank's experience. Washington, D.C.: World Bank.

World Bank. (1997). World development report 1997: The state in a changing world. New York: Oxford University Press.

World Bank. (1998). World development report 1997: The state in a changing world overview. IDS Bulletin, 29(2). Washington, D.C.: World Bank.

World Bank. (2002). Building institutions for markets. New York: Oxford University Press.

World Bank. (2011). Economic adaptation to climate change. International Bank for reconstruction and development. Washington D.C.: The World Bank.

World Bank. (2014). Corporate governance of state-owned enterprises: A toolkit. Washington, DC.: World Bank.

World Bank. (2017). Governance and the law. Washington, D.C.: The World Bank.

World Bank. (2019). Economy profile of Tonga. Doing business 2020. Washington, DC.: World Bank.

World Bank. (2020a). Evaluation of its support to reform SOEs - 2008-2018. Washington, DC.: World Bank. 
World Bank (2020b). Human capital index 2020. Samoa.

https://databank.worldbank.org/data/download/hci/HCl_2pager_WSM.pdf?cid=GGH_e_hc pexternal_en_ext

World Bank. (2021). World development report 2021: Data for better lives. Washington, DC.: World Bank.

World Economic Forum (2016). The new paradigm: A roadmap for an implicit corporate governance partnership between corporations and investors to achieve sustainable longterm investment and growth. World Economic Forum.

Wyeth, G. (2017). Samoa officially becomes a Christian state: The constitutional change is aimed at avoiding religious unrest. The Diplomat, 16 June, 2017.

Yusoff, W. \& Alhaji, I. (2012). Insight of corporate governance theories. Journal of Business \& Management, 1(1), 52-63. 


\section{APPENDICES}

Appendix A: VUW Ethics Approval Letter

Appendix B: Letter of Introduction

Appendix C: Information Sheet

Appendix D: Consent Form

Appendix E: Interview Guide 


\section{Appendix A: VUW Ethics Approval Letter}

Dear Head of School or delegate,

A Human Ethics application has been approved for a researcher in your School. The application details are below. You have online access to this form through ResearchMaster here:

https://rme6.vuw.ac.nz/RME6/.

Application ID: 0000027181

Application title: What is good governance in the Pacific, and how are notions of good governance applied alongside local values and practices?

Researcher: Poppelwell

Thank you

ResearchMaster 


\title{
Appendix B: Letter of Introduction
}

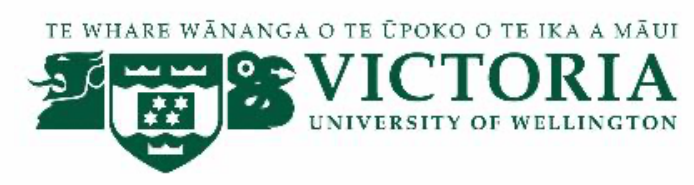

\section{What is good governance in the Pacific, and how are notions of good governance applied alongside local values and practices?}

\section{LETTERS OF INTRODUCTION - TEMPLATE}

\author{
[name of participant] \\ [role] \\ [name of organisation]
}

[Appropriate greeting, title, and name of participant]

My name is Elisabeth Poppelwell and I am currently enrolled as a PhD student at Victoria University of Wellington, New Zealand. My research is on state-owned enterprise (SOE) governance.

I am writing to you as I hope you can find time in your busy schedule to meet with me when I visit [name of country] in [date]. As a [SOE board chair/SOE board director/SOE government official], I would greatly appreciate it if I can get your insights on the changing nature of corporate governance within SOEs.

My research will look at the discussions on corporate governance, and how these views change over time to take into account local, social and cultural contexts, and political contexts. It provides an opportunity to learn about how SOE boards in [name of country] are responding to changing views of governance, and whether they are adopting hybrid governance models that use both localised and Western approaches.

The research will look at whether contemporary governance practice internationally could be enhanced by knowledge of localised cultural values and principles, and whether there are learnings that could be applied more broadly to other SOEs internationally.

Taking part in the research is voluntary and I am attaching a copy of the research information sheet. If you have any queries about my study, or would like more information, please contact me or my supervisor Professor John Overton. Our contact details are on the information sheet.

I will contact you shortly to see whether you are available to take part in the research. I look forward to meeting you.

[appropriate signoff]

Elisabeth Poppelwell

elisabeth.poppelwell@vuw.ac.nz 


\section{Appendix C: Information Sheet}

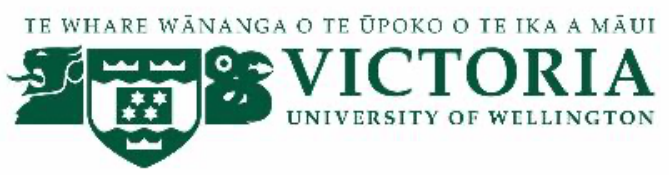

\section{What is good governance in the Pacific, and how are notions of good governance applied alongside local values and practices?}

\section{INFORMATION SHEET FOR INTERVIEWS WITH PARTICIPANTS}

You are invited to take part in this research. Please read this information before deciding whether or not to take part. If you decide to participate, thank you. If you decide not to participate, thank you for considering this request.

\section{Who am I?}

My name is Elisabeth Poppelwell and I am a Doctoral student in Development Studies at Victoria University of Wellington. This research project is work towards my dissertation.

\section{What is the aim of the project?}

This project looks at how Pacific state-owned enterprise (SOE) boards approach their governance roles, especially as concepts of good corporate governance are changing internationally. The research will look at whether contemporary governance practice internationally could be enhanced by knowledge of local cultural values and principles, and whether there are learnings from your country that could be shared more broadly.

Your participation will support this research by discussing your own experiences and insights on your board's approach to governance. The research findings will also provide useful learnings for your board on how other SOE boards overcome any challenges through innovative approaches.

This research has been approved by the Victoria University of Wellington Human Ethics Committee \#0000027181.

\section{How can you help?}

You have been invited to participate because you are a Chair / Director on a SOE board / senior government SOE official. If you agree to take part, I will interview you either at your office or at a location of your choice. I will ask you questions about your SOE role. The interview will take 30-40 mins. I will audio record the interview with your permission and write it up later. You can choose to not answer any question or stop the interview at any time, without giving a reason. You can withdraw from the study by contacting me at any time 
before 1 August 2019. If you withdraw, the information you provided will be destroyed or returned to you.

\section{What will happen to the information you give?}

This research is confidential. This means that the researchers named below will be aware of your identity, but the research data will be combined, and your identity will not be revealed in any reports, presentations, or public documentation.

Only my supervisor and I will read the notes or transcript of the interview. The interview transcripts, summaries and any recordings will be kept securely and destroyed on 1/12/2023.

\section{What will the project produce?}

The information from my research will be used in my PhD dissertation, academic publications and conferences.

\section{If you accept this invitation, what are your rights as a research participant?}

You do not have to accept this invitation if you don't want to. If you do decide to participate, you have the right to:

- $\quad$ choose not to answer any question;

- $\quad$ ask for the recorder to be turned off at any time during the interview if it is recorded;

- $\quad$ withdraw from the study before 1 August 2019;

- $\quad$ ask any questions about the study at any time;

- $\quad$ read over and comment on a written summary of your interview;

- be able to read any reports of this research by emailing the researcher to request a copy.

\section{If you have any questions or problems, who can you contact?}

If you have any questions, either now or in the future, please feel free to contact my supervisor or me.

\section{Student:}

Name: Elisabeth Poppelwell

University email address:

elisabeth.poppelwell@vuw.ac.nz

\section{Supervisor:}

Name: Professor John Overton

Role: Research Supervisor and Programme

Director

School: Development Studies, School of Geography, Environment and Earth Sciences.

Phone: +64 44635281

Email: john.overton@vuw.ac.nz

\section{Human Ethics Committee information}

If you have any concerns about the ethical conduct of the research you may contact the Victoria University HEC Convenor: Dr Judith Loveridge. Email hec@vuw.ac.nz or telephone +64-4-463 6028. 


\section{Appendix D: Consent Form}

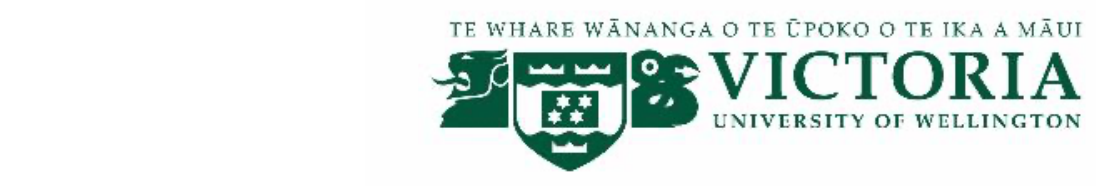

\section{What is good governance in the Pacific, and how are notions of good governance applied alongside local values and practices}

\section{CONSENT TO INTERVIEW}

This consent form will be held for five years.

Researcher: Elisabeth Poppelwell, School of Geography, Environment and Earth Sciences, Victoria University of Wellington, New Zealand.

I have read the Information Sheet and the project has been explained to me. My questions have been answered to my satisfaction. I understand that I can ask further questions at any time.

I agree to take part in an audio recorded interview.

Yes $\square$ No $\square$

I agree to take part in an unrecorded interview.

Yes $\square$ No $\square$

I understand that:

I may withdraw from this study at any point before 1 August 2019 and any information that I have provided will be returned to me or destroyed.

The identifiable information I have provided will be destroyed on 1/12/2023.

Any information I provide will be kept confidential to the researcher and the supervisor.

I understand that the findings may be used for a PhD dissertation, academic publications and presented to conferences.

I understand that the observation notes and recordings will be kept confidential to the researcher and the supervisor.

My name will not be used in reports and utmost care will be taken not to disclose any information that would identify me.

I would like a summary of my interview for checking:

Yes $\square$ No

I would like to receive a copy of the final report and have added my email address below.

Yes $\square \quad$ No $\square$ 
Signature of participant:

Name of participant:

Date:

Contact details: 


\section{Appendix E: Interview Guide}

TE WHARE WĀNANGA O TE T̈POKO O TE IKA A MĀUI

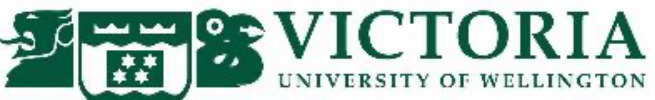

\section{What is good governance in the Pacific, and how are notions of good governance applied alongside local values and practices?}

\section{INTERVIEW GUIDE FOR CURRENT AND FORMER SOE BOARD DIRECTORS}

Talofa lava (Mālō e lelei for the Tongan information sheet)

\section{Introduction}

Recap purpose of the research - there is a call for more diversity on boards, and different approaches to board governance. This research will look at whether contemporary governance practice internationally could be enhanced by knowledge of local cultural values and principles, and whether there are learnings that could be applied more broadly.

1. a) Please tell me about your role, b) your skills and experience, and c) why you became a SOE board director?

2. a) What is your understanding of good corporate governance principles?

b) Can you give me examples of how you use them in your governing role?

3. a) Do you take into account local values and practices in using good governance?

b) If you do, can you give me examples how you do this?

4. What issues do you and your fellow directors face implementing good corporate governance? (Prompts if needed - i.e. Long-term thinking? Merit based appointments? Diversity? Recruiting and monitoring management? Revenue constraints with small populations?)

5. What approaches or solutions have you and your fellow directors taken to address these issues?

6. a) What do you think prevents you and your fellow directors from achieving your governance objectives? b) What does your board do to address these challenges?

7. a) Do you think your learnings can be used elsewhere by other SOEs? b) If not, why not? c) If yes, which learnings do you think could be shared elsewhere?

8. Is there anything else you would like to discuss with me regarding SOE board governance? 
Thank you (Faafetai /Malo) for your time today. When I have completed the research, I would like to share with you a brief summary of the findings, and also a presentation of the research either in person or via Skype. 


\section{What is good governance in the Pacific, and how are notions of good governance applied alongside local values and practices?}

\section{INTERVIEW GUIDE FOR OTHER KEY INFORMANTS, INCL. GOVERNMENT OFFICIALS}

Talofa lava (Mālō e lelei for the Tongan information sheet)

\section{Introduction}

Recap purpose of the research - there is a call for more diversity on boards, and different approaches to board governance. This research will look at whether contemporary governance practice internationally could be enhanced by knowledge of local cultural values and principles, and whether there are learnings that could be applied more broadly.

1. a) Please tell me about your role; b) your skills and experience

2. What is your understanding of good corporate governance principles?

3. a) Do you think SOE boards are aware of international changes in corporate governance? b) If so, how do you think they are moving to respond to any of these changes? c) If no, why do you think there is a lack of awareness of these changes?

4. Can you give me examples of how SOE boards that you deal with, use good corporate governance principles in their governing role?

5. How do the boards pursue quality performance measures for the organisation and the CEO?

6. Do you feel that boards you deal with apply good governance that fits with local values?

7. a) Do you think board directors take into account local values and practices in using good governance? b) If yes, can you give me examples how they do this? c) If there are problems, what do you think could be done about them?

8. What issues do you think directors face implementing good corporate governance? (Prompts if needed - i.e. Long-term thinking? Merit based appointments? Diversity? Recruiting and monitoring management? Revenue constraints with small populations?)

9. What approaches or solutions have directors taken to address these issues?

10. a) What do you feel prevents directors from achieving their governance objectives? b) How do boards address these challenges? 
11. a) Do you think there are learnings that can be used elsewhere by other SOEs? b) If not, why not? c) If yes, which learnings do you think could be shared elsewhere?

12. Is there anything else you would like to discuss with me regarding SOE board governance?

Thank you (Faafetai /Malo) for your time today. When I have completed the research, I would like to share with you a brief summary of the findings, and also a presentation of the research either in person or via Skype. 